\title{
Life Cycle Assessment of Coal-fired Power Production
}

\section{Pamela L. Spath}

Margaret K. Mann

Dawn R. Kerr

Including contributions on process definition and data acquisition from: John Marano and Massood Ramezan, Federal Energy Technology Center
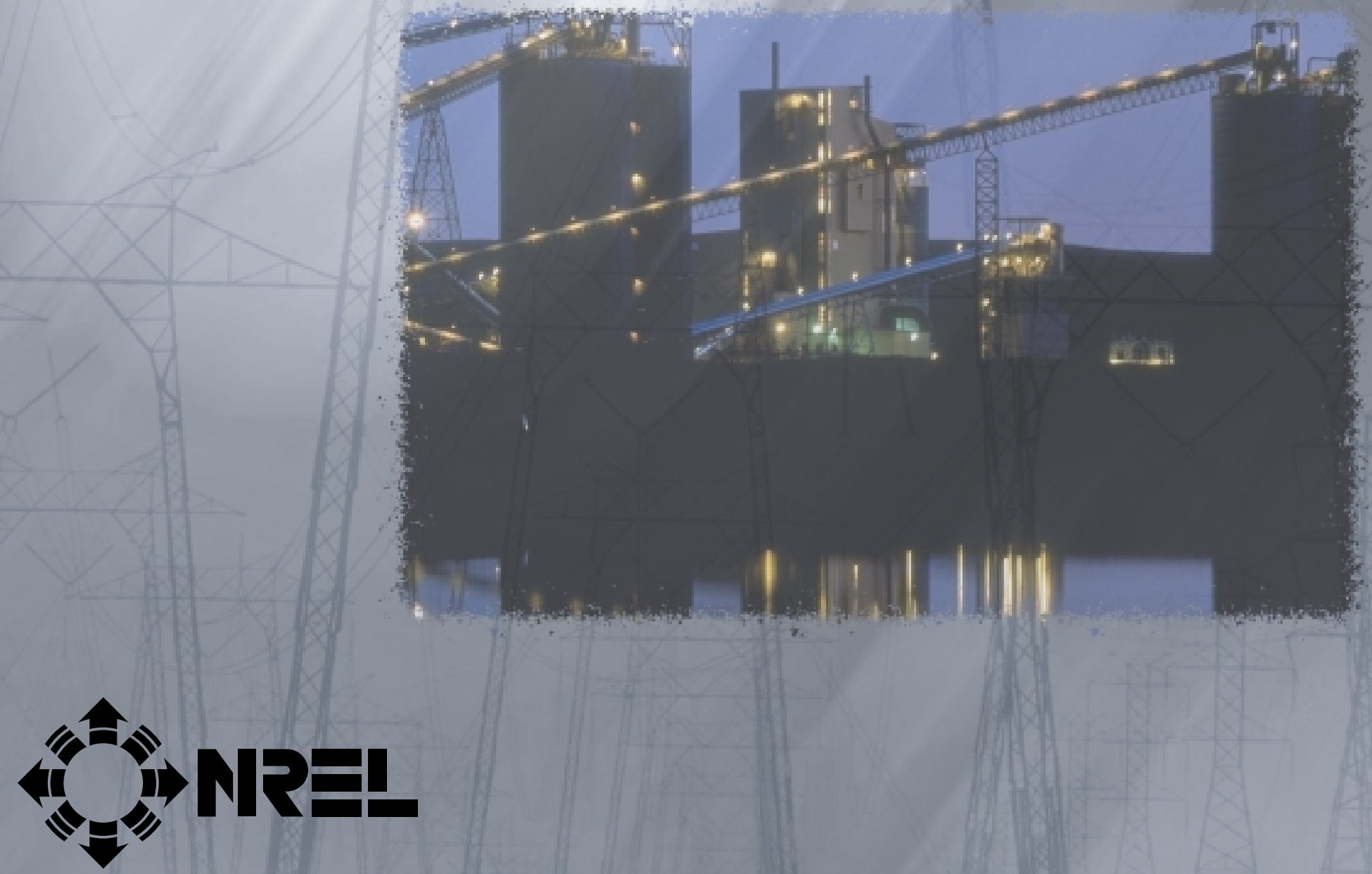

\section{Life Cycle Assessment}




\section{NOTICE}

This report was prepared as an account of work sponsored by an agency of the United States government. Neither the United States government nor any agency thereof, nor any of their employees, makes any warranty, express or implied, or assumes any legal liability or responsibility for the accuracy, completeness, or usefulness of any information, apparatus, product, or process disclosed, or represents that its use would not infringe privately owned rights. Reference herein to any specific commercial product, process, or service by trade name, trademark, manufacturer, or otherwise does not necessarily constitute or imply its endorsement, recommendation, or favoring by the United States government or any agency thereof. The views and opinions of authors expressed herein do not necessarily state or reflect those of the United States government or any agency thereof.

Available to DOE and DOE contractors from:

Office of Scientific and Technical Information (OSTI)

P.O. Box 62

Oak Ridge, TN 37831

Prices available by calling 423-576-8401

Available to the public from:

National Technical Information Service (NTIS)

U.S. Department of Commerce

5285 Port Royal Road

Springfield, VA 22161

$703-605-6000$ or $800-553-6847$

or

DOE Information Bridge

http://www.doe.gov/bridge/home.html

Printed on paper containing at least $50 \%$ wastepaper, including $20 \%$ postconsumer waste 


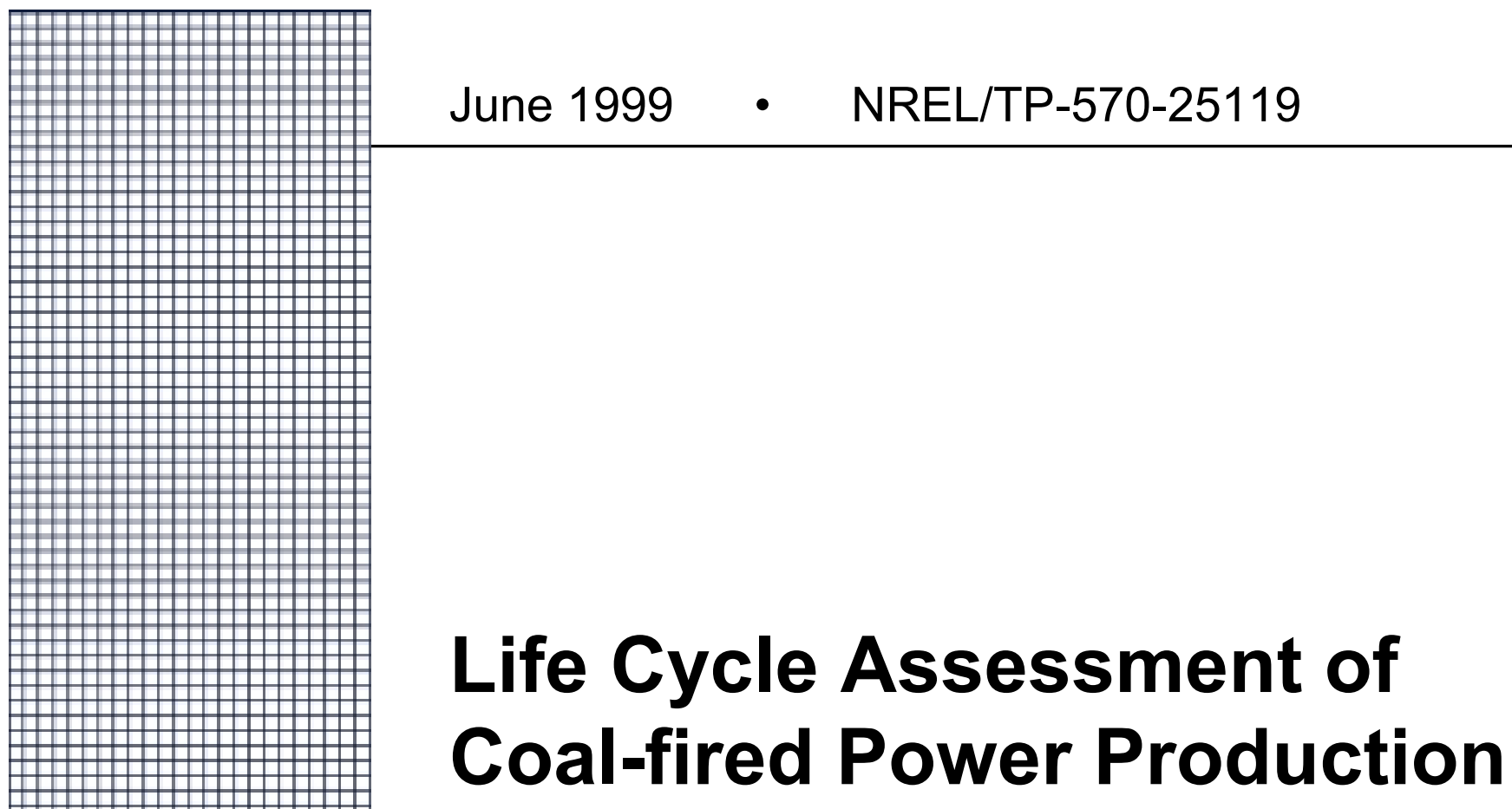

Pamela L. Spath, Margaret K. Mann, and Dawn R. Kerr

Including contributions on process definition and data acquisition from: John Marano and Massood Ramezan Federal Energy Technology Center

Prepared under Task No. BP911030

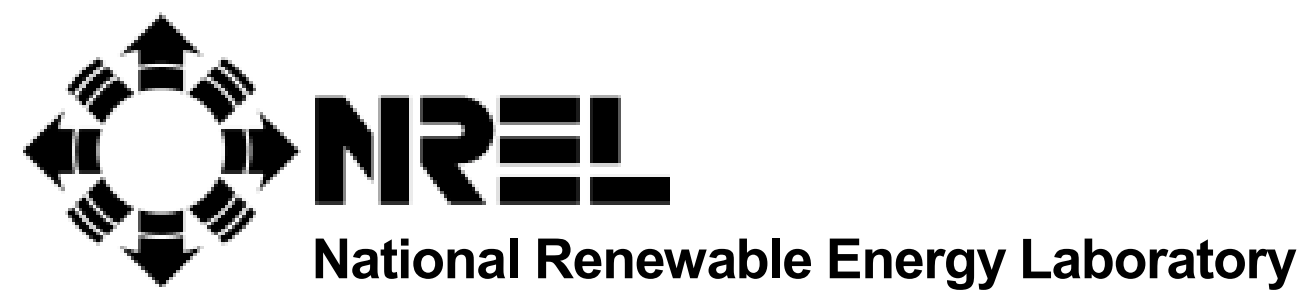

1617 Cole Boulevard

Golden, Colorado 80401-3393

NREL is a U.S. Department of Energy Laboratory

Operated by Midwest Research Institute • Battelle • Bechtel

Contract No. DE-AC36-98-G010337 


\section{EXECUTIVE SUMMARY}

Coal has the largest share of utility power generation in the United States, accounting for approximately $56 \%$ of all utility-produced electricity (U.S. DOE, 1998). Therefore, understanding the environmental implications of producing electricity from coal is an important component of any plan to reduce total emissions and resource consumption. A life cycle assessment (LCA) on the production of electricity from coal was performed in order to examine the environmental aspects of current and future pulverized coal boiler systems. Three systems were examined: 1) a plant that represents the average emissions and efficiency of currently operating coal-fired power plants in the U.S. (this tells us about the status quo), 2) a new coal-fired power plant that meets the New Source Performance Standards (NSPS), and 3) a highly advanced coal-fired power plant utilizing a low emission boiler system (LEBS).

LCA is a systematic analytical method that helps identify, evaluate, and minimize the environmental impacts of a specific process or competing processes. Material and energy balances are used to quantify the emissions, resource consumption, and energy use (i.e., stressors) of all processes between transformation of raw materials into useful products and the final disposal of all products and byproducts. The results are then used to evaluate the environmental impacts of the process so that efforts can be focused on mitigating possible effects.

Each system analyzed consists of coal mining, transportation, and electricity generation. In keeping with the cradle-to-grave concept of LCA, upstream processes required for the operation of these three subsystems were also included in this study. Both surface and underground mining were examined, with the coal being surface mined by strip mining or by the underground technique of longwall mining. The coal is transported via rail, truck, or a combination of rail and barge by one of four cases tested: average user by land, average user by river, farthest user, and mine mouth.

As expected, because coal combustion results in the production of $\mathrm{CO}_{2}$ from carbon that was previously sequestered underground, $\mathrm{CO}_{2}$ accounts for the vast majority (98\%-99\% by weight) of the total air emissions from each system examined. The rate of production is $1,022 \mathrm{~g} / \mathrm{kWh}, 941 \mathrm{~g} / \mathrm{kWh}$, and 741 $\mathrm{g} / \mathrm{kWh}$ for the Average, NSPS, and LEBS systems, respectively. Two other climate change gases, methane and nitrous oxide, are also emitted from the system. Although the global warming potential (GWP) of these gases is much higher than that of $\mathrm{CO}_{2}$, they are emitted in much smaller quantities and therefore do not significantly change the GWP of the overall systems.

Apart from the $\mathrm{CO}_{2}$ produced during coal combustion, operations related to flue gas clean-up produce more $\mathrm{CO}_{2}$ than any other upstream process. Limestone production, transportation, and use account for $59 \%$ and $62 \%$ of the non-coal $\mathrm{CO}_{2}$ emissions in the Average and NSPS systems. These amounts are greater than twice the $\mathrm{CO}_{2}$ emissions related to transportation of the coal. In the LEBS system, operations associated with the production and use of natural gas to regenerate the $\mathrm{CuO}$ sorbent are responsible for $35 \%$ of the total non-coal $\mathrm{CO}_{2}$ emissions. Coal transportation, in this system, produces nearly $40 \%$ of the non-coal $\mathrm{CO}_{2}$. 
Other major air emissions from the system are particulates, $\mathrm{SO}_{\mathrm{x}}, \mathrm{NO}_{\mathrm{x}}$, $\mathrm{CH}_{4}$, and $\mathrm{CO}$. In all three systems, the power plant produces most of the $\mathrm{SO}_{\mathrm{x}}, \mathrm{NO}_{\mathrm{x}}$, and $\mathrm{CO}$, while the methane comes primarily from the coal mine. For the Average and NSPS systems, the majority of the particulates come from the production of limestone. Particulate emissions from the LEBS system are considerably reduced because of the incorporation of a copper oxide sorbent instead of limestone in flue gas clean-up. Ironically, the amount

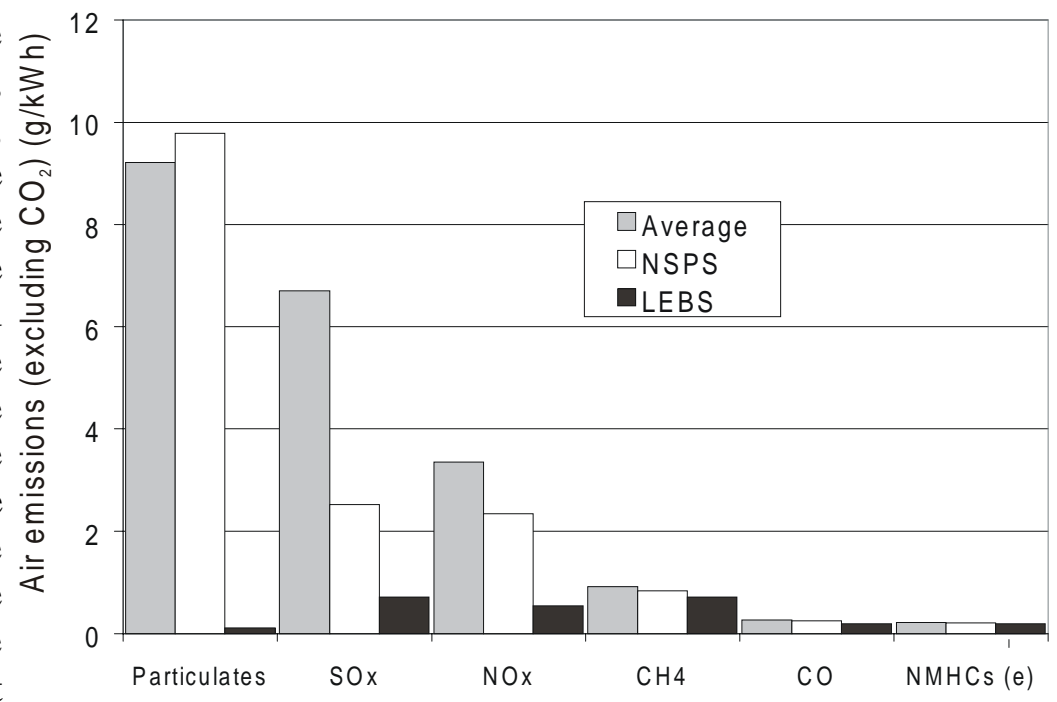
of particulates released during limestone production from the Average and NSPS systems is greater than the limit set by federal air regulations for coal-fired power plants.

Given that the processes studied exist for the sole purpose of generating electricity, an examination of the energy balance of each system was made. In addition to the standard power plant efficiency, which is the energy delivered to the grid divided by the energy in the feedstock to the power plant, four other measures of efficiency were defined as follows:

\section{Energy Efficiency and Ratio Definitions}

\begin{tabular}{|l|c|c|c|}
\hline Life cycle efficiency (\%) (a) & $\begin{array}{c}\text { External energy } \\
\text { efficiency (\%) (b) }\end{array}$ & Net energy ratio (c) & External energy ratio (d) \\
\hline$=\frac{E g-E u-E c-E n}{E c+E n}$ & $=\frac{E g-E u}{E c+E n}$ & $=\frac{E g}{E f f-E c-E n}$ \\
\hline $\begin{array}{l}\text { where: } \\
\text { Eg = electric energy delivered to the utility grid } \\
\text { Eu = energy consumed by all upstream processes required to operate power plant } \\
\text { Ec = energy contained in the coal fed to the power plant } \\
\text { En = energy contained in the natural gas fed to the power plant (LEBS system only) } \\
\text { Eff = fossil fuel energy consumed within the system (e) }\end{array}$ & \\
\hline
\end{tabular}

(a) Includes the energy consumed by all of the processes.

(b) Excludes the heating value of the coal and natural gas feedstock from the life cycle efficiency formula.

(c) Illustrates how much energy is produced for each unit of fossil fuel energy consumed.

(d) Excludes the energy of the coal and natural gas to the power plant.

(e) Includes the coal and natural gas fed to the power plant since these resources are consumed within the boundaries of the system.

Because the energy in the coal is greater than the energy delivered as electricity, the life cycle efficiency is negative. This reflects the fact that since coal is a non-renewable resource, more energy is consumed by these systems than is produced. The net energy ratio likewise, indicates that only about one-third of 
every unit of energy into the system is obtained as electricity. Although the net energy ratio is a more correct measure of the net energy balance of the system, the external measures are useful because they expose the rate of energy consumption by upstream operations.

\section{Efficiencies and Energy Ratio Results}

\begin{tabular}{|l|c|c|c|c|c|}
\hline $\begin{array}{c}\text { System } \\
(\mathrm{a}, \mathrm{b})\end{array}$ & $\begin{array}{c}\text { Power plant } \\
\text { efficiency } \\
(\%)(\mathrm{c})\end{array}$ & $\begin{array}{c}\text { Life cycle } \\
\text { efficiency } \\
(\%)(\mathrm{c})\end{array}$ & $\begin{array}{c}\text { External energy } \\
\text { efficiency } \\
(\%)(\mathrm{c})\end{array}$ & $\begin{array}{c}\text { Net energy } \\
\text { ratio }\end{array}$ & $\begin{array}{c}\text { External } \\
\text { energy ratio }\end{array}$ \\
\hline Average & 32 & -76 & 24 & 0.29 & 5.0 \\
\hline NSPS & 35 & -73 & 27 & 0.31 & 5.1 \\
\hline LEBS & 42 & -66 & 34 & 0.38 & 6.7 \\
\hline
\end{tabular}

(a) Results are reported for the surface mining case, with the underground mining numbers being similar.

(b) Coal transportation = average user by river.

(c) Efficiencies are on a higher heating value basis.

Excluding the consumption of fossil fuels by the power plant, the external energy efficiency and external energy ratio indicate that upstream processes are large consumers of energy. In fact, two operations, those related to flue gas clean-up and coal transportation, account for between $3.8 \%$ and $4.2 \%$ of the total system energy consumption, and between $67.4 \%$ and $70.5 \%$ of the non-coal energy. Processes involved in the gas clean-up operations include the production, transport, and use of limestone and lime in the Average and NSPS systems, and the production, distribution, and combustion of natural gas in the LEBS system. These operations consume between $35.3 \%$ and $38.5 \%$ of the non-coal energy, and between $2.0 \%$ and $2.4 \%$ of the total energy of the systems. Transportation of the coal uses similar amounts: between $30.1 \%$ and $32.2 \%$ of non-coal, and $1.8 \%$ of total system energy.

As expected, the amount of resources consumed, emissions produced, and energy used, are small for the mine mouth transportation case. It was found that the transportation distance has a significant effect on the oil consumption, a few of the systems emissions, and the energy consumption, whereas the mode of transportation has virtually no effect on the results. Although energy consumption is significant, transportation required fewer resources and had lower air, water, and solid waste emissions than either the mining or electricity generation subsystems.

In terms of resource consumption, coal is used at the highest rate. For the Average and NSPS systems, limestone accounts for the majority of the other resources consumed, compared to the LEBS system, which consumes large quantities of natural gas. Both limestone and natural gas are used in flue gas clean-up. In the Average and NSPS systems, this process step is responsible for producing the majority of the solid waste, which is primarily

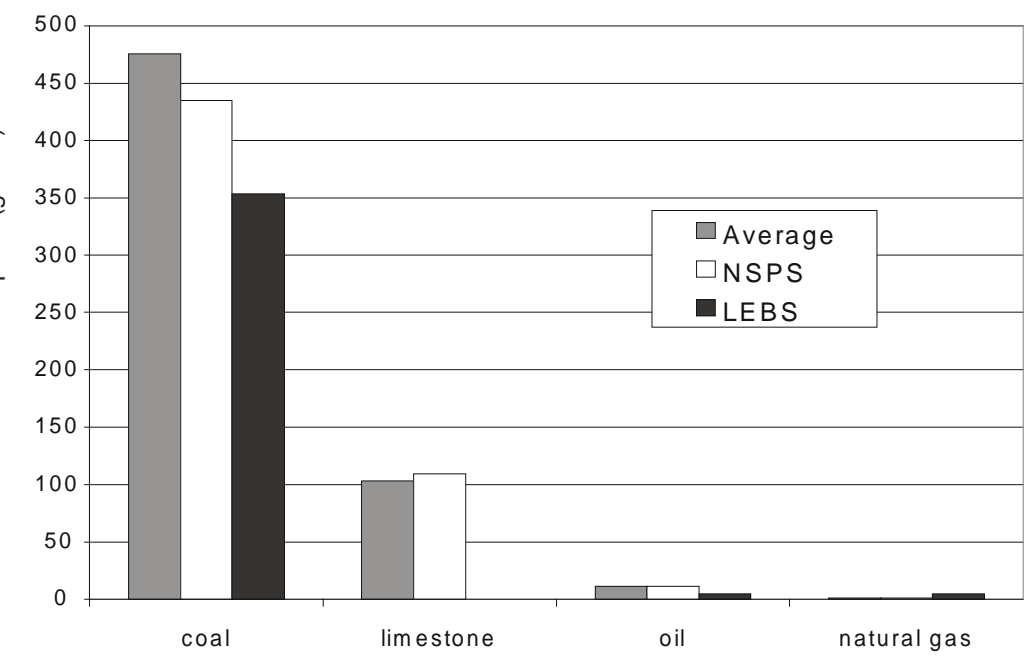


clean-up waste and ash that must be landfilled. The flue gas clean-up process for the LEBS system utilizes a regenerable sorbent, therefore, the bulk of the waste from this system is ash.

Overall, the environmental impacts from surface are similar to those of underground mining. One difference is that the surface mining subsystem results in a higher amount of airborne ammonia emissions due to the production of ammonium nitrate explosives used at the mine. Another important difference is that underground mining requires limestone which emits a large amount of particulates during its production. Therefore the particulate emissions will be higher for underground mining compared to surface mining. Additionally, underground mining, because it is able to access deeper seams that have been under higher pressures, produces approximately twice the methane emissions as surface mining.

A sensitivity analysis was used to identify those parameters that most influence the major results of the study. Overall, finding ways to reduce the amount of coal being consumed, while still producing the same amount of electricity, offers the best opportunity to mitigate emissions, resource consumption, and energy use of these systems. Therefore, changing the power plant efficiency had the largest effect, since the change in the amount of coal not only changes the stressors directly associated with coal combustion, but also those stressors from upstream processes that are proportional to how much coal is used (e.g., limestone and transportation requirements). In general, the system was found to be sufficiently large, and the model reasonably robust, that the major conclusions remained the same for all cases tested.

Several areas were identified where design changes could improve the environmental impact of these coal-fired boiler systems. One obvious way to reduce the amount of waste generated by these power systems is to maximize the amount of flue gas clean-up waste and ash that is used in alternative services when possible. Additionally, because the largest portion of several stressors come from limestone production, the overall system would benefit from using a type of gas clean-up other than conventional limestone scrubbing. Care should be taken, however, that the alternative technology does not adversely impact the environment in other ways. A third change that may improve the environmental outcome is capturing the methane emitted from the coal mine for uses such as power production, fuel use at the mine site (for water treatment or coal preparation), or as additional natural gas supply. 


\section{Table of Contents}

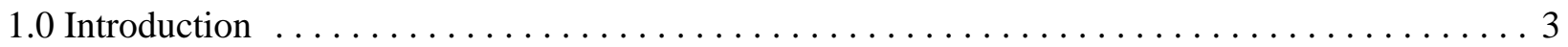

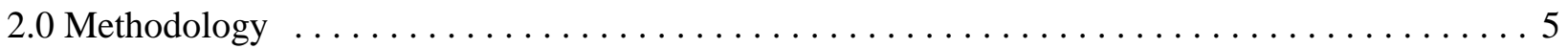

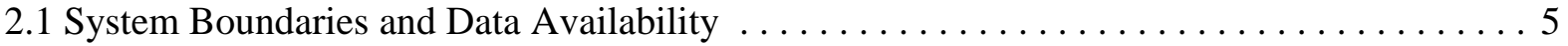

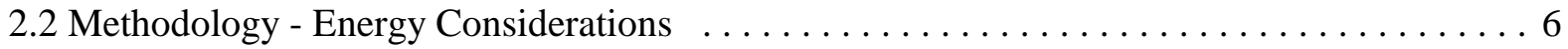

2.3 Methodology - Comparison with Other Systems $\ldots \ldots \ldots \ldots \ldots \ldots \ldots \ldots \ldots \ldots \ldots \ldots \ldots \ldots \ldots \ldots$

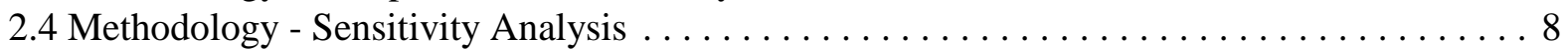

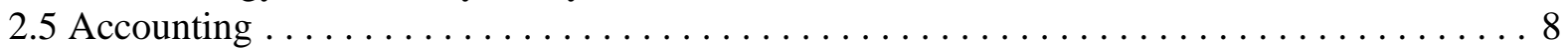

2.6 Time Frame and Issues in Assessing Environmental Consequences . . . . . . . . . . 9

3.0 Description of Pulverized Coal Boiler Plants Studied $\ldots \ldots \ldots \ldots \ldots \ldots \ldots \ldots \ldots \ldots \ldots$

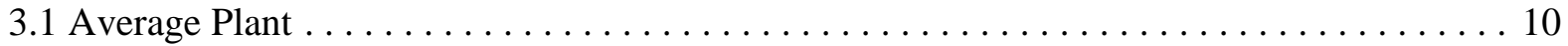

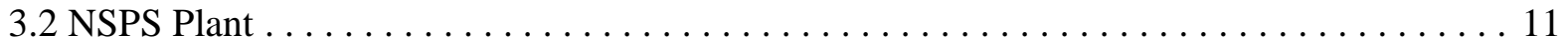

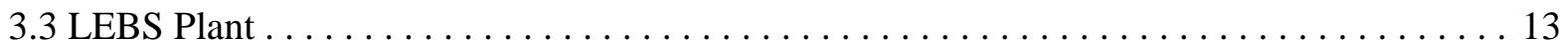

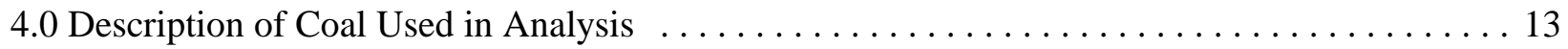

5.0 Description of Process Blocks Studied in the LCA $\ldots \ldots \ldots \ldots \ldots \ldots \ldots \ldots \ldots \ldots$

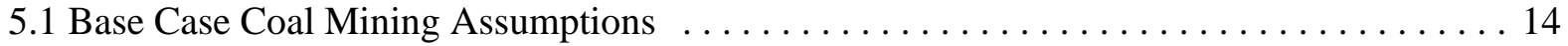

5.1.1 Surface Coal Mining Equipment \& Mine Requirements $\ldots \ldots \ldots \ldots \ldots \ldots \ldots \ldots$

5.1 .2 Surface Coal Mining Reclamation Requirements . . . . . . . . . . . . . . 16

5.1.3 Underground Coal Mining Equipment \& Mine Requirements . . . . . . . . . . 17

5.1 .4 Coal Preparation/Cleaning . . . . . . . . . . . . . . . . . . . . . 19

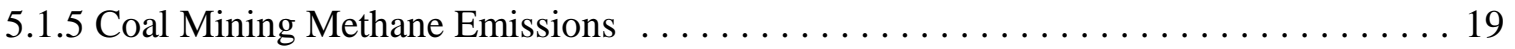

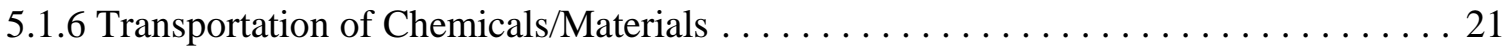

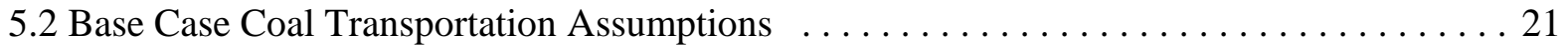

5.3 Base Case Power Plant Construction \& Decommissioning Assumptions . . . . . . . . . 24

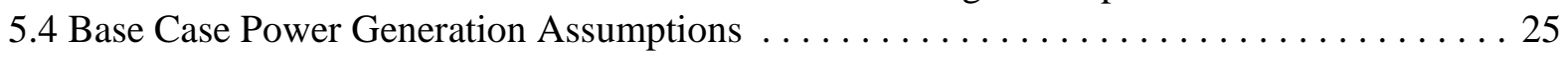

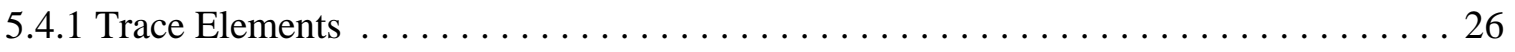

5.4.2 Recycling of Power Plant Flue Gas Clean-up Waste and Ash . . . . . . . . . . . 27

5.4.3 Landfilling of Flue Gas Clean-up Waste, Ash, and Refuse . . . . . . . . . . . 28

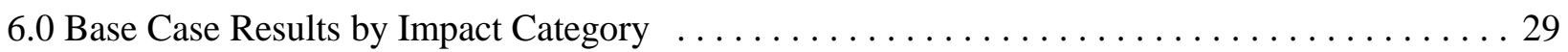

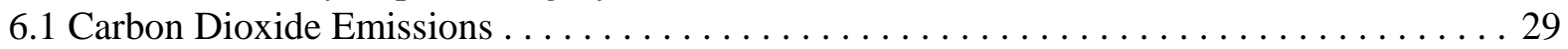

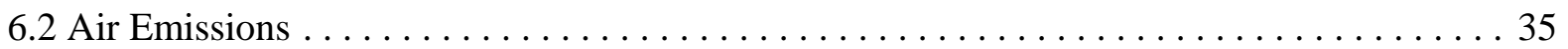

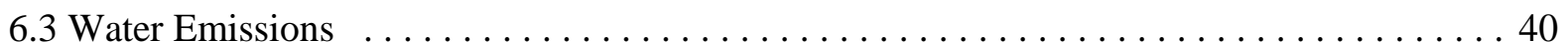

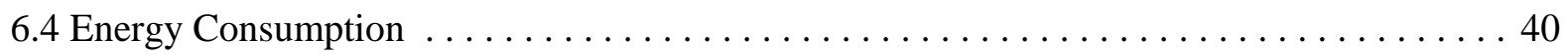

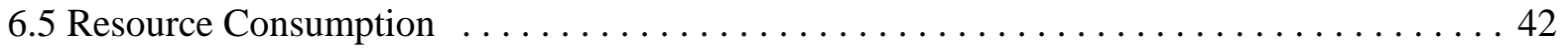

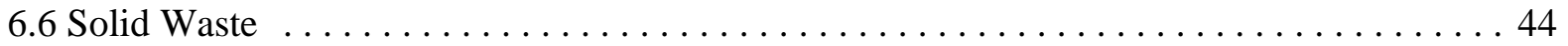

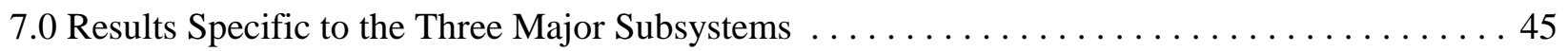

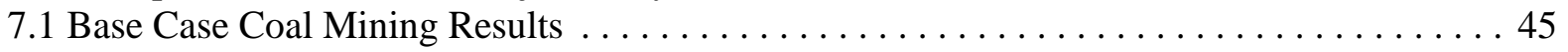

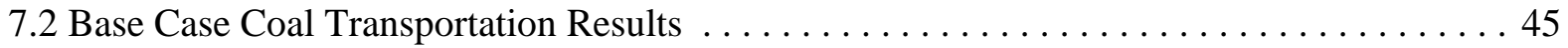

7.3 Base Case Power Plant Construction \& Decommissioning Results . . . . . . . . . . . . . 46 
7.4 Base Case Power Generation Results . . . . . . . . . . . . . . . . ......... 46

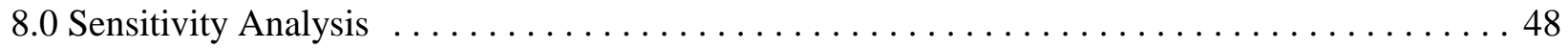

8.1 Power Plant Efficiency Sensitivity Analysis (Case A-B) . . . . . . . . . . . . . . 53

8.2 Pond Versus Landfilling of Power Plant Ash Sensitivity Analysis (Case C) . . . . . . . . 54

8.3 Power Plant Construction \& Decommissioning Sensitivity Analysis (Case D) . . . . . . . 54

8.4 Coal Mining Methane Emissions Sensitivity Analysis (Case E) $\ldots \ldots \ldots \ldots \ldots \ldots \ldots$

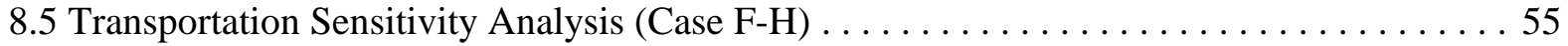

8.5.1 Mine Mouth Case (Case F) ................................. 57

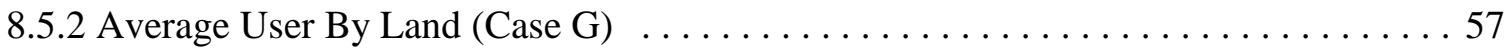

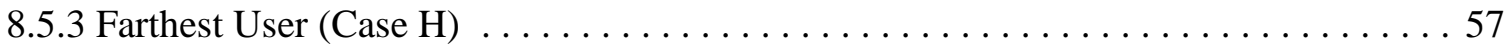

8.6 Flue Gas Clean-up Waste \& Ash Recovery and Disposal Sensitivity Analysis

$($ Cases I-L \& Q-T) ..................................... 57

8.7 Power Plant Operating Capacity Factor Sensitivity Analysis (Case M) . . . . . . . . . . 58

8.8 Mining Equipment Materials Sensitivity Analysis (Case N-O) $\ldots \ldots \ldots \ldots \ldots \ldots \ldots$

8.9 Landfilling versus Recycling Sensitivity Analysis (Case P) . . . . . . . . . . . . . . 59

9.0 Impact Assessment . . . . . . . . . . . . . . . . . . . . . . . . . . . . . . . . . . . . . 59

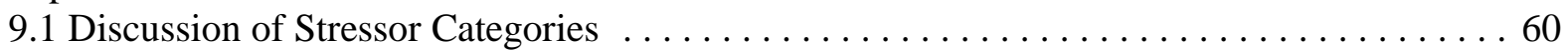

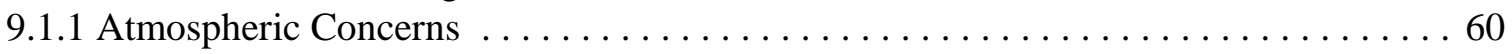

9.1 .2 Climate Change .......................................... 61

9.1 .3 Greenhouse Gases . . . . . . . . . . . . . . . . . . . . . . . . . . . 61

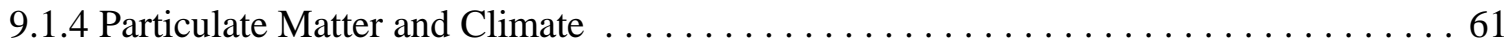

9.1 .5 Ozone Depletion Compounds .................................. 64

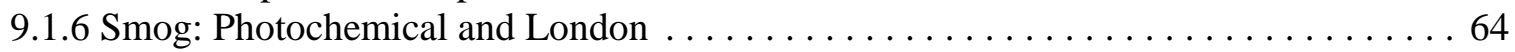

9.1 .7 Acid Deposition ...................................... 67

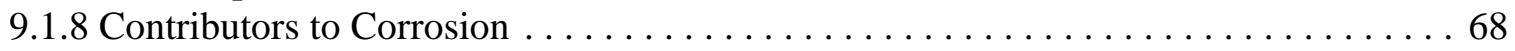

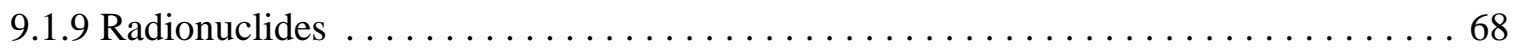

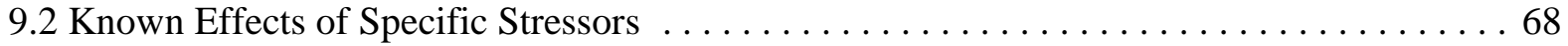

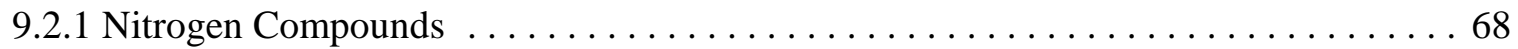

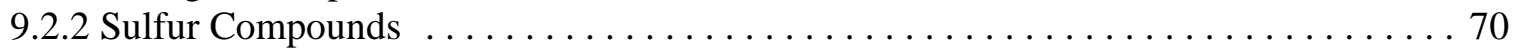

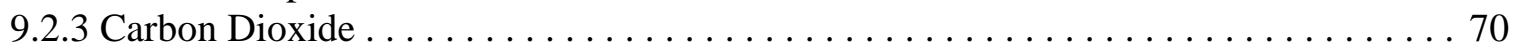

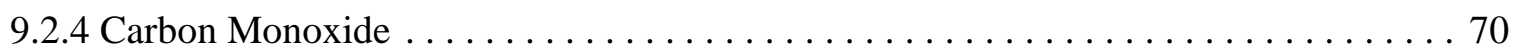

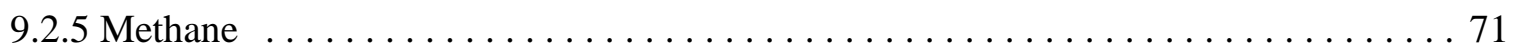

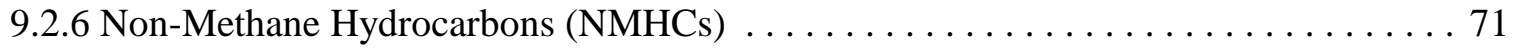

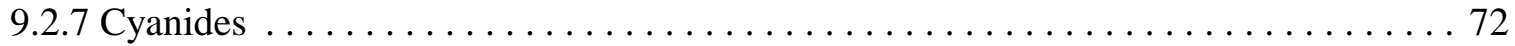

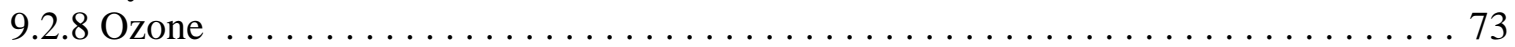

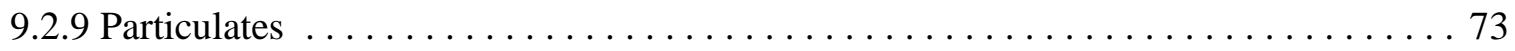

9.2.10 Trace Elements and Their Compounds $\ldots \ldots \ldots \ldots \ldots \ldots \ldots \ldots \ldots \ldots \ldots$

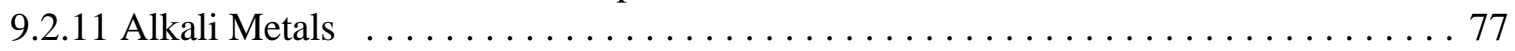

9.2.12 Fluorine, Fluorides, and Hydrogen Fluoride . . . . . . . . . . . . . . . . . . . . . . 77

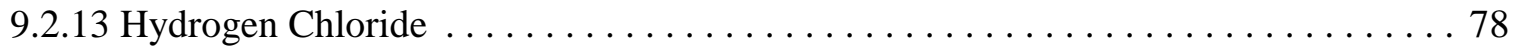

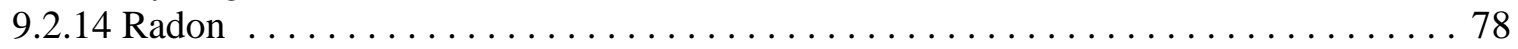

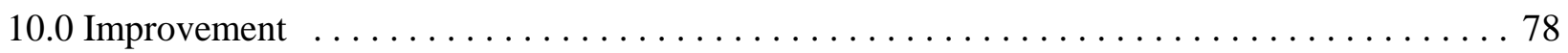

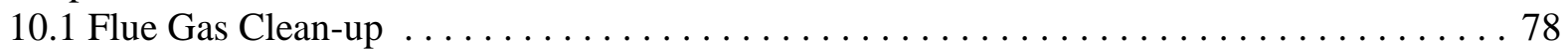

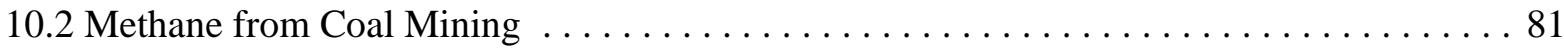




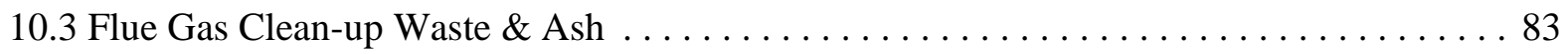

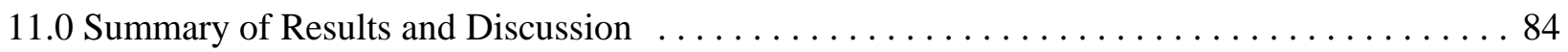

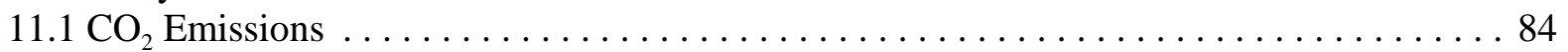

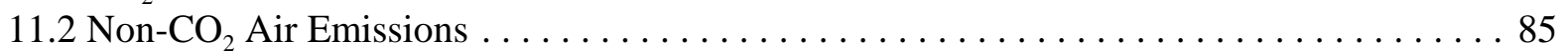

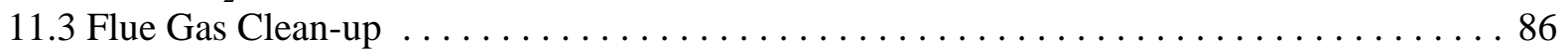

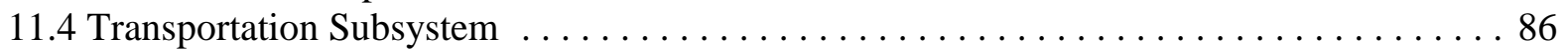

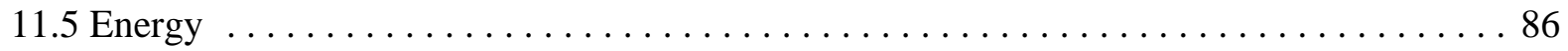

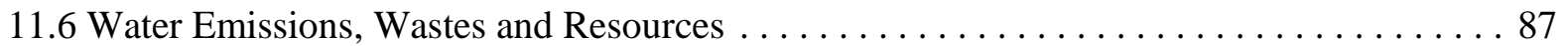

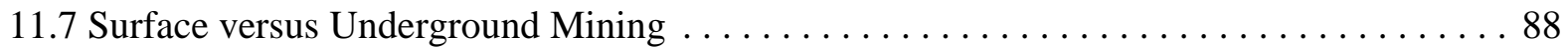

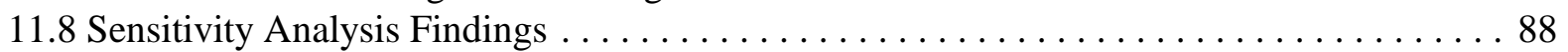

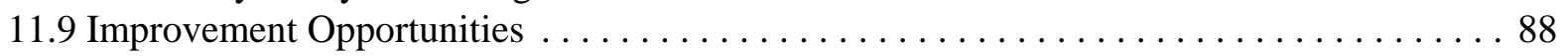

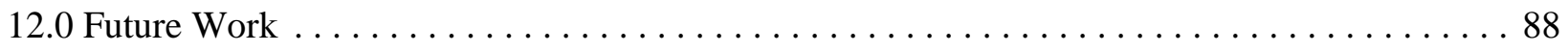

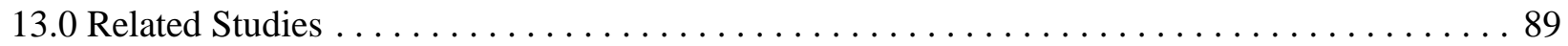

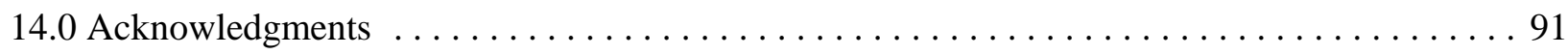

15.0 References and Pertinent Literature $\ldots \ldots \ldots \ldots \ldots \ldots \ldots \ldots \ldots \ldots \ldots \ldots \ldots \ldots \ldots \ldots \ldots \ldots \ldots \ldots$

\section{Appendices}

Appendix A: Graphical Representation of the LCA System in TEAM ${ }^{\circledR}$

Appendix B: Additional Results Tables

Appendix C: Additional Figures 


\section{List of Figures}

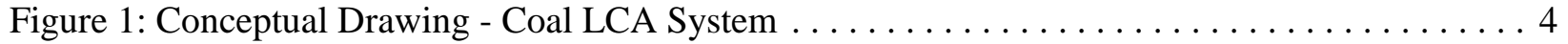

Figure 2: Coal Production and Transportation Boundaries for Life Cycle Assessment . . . . . . . 7

Figure 3: Power Generation and Transportation Boundaries for Life Cycle Assessment . . . . . . 7

Figure 4: Schematic of a Typical Coal-fired Power Plant $\ldots \ldots \ldots \ldots \ldots \ldots \ldots \ldots \ldots \ldots \ldots$

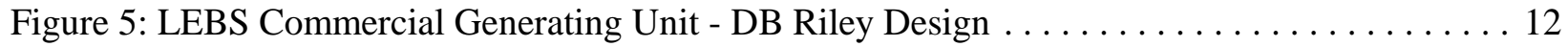

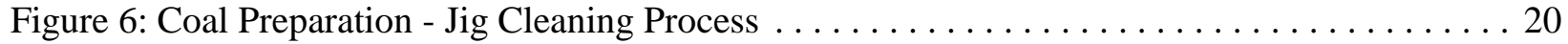

Figure 7: Coal LCA $\mathrm{CO}_{2}$ Results - Average System $\ldots \ldots \ldots \ldots \ldots \ldots \ldots \ldots \ldots \ldots \ldots \ldots \ldots \ldots \ldots \ldots$

Figure 8: Yearly Carbon Dioxide Emissions (surface mining \& average user by river) $\ldots \ldots \ldots 33$

Figure 9: Yearly Particulate Emissions (surface mining $\&$ average user by river) . . . . . . . 37

Figure 10: Yearly Particulate Emissions (underground mining \& average user by river) . . . . . 37

Figure 11: Yearly Sulfur Oxide Emissions $\left(\mathrm{SO}_{\mathrm{x}}\right.$ as $\left.\mathrm{SO}_{2}\right)$

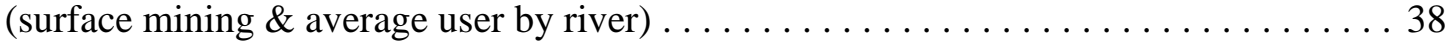

Figure 12: Yearly Nitrogen Oxide Emissions $\left(\mathrm{NO}_{\mathrm{x}}\right.$ as $\left.\mathrm{NO}_{2}\right)$

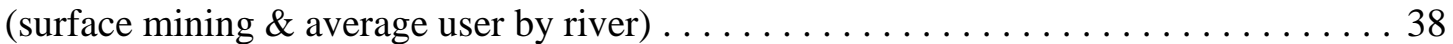

Figure 13: Yearly Methane Emissions (surface mining $\&$ average user by river) . . . . . . . . 39

Figure 14: Yearly Total Non-Coal Energy Consumption

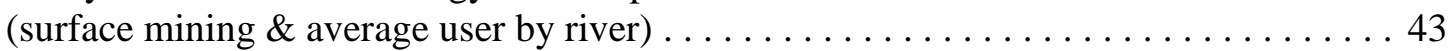

Figure 15: Yearly Iron Ore Consumption (surface mining \& average user by river) . . . . . . 47

Figure 16: Sensitivity Results for Life Cycle Efficiency -

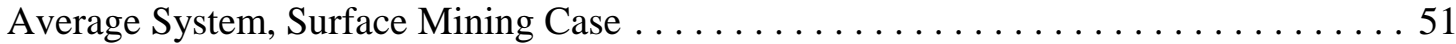

Figure 17: Sensitivity Results for External Energy Efficiency -

Average System, Surface Mining Case . . . . . . . . . . . . . . . . . 51

Figure 18: Sensitivity Results for Net Energy Ratio -

Average System, Surface Mining Case . . . . . . . . . . . . . . . . 52

Figure 19: Sensitivity Results for External Energy Ratio -

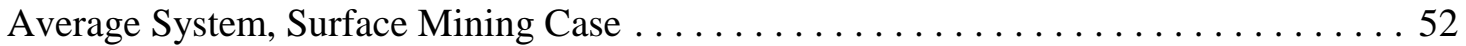

Figure 20: Concentration of Carbon Dioxide in the Earth's Atmosphere . . . . . . . . . . . . 62

Figure 21: Absorptivity Spectrum for a Few Atmospheric Gases $\ldots \ldots \ldots \ldots \ldots \ldots \ldots \ldots$ 


\section{List of Tables}

Table 1: Process Blocks Taken from DEAM $\ldots \ldots \ldots \ldots \ldots \ldots \ldots \ldots \ldots \ldots \ldots \ldots$

Table 2: Major Yearly Operations of the Three Subsystems $\ldots \ldots \ldots \ldots \ldots \ldots \ldots \ldots \ldots \ldots$

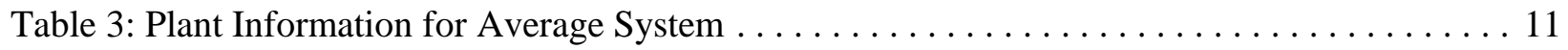

Table 4: New Source Performance Standards for Fossil-Fueled Power Plants . . . . . . . . . . 11

Table 5: Plant Information for NSPS System $\ldots \ldots \ldots \ldots \ldots \ldots \ldots \ldots \ldots \ldots \ldots \ldots \ldots \ldots$

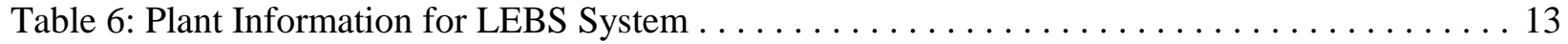

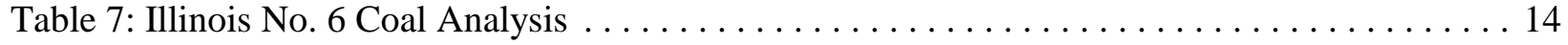

Table 8: Surface Mining Equipment Material Requirements (Base Case) . . . . . . . . . . . 15

Table 9: Reclamation Mulching and Seeding Requirements (Base Case) . . . . . . . . . . 17

Table 10: Underground Mining Equipment Material Requirements (Base Case) . . . . . . . . 17

Table 11: Underground Mining Electrical Requirements (Base Case) . . . . . . . . . . . 18

Table 12: Coal Cleaning Utility and Landfilling Requirements (Base Case) . . . . . . . . . . . . 19

Table 13: Coal Mining Methane Emissions (Base Case) $\ldots \ldots \ldots \ldots \ldots \ldots \ldots \ldots \ldots \ldots \ldots \ldots \ldots$

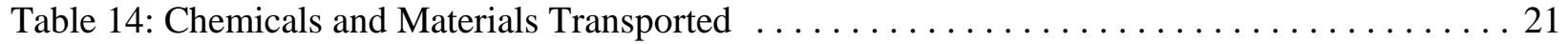

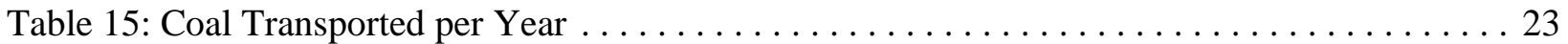

Table 16: Yearly Barge \& Train Deliveries Required for Coal Transport -

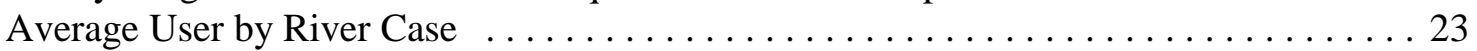

Table 17: Barge, Train, and Truck Material Requirements $\ldots \ldots \ldots \ldots \ldots \ldots \ldots \ldots \ldots \ldots$

Table 18: Plant Material Requirements (Base Case) $\ldots \ldots \ldots \ldots \ldots \ldots \ldots \ldots \ldots \ldots \ldots \ldots$

Table 19: Power Plant Resource/Input Requirements (Base Case) . . . . . . . . . . . . . . . . 25

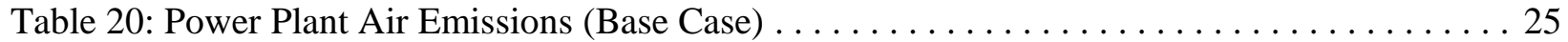

Table 21: Power Plant Solid Wastes (Base Case) . . . . . . . . . . . . . . . . . . . . . 26

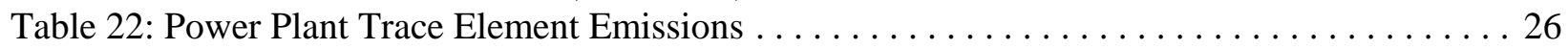

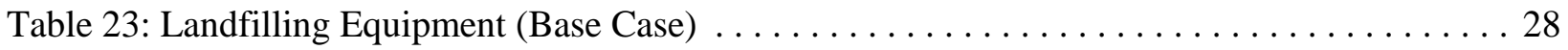

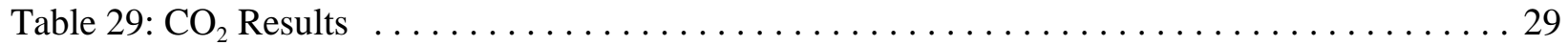

Table 24: Average Resource Consumption per kWh of Net Electricity Produced -

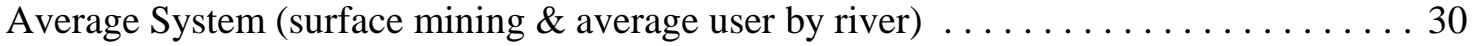

Table 25: Average Air Emissions per kWh of Net Electricity Produced -

Average System (surface mining \& average user by river) $\ldots \ldots \ldots \ldots \ldots \ldots \ldots$

Table 26: Average Water Emissions per kWh of Net Electricity Produced -

Average System (surface mining $\&$ average user by river) $\ldots \ldots \ldots \ldots \ldots \ldots \ldots$

Table 27: Average Energy Requirements per kWh of Net Electricity Produced -

Average System (surface mining $\&$ average user by river) $\ldots \ldots \ldots \ldots \ldots \ldots \ldots \ldots$

Table 28: Average Solid Waste Generation per kWh of Net Electricity Produced -

Average System (surface mining \& average user by river) $\ldots \ldots \ldots \ldots \ldots \ldots \ldots \ldots \ldots \ldots \ldots$

Table 30: Measuring $\mathrm{CO}_{2}$ Emissions - Definitions and Numbers $\ldots \ldots \ldots \ldots \ldots \ldots \ldots \ldots \ldots$

Table 31: Breakdown of Non-Coal $\mathrm{CO}_{2}$ Results for Lime and Limestone $\ldots \ldots \ldots \ldots \ldots$

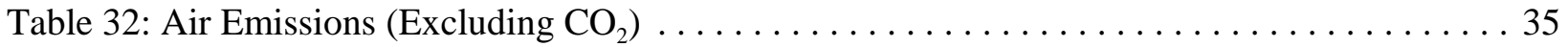

Table 33: Energy Efficiency and Energy Ratio Definitions $\ldots \ldots \ldots \ldots \ldots \ldots \ldots \ldots \ldots \ldots \ldots$

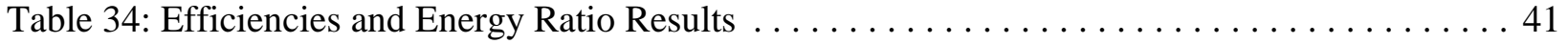

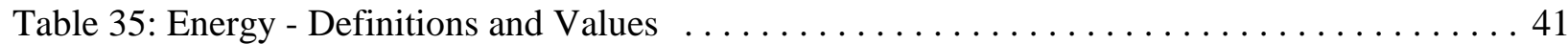

Table 36: Breakdown of Non-Coal Energy for Lime and Limestone $\ldots \ldots \ldots \ldots \ldots \ldots \ldots \ldots 42$

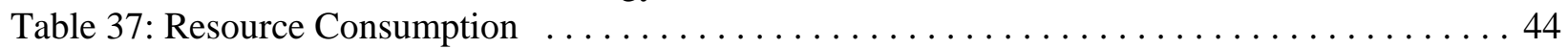

Table 38: Sensitivity Analysis Condensed Results - Average System (surface mining) . . . . . . . 49

Table 39: Sensitivity Analysis Efficiencies and Energy Ratios - Average System . . . . . . . . . 50 
Table 40: Sensitivity Results for Power Plant Efficiency - Percent Change . . . . . . . . . . 53

Table 41: Energy Efficiencies and Ratios -

Sensitivity Results for Changes in Power Plant Efficiency $\ldots \ldots \ldots \ldots \ldots \ldots \ldots$

Table 42: Plant Material Requirements Used in Sensitivity Analysis . . . . . . . . . . . . 54

Table 43: Coal Mining Methane Emissions Used in Sensitivity . . . . . . . . . . . 55

Table 44: Energy Efficiencies and Ratios - Sensitivity Results for Changes in Transportation . . . . 56

Table 45: Most Significant Stressor Results for Changes in Transportation . . . . . . . . . 56

Table 46: Recovered FGC Waste Sensitivity Numbers (Average and NSPS only) . . . . . . 58

Table 47: Recovered Ash Sensitivity Numbers (Average, NSPS, \& LEBS) . . . . . . . . . . 58

Table 48: Impacts Associated with Stressor Categories $\ldots \ldots \ldots \ldots \ldots \ldots \ldots \ldots \ldots \ldots \ldots \ldots$

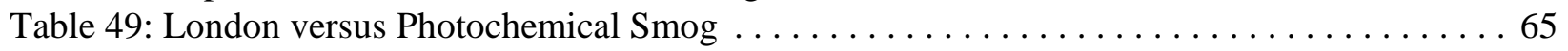

Table 50: Aquatic Organisms Lost - Due to Acidification of Lakes and Streams . . . . . . . . 67

Table 51: Comparison of Limestone FGC versus Copper Oxide Process . . . . . . . . . . . 80

Table 52: Coal Mining Methane Emissions for $1996 \ldots \ldots \ldots \ldots \ldots \ldots \ldots \ldots \ldots \ldots \ldots \ldots \ldots$

Table 53: Applications and Requirements for Recovered Methane . . . . . . . . . . . . 82

Table 54: Power Plant FGC Waste and Ash $\ldots \ldots \ldots \ldots \ldots \ldots \ldots \ldots \ldots \ldots \ldots \ldots \ldots$ 


\section{Contents of Appendix B: Additional Tables}

Table B1: Average Resource Consumption per kWh of Net Electricity Produced Average System (underground mining \& average user by river)

Table B2: Average Air Emissions per kWh of Net Electricity Produced Average System (underground mining \& average user by river)

Table B3: Average Water Emissions per kWh of Net Electricity Produced Average System (underground mining \& average user by river)

Table B4: Average Energy Requirements per kWh of Net Electricity Produced Average System (underground mining \& average user by river)

Table B5: Average Solid Waste Generation per kWh of Net Electricity Produced Average System (underground mining \& average user by river)

Table B6: Average Resource Consumption per kWh of Net Electricity Produced NSPS System (surface mining \& average user by river)

Table B7: Average Air Emissions per kWh of Net Electricity Produced NSPS System (surface mining \& average user by river)

Table B8: Average Water Emissions per kWh of Net Electricity Produced NSPS System (surface mining \& average user by river)

Table B9: Average Energy Requirements per kWh of Net Electricity Produced NSPS System (surface mining \& average user by river)

Table B10: Average Solid Waste Generation per kWh of Net Electricity Produced NSPS System (surface mining \& average user by river)

Table B11: Average Resource Consumption per kWh of Net Electricity Produced NSPS System (underground mining \& average user by river)

Table B12: Average Air Emissions per kWh of Net Electricity Produced NSPS System (underground mining \& average user by river)

Table B13: Average Water Emissions per kWh of Net Electricity Produced NSPS System (underground mining \& average user by river)

Table B14: Average Energy Requirements per kWh of Net Electricity Produced NSPS System (underground mining \& average user by river)

Table B15: Average Solid Waste Generation per kWh of Net Electricity Produced NSPS System (underground mining \& average user by river)

Table B16: Average Resource Consumption per kWh of Net Electricity Produced LEBS System (surface mining \& average user by river)

Table B17: Average Air Emissions per kWh of Net Electricity Produced LEBS System (surface mining \& average user by river)

Table B18: Average Water Emissions per kWh of Net Electricity Produced LEBS System (surface mining \& average user by river)

Table B19: Average Energy Requirements per kWh of Net Electricity Produced LEBS System (surface mining \& average user by river)

Table B20: Average Solid Waste Generation per kWh of Net Electricity Produced LEBS System (surface mining \& average user by river)

Table B21: Average Resource Consumption per kWh of Net Electricity Produced LEBS System (underground mining \& average user by river)

Table B22: Average Air Emissions per kWh of Net Electricity Produced LEBS System (underground mining \& average user by river) 
Table B23: Average Water Emissions per kWh of Net Electricity Produced -

LEBS System (underground mining \& average user by river)

Table B24: Average Energy Requirements per kWh of Net Electricity Produced LEBS System (underground mining \& average user by river)

Table B25: Average Solid Waste Generation per kWh of Net Electricity Produced LEBS System (underground mining \& average user by river)

Table B26: Sensitivity Analysis Condensed Results - Average System (underground mining)

Table B27: Sensitivity Analysis Condensed Results - NSPS System (surface mining)

Table B28: Sensitivity Analysis Condensed Results - NSPS System (underground mining)

Table B29: Sensitivity Analysis Condensed Results - LEBS System (surface mining)

Table B30: Sensitivity Analysis Condensed Results - LEBS System (underground mining)

Table B31: Sensitivity Analysis Efficiencies and Energy Ratios - NSPS System

Table B32: Sensitivity Analysis Efficiencies and Energy Ratios - LEBS System 


\section{Contents of Appendix C: Additional Figures}

Figure C1: Yearly Carbon Dioxide Emissions (underground mining \& average user by river)

Figure $\mathrm{C} 2$ : Yearly Sulfur Oxide Emissions $\left(\mathrm{SO}_{\mathrm{x}}\right.$ as $\left.\mathrm{SO}_{2}\right)$ (underground mining \& average user by river) Figure C3: Yearly Nitrogen Oxide Emissions $\left(\mathrm{NO}_{\mathrm{x}}\right.$ as $\left.\mathrm{NO}_{2}\right)$ (underground mining \& average user by river)

Figure C4: Yearly Methane Emissions (underground mining \& average user by river)

Figure C5: Yearly Total Non-Coal Energy Consumption (underground mining \& average user by river)

Figure C6: Sensitivity Results for Life Cycle Efficiency - NSPS System, Surface Mining Case

Figure C7: Sensitivity Results for External Energy Efficiency - NSPS System, Surface Mining Case

Figure C8: Sensitivity Results for Net Energy Ratio - NSPS System, Surface Mining Case

Figure C9: Sensitivity Results for External Energy Ratio - NSPS System, Surface Mining Case

Figure C10: Sensitivity Results for Life Cycle Efficiency - LEBS System, Surface Mining Case

Figure C11: Sensitivity Results for External Energy Efficiency - LEBS System, Surface Mining Case

Figure C12: Sensitivity Results for Net Energy Ratio - LEBS System, Surface Mining Case

Figure C13: Sensitivity Results for External Energy Ratio - LEBS System, Surface Mining Case 


\section{Units of Measure}

Metric units of measure are used in this report. Therefore, material consumption is reported in units based on the gram (e.g., kilogram or megagram), energy consumption based on the joule (e.g., kilojoule or megajoule), and distance based on the meter (e.g., kilometer). When it can contribute to the understanding of the analysis, the English system equivalent is stated in parenthesis. The metric units used for each parameter are given below, with the corresponding conversion to English units.

Mass: $\quad$ kilogram $(\mathrm{kg})=2.205$ pounds

megagram $(\mathrm{Mg})=$ metric tonne $(\mathrm{T})=1 \times 10^{6} \mathrm{~g}=1.102$ ton $(\mathrm{t})$

Distance: $\quad$ kilometer $(\mathrm{km})=0.62$ mile $=3,281$ feet

Area: $\quad$ hectare $\left(\right.$ ha) $=10,000 \mathrm{~m}^{2}=2.47$ acres

Volume: $\quad$ cubic meter $\left(\mathrm{m}^{3}\right)=264.17$ gallons

Pressure: $\quad$ kilopascals $(\mathrm{kPa})=0.145$ pounds per square inch

Energy: $\quad$ gigajoule $(\mathrm{GJ})=0.9488 \mathrm{MMBtu}($ million $\mathrm{Btu})$

kilowatt-hour $(\mathrm{kWh})=3,414.7 \mathrm{Btu}$

gigawatt-hour $(\mathrm{GWh})=3.4 \times 10^{9} \mathrm{Btu}$

Power: megawatt $(\mathrm{MW})=1 \times 10^{6} \mathrm{~J} / \mathrm{s}$

Temperature: ${ }^{\circ} \mathrm{C}=\left({ }^{\circ} \mathrm{F}-32\right) / 1.8$ 


\section{Abbreviations and Terms}

CAAA - 1990 Clean Air Act Amendments

CFC - chloroflourocarbons

CFR - Code of Federal Regulations

DEAM - Data for Environmental Analysis and Management (TEAM ${ }^{\circledR}$ database)

EIA - Energy Information Administration

EPRI - Electric Power Research Institute

FETC - Federal Energy Technology Center

FGC - flue gas clean-up

GWP - global warming potential

HAP - hazardous air pollutant

HHV - higher heating value

IEA - International Energy Agency

IGCC - integrated gasification combined cycle

IPCC - Intergovernmental Panel on Climate Change

LCA - life cycle assessment

LEBS - low emission boiler system

MAF - moisture and ash free (coal)

MM - million

MMBtu - million British thermal units

Mulch - A natural or artificial layer of plant residue or other materials placed on the soil surface to protect seeds, to prevent blowing, to retain soil moisture, to curtail erosion, and to modify soil temperature

non-coal $\mathrm{CO}_{2}$ - Total system $\mathrm{CO}_{2}$ emissions minus the $\mathrm{CO}_{2}$ emissions generated from coal combustion

non-coal energy - The total energy consumed by the system excluding the energy content of the coal to the power plant

NMHCs - non-methane hydrocarbons, including VOCs

NREL - National Renewable Energy Laboratory

NSPS - New Source Performance Standard

OECD - Organization for Economic Co-operation and Development

Overburden - The earth, rock, and other material that lie above the coal

PAN - peroxyacetal nitrate

ppmv - parts per million by volume

Reclamation- The process of reconverting mined land to its former or other productive uses

Stressor - A term that collectively defines emissions, resource consumption, and energy use; a substance or activity that results in a change to the natural environment

Stressor category - A group of stressors that defines possible impacts

TEAM $^{\circledR}$ - Tools for Environmental Analysis and Management (software by Ecobalance, Inc.)

U.S. DOE - United States Department of Energy

U.S. EPA - United States Environmental Protection Agency

VOC - volatile organic compound 


\subsection{Introduction}

The history of the United States is closely linked with the availability and use of coal (U.S. DOE, 1995). Since 1984, and at varying times before that, coal has been the leading single source of energy in the U.S. (U.S. DOE, 1998), now accounting for $35.3 \%$ of all energy produced. Coal accounts for greater than $56 \%$ of the fuel consumed in making electricity in the U.S., and $87 \%$ of all coal consumed is used in coalfired power plants. Along with its enormous contributions to society's demand for energy, the use of coal has resulted in some negative environmental effects. Coal mining can result in the destruction of land which is strip mined, the production of overburden waste and slag heaps, mine fires, and the occasional collapse of underground mines. At the power plant, sulfur dioxide, $\mathrm{NO}_{\mathrm{x}}$, and particulate matter are released into the air. In the production of electricity, coal is responsible for $93.4 \%$ and $80.2 \%$ of total U.S. $\mathrm{SO}_{2}$ and $\mathrm{NO}_{\mathrm{x}}$ emissions, respectively. Additionally, because coal is a fossil fuel, its use results in the production of $\mathrm{CO}_{2}$. In the U.S., coal is responsible for $35.8 \%$ of all $\mathrm{CO}_{2}$ production, and $73.5 \%$ of electric power plant $\mathrm{CO}_{2}$ (1997 AER, figure 12.5). The use of pollution control technologies and lowsulfur coals can result in dramatically lower environmental emissions from coal-fired power plants. Additionally, efforts to reclaim coal mines have minimized permanent damage to coal-bearing lands.

Because coal plays such a significant role in the generation of electricity in the U.S., understanding the impact it has on the environment is an important part of understanding energy and environmental issues in general. To this end, the National Renewable Energy Laboratory (NREL) has performed a life cycle assessment (LCA) on three coal-fired power systems. In addition to focusing on the impacts from the power plant, the emissions, resource consumption, and energy use of all processes required for the power plant to operate, including any necessary waste disposal and material recycling, were assessed. Figure 1 is a conceptual drawing of the coal-to-electricity system that was studied. To examine both the current status of electricity from coal as well as emerging and future technologies, three systems were examined: 1) a plant that represents the average emissions and efficiency of currently operating coal-fired power plants in the U.S., 2) a new coal-fired power plant that meets the New Source Performance Standards (NSPS), and 3) a highly advanced coal-fired power plant utilizing a low emission boiler system (LEBS).

All three power plants were assumed to use Illinois No. 6 coal, excavated from a mine located in central Illinois. Both surface (strip) and underground (longwall) mining were examined. The coal is transported via rail, truck, or a combination of rail and barge by one of four cases tested: average user by land, average user by river, farthest user, and mine mouth. Other materials such as chemicals and wastes are transported via truck and rail. The sizes of the Average, NSPS, and LEBS power plants are $360 \mathrm{MW}$, $425 \mathrm{MW}$, and $404 \mathrm{MW}$, respectively, and factor for the base case analysis each plant was assumed to operate at a $60 \%$ capacity.

The primary goal of this life cycle assessment is to quantify and analyze the environmental aspects of producing electricity from a coal-fired power system. All resources, emissions, and energy flows of each system were inventoried in a cradle-to-grave manner, including processes that are common between the three systems. These analyses, therefore, can be compared, but were not conducted for the purpose of

comparison. Rather, the total environmental picture of each system, distinct from the others, can be discerned from this analysis.

To quantify the total economic and environmental benefits and drawbacks of a process, an LCA can be performed in conjunction with a technoeconomic analysis. The results of the LCA can be used to 
Figure 1: Conceptual Drawing: Coal LCA System

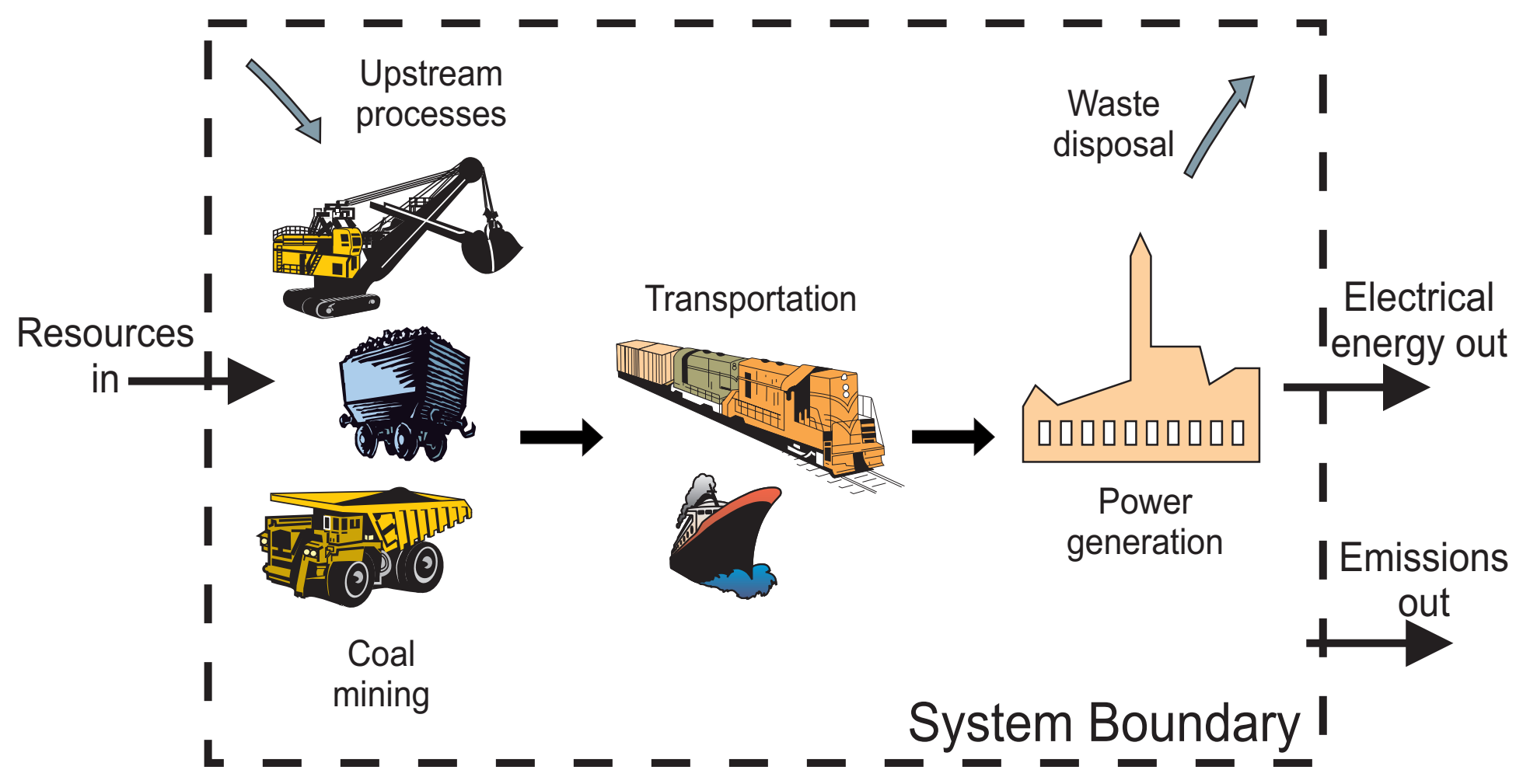


identify opportunities to reduce the environmental burden of the system through design improvements. The cost of these changes, can then be assessed using the model developed for the economic analysis. Because many economic studies have been conducted on these coal systems in the past by groups such as the Federal Energy Technology Center (FETC), the Electric Power Research Institute (EPRI), Bechtel, and others, economics were not examined as a part of this work. However, recommendations on design changes to be incorporated in the future are made, in section 10.0 and the parts of the system that are responsible for the highest rates of emissions, resource consumption, and energy use are identified in section 6.0 of the report.

\subsection{Methodology}

The methodology used in conducting this LCA is based on the standard three-component model set forth by the Society of Environmental Toxicology and Chemistry (SETAC, 1991). The first component, inventory, consists of material and energy balances for each process within the system. These flows are added to give the total emissions, resource consumption, and energy use for the system. In performing the second component, improvement, the results of the inventory step are assessed to identify opportunities to reduce the effects the system has on the environment. Process changes, material substitution, and recycling possibilities are explored.

The third component, impact assessment, is the least developed and most controversial of the three. Several options for describing the possible impacts on the environment as a result of the system exist. The method for impact assessment that is often the most attractive, valuation, is also the most subjective. It involves assigning values to each environmental stressor (emission, resource used, or amount of energy consumed) based on its perceived impact; a total "score" or "set of scores" can then be determined for each system studied. The determination of the severity of an impact when assigning a score to it is highly dependent upon the frame of reference of the analyst or purpose of the study. A less contentious method is known as categorization. Each stressor is assigned to one or more stressor categories to obtain a qualitative picture of the possible impacts on the environment. Example stressor categories are greenhouse gases, ozone depleters, carcinogens, resource depletion, and habitat changes. This method, while not providing a quantitative measure of the potential environmental damages, assists in the overall understanding of environmental benefits and drawbacks of a process. Finally, a less-is-better approach may be taken during the impact assessment phase of conducting an LCA. In this method, fewer emissions, less resource consumption, and less energy use are aimed for. This approach can be applied to either analyses of single systems by revealing whether or not design changes made during the improvement stage of the assessment actually reduced environmental damage, or to comparative analyses by determining which system results in lower amounts of a certain stressor. This method cannot, however, distinguish which system has the greatest consequences if they result in different stressors. For example, it is difficult and debatable to say whether a system that emits higher levels of greenhouse gases is better or worse than a system that results in the release of carcinogens to the environment. For this study, the less-is-better and categorization approaches were taken.

\subsection{System Boundaries and Data Availability}

The system boundaries for this LCA were drawn as broadly as possible; all of the major processes necessary to produce electricity from coal such as coal mining, equipment manufacturing, transportation, and chemicals production for the mining and power plant operations were included. The material and energy flows of processes involved in the extraction of raw materials and the production of intermediate 
feedstocks (e.g., limestone used in the gas clean-up process at the power plant) as well as the disposal of wastes were included. Figures 2 and 3 show the processes analyzed. The solid lines in these figures represent actual material and energy flows, while the dotted lines indicate logical connections between process blocks. "Other upstream processes" refers to major manufacturing steps needed to produce intermediate feedstocks such as ammonia required for the ammonium nitrate production used in surface mining.

\subsection{Methodology - Energy Considerations}

The energy use within the system was tracked so that the net energy production could be assessed. The two types of energy that were accounted for are: 1) the energy used directly in each process block, and 2 ) the energy contained in the materials used in each process block. The second type of energy is the sum of combustion and process energies which is sometimes referred to as the embodied energy of a material. Refer to Mann and Spath (1997) for an explanation of these types of energy. To determine the net energy in this LCA, the energy used directly in each process block plus the embodied energy of all materials consumed by the system, were subtracted from the energy produced by the power plant.

The non-coal energy consumption is defined as the total energy consumed by the system excluding the energy content of the coal to the power plant. As expected, this accounts for the majority of the total energy consumed, thus overshadowing other consumers of energy within the system. Results in this report will be given in terms of the non-coal energy, although the life cycle efficiency parameter, defined in section 6.4, illustrates the effect the coal energy has on the overall system energy results.

The methodology used to track energy in these systems is based on what is commonly known as a "first law analysis." This means that the amount reported is based on the total energy contained in the various materials flowing through the systems. Therefore, the net energy does not represent the total amount of available energy, calculated in what is commonly known as an exergy or "second law" analysis. Available energy is a representation of the energy of the various materials in the system, standardized to the amount of useful work that could be derived from them. For example, a joule of energy in the coal, derived from its higher heating value, cannot do the same amount of work as a joule of energy in the form of the product electricity. Although a second law energy analysis puts all forms of energy onto a common basis, first law analyses are well-accepted and well-understood within scientific communities. Future life cycle assessments will be performed to include both types of energy analysis. For a more detailed description of the complicated notion of second law analysis, see Moran (1989).

\subsection{Methodology - Comparison with Other Systems}

This LCA was performed as a stand-alone analysis (i.e., no comparative analysis was performed) studied in a cradle-to-grave manner. This was done so that the practice of not including operations that are common between competing processes would be avoided. Thus, the assessment reveals the total life cycle emissions, resource consumption, and energy use of these systems, irrespective of any competing technologies. Ultimately, the results from this analysis will be compared to a previously completed LCA of electricity production from a biomass gasification combined-cycle (BIGCC) power plant (Mann and Spath, 1997). Additionally, because the methodology used is applicable to all manufacturing and energyproducing systems, comparisons can be made with other studies as they are completed. The next step will be to examine electricity production via co-firing biomass in a coal-fired boiler. Other future 
Figure 2: Coal Production and Transportation Boundaries for Life Cycle Assessment

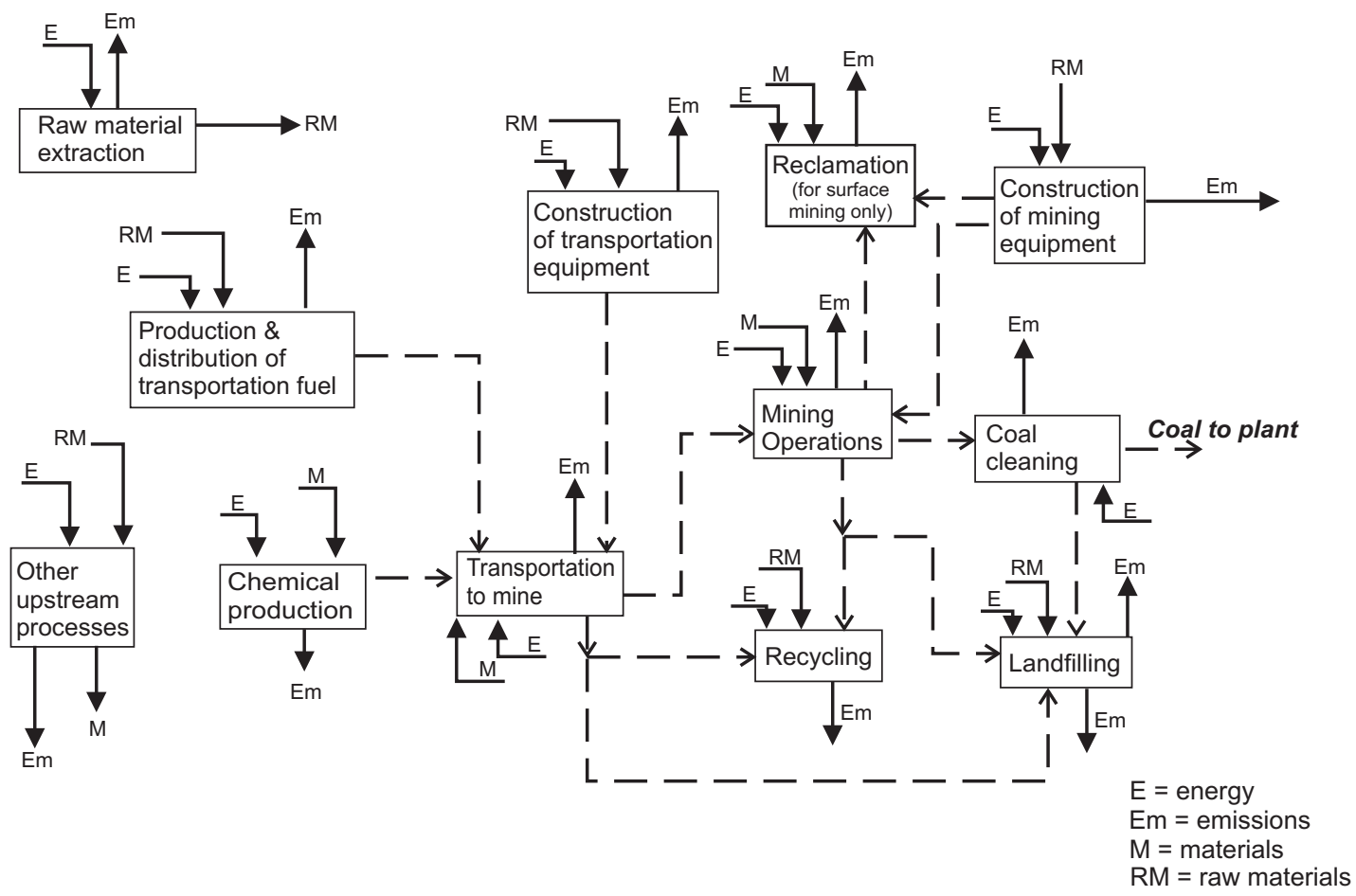

Figure 3: Power Generation and Transportation Boundaries for Life Cycle Assessment

E

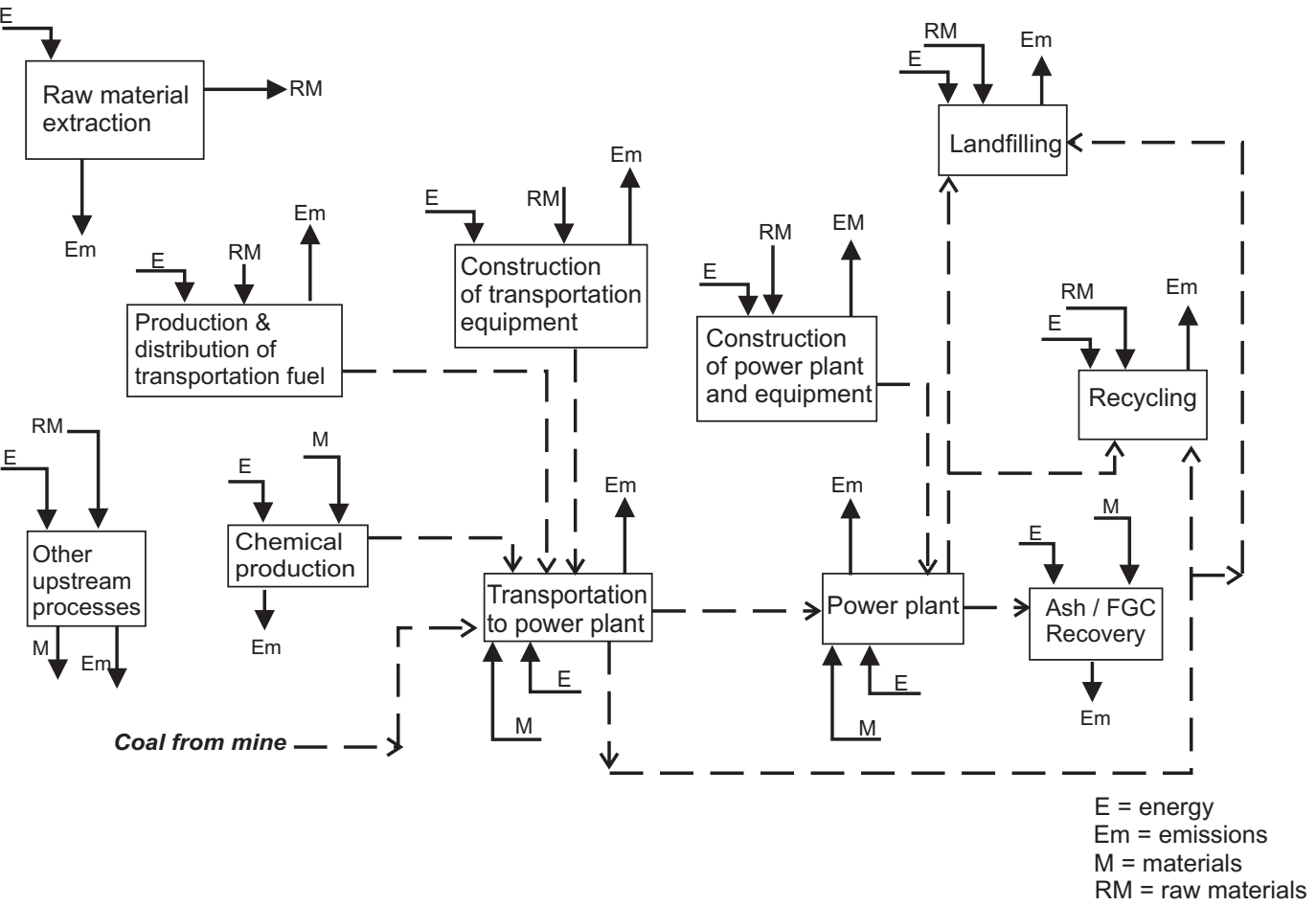


studies include electricity generation systems for direct wood combustion, natural gas-fired power systems, and power plants using different biomass feedstocks such as alfalfa and switchgrass.

\subsection{Methodology - Sensitivity Analysis}

A sensitivity analysis was conducted to determine the parameters that had the largest effects on the results and to determine the impact of estimated data as well as variations in data on the conclusions. Variables included in the sensitivity analysis were chosen to reflect system areas that had inherently more unknowns in the data as well as areas in which variations will likely occur during normal operations. Each parameter was changed independently of all others so that the magnitude of its effect on the base case could be assessed. Therefore, no one single sensitivity case reflects the best or worse-case scenarios for this system. However, any dependence other variables have on the variable being changed is taken into account. For instance, changing the power plant efficiency affects the amount of coal required at the plant, which in turn affects the coal mining and transportation requirements. These effects were taken into account automatically in the LCA model.

\subsection{Accounting}

The software package used for this study to track the material and energy flows between the process blocks within the system was Tools for Environmental Analysis and Management $\left(\mathrm{TEAM}^{\circledR}\right)$, by Ecobalance, Inc. The process blocks within the coal-fired power production system that were available in the TEAM ${ }^{\circledR}$ database, known as Data for Environmental Analysis and Management (DEAM), are shown in Table 1. Note that this table does not encompass all processes analyzed, but only those taken from the DEAM database.

Table 1: Process Blocks Taken from DEAM

\begin{tabular}{|ll|}
\hline - Natural gas production & $\bullet$ Aluminum production from ore and scrap \\
- Electricity production (U.S. overall and region-specific) & - Steel production from ore and scrap \\
- Diesel oil production & $\bullet$ Iron production from ore and scrap \\
- Liesel oil combustion & $\bullet$ Landfilling waste materials \\
- Light fuel oil combustion & $\bullet$ Ammonia production \\
- Heavy fuel oil production & - Sulfuric acid production \\
- Heavy fuel oil combustion & $\bullet$ Lime production \\
\hline
\end{tabular}

Processes within the system that were not available in DEAM were constructed manually. Data were obtained from the literature and from industry, and entered into TEAM ${ }^{\circledR}$. Calculations were then performed using TEAM $^{\circledR}$ on the entire coal system and reported in spreadsheet format. Appendix A contains the screen printouts for this analysis from the TEAM ${ }^{\circledR}$ software. In rare cases in this assessment, data for some parts of the coal system were sparse or inaccessible, or available for only some elements of a process. For example, water emissions resulting from coal leachate and from mine drainage were not included in this analysis due to lack of data. Such instances are specifically stated in this report.

The functional unit, also known as the production amount that represents the basis for the analysis, was chosen to be the unit of energy produced. Most results are presented per kWh or per MWh of net electricity produced by the power plant. Because the resources consumed, emissions, and energy use 
are functions of the size of the plant and the technology, care should be taken in scaling results to larger or smaller facilities, or applying them to other coal systems.

\subsection{Time Frame and Issues in Assessing Environmental Consequences}

Most life cycle assessments are performed on a plant-life basis. That is, the material and energy flows represent values seen in normal operating years or values averaged as though they are the same each year. However, because the environment experiences the impacts when they actually occur, averaging emissions and resource depletion makes the consequences look better or worse than they really are at any time during system operation. Therefore, this study was conducted on a yearly basis, taking into account each emission and resource use in the year it occurs. To obtain this information, a separate inventory of the system was conducted 32 times, once for each year of operation. This was done for each of the three power plant systems examined, resulting in a total of 96 separate analyses.

The power plant life was set at 30 years. Year one is that in which the power plant begins to operate; plant construction takes place in the two years before start-up (years negative two and negative one). In years one through 29, coal mining and normal plant operation occur and in year 30 the power plant is decommissioned. Table 2 more clearly spells out the yearly operations.

Table 2: Major Yearly Operations of the Three Subsystems

\begin{tabular}{|c|c|c|c|}
\hline \multirow[t]{2}{*}{ Year } & \multicolumn{3}{|c|}{ System operations } \\
\hline & Coal mining & Transportation & Electricity generation \\
\hline-2 & None & $\begin{array}{l}\text { Rail car and truck production for } \\
\text { equipment transport } \\
\text { Transport of power plant equipment }\end{array}$ & $\begin{array}{l}\text { Power plant } \\
\text { construction }\end{array}$ \\
\hline-1 & None & $\begin{array}{l}\text { Decommissioning of trucks and rail car } \\
\text { used for equipment transport } \\
\text { Transport of power plant equipment }\end{array}$ & $\begin{array}{l}\text { Power plant } \\
\text { construction }\end{array}$ \\
\hline 1 & $\begin{array}{l}\text { Mining equipment production } \\
\text { Mining of the coal required for } \\
\text { power plant operation in year } 1\end{array}$ & $\begin{array}{l}\text { Rail car, barge, and truck production } \\
\text { Transport } 50 \% \text { of the coal required for } \\
\text { operation of the power plant at } 60 \% \\
\text { capacity }\end{array}$ & $\begin{array}{l}\text { Operation at } 50 \% \text { of } \\
60 \% \text { of capacity } \\
\text { ( } 30 \% \text { capacity factor) }\end{array}$ \\
\hline $2-29$ & $\begin{array}{l}\text { Mining of the coal required for } \\
\text { power plant operation } \\
\text { Surface mining equipment } \\
\text { production and decommissioning in } \\
\text { years } 10,12,20 \text {, and } 24 \\
\text { Underground mining equipment } \\
\text { production and decommissioning in } \\
\text { years } 5,8,10,15,16,20,24 \text {, and } 25\end{array}$ & $\begin{array}{l}\text { Transport all of the coal required for } \\
\text { operation of the power plant at } 60 \% \\
\text { capacity } \\
\text { Truck production and decommissioning } \\
\text { of trucks in years } 7,15 \text {, and } 22\end{array}$ & $\begin{array}{l}\text { Operation at } 60 \% \text { of } \\
\text { capacity }\end{array}$ \\
\hline
\end{tabular}




\begin{tabular}{|c|l|l|l|}
\hline \multirow{2}{*}{ Year } & \multicolumn{3}{|c|}{ System operations } \\
\cline { 2 - 4 } & \multicolumn{1}{|c|}{ Coal mining } & \multicolumn{1}{|c|}{ Transportation } & Electricity generation \\
\hline 30 & $\begin{array}{l}\text { Mining of the coal required for } \\
\text { power plant operation in year 30 } \\
\text { Reclamation for surface mining } \\
\begin{array}{l}\text { Decommissioning of mining } \\
\text { equipment }\end{array}\end{array}$ & $\begin{array}{l}\text { Transport 75\% of the coal required for } \\
\text { operation of the power plant at 60\% } \\
\text { capacity } \\
\text { Decommissioning of rail cars, barges, } \\
\text { and trucks }\end{array}$ & $\begin{array}{l}\text { Operation at 75\% of } \\
60 \% \text { of capacity } \\
\text { (45\% capacity factor) } \\
\text { Decommissioning of } \\
\text { power plant }\end{array}$ \\
\hline
\end{tabular}

\subsection{Description of Pulverized Coal Boiler Plants Studied}

All three power plant systems examined (Average, NSPS, and LEBS) incorporate pulverized coal boilers. From their extensive data sets and expertise in the field, researchers at the Federal Energy Technology Center provided information on the performance, resource consumption, emissions, and waste generation for the three power plant designs. A separate LCA was conducted for each system. Because the power plant data for each case were taken from a specific plant or model, detailed in the following sections, the plant sizes for the Average, NSPS, and LEBS systems vary from $360 \mathrm{MW}$ to $425 \mathrm{MW}$. The methodology and assumptions for the mining and transportation subsystems remained the same from system to system, but varied according to the amount of coal required by each plant. The electricity generation subsystem was changed to match the material and energy requirements of the power plants as outlined in the following three sections (see section 5.4 for more details about the specific resource and emissions data used for each system).

An entirely different coal technology, integrated gasification combined cycle (IGCC), was not included in this analysis. Rather than using a pulverized coal boiler and a steam cycle, IGCC uses coal gasification to produce a combustible gas that generates electricity in a gas turbine; steam is produced in a heat recovery steam generator, and used to produce more electricity in a steam turbine. Current plans are to examine this system in future LCAs conducted by NREL and FETC.

\subsection{Average Plant}

The Average coal power plant consists of the following main equipment/process steps: pulverized coal boiler, baghouse filter, conventional limestone flue gas clean-up (FGC) system, heat recovery steam generator, and steam turbine (see Figure 4). The emissions for this system represent the average emissions from all U.S. coal-fired power plants in 1995. These were calculated by dividing the total coalgenerated U.S. emissions of a particular pollutant on a weight basis $(\mathrm{kg})$ by the total electricity generated $(\mathrm{kWh})$ from coal in the U.S. (Utility Data Institute, 1996). To maintain a mass balance around the power plant, a specific plant with emissions similar to the calculated averages and feeding the designated type of coal for this LCA was identified from the database. The actual resource requirements, final emissions, and energy consumption from this identified plant were used to represent the Average power plant in the study. The efficiency is typical of an average base-load plant operating in the U.S. in 1995. Table 3 contains the key power plant parameters for this system. 
Table 3: Plant Information for Average System

\begin{tabular}{|l|l|}
\hline \multicolumn{1}{|c|}{ Design parameter } & \multicolumn{1}{|c|}{ Data } \\
\hline Plant capacity & $360 \mathrm{MW}$ (net, 100\% capacity) \\
\hline Operating capacity factor - base case & $60 \%$ \\
\hline Coal feed rate @ 100\% operating capacity & $3,872,198 \mathrm{~kg} /$ day (as-received) \\
\hline Power plant efficiency & $32 \%$ \\
\hline
\end{tabular}

\subsection{NSPS Plant}

Emissions for this system are calculated based on flue gas clean-up removal efficiencies such that the power plant meets the New Source Performance Standards (NSPS). Table 4 indicates the standards of performance for new electric utility steam generating units using fossil fuels, taken from the Code of Federal Regulations (40 CFR 60.42a, 60.43a, and 60.44a; Office of the Federal Register National Archives and Records Administration, 1996). New plants built after 1978 are required to meet these standards. This system has the same process configuration as the Average plant except that higher flue gas clean-up removal efficiencies are achieved through design changes such as boiler modifications such as low $\mathrm{NO}_{\mathrm{x}}$ burners or staged combustion.

Table 4: New Source Performance Standards for Fossil-Fueled Power Plants

\begin{tabular}{|l|c|}
\hline & $\begin{array}{c}\text { g/GJ heat input, HHV } \\
\text { (lb/MMBtu) }\end{array}$ \\
\hline $\mathrm{NO}_{\mathrm{x}}$ & $258(0.60)$ \\
\hline $\mathrm{SO}_{\mathrm{x}}$ & $258(0.60)$ \\
\hline Particulates & $13(0.03)$ \\
\hline
\end{tabular}

Table 5 contains power plant information used in this analysis for the NSPS system. The efficiency is typical of a base-load power plant which meets the NSPS standards.

Table 5: Plant Information for NSPS System

\begin{tabular}{|l|l|}
\hline \multicolumn{1}{|c|}{ Design parameter } & \multicolumn{1}{|c|}{ Data } \\
\hline Plant capacity & $425 \mathrm{MW}$ (net, 100\% capacity) \\
\hline Operating capacity factor - base case & $60 \%$ \\
\hline Coal feed rate @ 100\% operating capacity & $4,179,515 \mathrm{~kg} / \mathrm{day}$ (as-received) \\
\hline Power plant efficiency & $35 \%$ \\
\hline
\end{tabular}

In October 1998, the EPA enacted a regulatory requirement specifying a $\mathrm{NO}_{\mathrm{x}}$ emission reduction from 22 states east of the Mississippi River and the District of Columbia in order to reduce regional transport of ozone (Code of Federal Regulations, 1998). The designated states can meet the regulatory requirement by reducing emissions from any combination of large stationary sources. However, the largest $\mathrm{NO}_{\mathrm{x}}$ emitters are utilities and large non-utility point sources. The EPA has chosen to reduce 
Figure 4: Schematic of a Typical Coal-fired Power Plant

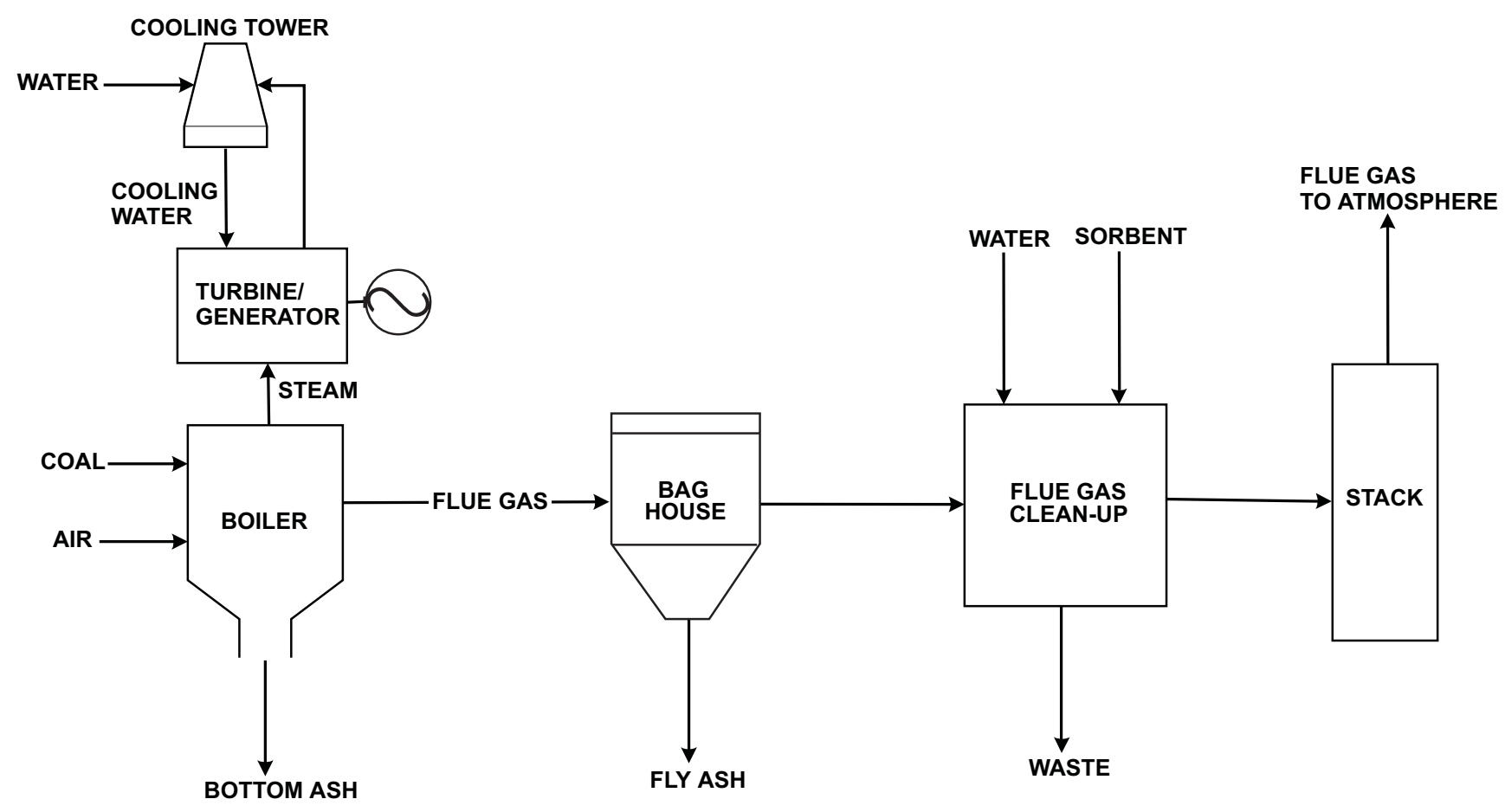

Figure 5: LEBS Commercial Generating Unit

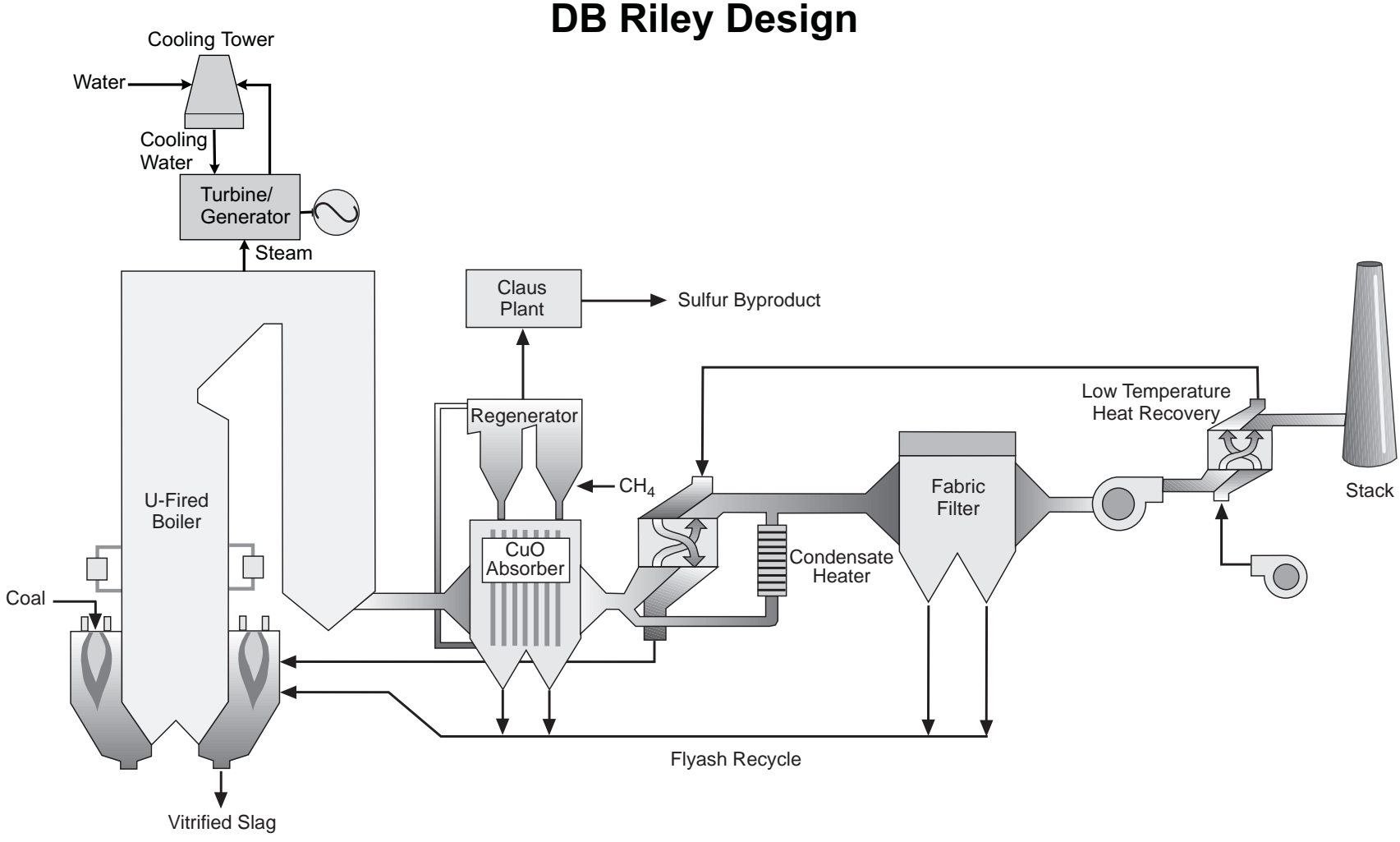


emissions to $65 \mathrm{~g}$ of $\mathrm{NO}_{\mathrm{x}} / \mathrm{GJ}$ of heat input $(0.15 \mathrm{lb} / \mathrm{MMBtu})$ from a power generation facility. This level is significantly less than the NSPS limit of $258 \mathrm{~g} / \mathrm{GJ}(0.60 \mathrm{lb} / \mathrm{MMBtu})$ listed in Table 4 . In response to this regulation, many power generation facilities will reduce their $\mathrm{NO}_{\mathrm{x}}$ emissions by adding a process step that incorporates selective catalytic reduction or selective noncatalytic reduction. This LCA could be modified to include one of these $\mathrm{NO}_{\mathrm{x}}$ reduction technologies by incorporating the resources, energy, and emissions related to ammonia production, transport, and use.

\subsection{LEBS Plant}

Emissions for this system are those forecasted from a future plant utilizing a Low Emission Boiler System. LEBS is projected to have significantly higher thermal efficiency, better performance, and a lower cost of electricity than current coal-fired power plants. The technology being considered in this assessment is by the developer, DB Riley Inc. (Ruth, 1997), and is being researched under the Department of Energy's sponsorship. The objective of the LEBS program is to produce technologies that result in lower emissions such that $\mathrm{NO}_{\mathrm{x}}$ and $\mathrm{SO}_{\mathrm{x}}$ emissions are 1/6 of those specified by NSPS and particulate emissions are $1 / 3$ of NSPS. The DB Riley technology uses a low- $\mathrm{NO}_{\mathrm{x}}$ system with advanced burners, air staging, and a wet ash slagging system. The copper oxide flue gas clean-up process utilizes a regenerable sorbent, removing both $\mathrm{SO}_{2}$ and $\mathrm{NO}_{\mathrm{x}}$ from the flue gas and producing sulfuric acid or sulfur as a by-product instead of creating a solid waste. $\mathrm{NO}_{\mathrm{x}}$ reduction occurs through the reaction of the sulfated sorbent with ammonia, which is injected prior to catalyst rejuvenation. The sorbent is then regenerated using natural gas as the reducing agent. Figure 5 is a sketch of what this theoretical plant would look like. Table 6 contains power plant information used in this analysis for the LEBS system.

Table 6: Plant Information for LEBS System

\begin{tabular}{|l|l|}
\hline \multicolumn{1}{|c|}{ Design parameter } & \multicolumn{1}{c|}{ Data } \\
\hline Plant capacity & $404 \mathrm{MW}$ (net, 100\% capacity) \\
\hline Operating capacity factor - base case & $60 \%$ \\
\hline Coal feed rate @ 100\% operating capacity & $3,229,556 \mathrm{~kg} / \mathrm{day}$ (as-received) \\
\hline Power plant efficiency & $42 \%$ \\
\hline
\end{tabular}

\subsection{Description of Coal Used in Analysis}

Many grades of coal are being used today to produce power. In general, coal is classified into one of four categories: lignite, subbituminous, bituminous, and anthracite. Often, depending on emissions requirements and economic considerations, a mix of different coals is used. For this analysis, the three power plant systems are assumed to use Illinois No. 6. This coal was chosen because it is representative of a widely available bituminous coal, for which a considerable amount of analysis work has been performed. Table 7 contains the elemental analysis and heating value of the coal used in this study. 
Table 7: Illinois No. 6 Coal Analysis

\begin{tabular}{|l|c|}
\hline Ultimate Analysis & (Weight $\%$, dry basis) \\
\hline Carbon & 70.0 \\
Oxygen & 10.3 \\
Hydrogen & 5.0 \\
Nitrogen & 1.1 \\
Sulfur & 4.0 \\
Chlorine & 0.1 \\
Ash & 9.5 \\
\hline Moisture, as-received (wt\%) & 15.5 \\
\hline Heat of combustion, & $25,120 \mathrm{~J} / \mathrm{g}$ \\
HHV, wet basis & $(10,800 \mathrm{Btu} / \mathrm{lb})$ \\
\hline
\end{tabular}

Illinois No. 6 coal accounts for roughly $80 \%$ of the coal mined in the State of Illinois and it is also mined in the adjacent States of Indiana and Kentucky. For this LCA the coal was assumed to be excavated from a mine located in central Illinois.

\subsection{Description of Process Blocks Studied in the LCA}

The processes studied in this life cycle assessment can be divided into three main subsystems: coal mining, transportation, and electricity generation. Refer again to Figures 2 and 3 for the operations within these subsystems that were examined. Material and energy flows were quantified for each process block; assumptions and data sources are given in the subsequent sections. The integration of each process within the entire system is shown in the TEAM $^{\circledR}$ software screen printouts attached as Appendix A. Resources, emissions, and energy use of some upstream processes were taken from the DEAM database (see section 2.5). Electricity production for use in upstream process blocks was assumed to be the generation mix of the mid-continental United States, which according to the National Electric Reliability Council, is composed of $64.7 \%$ coal, $5.1 \%$ lignite, $18.4 \%$ nuclear, $10.3 \%$ hydro, $1.4 \%$ natural gas, and $0.1 \%$ oil; distribution losses are taken at $7.03 \%$.

\subsection{Base Case Coal Mining Assumptions}

Depending on geological conditions, coal is obtained either by surface mining of outcrops or seams near the surface, or by underground mining. Where coal lies close enough to the surface and the cost to remove the coal is sufficiently low, the coal is mined by opencut or strip mining (Encyclopedia Americana, Intl. Ed., 1986). Surface mining involves fracturing and removing the overlying soil and rock, otherwise known as overburden, breaking the coal by blasting or mechanical means, and loading the coal for transport to its final destination. Two methods of underground mining commonly used are room-and-pillar and longwall. In room-and-pillar mining, the coal is removed from two sets of corridors that advance through the mine at right angles to each other. Regularly spaced pillars, constituting about half the coal seam, are left behind to support the overhead layers in the mined areas. The pillars may later be removed, leading to probable subsidence of the surface (Kirk-Othmer's Encyclopedia of Chemical Technology, 1993). In longwall mining two parallel headings are made about 100-200 meters apart and at right angles to the main heading. The longwall between the two headings is then mined away from the main heading. The equipment provides a movable roof support system that advances as the coal is mined and allows the roof to collapse in a controlled manner behind it. This method also leads to subsidence of the overhead layers (Kirk-Othmer's Encyclopedia of Chemical Technology, 1993). Approximately 
$62 \%$ of the coal in the U.S. is mined by surface mining, while $38 \%$ is obtained by underground mining (U.S. DOE, 1997).

The resources, environmental emissions, and energy use associated with the excavation of coal were included in this LCA. The processes studied include raw material extraction, equipment manufacture, coal mining, coal preparation/cleaning, all necessary transportation of chemicals, and any upstream processes (refer again to Figures 2 and 3 and to the TEAM ${ }^{\circledR}$ screen printouts in Appendix A). Both surface and underground mining were examined. The coal is either surface mined via strip mining or mined by the underground technique of longwall mining. The resources, energy, and emissions associated with the mining equipment are based on the types of machinery used for each coal excavation process, the fuel requirements, and the lifetime of the machinery. This information was gathered from various literature sources and mining companies. Additionally, the process steps involved in land reclamation are included in the surface mining option. As stated earlier, the mining techniques for a particular region are dictated by the geological and topographical conditions. Even where techniques are generally comparable, equipment choices and operation procedures may differ (Ullmann's Encyclopedia of Industrial Chemistry, 1986). Since a specific mine site was not chosen, the mining requirements for both surface and underground mining were based on previous studies by the Bureau of Mines (Sidney et al, 1976 and Duda and Hemingway, 1976, respectively). The following sections contain the details used in this analysis for each mining technique.

\subsubsection{Surface Coal Mining Equipment \& Mine Requirements}

Surface mining machinery is required for stripping, drilling, blasting, excavating, and hauling the coal. The coal surface mining requirements for each power plant system in this study were ratioed from the data given in Table 8 for a 4.4 MM tonne/year coal mine (Sidney et al, 1976). This information comes from an older mine design. Because it is anticipated that today's machinery has changed and possibly become more efficient, a sensitivity analysis was conducted to see how the surface mining requirements affect the results of this LCA (see section 8.8). The data in Table 8 were ratioed based on the following coal requirements for each power plant system: 0.89, 0.96, and 0.74 MM tonne/year of coal mined for the Average, NSPS, and LEBS system, respectively. These numbers are for a power plant operating at a $60 \%$ capacity factor and include a $5 \%$ haul loss.

Table 8: Surface Mining Equipment Material Requirements (Base Case)

\begin{tabular}{|l|r|r|r|r|}
\hline \multicolumn{1}{|c|}{ Equipment (a, b) } & Quantity & $\begin{array}{l}\text { Weight per piece of } \\
\text { equipment }(\mathrm{Mg})(\mathrm{c})\end{array}$ & $\begin{array}{c}\text { Assumed life } \\
\text { (years) }\end{array}$ & $\begin{array}{l}\text { Total steel requirement (Mg } \\
\text { per MM tonne/year of coal) }\end{array}$ \\
\hline $\begin{array}{l}\text { Stripping shovel } \\
\text { (removes overburden) }\end{array}$ & 2 & 3,799 & 30 & 1,727 \\
\hline Drill (overburden) & 4 & 97 & 12 & 88 \\
\hline Bulldozers & 8 & 43 & 10 & 78 \\
\hline $\begin{array}{l}\text { Coal shovel (loads coal into } \\
109 \text { tonne trucks) }\end{array}$ & 2 & 450 & 30 & 38 \\
\hline $\begin{array}{l}\text { Front-end loader } \\
\text { (with coal shovel) }\end{array}$ & 2 & 83 & 10 & 113 \\
\hline Truck (coal hauler - 109 tonne) & 7 & 71 & 12 & 38 \\
\hline
\end{tabular}




\begin{tabular}{|l|r|r|r|r|}
\hline \multicolumn{1}{|c|}{ Equipment (a, b) } & Quantity & $\begin{array}{c}\text { Weight per piece of } \\
\text { equipment }(\mathrm{Mg})(\mathrm{c})\end{array}$ & $\begin{array}{c}\text { Assumed life } \\
\text { (years) }\end{array}$ & $\begin{array}{l}\text { Total steel requirement (Mg } \\
\text { per MM tonne/year of coal) }\end{array}$ \\
\hline $\begin{array}{l}\text { Wheel tractor scraper } \\
\text { (reclamation \& roads) }\end{array}$ & 4 & 37 & 10 & 34 \\
\hline $\begin{array}{l}\text { Miscellaneous trucks: water, } \\
\text { lubrication service, mechanic, } \\
\text { welding, electrician, supply, } \\
\text { explosive, pickup, crane }\end{array}$ & 17 & 1.6 & 10 & \\
\hline
\end{tabular}

(a) Additional equipment for which specific data could not be obtained: road grader, cable handler and reel, and forklift.

(b) Includes reclamation equipment for regrading but not for mulching, liming, fertilizing, and seeding.

(c) Mining equipment weights were obtained from Martin et al, 1982 except for miscellaneous truck weights which were obtained from DynCorp, 1995.

The following are the utility and chemical requirements of the 4.4 MM tonne/year surface coal mine:

- electricity = 14,300 MWh/year/MM tonne of coal mined,

- fuel and oil = $269 \mathrm{~m}^{3} /$ year/MM tonne of coal mined, and

- ammonium nitrate $=2,070 \mathrm{Mg} / \mathrm{year} / \mathrm{MM}$ tonne of coal mined.

Again, these numbers were ratioed with the amount of coal mined to determine the quantities required for the Average, NSPS, and LEBS power plant.

\subsubsection{Surface Coal Mining Reclamation Requirements}

Surface mining completely alters the topography of the earth's surface and destroys the usefulness of the land for agriculture and other purposes. Many states have laws that require the reclamation of land after strip mining. The term "mined-land reclamation" refers to returning the disturbed land to a condition and/or use equal to or higher than that prior to mining (Persse et al, 1977). Normally, the land is reclaimed for agricultural use, rangeland, tree groves, or recreation. As a general rule, the use for which a mined area can best be reclaimed depends upon several factors that can be determined in the field (The American Institute of Mining, Metallurgical, and Petroleum Engineers, Inc., 1968 - Surface Mining.):

- the percentage of hard rock or shale in the overburden,

- the amount of sulfides or other materials toxic to plant growth in the rock or shale,

- the percentage of soil size particles, and

- the amount of lime, phosphate, and potash available for plant growth.

Land reclamation is included in the surface mining option of this LCA. The application of lime is not necessary in the State of Illinois because the $\mathrm{pH}$ of the soil is already high enough. Also, fertilizers are often not necessary because topsoil is replaced during the mining process. Therefore, neither component was included in this analysis. In addition to the equipment listed in Table 8, a tractor with disk was included in the analysis of the surface mining case. This uses $0.30 \mathrm{~m}^{3} /$ day of diesel fuel for 28 hectares of land coverage and has an equipment weight of $28 \mathrm{Mg}$ (Kerr, 1998). Additionally, an airplane for spring seeding and a grain drill for fall seeding are used in reclamation but was not included in this LCA due to lack of data. Table 9 contains the mulching and seeding requirements for reclamation of a 0.41 MM tonne/year mine (Spindler, 1998). These numbers were used to calculate the total amount of materials delivered to the mine site which in turn determined the transportation requirements including 
the number of trucks and trains and the fuel use. For this study the numbers in Table 9 were ratioed to match the coal requirements of the three power plant systems.

Table 9: Reclamation Mulching and Seeding Requirements (Base Case)

\begin{tabular}{|l|l|}
\hline \multicolumn{1}{|c|}{ Material } & \multicolumn{1}{c|}{ Application amount (kg/ha) } \\
\hline Straw & 4,482 (where necessary) \\
\hline Wheat & 101 (in the fall) \\
\hline Alfalfa & 11 \\
\hline Bromegrass & 6 \\
\hline Orchardgrass & 3 (in the spring) \\
\hline
\end{tabular}

\subsubsection{Underground Coal Mining Equipment \& Mine Requirements}

Underground mining operations include: cutting, drilling, blasting, loading, and hauling. Auxiliary operations include ventilation, drainage, power, communications, and lighting. Roof support is another task which was considered to be a unit operation. The underground coal mining requirements for this study were ratioed from the data given in Table 10 for a $1.4 \mathrm{MM}$ tonne/year coal mine (Duda and Hemingway, 1976). Similar to the surface mining option, a sensitivity analysis was conducted to see how the underground mining requirements affect the results of this LCA. Again, the data were ratioed based on the coal requirements for each power plant system.

Table 10: Underground Mining Equipment Material Requirements (Base Case)

\begin{tabular}{|c|c|c|c|c|}
\hline Equipment (a) & Quantity & $\begin{array}{l}\text { Weight per piece of } \\
\text { equipment }(\mathrm{Mg})(\mathrm{b})\end{array}$ & $\begin{array}{l}\text { Assumed life } \\
\quad(\mathrm{yrs})\end{array}$ & $\begin{array}{l}\text { Total steel requirement }(\mathrm{Mg} \\
\text { per } \mathrm{MM} \text { tonne/yr of coal })\end{array}$ \\
\hline Longwall unit & 2 & 45 & 5 & 64 \\
\hline Continuous miner & 3 & 50 & 10 & 107 \\
\hline Shuttle car & 6 & 18 & 8 & 77 \\
\hline Roof bolter & 4 & 14 & 20 & 40 \\
\hline Ratio feeder & 3 & 19 & 8 & 41 \\
\hline $\begin{array}{l}\text { Mantrip jeep, mechanic } \\
\text { jeep, personnel jeep }\end{array}$ & 11 & 1.6 & 10 & 13 \\
\hline Triple-rock duster & 3 & 6 & 8 & 13 \\
\hline Trickle duster & 3 & 6 & 8 & 13 \\
\hline Supply car & 30 & 1.9 & 8 & 41 \\
\hline 36 inch rope-type conveyor & $7.3 \mathrm{~km}$ & N/A & 30 & 798 \\
\hline Track & $8.4 \mathrm{~km}$ & N/A & 30 & 137 \\
\hline Front-end loader & 1 & 83 & 10 & 59 \\
\hline
\end{tabular}




\begin{tabular}{|l|r|r|r|r|}
\hline \multicolumn{1}{|c|}{ Equipment (a) } & Quantity & $\begin{array}{c}\text { Weight per piece of } \\
\text { equipment (Mg) (b) }\end{array}$ & $\begin{array}{c}\text { Assumed life } \\
\text { (yrs) }\end{array}$ & $\begin{array}{c}\text { Total steel requirement (Mg } \\
\text { per MM tonne/yr of coal) }\end{array}$ \\
\hline Bulldozer & 1 & 43 & 10 & 31 \\
\hline Utility truck, pickup truck & 2 & 1.6 & 10 & 2 \\
\hline
\end{tabular}

(a) Additional equipment for which specific data could not be obtained: loading machine, auxiliary fan, supply motor, ventilation fan, and forklift.

(b) Mining equipment weights were obtained from the following sources: Coal Age Equipment Guide, 1982; Hinser, 1998; Lucas, 1998; and Peele, 1927. Truck and jeep weights were obtained from DynCorp, 1995.

Dust results from the breaking of coal as it is excavated and transported through the underground mine. Rockdusting in which limestone is spread over the mine surfaces helps prevent coal dust explosions (Kirk-Othmer's Encyclopedia of Chemical Technology, 1993). The limestone required is 16,263 $\mathrm{Mg} /$ year/MM tonne of coal mined. Water and electricity requirements are $84,482 \mathrm{~m}^{3}$ and $12,755 \mathrm{MWh}$, respectively, per year per MM tonne of coal mined. The quantities used in the analyses of the Average, NSPS, and LEBS plants were ratioed from these data based on the coal requirements for each power plant system $(0.89,0.96$, and $0.74 \mathrm{MM}$ tonne/year of coal mined for the Average, NSPS, and LEBS system, respectively).

Table 11 gives a breakdown of the electrical details for the underground mining case. Again, these numbers are for a 1.4 MM tonne/year coal mine (Duda and Hemingway, 1976) and each system was ratioed from these figures.

Table 11: Underground Mining Electrical Requirements (Base Case)

\begin{tabular}{|c|c|c|c|c|c|}
\hline \multirow{2}{*}{ Equipment } & \multirow[b]{2}{*}{$\begin{array}{l}\text { Total } \\
\mathrm{kW}\end{array}$} & \multirow[b]{2}{*}{$\begin{array}{l}\text { Hours } \\
\text { used/day }\end{array}$} & \multirow[b]{2}{*}{$\begin{array}{l}\text { Load } \\
(\mathrm{kW})\end{array}$} & \multicolumn{2}{|c|}{ Electrical consumption } \\
\hline & & & & (MWh/day) & $\begin{array}{l}\text { (MWh/day/MM tonne } \\
\text { of coal mined) }\end{array}$ \\
\hline Longwall unit & 1,790 & 16 & 1,790 & 28.6 & 20.4 \\
\hline Continuous miner & 895 & 10 & 895 & 9.0 & 6.4 \\
\hline Loading machine & 239 & 10 & 239 & 2.4 & 1.7 \\
\hline Shuttle car & 403 & 10 & 403 & 4.0 & 2.9 \\
\hline Roof bolter & 75 & 12 & 75 & 0.9 & 0.6 \\
\hline Ratio feeder & 186 & 10 & 187 & 1.9 & 1.4 \\
\hline Auxiliary fan & 22 & 18 & 22 & 0.4 & 0.3 \\
\hline Mantrip jeep & 45 & 4 & 45 & 0.2 & 0.1 \\
\hline Mechanic jeep & 34 & 15 & 34 & 0.5 & 0.4 \\
\hline Personnel jeep & 22 & 15 & 22 & 0.3 & 0.2 \\
\hline Supply motor & 179 & 12 & 179 & 2.1 & 1.5 \\
\hline Triple-rock duster & 67 & 12 & 67 & 0.8 & 0.6 \\
\hline
\end{tabular}




\begin{tabular}{|c|c|c|c|c|c|}
\hline \multirow{2}{*}{ Equipment } & \multirow{2}{*}{$\begin{array}{l}\text { Total } \\
\mathrm{kW}\end{array}$} & \multirow{2}{*}{$\begin{array}{c}\text { Hours } \\
\text { used/day }\end{array}$} & \multirow{2}{*}{$\begin{array}{l}\text { Load } \\
(\mathrm{kW})\end{array}$} & \multicolumn{2}{|c|}{ Electrical consumption } \\
\hline & & & & (MWh/day) & $\begin{array}{l}\text { (MWh/day/MM tonne } \\
\text { of coal mined) }\end{array}$ \\
\hline 36 inch rope-type conveyor & 597 & 16 & 597 & 9.6 & 6.9 \\
\hline Ventilation fan & 373 & 24 & 373 & 9.0 & 6.4 \\
\hline Pumps, bolting, etc & 298 & 10 & 298 & 3.0 & 2.1 \\
\hline Shops, lighting, etc. & N/A & 24 & 268 & 6.4 & 4.6 \\
\hline
\end{tabular}

\subsubsection{Coal Preparation/Cleaning}

Coal preparation normally involves some size reduction of the mined coal and the removal of some ashforming material and rocks as well as very fine coal. Jig washing is the most widely used of all cleaning methods and therefore this is the technique used in this LCA (Kirk-Othmer's Encyclopedia of Chemical Technology, 1993). In the Jig cleaning process the coal is separated from the refuse by a pulsating flow of water. The lighter clean coal particulates exit at the top of the Jig and the heavier refuse particles go out the bottom. Once the coal has been cleaned, it is dewatered through the use of vibrating screens and centrifuges. See Figure 6 for a block flow diagram of the cleaning process used in this assessment. The clean coal is transported to the power plant and the refuse is landfilled (see section 5.2 and 5.4 .3 for details about the assumptions for these two process steps).

Table 12 contains the utility and landfilling requirements for the coal cleaning process (Bechtel and Amoco, 1993). Some dust particles will be produced during coal handling; however, because Jigging is a wet process the dust problem will be minimal.

Table 12: Coal Cleaning Utility and Landfilling Requirements (Base Case)

\begin{tabular}{|c|c|c|}
\hline $\begin{array}{c}\text { Electricity requirement } \\
\text { (MJ/Mg of MAF raw coal) }\end{array}$ & $\begin{array}{c}\text { Water requirement } \\
\left(\mathrm{m}^{3} / \mathrm{Mg} \text { of MAF raw coal }\right)\end{array}$ & $\begin{array}{c}\text { Refuse landfilled } \\
\text { (dry Mg/Mg of MAF raw coal })\end{array}$ \\
\hline 0.79 & 0.17 & 0.35 \\
\hline
\end{tabular}

\subsubsection{Coal Mining Methane Emissions}

Methane is emitted from the coal seam during the mining operations. Methane is generated through anaerobic digestion of plant material during the process of coal formation and is subsequently stored in the coal seams and surrounding rock strata. The amount of methane stored is controlled by the pressure and temperature of the coal seam, and will remain stored until the pressure is reduced during erosion of overlying strata or coal mining activities. In general, larger methane emissions are associated with underground mining than with surface mining because the deeper coal beds are under greater pressure and often contain more methane (IFC Resources Inc.). For the most part, methane from underground mines is vented to the atmosphere; this is the assumption used in this LCA, although a number of underground mines have begun to recover some methane for other uses such as power production, fuel use at the mine site (for water treatment or coal preparation), or additional natural gas supply. See section 10.2 for a discussion of these options and how they may help improve the environmental burden of coalfired power plants. 
Figure 6: Coal Preparation - Jig Cleaning Process

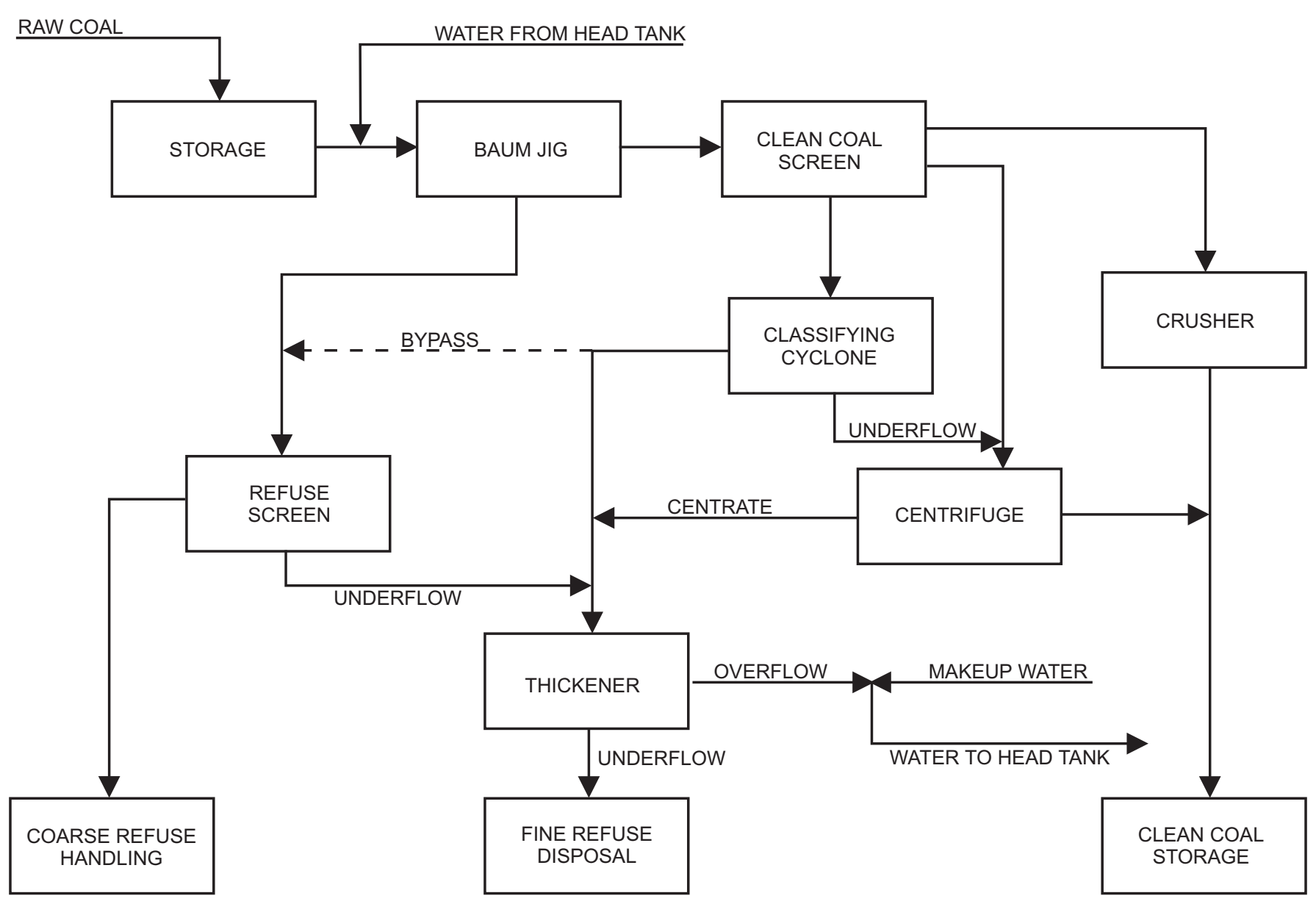


Table 13 shows the surface and underground mining methane emissions used in the base case of this LCA (U.S. EPA, 1998). These are the average methane emissions for the Illinois region in 1996 for both mining techniques. A sensitivity analysis was conducted using numbers from another data source to determine the effect of the assumed value used in this LCA.

Table 13: Coal Mining Methane Emissions (Base Case)

\begin{tabular}{|l|c|}
\hline Mining technique & $\begin{array}{c}\text { Methane emissions } \\
\text { (g of } \mathrm{CH}_{4} / \mathrm{kg} \text { of as-received coal) }\end{array}$ \\
\hline Surface & 1.91 \\
\hline Underground & 4.23 \\
\hline
\end{tabular}

\subsubsection{Transportation of Chemicals/Materials}

Chemicals and materials must be transported from their point of production to either the coal mine or the power plant. The transportation requirements were assumed to be $60 \%$ by rail and $40 \%$ by truck over an average distance of $640 \mathrm{~km}$ (based on details gathered for NREL's biomass power LCA study - Mann and Spath, 1997). Table 14 contains a list of specific chemicals and materials that are transported in this coal study:

Table 14: Chemicals and Materials Transported

\begin{tabular}{|l|l|l|}
\hline \multicolumn{1}{|c|}{ Chemical/material } & \multicolumn{1}{|c|}{ Unit operation } & \multicolumn{1}{c|}{ Destination } \\
\hline Limestone & Underground mining & Coal mine \\
\hline Ammonium nitrate & Surface mining & Coal mine \\
\hline Seeds & Reclamation & Coal mine \\
\hline Lime & Power plant operation & Power plant (Average \& NSPS case) \\
\hline Limestone & Power plant operation & Power plant (Average \& NSPS case) \\
\hline Ammonia & Power plant operation & Power plant (LEBS case) \\
\hline
\end{tabular}

Light fuel oil and diesel are used in the trains and trucks, respectively. Similar to coal transport (discussed in section 5.2), the resources, energy, and emissions related to extracting crude oil, distilling it, producing a usable transportation fuel, and distributing it to refueling stations plus the emissions produced during combustion of the fuel were included in the LCA. Additionally, the stressors associated with manufacturing the trains and trucks were included.

\subsection{Base Case Coal Transportation Assumptions}

The inventory assessment for the transportation subsystem includes the energy required and emissions generated for the transportation of coal by barge, train, or truck between the boundaries of the coal mining and power generation subsystems. Any transportation requirements within the boundaries of the coal mining and power generation subsystems are included in the inventory assessment for that subsystem (see sections 5.1.6 and 5.4.3 for details about chemical/material transport and waste transport to a landfill, respectively). 
Three modes of transportation were considered for the coal-to-electricity system outlined in this report: barges, trains, and trucks. Data indicate that except for mine mouth operations, coal transport by trucks is rare, and therefore is assumed to be zero in this analysis. However, some amount of truck transport was considered for hauling other items such as chemicals and wastes. The area where Illinois No. 6 coal is mined is landlocked, so some coal delivery by railcar is required even when considering barges as the primary means of transport. Also, some of the coal that travels by barge is later transferred to rail car for overland shipment to its final destination.

The following four transportation cases were examined for this study:

- $\quad$ average user by land: railcar $=483 \mathrm{~km}$,

- $\quad$ average user by river: railcar $=48 \mathrm{~km}$ plus barge $=434 \mathrm{~km}$,

- farthest user: railcar $=1,538 \mathrm{~km}$ plus barge $=504 \mathrm{~km}$, and

- $\quad$ mine mouth: minimal truck transport $=2 \mathrm{~km}$.

The results given in later sections of this report are for the average user by river case. The other three transportation cases are discussed in the Base Case Coal Transportation Results section (section 7.2) and in the sensitivity analysis section (section 8.9).

The average user by land was determined based on the location of most of the utilities serviced by a mine in the Perry County region. This distance also includes parts of the States of Illinois, Wisconsin, Iowa, Indiana, Kentucky, Alabama, Mississippi, and Missouri, which all use some Illinois \#6 coal. When considering barge transport, the coal must first be hauled $48 \mathrm{~km}$ by rail to the Mississippi River before being loaded onto a coal barge. The barge distance of $434 \mathrm{~km}$ listed above for the average user by river case reaches up the Mississippi River to Iowa or down the river to the State of Mississippi and could include traffic up the Ohio River. The farthest user consists of rail transport to the Mississippi River (48 $\mathrm{km})$, then river transport to Memphis, Tennessee $(504 \mathrm{~km})$, and finally rail transport to central Florida $(1,490 \mathrm{~km})$. Coal transfer operations between rail and barge were not included but should be minimal compared to the actual transportation of the coal. All rail mileage was obtained using distances for existing rail lines (Rand McNally Commercial Atlas and Marketing Guide, 1994) and the barge distances were obtained using data from the Inland Waterways Mileage Guide (1980).

The trucks, trains, and barges use diesel fuel, light fuel oil, and heavy fuel oil, respectively. The resources, energy, and emissions related to extracting crude oil, distilling it, producing a usable transportation fuel, and distributing it to refueling stations, plus the emissions produced during combustion of the fuel, were included in the total inventory. These data were taken from the DEAM database, of which some details are shown in Appendix B of NREL's biomass power LCA report (Mann and Spath, 1997). The material requirements for each of the various modes of transportation were used in determining the environmental stressors associated with vehicle production and decommissioning.

Rail transport is assumed to be by conventional freight trains made up of 85 cars with 17 of the cars carrying $77 \mathrm{Mg}$ (85 tons) of coal each. The capacity of each coal barge is $19,050 \mathrm{Mg}(21,000$ tons) and the capacity of each truck is $23 \mathrm{Mg}$ ( 25 tons). Coal haul losses are assumed to be $5 \%$. Using this number and an operating capacity of $60 \%$ the amount of as-received coal transported to the power plant for each of the three systems is shown in Table 15. 
Table 15: Coal Transported per Year

\begin{tabular}{|l|c|}
\hline \multicolumn{1}{|c|}{ System } & $\begin{array}{c}\text { Coal transported }(\mathrm{kg} / \mathrm{yr}) \\
\text { as-received basis, at 60\% plant } \\
\text { capacity, including 5\% haul loss }\end{array}$ \\
\hline Average & $892,643,539$ \\
\hline NSPS & $963,488,195$ \\
\hline LEBS & $744,497,646$ \\
\hline
\end{tabular}

Using the quantities in Table 15 and the given barge and train capacities, the numbers of barge and train deliveries per year were calculated for the average user by river transport case and are shown in Table 16. Because a barge can carry 14.6 times more coal than a train, the number of barge loads required is considerably less than the number of train loads.

Table 16: Yearly Barge \& Train Deliveries Required for Coal Transport - Average User by River Case

\begin{tabular}{|l|c|c|}
\hline \multirow{2}{*}{ System } & \multicolumn{2}{|c|}{ Number required per year } \\
\cline { 2 - 3 } & Barge deliveries & Train deliveries \\
\hline Average & 47 & 682 \\
\hline NSPS & 51 & 736 \\
\hline LEBS & 39 & 569 \\
\hline
\end{tabular}

Table 17 shows the primary materials used in the production of barges, trains, and trucks (DynCorp, 1995 and U.S. DOE, 1983). Steel is the main ingredient in each piece of transportation equipment. The emissions associated with vehicle production and decommissioning are included in the inventory assessment in the year that they are actually produced and disassembled. The lifetime of a train and a barge is considered to be 30 years (DynCorp, 1995). Therefore, the emissions associated with train or barge construction are taken into account in year one and the rail cars or barge are decommissioned in year 30, the last year of operation. The lifetime of a truck is assumed to be 7.5 years based on mileage traveled. The barge, train, and truck bodies are shredded or crushed and $75 \%$ of the materials are recycled and used as scrap metal in secondary metal production operations. For all materials that are recycled, a credit is given for the avoidance of the normal route of manufacture from scrap or virgin materials.

Table 17: Barge, Train, and Truck Material Requirements

\begin{tabular}{|l|r|r|r|}
\hline \multirow{2}{*}{ Material } & \multicolumn{3}{|c|}{ Amount required } \\
\cline { 2 - 4 } & \multicolumn{1}{|c|}{$(\mathrm{kg} / \mathrm{barge})$} & $(\mathrm{kg} / \mathrm{rail}$ car $)$ & $(\mathrm{kg} /$ truck $)$ \\
\hline Steel & $3,465,400$ & 6,713 & 13,789 \\
\hline Iron & 94,347 & none & 272 \\
\hline Aluminum & 31,752 & 45 & none \\
\hline
\end{tabular}




\subsection{Base Case Power Plant Construction \& Decommissioning Assumptions}

For this analysis, the plant is being constructed over a two year period with startup at $30 \%$ (50\% of 60\%) operation in year one. During the years following construction the plant will operate at a $60 \%$ capacity factor. The life of the plant is assumed to be 30 years; during the last year the plant will be in operation $45 \%$ (75\% of $60 \%$ ) of the time because of decommissioning during the last quarter of that year. Changing the percent that the power plant operates in the first and last years will have a minimal effect on the results of this study, as demonstrated in the sensitivity analysis (see section 8.7).

During construction, particulate matter emissions will be high due to the activities associated with land preparation, drilling and blasting, ground excavation, earth moving, and the building of the power plant. Additionally, significant particulate emissions will result from equipment traffic over temporary roads. The total amount of particulates during construction is equivalent to $2.6 \mathrm{Mg}$ per hectare of site area per month of activity. Wet suppression of the land is used to control particulate emissions from the construction site and road paving will begin in the first year of construction. All asphalt surfaces are composed of compacted aggregate and an asphalt binder (U.S. EPA, 1995 - Compilation). The primary pollutants of concern from the asphalt paving operations are volatile organic compounds (VOCs). There are two types of asphalts: cutback and emulsified. Cutback asphalts, which have been the primary asphalt used in the past, contain petroleum distillate solvents that are released into the atmosphere during the curing process. Emulsified asphalts rely on water evaporation for curing, thus minimizing any hydrocarbon emissions. This analysis assumes that an emulsified asphalt is used since it is appropriate for almost any type of asphalt application. Particulate and asphalt emissions associated with construction were built into TEAM $^{\circledR}$ using data from several literature sources including U.S. EPA (1995 Compilation) and Ullmann's Encyclopedia of Industrial Chemistry (1986).

Table 18 shows the primary materials used for constructing the power plant (DynCorp, 1995). As expected, concrete and steel are consumed in the largest quantities. Different values found in the literature were tested in a sensitivity analysis to determine the effect of this parameter on the assessment results. Because it is the most common type of cement used for structural applications, gray Portland cement was assumed for plant construction. Cement manufacturing consists of the following processes: raw materials acquisition and handling, kiln feed preparation, pyroprocessing, and finished cement grinding (U.S. EPA, 1995 - Compilation). More than 30 raw materials are used in manufacturing cement, most obtained from open-pit quarries or mines. However, some are acquired through underground mines or dredging operations. The raw materials are delivered to the plant and the cement is batched on-site. Particulate matter from cement dust and sand aggregate is the primary pollutant generated in this step. These emissions, along with the air emissions and energy requirement from the other processing steps, were input into TEAM $^{\circledR}$ from the information contained in the U.S. EPA (1995 - Compilation) reference.

Table 18: Plant Material Requirements (Base Case)

\begin{tabular}{|l|c|}
\hline \multicolumn{1}{|c|}{ Material } & $\begin{array}{c}\text { Amount required } \\
\text { (kg/MW plant capacity) }\end{array}$ \\
\hline Concrete & 158,758 \\
\hline Steel & 50,721 \\
\hline Aluminum & 419 \\
\hline Iron & 619 \\
\hline
\end{tabular}


The power plant is decommissioned in the last quarter of year 30, the last year of operation. For this LCA, $75 \%$ of the steel, aluminum, and iron used in constructing the plant are recycled and used as scrap metal in secondary metal production operations. Similar to the way the recycled materials are handled when decommissioning the transportation vehicles, a credit is given for the avoidance of the normal route of manufacture from scrap or virgin materials. No information was found regarding the requirements for restoring the site back to greenfield conditions. Therefore, no additional emissions associated with the activities necessary for this task are included. Some steps that might be involved in the reclamation process include hauling of contaminated soil to a landfill site, earth moving, and re-vegetating the top soil.

\subsection{Base Case Power Generation Assumptions}

The inventory assessment for the power generation subsystem begins at the plant gate of the power plant and ends with the production of electricity. Tables 19-21 summarizes the power plant resources/inputs, operating emissions, and solid wastes used in this study. These data were determined using database information and other literature sources provided by FETC (Utility Data Institute, 1993, 1993, \& 1996; Keeth et al, 1983; U.S. EPA., 1985; Schultz, and Kitto, 1992; Combustion Engineering, Inc., 1981; Ladino et al, 1982; Walas, 1988; Collins, 1994; Larinoff, 1994; and Darguzas et al, 1997). Design parameters for the three power plant systems were discussed earlier in section 3.0.

Table 19: Power Plant Resource/Input Requirements (Base Case)

\begin{tabular}{|l|r|r|r|}
\hline \multirow{2}{*}{ Resource/input } & \multicolumn{3}{c|}{ Emission amount } \\
\cline { 2 - 4 } & \multicolumn{1}{|c|}{ Average } & \multicolumn{1}{c|}{ NSPS } & \multicolumn{1}{c|}{ LEBS } \\
\hline Coal (as-received) & 448,171 & 409,756 & 333,081 \\
\hline Lime for FGC waste treatment & 6,769 & 7,207 & N/A \\
\hline Limestone & 90,704 & 96,576 & N/A \\
\hline Copper oxide for gas clean-up & N/A & N/A & 268 \\
\hline Ammonia for NO Nemoval $_{x}$ & N/A & N/A & 136 \\
\hline $\begin{array}{l}\text { Natural gas to regenerate the } \\
\text { CuO sorbent }\end{array}$ & N/A & N/A & 3,810 \\
\hline
\end{tabular}

Table 20: Power Plant Air Emissions (Base Case)

\begin{tabular}{|l|r|r|r|}
\hline \multirow{2}{*}{ Compound } & \multicolumn{3}{|c|}{ Emission amount } \\
& \multicolumn{1}{c|}{ kg/GWh of net electricity produced $)$} \\
\cline { 2 - 4 } & Average & \multicolumn{1}{c|}{ NSPS } & \multicolumn{1}{c|}{ LEBS } \\
\hline $\mathrm{NO}_{\mathrm{x}}$ & 3,039 & 2,041 & 358 \\
\hline $\mathrm{SO}_{\mathrm{x}}$ & 6,400 & 2,229 & 358 \\
\hline $\mathrm{CO}$ & 134 & 123 & 100 \\
\hline $\mathrm{CO}_{2}$ & 969,925 & 889,279 & 719,026 \\
\hline $\mathrm{Particulates}$ & 135 & 123 & 53 \\
\hline VOCs & 16 & 14 & 12 \\
\hline
\end{tabular}


Table 21: Power Plant Solid Wastes (Base Case)

\begin{tabular}{|c|c|c|c|}
\hline \multirow[t]{2}{*}{ Solid waste } & \multicolumn{3}{|c|}{$\begin{array}{c}\text { Emission amount } \\
(\mathrm{kg} / \mathrm{GWh} \text { of net electricity produced) }\end{array}$} \\
\hline & Average & NSPS & LEBS \\
\hline $\begin{array}{l}\text { FGC waste - dry total } \\
\text { FGC waste - dry landfilled }\end{array}$ & $\begin{array}{l}85,952(a) \\
64,722\end{array}$ & $\begin{array}{l}91,516(a) \\
68,912\end{array}$ & $\begin{array}{c}34,201(b) \\
0\end{array}$ \\
\hline $\begin{array}{l}\text { Ash - moisture free total } \\
\text { Ash - moisture free landfilled }\end{array}$ & $\begin{array}{l}35,685(\mathrm{c}) \\
25,693\end{array}$ & $\begin{array}{l}32,626(\mathrm{c}) \\
23491\end{array}$ & $\begin{array}{l}26,580(\mathrm{c}) \\
19,138\end{array}$ \\
\hline
\end{tabular}

(a) For the base case $75.3 \%$ of FGC waste is landfilled.

(b) Used in the production of elemental sulfur, sulfuric acid, or phosphate fertilizer. Thus, ultimately this stream is not a waste.

(c) For the base case $72.0 \%$ of ash is landfilled.

\subsubsection{Trace Elements}

Other emissions of concern from coal-fired power plants are trace elements. Title III, Hazardous Air Pollutants (HAPs), of the 1990 Clean Air Act Amendments (CAAA) requires the U.S. EPA to establish stationary source categories and to implement regulatory standards for 189 air toxics from the source categories emitting 25 tons of any combination of pollutants or 10 tons of a single pollutant annually (U.S. DOE, September 1996.). In general, the amount of trace elements contained in various types of coal can be easily obtained; however, documented material balance data on trace elements emitted from coalfired power plants could only be found in two sources: Radziwon and Winter (1996) and U.S. DOE (September 1996). The first source contains trace element amounts in the flue gas, ash, and other waste streams for nine different coal-fired power plants. The second source contains trace element information for only the stack gas of these same nine plants. The data in Table 22 were obtained using the average of six of the nine power plants. These numbers were incorporated into the analysis with the emissions from these six plants because they use the same type of (bituminous) coal as this LCA; Illinois No. 6. As can be seen from Table 22, the majority of the trace elements leave the plant with the boiler bottom ash.

Table 22: Power Plant Trace Element Emissions

\begin{tabular}{|l|c|c|c|c|c|c|}
\hline \multirow{2}{*}{ Compound } & \multicolumn{3}{|c|}{$\begin{array}{c}\text { Flue gas emissions } \\
\text { (kg/kWh of net electricity) }\end{array}$} & \multicolumn{3}{c|}{$\begin{array}{c}\text { Solid emissions } \\
\text { (kg/kWh of net electricity) }\end{array}$} \\
\cline { 2 - 7 } & Average & NSPS & LEBS & Average & NSPS & LEBS \\
\hline Antimony & 0.0041 & 0.0038 & 0.0031 & 0.015 & 0.014 & 0.011 \\
\hline Arsenic & 0.049 & 0.045 & 0.037 & 0.13 & 0.12 & 0.097 \\
\hline Barium & 0.013 & 0.012 & 0.0095 & 0.44 & 0.40 & 0.33 \\
\hline Beryllium & 0.0016 & 0.0015 & 0.0012 & 0.014 & 0.013 & 0.010 \\
\hline Boron & 17.0 & 15.5 & 12.6 & 0.72 & 0.66 & 0.53 \\
\hline Cadmium & 0.0041 & 0.0037 & 0.0030 & 0.0098 & 0.0090 & 0.0073 \\
\hline Chromium & 0.059 & 0.054 & 0.044 & 0.22 & 0.20 & 0.16 \\
\hline
\end{tabular}




\begin{tabular}{|l|c|c|c|c|c|c|}
\hline \multirow{2}{*}{ Compound } & \multicolumn{3}{|c|}{$\begin{array}{c}\text { Flue gas emissions } \\
\text { (kg/kWh of net electricity) }\end{array}$} & \multicolumn{3}{c|}{$\begin{array}{c}\text { Solid emissions } \\
\text { (kg/kWh of net electricity) }\end{array}$} \\
\cline { 2 - 7 } & Average & NSPS & LEBS & Average & NSPS & LEBS \\
\hline Cobalt & 0.0069 & 0.0063 & 0.0051 & 0.047 & 0.043 & 0.035 \\
\hline Copper & 0.023 & 0.021 & 0.017 & 0.11 & 0.10 & 0.085 \\
\hline Lead & 0.030 & 0.027 & 0.022 & 0.10 & 0.091 & 0.074 \\
\hline Manganese & 00043 & 0.039 & 0.032 & 0.27 & 0.25 & 0.20 \\
\hline Mercury & 0.037 & 0.033 & 0.027 & 0.00017 & 0.00015 & 0.00012 \\
\hline Molybdenum & 0.038 & 0.035 & 0.028 & 0.039 & 0.036 & 0.029 \\
\hline Nickel & 0.058 & 0.053 & 0.043 & 0.16 & 0.14 & 0.12 \\
\hline Selenium & 0.41 & 0.37 & 0.30 & 0.010 & 0.009 & 0.008 \\
\hline Vanadium & 0.088 & 0.080 & 0.065 & 0.32 & 0.29 & 0.24 \\
\hline
\end{tabular}

\subsubsection{Recycling of Power Plant Flue Gas Clean-up Waste and Ash}

Each coal plant produces a considerable amount of flue gas clean-up waste and ash that must be disposed of in a landfill or used in some alternative service. The FGC waste from the LEBS plant is used in the production of elemental sulfur, sulfuric acid, or phosphate fertilizer. The entire stream is assumed to be used in one or a combination of these options; thus, no disposal of the FGC waste was required from the LEBS plant. However, neither emissions nor any credits, where appropriate, were applied for producing elemental sulfur, sulfuric acid, or phosphate fertilizer because the material balance data for using this waste stream for these processes are not known at this time. For both the Average and NSPS plants, a portion of the FGC waste is used in an alternative service which is discussed below; the remainder is dewatered and mixed with fly ash and lime to produce a waste that is suitable for landfilling (see the following section, 5.4.3, for landfilling and landfill transportation details).

The statistics on FGC waste utilization were taken from the American Coal Ash Association (1996), which compiles average data across the U.S. for coal-fired power plants. Based on these statistics, for the Average and NSPS base case, $24.7 \%$ of the FGC waste was assumed to be recovered and the remaining $75.3 \%$ was landfilled. Of the recovered amount, $7 \%$ was used in asphalt production and an emissions credit was taken using data from U.S. EPA (1995 - Compilation) for particulates, $\mathrm{CO}, \mathrm{CO}_{2}$, $\mathrm{NO}_{\mathrm{x}}, \mathrm{SO}_{\mathrm{x}}, \mathrm{CH}_{4}$, and VOCs. Approximately 53\% of the recovered material is used in wallboard for which production material and energy balance data could not be obtained; $27 \%$ is used in other miscellaneous processes. Because data for the additional uses were not found, no other resource, energy, or emission credits were taken for the remaining recovered FGC waste.

The statistics on coal ash utilization were also taken from the American Coal Ash Association (1996). Based on these statistics, for the Average, NSPS, and LEBS base case, 28.0\% of the ash was assumed to be recovered and the remaining $72.0 \%$ was landfilled. Of the recovered amount $42 \%$ was used in cement production. The ash could be used in one of two ways: as a cementitious material supplement that is either ground with Portland cement clinker or as a blended addition to the finished cement at the point of mixing into concrete (Barry Lawson Associates, 1997). An emissions and energy credit was taken 
assuming that the ash was mixed with finished cement. The emissions data were obtained from U.S. EPA (1995 - Compilation) and the energy data from Boustead and Hancock (1979). The energy credit displaced the resources, energy, and emissions associated with electricity production for the generation mix of the mid-continental United States (see section 5.0 for a breakdown of this mix). Other ash uses for which material and energy balance data could not be determined include structural fills (13\% of recovered material), waste stabilization (11\% of recovered material), and misc/other (17\% of recovered material). Because data for these other uses were not found, no additional resource, energy, or emission credits were taken for the remaining recovered ash.

A sensitivity analysis was performed on both the FGC waste recovery and ash recovery because the amount of either waste recovered and its end use will be site-specific and will depend on the composition of the waste.

\subsubsection{Landfilling of Flue Gas Clean-up Waste, Ash, and Refuse}

The portion of the FGC waste and ash that is not recovered must be disposed of in a landfill. The coal preparation/cleaning process also produces a refuse stream that must be landfilled. All landfilled material is assumed to be transported via trucks and the distance from the power plant or mine (coal cleaning) to the landfill is assumed to be $5 \mathrm{~km}$.

The equipment required to spread and compact the landfilled material, maintain haul roads, and provide water for moisture control and dust suppression are shown in Table 23 (GAI Consultants, Inc., 1995). This equipment was used to determine the diesel fuel use; however, no additional materials were included for equipment manufacture and thus no credits were applied for decommissioning the equipment.

Table 23: Landfilling Equipment (Base Case)

\begin{tabular}{|l|c|c|}
\hline \multicolumn{1}{|c|}{ Equipment } & Quantity & $\begin{array}{c}\text { Fuel use } \\
(1000 \text { liters/kg of dry material })\end{array}$ \\
\hline 123-kW bulldozer & 1 & 0.23 \\
\hline 161-kW tamping foot compactor & 1 & 0.43 \\
\hline 149-kW grader & 1 & 0.31 \\
\hline 52-kW backhoe & 1 & 0.078 \\
\hline 30,280 liter water truck & 1 & 0.16 \\
\hline
\end{tabular}

The following are the fuel and water use rates used in this LCA for landfilling of FGC waste, ash, and refuse:

- diesel fuel use $=0.0012$ liters/kg of dry material, and

- $\quad$ water use $=0.076$ liters $/ \mathrm{kg}$ of dry material.

When ash is placed into a landfill, the resulting leachate depends on conditions such as precipitation, leachability of the fly ash, type of fly ash, and soil factors such as source (urban or rural location), age, mineral compositions, as well as the degree to which the soil is weathered. The residence time at the landfill also affects the amount of leachate generated. Summing all these factors makes it impossible to predict any specific leachability; therefore, resulting water emissions were not included in this LCA. 
Although studies are limited, the concentration of most of the elements in leachate samples collected and analyzed either meet or exceed drinking water standards (Ecobalance, Inc., 1997).

\subsection{Base Case Results by Impact Category}

Although the material and energy balances for each subsystem (coal mining, transportation, and electricity generation) were examined for each year of production, the resulting impacts were averaged over the life of the system to examine the relative percent of emissions from each. Tables 24 through 28 show the average amount of resources consumed, emissions produced, and energy used per unit of energy delivered to the utility grid for the Average system (see Tables B1-B25 in Appendix B for the NSPS and LEBS systems). These tables contain data for each of the three subsystems (coal mining, transportation, and electricity generation) for both surface and underground mining.

The quantity of almost all environmental stressors from surface mining was not found to be significantly different from those from underground mining. Therefore, unless specifically stated, results are presented for the surface mining case.

\subsection{Carbon Dioxide Emissions}

In terms of total air emissions, $\mathrm{CO}_{2}$ is emitted in the greatest quantity, accounting for $98-99 \mathrm{wt} \%$ of the total air emissions for all systems examined. The vast majority of the $\mathrm{CO}_{2}$, greater than $93 \%$, is emitted from the power plant when the coal is combusted. Figure 7 shows the $\mathrm{CO}_{2}$ emissions for the Average system while Table 29 gives a breakdown of the emissions for all three system designs.

Table 29: $\mathrm{CO}_{2}$ Results

\begin{tabular}{|c|c|c|c|c|c|c|c|}
\hline \multirow[t]{2}{*}{ System } & \multirow{2}{*}{$\begin{array}{c}\text { Total } \mathrm{CO}_{2} \\
\text { emissions } \\
(\mathrm{g} / \mathrm{kWh}) \\
\text { (a) }\end{array}$} & \multicolumn{2}{|c|}{$\begin{array}{c}\mathrm{CO}_{2} \text { from surface mining } \\
\text { subsystem (b) }\end{array}$} & \multicolumn{2}{|c|}{$\begin{array}{c}\mathrm{CO}_{2} \text { from transportation } \\
\text { subsystem (c) }\end{array}$} & \multicolumn{2}{|c|}{$\begin{array}{c}\mathrm{CO}_{2} \text { from power } \\
\text { generation subsystem }\end{array}$} \\
\hline & & $\begin{array}{l}(\mathrm{g} / \mathrm{kWh}) \\
\text { (a) }\end{array}$ & $(\%)$ & $\begin{array}{c}(\mathrm{g} / \mathrm{kWh}) \\
\text { (a) }\end{array}$ & $(\%)$ & $\begin{array}{c}(\mathrm{g} / \mathrm{kWh}) \\
\text { (a) }\end{array}$ & $(\%)$ \\
\hline Average & 1,022 & 9 & 0.9 & 17 & 1.7 & 996 & 97.3 \\
\hline NSPS & 941 & 8 & 0.9 & 16 & 1.7 & 917 & 97.4 \\
\hline LEBS & 741 & 7 & 1.0 & 13 & 1.8 & 721 & 97.3 \\
\hline
\end{tabular}

(a) $\mathrm{CO}_{2}$ emissions per $\mathrm{kWh}$ of net electricity produced averaged over the life of the system.

(b) Results are reported for the surface mining case. However, the underground mining numbers are similar to those listed here.

(c) Coal transportation $=$ average user by river.

Figure 8 shows the yearly $\mathrm{CO}_{2}$ emissions per the average amount of power production over the life of the system for surface mining (See Appendix C, Figure C1, for the underground mining case which is similar to the surface mining results.). There is a sharp increase from year negative one to year one and two when the power plant starts up and begins to operate. The $\mathrm{CO}_{2}$ is fairly constant during the normal operating years because most of it is emitted from the power plant. There is a decrease from year 29 to 30 when the power plant shuts down and is decommissioned. 
Table 24: Average Resource Consumption per kWh of Net Electricity Produced - Average System (surface mining \& average user by river)

\begin{tabular}{|c|c|c|c|c|c|}
\hline & $\begin{array}{c}\% \text { of Total in this } \\
\text { Table }\end{array}$ & Total (g/kWh) & $\begin{array}{c}\% \text { of Total from } \\
\text { Surface Coal } \\
\text { Mining }\end{array}$ & $\begin{array}{l}\% \text { of Total from } \\
\text { Transportation }\end{array}$ & $\begin{array}{c}\% \text { of Total from } \\
\text { Electricity } \\
\text { Generation }\end{array}$ \\
\hline (r) Bauxite (Al2O3, ore) & $0.00 \%$ & $2.54 \mathrm{E}-03$ & $0.00 \%$ & $4.90 \%$ & $95.09 \%$ \\
\hline (r) Clay (in ground) & $0.00 \%$ & 2.39E-08 & $23.24 \%$ & $2.56 \%$ & $74.19 \%$ \\
\hline (r) Coal (in ground) & $80.42 \%$ & $4.76 \mathrm{E}+02$ & $0.75 \%$ & $0.01 \%$ & $99.24 \%$ \\
\hline (r) Iron (Fe, ore) & $0.02 \%$ & 1.13E-01 & $26.48 \%$ & $2.22 \%$ & $71.30 \%$ \\
\hline (r) Limestone ( $\mathrm{CaCO} 3$, in ground) & $17.39 \%$ & $1.03 E+02$ & $0.04 \%$ & $0.00 \%$ & $99.96 \%$ \\
\hline (r) Natural Gas (in ground) & $0.21 \%$ & $1.25 \mathrm{E}+00$ & $38.54 \%$ & $1.72 \%$ & $59.74 \%$ \\
\hline (r) Oil (in ground) & $1.94 \%$ & $1.15 \mathrm{E}+01$ & $2.82 \%$ & $48.11 \%$ & $49.06 \%$ \\
\hline (r) Sand (in ground) & $0.00 \%$ & 2.27E-08 & $0.00 \%$ & $4.90 \%$ & $95.10 \%$ \\
\hline (r) Sodium Chloride ( $\mathrm{NaCl}$, in ground or in sea) & $0.00 \%$ & 7.35E-05 & $2.04 \%$ & $4.70 \%$ & $93.26 \%$ \\
\hline (r) Uranium (U, ore) & $0.00 \%$ & 4.53E-05 & $96.76 \%$ & $0.09 \%$ & $3.15 \%$ \\
\hline Aluminum Scrap & $0.00 \%$ & $6.22 \mathrm{E}-04$ & $0.00 \%$ & $4.90 \%$ & $95.10 \%$ \\
\hline Iron Scrap & $0.02 \%$ & $1.20 \mathrm{E}-01$ & $26.89 \%$ & $2.19 \%$ & $70.92 \%$ \\
\hline Lubricant & $0.00 \%$ & 2.05E-03 & $26.53 \%$ & $2.21 \%$ & $71.26 \%$ \\
\hline Trinitrotoluene (C6H3(NO2)3) & $0.00 \%$ & 4.53E-06 & $0.00 \%$ & $4.90 \%$ & $95.10 \%$ \\
\hline
\end{tabular}

Table 25: Average Air Emissions per kWh of Net Electricity Produced - Average System (surface mining \& average user by river)

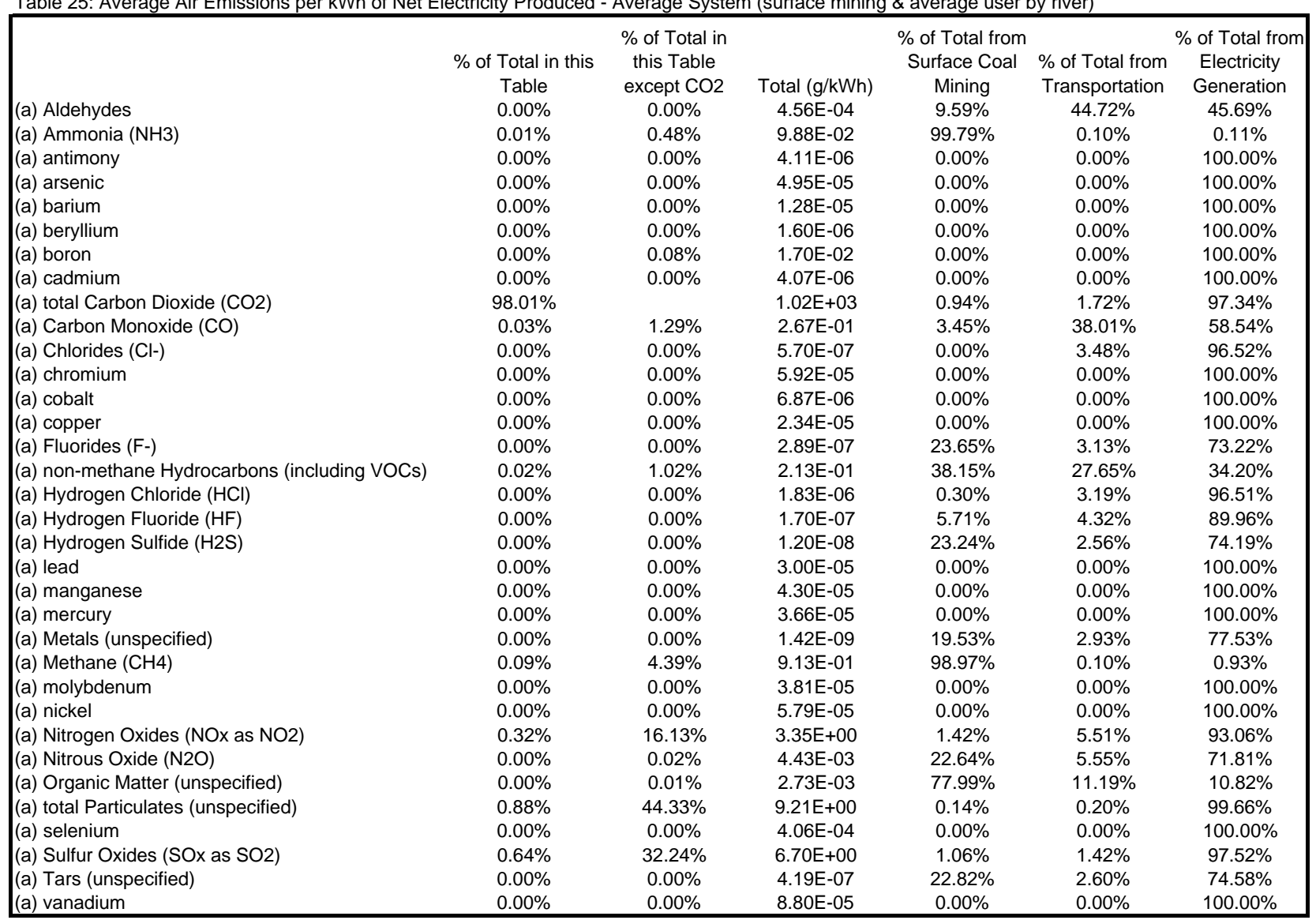

(a) = air emission 
Table 26: Average Water Emissions per kWh of Net Electricity Produced - Average System (surface mining \& average user by river)

(w) Acids $(\mathrm{H}+)$

(w) Ammonia (NH4+)

(w) Ammonia (NH4+, $\mathrm{NH} 3$, as $\mathrm{N})$

(w) TOTAL BOD5 (Biological Oxygen Demand)

(w) Chlorides (Cl-)

(w) COD (Chemical Oxygen Demand)

(w) Cyanides (CN-)

(w) Dissolved Matter (unspecified)

(w) Fluorides (F-)

(w) Inorganic Dissolved Matter (unspecified)

(w) Iron (Fe++, $\mathrm{Fe} 3+$ )

(w) Metals (unspecified)

(w) Nitrates (NO3-)

(w) Nitric acid

(w) Nitrogenous Matter (unspecified, as N)

(w) Oils

(w) Oils (unspecified)

(w) Organic Dissolved Matter (unspecified)

(w) Phenol $(\mathrm{C} 6 \mathrm{H} 6 \mathrm{O})$

(w) Sodium $(\mathrm{Na}+)$

(w) Sulfates (SO4--)

(w) Sulfides (S--)

(w) Suspended Matter (unspecified)

(w) Tars (unspecified)

(w) Water: Chemically Polluted

$(w)=$ water emission

\begin{tabular}{|c|c|c|c|c|}
\hline$\%$ of Total in this & & $\begin{array}{l}\% \text { of Total from } \\
\text { Surface Coal }\end{array}$ & $\%$ of Total from & $\begin{array}{c}\% \text { of Total from } \\
\text { Electricity }\end{array}$ \\
\hline Table & Total $(\mathrm{g} / \mathrm{kWh})$ & Mining & Transportation & Generation \\
\hline $0.01 \%$ & 2.57E-05 & $99.67 \%$ & $0.01 \%$ & $0.32 \%$ \\
\hline $13.02 \%$ & 2.35E-02 & $100.00 \%$ & $0.00 \%$ & $0.00 \%$ \\
\hline $0.00 \%$ & 3.76E-06 & $85.88 \%$ & $0.42 \%$ & $13.70 \%$ \\
\hline $0.33 \%$ & 5.96E-04 & $89.61 \%$ & $5.13 \%$ & $5.26 \%$ \\
\hline $0.00 \%$ & 3.44E-06 & $2.85 \%$ & $4.74 \%$ & $92.41 \%$ \\
\hline $0.99 \%$ & $1.79 \mathrm{E}-03$ & $89.68 \%$ & $5.12 \%$ & $5.20 \%$ \\
\hline $0.00 \%$ & 8.55E-09 & $26.48 \%$ & $2.22 \%$ & $71.30 \%$ \\
\hline $83.72 \%$ & $1.51 \mathrm{E}-01$ & $1.89 \%$ & $42.87 \%$ & $55.24 \%$ \\
\hline $0.00 \%$ & 8.01E-06 & $86.50 \%$ & $0.40 \%$ & $13.10 \%$ \\
\hline $0.00 \%$ & $6.04 \mathrm{E}-07$ & $23.03 \%$ & $2.58 \%$ & $74.39 \%$ \\
\hline $0.00 \%$ & 1.32E-08 & $96.76 \%$ & $0.09 \%$ & $3.15 \%$ \\
\hline $0.00 \%$ & 3.67E-07 & $22.74 \%$ & $2.61 \%$ & $74.65 \%$ \\
\hline $0.00 \%$ & $1.62 \mathrm{E}-06$ & $96.76 \%$ & $0.09 \%$ & $3.15 \%$ \\
\hline $0.72 \%$ & 1.30E-03 & $100.00 \%$ & $0.00 \%$ & $0.00 \%$ \\
\hline $0.00 \%$ & $1.20 \mathrm{E}-08$ & $23.24 \%$ & $2.56 \%$ & $74.19 \%$ \\
\hline $1.03 \%$ & 1.85E-03 & $4.64 \%$ & $44.98 \%$ & $50.39 \%$ \\
\hline $0.01 \%$ & $2.63 E-05$ & $0.00 \%$ & $0.00 \%$ & $100.00 \%$ \\
\hline $0.00 \%$ & 2.39E-08 & $23.24 \%$ & $2.56 \%$ & $74.19 \%$ \\
\hline $0.00 \%$ & $2.68 \mathrm{E}-08$ & $26.33 \%$ & $2.24 \%$ & $71.43 \%$ \\
\hline $0.00 \%$ & 1.59E-06 & $68.39 \%$ & $1.50 \%$ & $30.11 \%$ \\
\hline $0.00 \%$ & $1.89 \mathrm{E}-06$ & $74.06 \%$ & $1.22 \%$ & $24.72 \%$ \\
\hline $0.00 \%$ & $1.71 \mathrm{E}-08$ & $26.48 \%$ & $2.22 \%$ & $71.30 \%$ \\
\hline $0.13 \%$ & 2.30E-04 & $23.91 \%$ & $14.03 \%$ & $62.05 \%$ \\
\hline $0.00 \%$ & 5.98E-09 & $22.82 \%$ & $2.60 \%$ & $74.58 \%$ \\
\hline $0.02 \%$ & $3.11 \mathrm{E}-05$ & $0.00 \%$ & $3.79 \%$ & $96.21 \%$ \\
\hline
\end{tabular}

Table 27: Average Energy Requirements per kWh of Net Electricity Produced - Average System (surface mining \& average user by river)

\begin{tabular}{|c|c|c|c|c|}
\hline & Total (MJ/kWh) & $\begin{array}{c}\% \text { of Total from } \\
\text { Surface Coal } \\
\text { Mining }\end{array}$ & $\begin{array}{l}\% \text { of Total from } \\
\text { Transportation }\end{array}$ & $\begin{array}{c}\% \text { of Total from } \\
\text { Electricity } \\
\text { Generation }\end{array}$ \\
\hline Non-electric Energy Consumed by System (excluding coal energy) & 0.6900 & $21.27 \%$ & $33.59 \%$ & $45.15 \%$ \\
\hline Electricity Consumed by System & 0.0339 & $98.67 \%$ & $2.08 \%$ & $-0.74 \%$ \\
\hline Total Non-coal Energy Consumed by System & 0.7239 & $24.89 \%$ & $32.11 \%$ & $43.00 \%$ \\
\hline Energy in Coal to Power Plant & 11.8508 & $\mathrm{~N} / \mathrm{A}$ & $\mathrm{N} / \mathrm{A}$ & $\mathrm{N} / \mathrm{A}$ \\
\hline Total Energy Consumed by System & 12.5747 & $1.43 \%$ & $1.85 \%$ & $96.72 \%$ \\
\hline
\end{tabular}

Note: The electricity produced and consumed by the power plant is not included in this table.

The power plant energy and electricty requirements are from upstream processes, construction, and decommissioning. 
Table 28: Average Solid Waste Generation per kWh of Net Electricity Produced - Average System (surface mining \& average user by river)

(s) antimony

(s) arsenic

(s) barium

(s) beryllium

(s) boron

(s) cadmium

(s) chromium

(s) cobalt

(s) copper

(s) lead

(s) manganese

(s) mercury

(s) molybdenum

(s) nickel

(s) selenium

(s) vanadium

ash - landfilled (dry)

FGC waste (dry) - landfilled

Waste (hazardous)

Waste (municipal and industrial)

Waste (unspecified)
$\%$ of Total from

$\%$ of Total in this

Table

$0.00 \%$

$0.00 \%$

$0.00 \%$

$0.00 \%$

$0.00 \%$

$0.00 \%$

$0.00 \%$

$0.00 \%$

$0.00 \%$

$0.00 \%$

$0.00 \%$

$0.00 \%$

$0.00 \%$

$0.00 \%$

$0.00 \%$

$0.00 \%$

$23.27 \%$

$58.61 \%$

$0.00 \%$

$0.13 \%$

$17.99 \%$
Surface Coal

Mining

$0.00 \%$

$0.00 \%$

$0.00 \%$

$0.00 \%$

$0.00 \%$

$0.00 \%$

$0.00 \%$

$0.00 \%$

$0.00 \%$

$0.00 \%$

$0.00 \%$

$0.00 \%$

$0.00 \%$

$0.00 \%$

$0.00 \%$

$0.00 \%$

$0.00 \%$

$0.00 \%$

$8.02 \%$

$25.46 \%$

$9.26 \%$
$\%$ of Total from

$\%$ of Total from

Transportation

$0.00 \%$

$0.00 \%$

$0.00 \%$

$0.00 \%$

$0.00 \%$

$0.00 \%$

$0.00 \%$

$0.00 \%$

$0.00 \%$

$0.00 \%$

$0.00 \%$

$0.00 \%$

$0.00 \%$

$0.00 \%$

$0.00 \%$

$0.00 \%$

$0.00 \%$

$0.00 \%$

$4.09 \%$

$2.11 \%$

$0.06 \%$
Electricity

Generation

$100.00 \%$

$100.00 \%$

$100.00 \%$

$100.00 \%$

$100.00 \%$

$100.00 \%$

$100.00 \%$

$100.00 \%$

$100.00 \%$

$100.00 \%$

$100.00 \%$

$100.00 \%$

$100.00 \%$

$100.00 \%$

$100.00 \%$

$100.00 \%$

$100.00 \%$

$100.00 \%$

$87.89 \%$

$72.43 \%$

$90.68 \%$

(s) = solid emission 
Figure 7: Coal LCA CO${ }_{2}$ Results for Average System

(surface mining \& transport via average user by river)

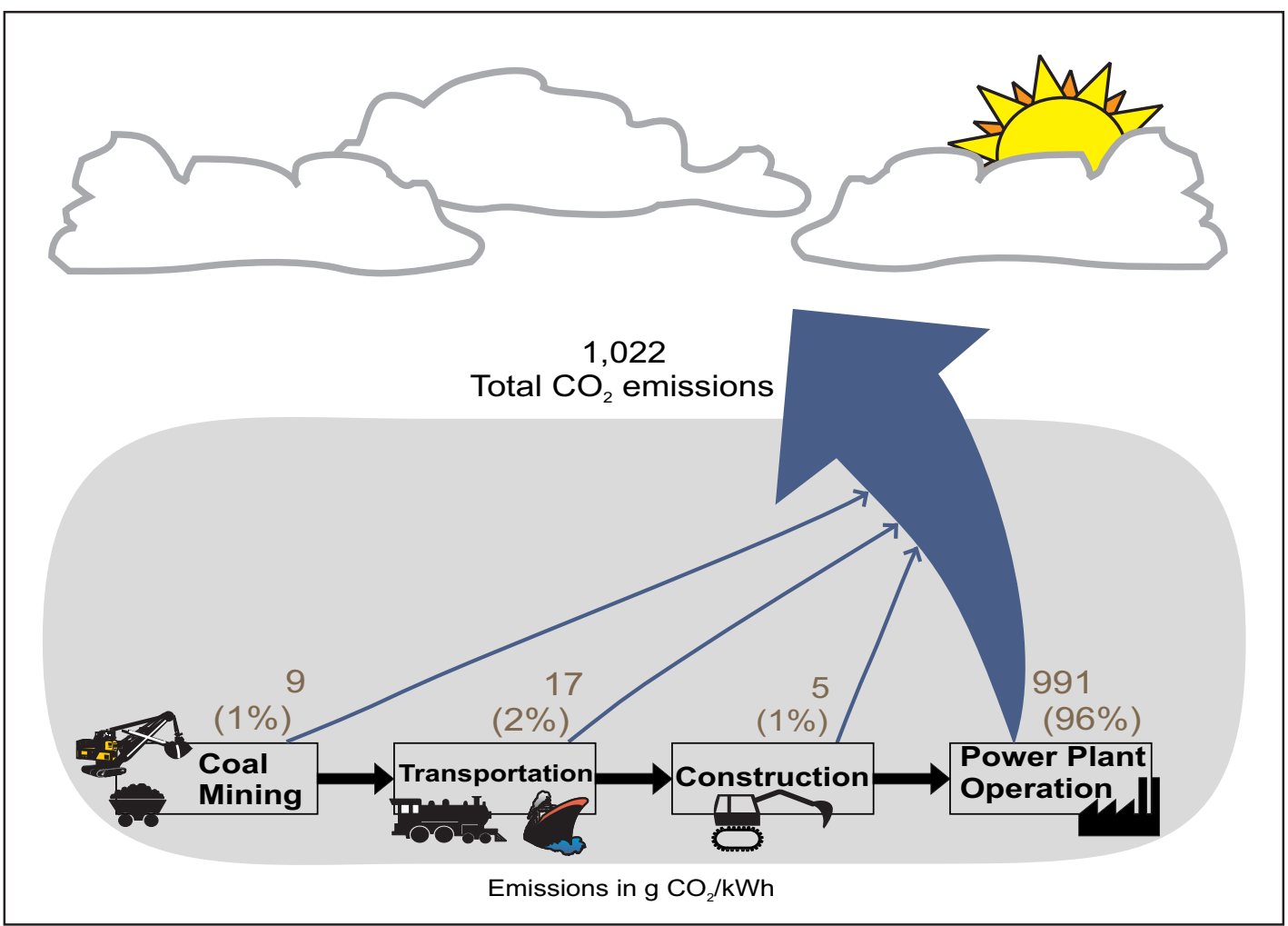

Figure 8: Yearly Carbon Dioxide Emissions

(surface mining \& average user by river)

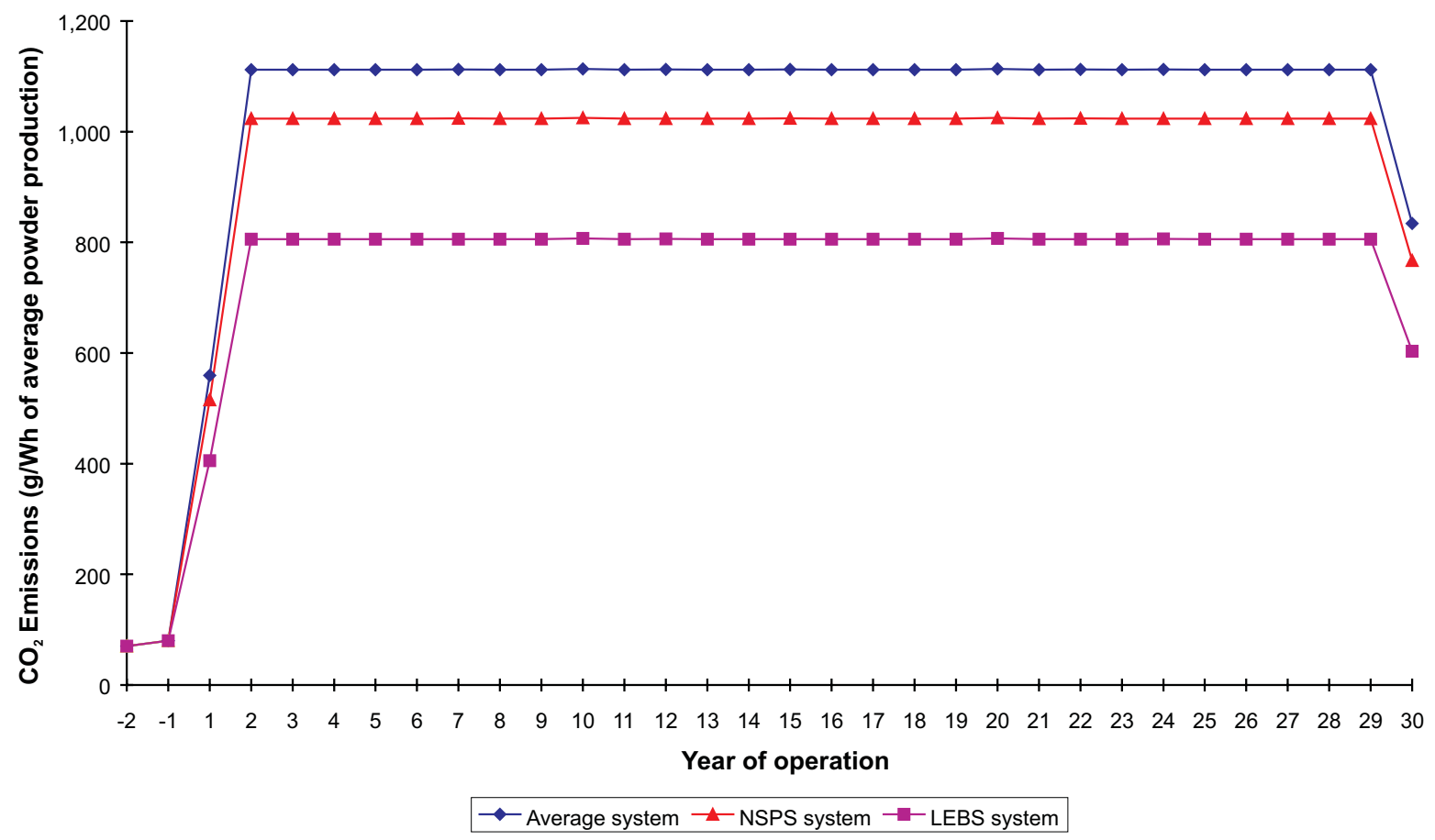


Because the amount of $\mathrm{CO}_{2}$ emitted during the combustion of the coal is so large (93\% of the total system $\mathrm{CO}_{2}$ for the Average and NSPS systems and $96 \%$ for the LEBS system), it masks the $\mathrm{CO}_{2}$ from the other process steps within the life cycle assessment. In the Average and NSPS systems, a very significant portion of the $\mathrm{CO}_{2}$ not produced during the combustion of coal is generated during the manufacture and transport of limestone and lime and during the limestone scrubbing reaction. For the following discussion the term non-coal $\mathrm{CO}_{2}$ emissions refers to the total system $\mathrm{CO}_{2}$ emissions minus the $\mathrm{CO}_{2}$ emissions generated from coal combustion. Table 30 shows the difference in the $\mathrm{CO}_{2}$ emissions when considering the entire system versus the non-coal $\mathrm{CO}_{2}$ emissions. Table 31 further breaks down the non-coal $\mathrm{CO}_{2}$ percentages from each process step for lime and limestone in the Average and NSPS systems because it is important to note that the majority of the non-coal $\mathrm{CO}_{2}$ comes from the manufacture $(20 \%-22 \%)$ and use $(24 \%-26 \%)$ of the limestone.

As these tables show, excluding the $\mathrm{CO}_{2}$ from the combustion of the coal at the power plant, the process steps involved in manufacturing and transporting limestone and lime along with limestone use, account for $59 \%$ and $62 \%$ of the system $\mathrm{CO}_{2}$ emissions for the Average and NSPS system, respectively. These emissions are larger than the $\mathrm{CO}_{2}$ produced during coal transportation which accounts for $26 \%$ and $23 \%$ of the non-coal $\mathrm{CO}_{2}$ in these two systems. Because the copper oxide sorbent replaces the traditional limestone scrubbing system in the LEBS system, associated $\mathrm{CO}_{2}$ emissions are not present. However, $35 \%$ of the $\mathrm{CO}_{2}$ generated during processes other than the combustion of coal is due to natural gas production $(3.2 \%)$ and combustion $(31.8 \%)$ for copper oxide regeneration. For this system, these numbers are somewhat less than the $\mathrm{CO}_{2}$ generated during coal transportation, which makes up $40 \%$ of the non-coal $\mathrm{CO}_{2}$.

Table 30: Measuring $\mathrm{CO}_{2}$ Emissions - Definitions and Numbers

\begin{tabular}{|c|c|c|c|c|c|}
\hline \multirow{3}{*}{$\begin{array}{l}\text { System } \\
\text { (a) }\end{array}$} & \multicolumn{3}{|c|}{$\%$ of total system $\mathrm{CO}_{2}(\mathrm{~b})$} & \multicolumn{2}{|c|}{$\%$ of total non-coal $\mathrm{CO}_{2}$ (c) } \\
\hline & $\begin{array}{c}\text { From } \\
\text { combustion of } \\
\text { coal }(\%)\end{array}$ & $\begin{array}{l}\text { From production, } \\
\text { transport, \& use of } \\
\text { limestone/lime or } \\
\text { natural gas }(\%)\end{array}$ & $\begin{array}{c}\text { From } \\
\text { transportation } \\
\text { of coal }(\%)\end{array}$ & $\begin{array}{l}\text { From production, } \\
\text { transport, \& use of } \\
\text { limestone/lime or } \\
\text { natural gas }(\%)\end{array}$ & $\begin{array}{c}\text { From transportation } \\
\text { of coal }(\%)\end{array}$ \\
\hline & $=\frac{\text { CO2coal }}{\text { CO2sys }}$ & $=\frac{C O 2 u p+C O 2 \text { use }}{C O 2 s y s}$ & $=\frac{\text { CO2trans }}{\text { CO2sys }}$ & $=\frac{\text { CO2up }+ \text { CO2use }}{\text { CO2sys }- \text { CO2coal }}$ & $=\frac{\text { CO2trans }}{\text { CO2sys }- \text { CO2coal }}$ \\
\hline Average & 93.3 & 4.0 & 1.7 & 59.2 & 25.7 \\
\hline NSPS & 92.7 & 4.6 & 1.7 & 62.3 & 23.3 \\
\hline LEBS & 95.6 & 4.5 & 1.8 & 34.9 & 39.6 \\
\hline \multicolumn{6}{|c|}{ 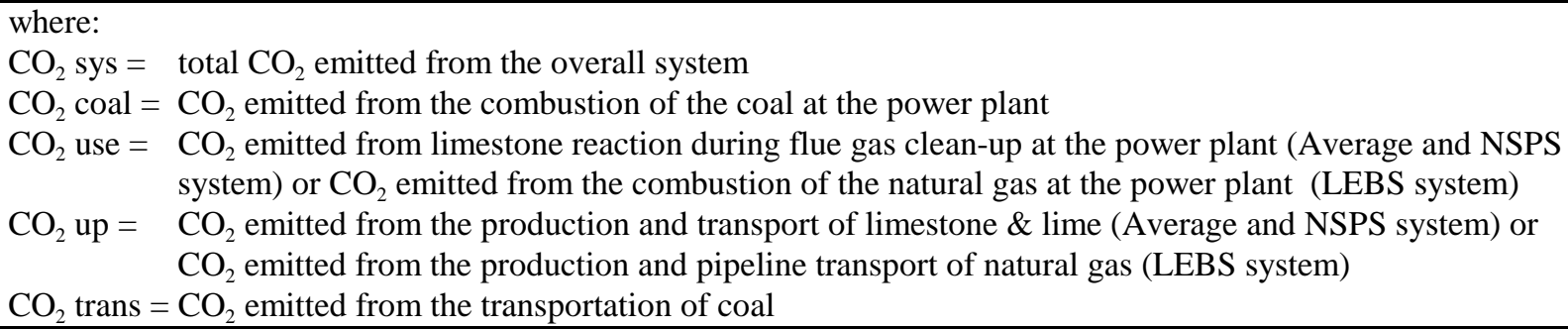 } \\
\hline
\end{tabular}


(a) Results are reported for the surface mining case. However, the underground mining numbers are similar to those listed here. Coal transportation $=$ average user by river.

(b) The numbers may add up to more than $100 \%$ because some $\mathrm{CO}_{2}$ credits are taken into account for recycling of metals and alternate uses of waste streams.

(c) Excludes the $\mathrm{CO}_{2}$ released from the coal during combustion.

Table 31: Breakdown of Non-Coal $\mathrm{CO}_{2}$ Results for Lime and Limestone

\begin{tabular}{|l|c|c|c|c|c|}
\hline \multirow{2}{*}{ System } & \multicolumn{5}{|c|}{$\%$ of total non-coal $\mathrm{CO}_{2}(\mathrm{a}),(\mathrm{b}),(\mathrm{c})$} \\
\cline { 2 - 6 } & $\begin{array}{c}\text { From production } \\
\text { of lime (\%) }\end{array}$ & $\begin{array}{c}\text { From production } \\
\text { of limestone (\%) }\end{array}$ & $\begin{array}{c}\text { From transportation of } \\
\text { lime \& limestone (\%) }\end{array}$ & $\begin{array}{c}\text { From limestone } \\
\text { scrubbing reaction (\%) }\end{array}$ & $\begin{array}{c}\text { Total } \\
(\%)\end{array}$ \\
\hline Average & 10.4 & 20.4 & 4.1 & 24.3 & 59.2 \\
\hline NSPS & 10.9 & 21.5 & 4.3 & 25.6 & 62.3 \\
\hline
\end{tabular}

(a) Excludes the $\mathrm{CO}_{2}$ released from the coal during combustion.

(b) Results are reported for the surface mining case. However, the underground mining numbers are similar to those listed here.

(c) Coal transportation $=$ average user by river.

\subsection{Air Emissions}

Other than $\mathrm{CO}_{2}$, Table 32 contains the next highest air emissions from the three systems examined in this LCA. Refer to Table 25 and Tables B2, B7, B12, B17, and B22 in Appendix B for a complete listing of all air emissions as well as a breakdown of the percent of each emission from the mining, transportation, and electricity generation subsystems.

Table 32: Air Emissions (Excluding $\mathrm{CO}_{2}$ )

\begin{tabular}{|l|c|c|c|c|c|c|}
\hline \multirow{2}{*}{ Air emission } & \multicolumn{2}{|c|}{$\begin{array}{c}\text { Average } \\
(\mathrm{a}, \mathrm{b})\end{array}$} & \multicolumn{2}{c|}{$\begin{array}{c}\text { NSPS } \\
(\mathrm{a}, \mathrm{b})\end{array}$} & \multicolumn{2}{c|}{$\begin{array}{c}\text { LEBS } \\
(\mathrm{a}, \mathrm{b})\end{array}$} \\
\cline { 2 - 8 } & $\begin{array}{c}\% \text { by } \\
\mathrm{wt}(\mathrm{c})\end{array}$ & $\begin{array}{c}\mathrm{g} / \mathrm{kWh} \\
(\mathrm{d})\end{array}$ & $\begin{array}{c}\% \text { by } \\
\mathrm{wt}(\mathrm{c})\end{array}$ & $\begin{array}{c}\mathrm{g} / \mathrm{kWh} \\
(\mathrm{d})\end{array}$ & $\begin{array}{c}\% \text { by } \\
\mathrm{wt}(\mathrm{c})\end{array}$ & $\begin{array}{c}\mathrm{g} / \mathrm{kWh} \\
(\mathrm{d})\end{array}$ \\
\hline Particulates & 44.3 & 9.21 & 61.0 & 9.78 & 4.4 & 0.11 \\
\hline $\mathrm{SO}_{x}$ & 32.2 & 6.70 & 15.7 & 2.53 & 28.0 & 0.72 \\
\hline $\mathrm{NO}_{x}$ & 16.1 & 3.35 & 14.6 & 2.34 & 21.3 & 0.54 \\
\hline $\mathrm{CH}_{4}$ & 4.4 & 0.91 & 5.2 & 0.84 & 27.9 & 0.75 \\
\hline $\mathrm{CO}$ & 1.3 & 0.27 & 1.5 & 0.25 & 7.5 & 0.19 \\
\hline $\mathrm{NMHCs}(\mathrm{e})$ & 1.0 & 0.21 & 1.3 & 0.20 & 7.5 & 0.19 \\
\hline
\end{tabular}

(a) Results are reported for the surface mining case. However, the underground mining numbers are similar to those listed here.

(b) Coal transportation $=$ average user by river.

(c) Percent of total air emissions excluding $\mathrm{CO}_{2}$ emissions. Not all resources consumed by the system are shown; therefore the numbers do not add up to $100 \%$.

(d) Air emissions per kWh of net electricity produced averaged over the life of the system.

(e) NMHCs $=$ non-methane hydrocarbons including volatile organic compounds (VOCs). 
The numbers in the following discussion are given for surface mining and transportation via the average user by river case. In all three systems the power plant produces most of the $\mathrm{SO}_{\mathrm{x}}, \mathrm{NO}_{\mathrm{x}}$, and $\mathrm{CO}$ while the methane comes primarily from the coal mine (see Table 25 and the following tables in Appendix B: B2, B7, B12, B17, and B22 for a breakdown). For the Average and NSPS system, the majority of the particulates come from the production of limestone (89\% of the total particulate emissions for both systems) and are created during the quarrying operations. Although the overall amount of particulates are considerably less for the LEBS system, the bulk of the particulates are emitted by the power plant during normal operation ( $47 \%$ of the total particulate emissions); the second predominant source of particulates is copper oxide production (22\% of the total particulate emissions). For all three systems, the NMHC emissions are evenly distributed among the mining, transportation, and power generation subsystems. However, for the LEBS system it should be noted that $36 \%$ of the total NMHC emissions are emitted during natural gas production.

Figures 9 and 10 show the yearly particulate emissions per the average amount of power production over the life of the system for both surface and underground mining. Figures 11 and 12 show the yearly $\mathrm{SO}_{\mathrm{x}}$, and $\mathrm{NO}_{\mathrm{x}}$ emissions for surface mining only (Figures $\mathrm{C} 2$ and $\mathrm{C} 3$, in Appendix $\mathrm{C}$ contain the yearly $\mathrm{SO}_{\mathrm{x}}$, and $\mathrm{NO}_{\mathrm{x}}$ results for the underground mining case. These graphs are similar to the surface mining ones.). Particulates, $\mathrm{SO}_{\mathrm{x}}$, and $\mathrm{NO}_{\mathrm{x}}$ are the criteria pollutants that fall under the New Source Performance Standards under the Code of Federal Regulations. As expected, the LEBS plant emits fewer particulates, $\mathrm{SO}_{\mathrm{x}}$, and $\mathrm{NO}_{\mathrm{x}}$ in accord with its design goals. Also, the particulate emissions from the LEBS system are considerably less than from the Average or NSPS plant. This is almost entirely due to the fact that the LEBS plant does not require limestone for flue gas clean-up, which during its production results in large quantities of particulates. Some limestone is used in underground mining, making the yearly particulate emissions using this mining technique higher than those from surface mining; this is evident when comparing Figures 9 and 10.

Figure 12 shows that the $\mathrm{NO}_{\mathrm{x}}$ emissions for the LEBS system in year one are less than the construction years because the amount of $\mathrm{NO}_{\mathrm{x}}$ produced during cement manufacturing is large compared to the amount of $\mathrm{NO}_{\mathrm{x}}$ produced from the plant which only operates at $50 \%$ capacity in year one. The yearly $\mathrm{CH}_{4}$ emissions are shown in Figure 13 (See Appendix C, Figure C4, for the yearly underground mining $\mathrm{CH}_{4}$ emissions.). These graphs differ from the particulates, $\mathrm{SO}_{x}$, and $\mathrm{NO}_{\mathrm{x}}$ figures in that the methane emissions for each of the three power plant systems are similar primarily because the majority of the methane comes from the coal mine. The average $\mathrm{CH}_{4}$ emissions over the life of the plant equal 0.91, 0.84, and $0.71 \mathrm{~g} / \mathrm{kWh}$ of average power production for the Average, NSPS, and LEBS system, respectively; by contrast, the $\mathrm{SO}_{\mathrm{x}}$ emissions for the three systems are $6.7,2.5$, and $0.72 \mathrm{~g} / \mathrm{kWh}$ of average power production for the Average, NSPS, and LEBS system, respectively.

Three air emissions that are generally believed to have the potential to contribute to global warming were emitted from these systems. They are $\mathrm{CO}_{2}, \mathrm{CH}_{4}$, and $\mathrm{N}_{2} \mathrm{O}$. To determine the total global warming potential (GWP) from these compounds, weighting factors determined by the Intergovernmental Panel on Climate Change (IPCC) were applied. The GWP of a gas reflects its cumulative radiative capacity over a specified period of time. For this study, the 100 year time frame factors were used. The recommended values, expressed as the GWP of a gas relative to $\mathrm{CO}_{2}$ on a mass basis, were 21 for methane and 310 for nitrous oxide (Houghton et al, 1996). For the Average system using surface mining, $\mathrm{CO}_{2}, \mathrm{CH}_{4}$, and $\mathrm{N}_{2} \mathrm{O}$ were found to be emitted at rates of $1,021.5 \mathrm{~g} / \mathrm{kWh}, 0.9 \mathrm{~g} / \mathrm{kWh}$, and $0.004 \mathrm{~g} / \mathrm{kWh}$, respectively. Applying the appropriate GWP factors, this equates to 1,021.5, 19.2, and $1.4 \mathrm{~g} \mathrm{CO}_{2}$ equivalent $/ \mathrm{kWh}$, respectively. Thus, the total potential of this system to contribute to global warming 
Figure 9: Yearly Particulate Emission

(surface mining \& average user by river)

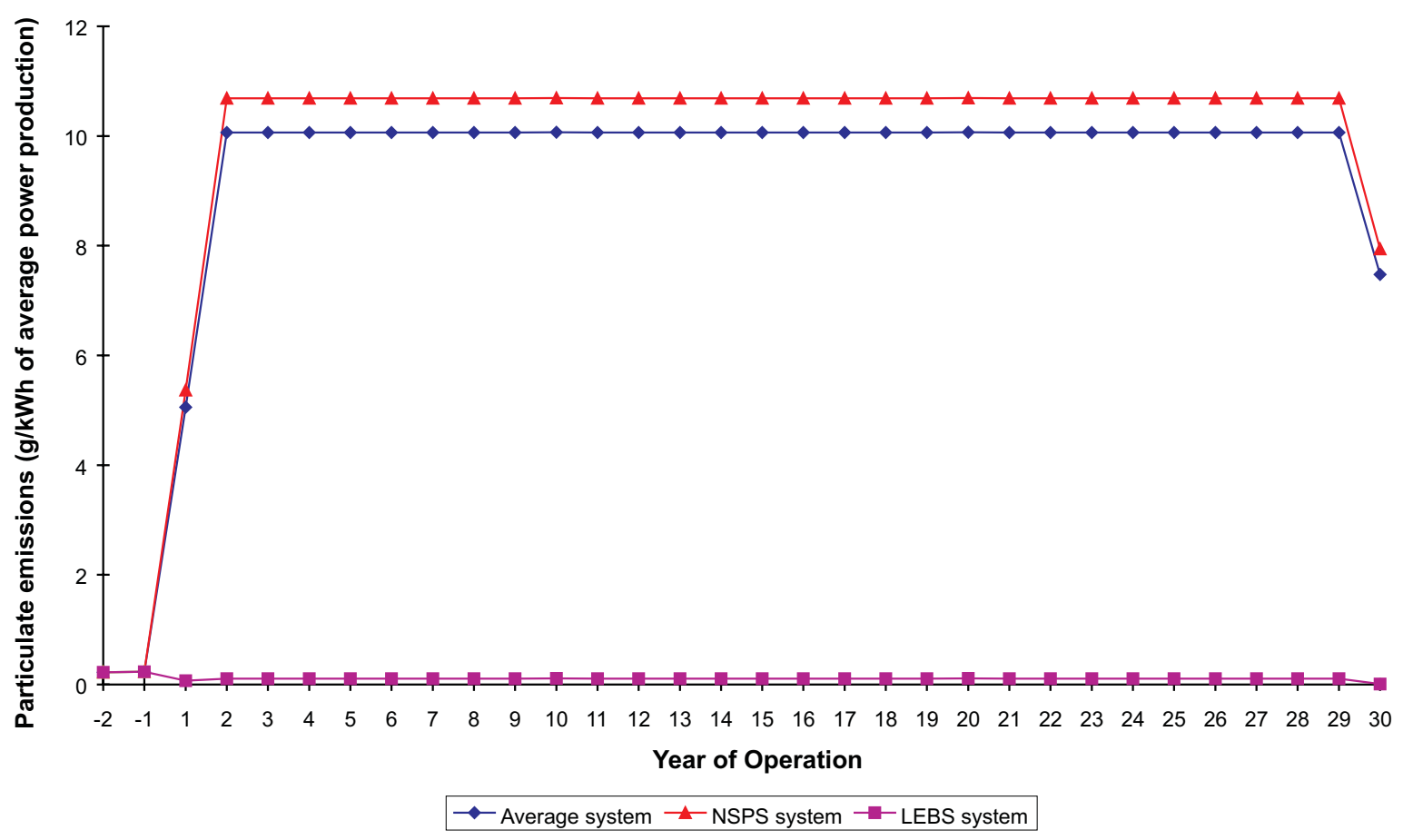

Figure 10: Yearly Particulate Emissions (underground mining \& average user by river)

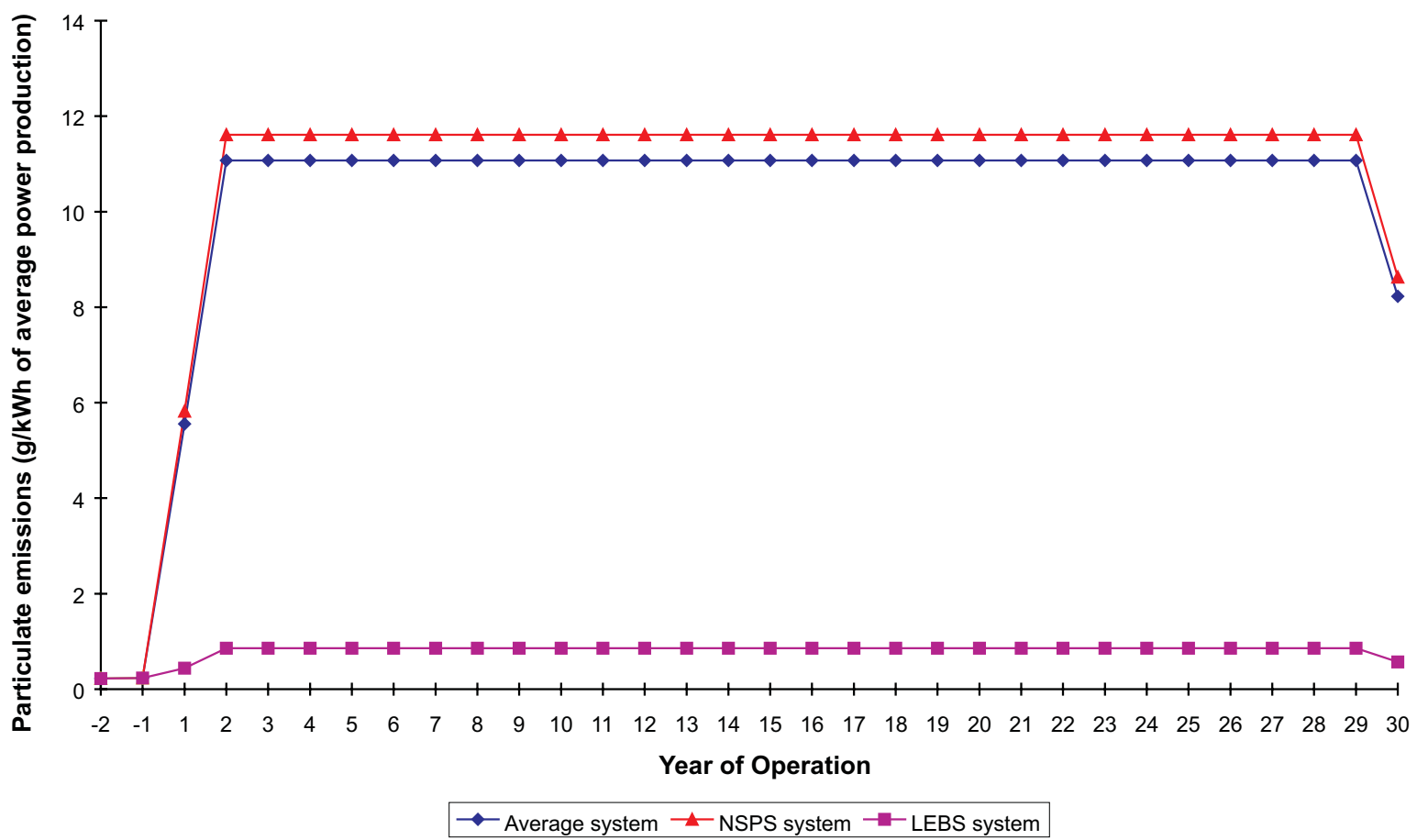


Figure 11: Yearly Sulfur Oxide Emissions $\left(\mathrm{SO}_{x}\right.$ as $\left.\mathrm{SO}_{2}\right)$ (surface mining $\&$ average user by river)

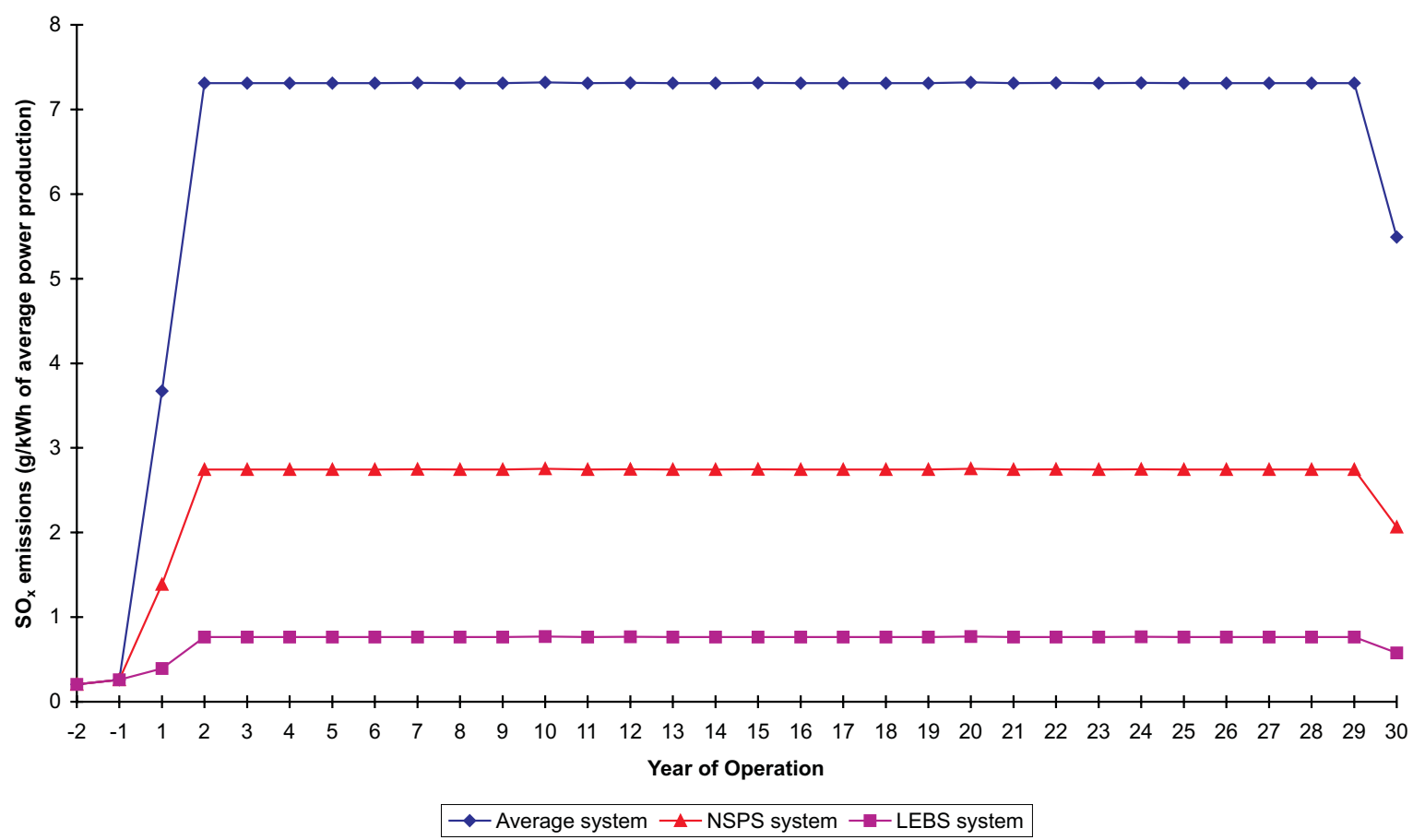

Figure 12: Yearly Nitrogen Oxide Emissions $\left(\mathrm{NO}_{\mathrm{x}}\right.$ as $\left.\mathrm{NO}_{2}\right)$ (surface mining \& average user by river)

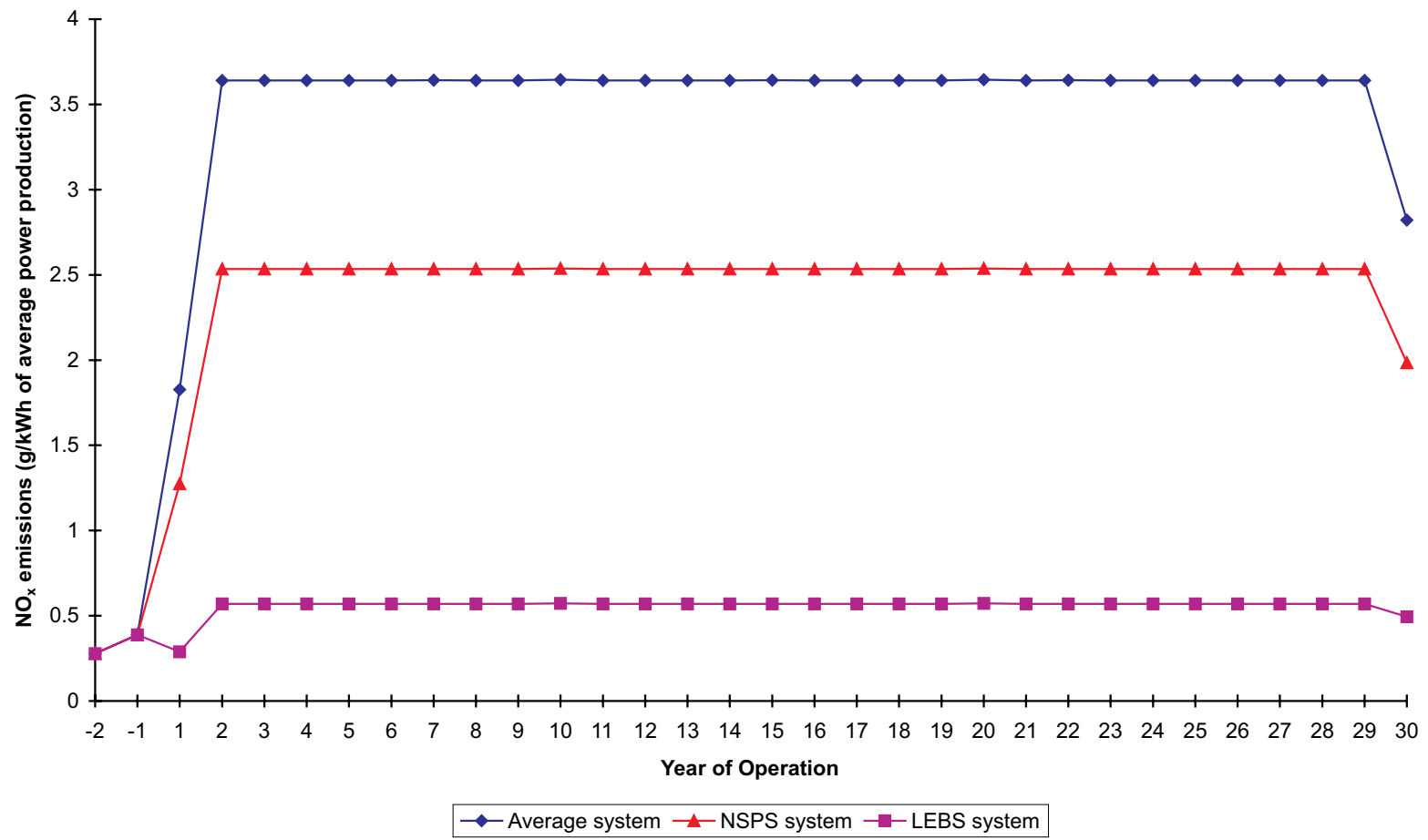


Figure 13: Yearly Methane Emissions

(surface mining \& average user by river)

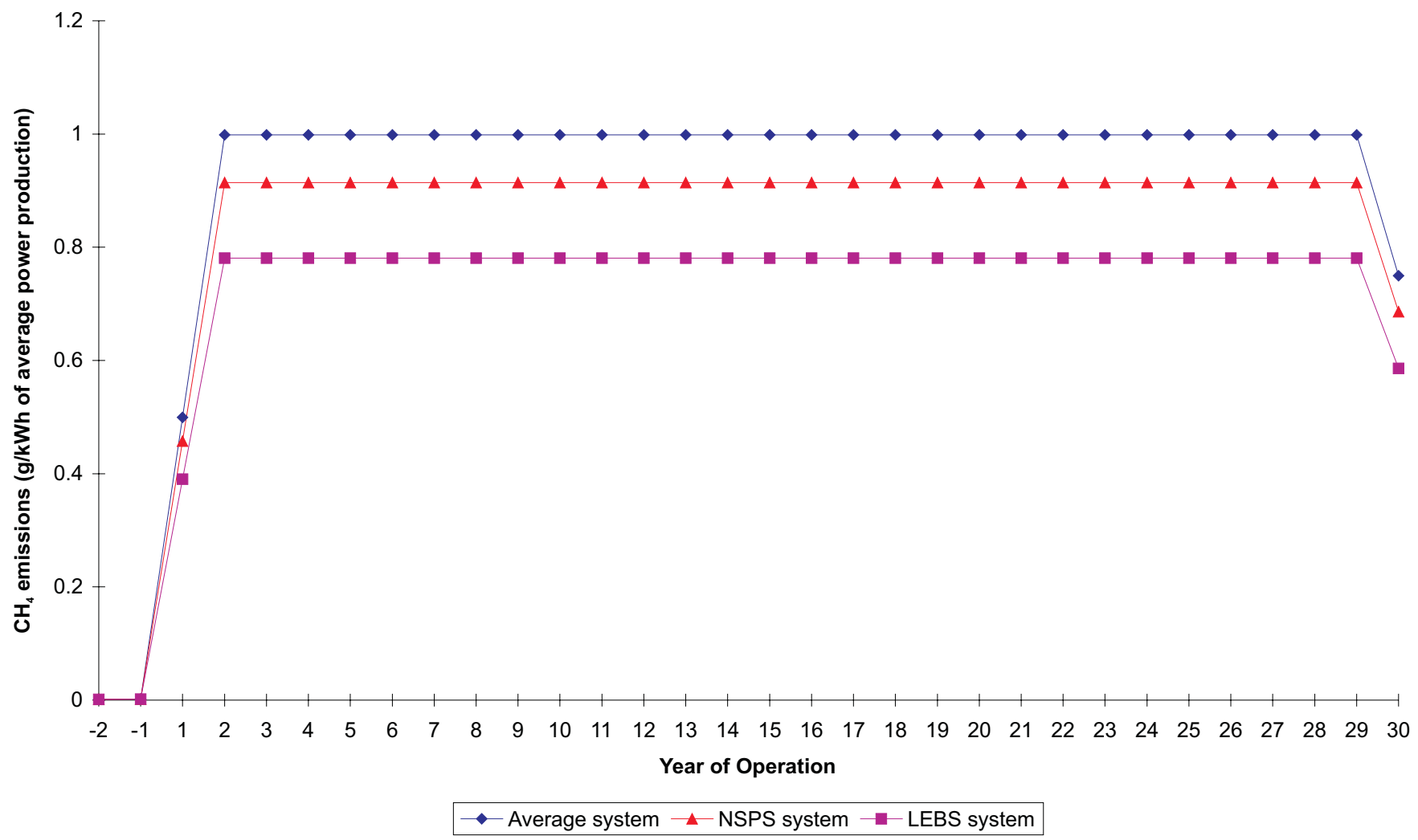


is equivalent to $1,042.1 \mathrm{~g}$ of $\mathrm{CO}_{2} / \mathrm{kWh}$, only $2.0 \%$ higher than the $\mathrm{GWP}$ of the $\mathrm{CO}_{2}$ alone. This is because even though methane and $\mathrm{N}_{2} \mathrm{O}$ have much greater potential to affect the climate, they are emitted in such small quantities compared to $\mathrm{CO}_{2}$ that they do not greatly influence the overall GWP of the system. The GWPs of the NSPS and LEBS systems are 959.5 and $756.9 \mathrm{~g} \mathrm{CO}_{2}$ equivalent $/ \mathrm{kWh}$; again approximately $2 \%$ higher than the rate of $\mathrm{CO}_{2}$ emissions alone. If underground mining is used, the methane emissions are approximately double, resulting in the GWP of the systems increasing to approximately $4 \%$ higher than that resulting only from the $\mathrm{CO}_{2}$ emissions.

\subsection{Water Emissions}

For all three systems, the majority of the water emissions from the system occurred in and were evenly distributed between the mining and power generation subsystems. Note that for each system examined the power plant produces a significant amount of water that is treated prior to discharge and thus this stream is not considered a waste stream. In general, though, the total amount of water pollutants was found to be small compared to other emissions (see Table 26 and the following tables in Appendix B: $\mathrm{B} 3, \mathrm{~B} 8, \mathrm{~B} 13, \mathrm{~B} 18$, and $\mathrm{B} 23)$.

\subsection{Energy Consumption}

The energy use within the system was tracked so the net energy production could be assessed. Several types of efficiencies can be defined to study the energy budget of the coal system. The first is the power plant efficiency which is defined in the traditional sense as the energy delivered to the grid divided by the energy in the feedstock to the power plant (coal and natural gas in the LEBS system). In the LEBS system, the natural gas is conventionally considered to be a fossil fuel input to the plant. Four other types of efficiencies can be defined as follows:

Table 33: Energy Efficiency and Energy Ratio Definitions

\begin{tabular}{|c|c|c|c|}
\hline Life cycle efficiency (\%) (a) & $\begin{array}{c}\text { External energy } \\
\text { efficiency (\%) (b) }\end{array}$ & Net energy ratio (c) & External energy ratio (d) \\
\hline$=\frac{E g-E u-E c-E n}{E c+E n}$ & $=\frac{E g-E u}{E c+E n}$ & $=\frac{E g}{E f f-E c-E n}$ \\
\hline where: $\quad \begin{aligned} E f f \\
\text { Eu }\end{aligned}$ & $=$ enectric energy delivered to the utility grid \\
Ec & $=$ energy contained in the coal fed to the power plant \\
En & $=$ energy contained in the natural gas fed to the power plant (LEBS system only) \\
Eff & $=$ fossil fuel energy consumed within the system (e)
\end{tabular}

(a) Includes the energy consumed by all of the processes.

(b) Excludes the heating value of the coal and natural gas feedstock from the life cycle efficiency formula.

(c) Illustrates how much energy is produced for each unit of fossil fuel energy consumed.

(d) Excludes the energy of the coal and natural gas to the power plant.

(e) Includes the coal and natural gas fed to the power plant since these resources are consumed within the boundaries of the system.

There are not standard terms corresponding to the definitions in Table 33. However, many studies have used these same definitions with their own terminology (Colorado Energy Research Institute, April 1976; 
Keoleian, 1997; and Waku et al, 1995.) The net energy ratio is a more accurate and rigorous measure of the net energy yield from the system than the external energy ratio because it accounts for all of the fossil energy inputs. Table 34 contains the resulting efficiencies and energy ratios for each system.

Table 34: Efficiencies and Energy Ratio Results

\begin{tabular}{|l|c|c|c|c|c|}
\hline \multicolumn{1}{|c|}{$\begin{array}{c}\text { System } \\
(\mathrm{a}, \mathrm{b})\end{array}$} & $\begin{array}{c}\text { Power plant } \\
\text { efficiency } \\
(\%)(\mathrm{c})\end{array}$ & $\begin{array}{c}\text { Life cycle } \\
\text { efficiency } \\
(\%)(\mathrm{c})\end{array}$ & $\begin{array}{c}\text { External energy } \\
\text { efficiency } \\
(\%)(\mathrm{c})\end{array}$ & $\begin{array}{c}\text { Net energy } \\
\text { ratio }\end{array}$ & $\begin{array}{c}\text { External } \\
\text { energy ratio }\end{array}$ \\
\hline Average & 32 & -76 & 24 & 0.29 & 5.0 \\
\hline NSPS & 35 & -73 & 27 & 0.31 & 5.1 \\
\hline LEBS & 42 & -66 & 34 & 0.38 & 6.7 \\
\hline
\end{tabular}

(a) Results are reported for the surface mining case. However, the underground mining numbers are similar to those listed here.

(b) Coal transportation $=$ average user by river.

(c) Efficiencies are on a higher heating value basis.

Table 35: Energy - Definitions and Values

\begin{tabular}{|c|c|c|c|c|}
\hline \multirow{3}{*}{$\begin{array}{l}\text { System } \\
\text { (a) }\end{array}$} & \multicolumn{2}{|c|}{$\%$ of total non-coal energy (b) } & \multicolumn{2}{|c|}{$\%$ of total system energy } \\
\hline & $\begin{array}{l}\text { For production, } \\
\text { transport, \& use of } \\
\text { limestone/lime or } \\
\text { natural gas }(\%)\end{array}$ & $\begin{array}{c}\text { For transportation } \\
\text { of coal }(\%)\end{array}$ & $\begin{array}{l}\text { For production, } \\
\text { transport, \& use of } \\
\text { limestone/lime or } \\
\text { natural gas }(\%)\end{array}$ & $\begin{array}{c}\text { For transportation } \\
\text { of coal }(\%)\end{array}$ \\
\hline & $=\frac{\text { Eup }}{\text { Esys }- \text { Ecoal }}$ & $=\frac{\text { Etrans }}{\text { Esys }- \text { Ecoal }}$ & $=\frac{E u p}{E s y s}$ & $=\frac{\text { Etrans }}{\text { Esys }}$ \\
\hline Average & 35.3 & 32.1 & 2.0 & 1.8 \\
\hline NSPS & 38.5 & 30.1 & 2.4 & 1.8 \\
\hline LEBS & 38.3 & 32.2 & 2.2 & 1.8 \\
\hline \multicolumn{5}{|c|}{$\begin{array}{l}\text { energy content of th } \\
\text { energy required for } \\
\text { NSPS system) or en } \\
\text { gas (LEBS system) }\end{array}$} \\
\hline
\end{tabular}

(a) Results are reported for the surface mining case. However, the underground mining numbers are similar to those listed here. Coal transportation $=$ average user by river.

(b) Excludes the energy content of the coal.

The large difference between the life cycle efficiency and the external energy efficiency is due solely to the energy contained in the coal used at the power plants (see Table 27 and the following tables in Appendix B: B4, B9, B14, B19, and B24). Because this energy is so large, subsequent energy discussions will be presented in terms of the non-coal energy consumption of the system so the effect of other energy consumers can be more clearly seen. The non-coal energy consumption is defined as the total energy 
consumed by the system excluding the energy content of the coal to the power plant (see Table 35 above). For example, for all three systems examined (Average, NSPS, and LEBS), a large amount of energy is consumed in the transportation subsystem, primarily from the energy required to extract crude oil, distill it, produce a usable transportation fuel, and distribute it to refueling stations. For all three power plant systems the energy consumed to transport the coal by a combination of train and barge accounts for $30 \%$ $32 \%$ of the total non-coal system energy consumption. If the energy in the coal is taken into account, this number decreases to about 2\%, as seen in Table 35 (also, refer to Table 27 and the following tables in Appendix B: B4, B9, B14, B19, and B24).

One of the more important results of this study was the large amount of energy that is consumed in upstream processes required for flue gas clean-up. For the Average and NSPS systems, limestone production accounts for a very significant portion of the non-coal system energy consumption (see Table 36). In the case of the LEBS plant, the largest consumer of energy is the production and use of natural gas used to regenerate the flue gas clean-up sorbent. Limestone production accounts for $25 \%$ and $28 \%$ of the total non-coal system energy consumption for the Average and NSPS system, respectively; natural gas production and use accounts for $37 \%$ of the total non-coal system energy for the LEBS system.

Table 36: Breakdown of Non-Coal Energy for Lime and Limestone

\begin{tabular}{|l|c|c|c|c|}
\hline \multirow{2}{*}{ System } & \multicolumn{4}{|c|}{$\%$ of total non-coal energy (a), (b), (c) } \\
\cline { 2 - 5 } & $\begin{array}{c}\text { For production } \\
\text { of lime (\%) }\end{array}$ & $\begin{array}{c}\text { For production } \\
\text { of limestone (\%) }\end{array}$ & $\begin{array}{c}\text { For transportation of } \\
\text { lime \& limestone (\%) }\end{array}$ & $\begin{array}{c}\text { Total } \\
(\%)\end{array}$ \\
\hline Average & 4.8 & 25.2 & 5.3 & 35.3 \\
\hline NSPS & 5.3 & 27.5 & 5.7 & 38.5 \\
\hline
\end{tabular}

(a) Excludes the energy content of the coal.

(b) Results are reported for the surface mining case. However, the underground mining numbers are similar to those listed here.

(c) Coal transportation $=$ average user by river.

Figure 14 shows the yearly non-coal energy consumption per the average amount of power production over the life of the system for surface mining (See Appendix C, Figure C5, for the underground mining case which is similar to the surface mining results.). Because the power plant operates only $50 \%$ of the first year, the total non-coal system energy consumption is less than during the second construction year.

\subsection{Resource Consumption}

Fossil fuels, metals, and minerals are used in all of the process steps required to convert coal to electricity. Table 37 shows the majority of the resources used for each system studied. For all three systems, coal is used at the highest rate. For the Average and NSPS systems, limestone and oil account for the bulk of the remaining resources consumed, whereas for the LEBS system, natural gas and oil account for the majority. Table 24 and Tables B1, B6, B11, B16, and B21 in Appendix B contain detailed information about the resource consumption for each subsystem for both surface and underground mining, with coal transport to the average user by river. 
Figure 14: Yearly Total Non-Coal Energy Consumption

(surface mining \& average user by river)

(Note: Electricity produced and consumed by the power plant not included)

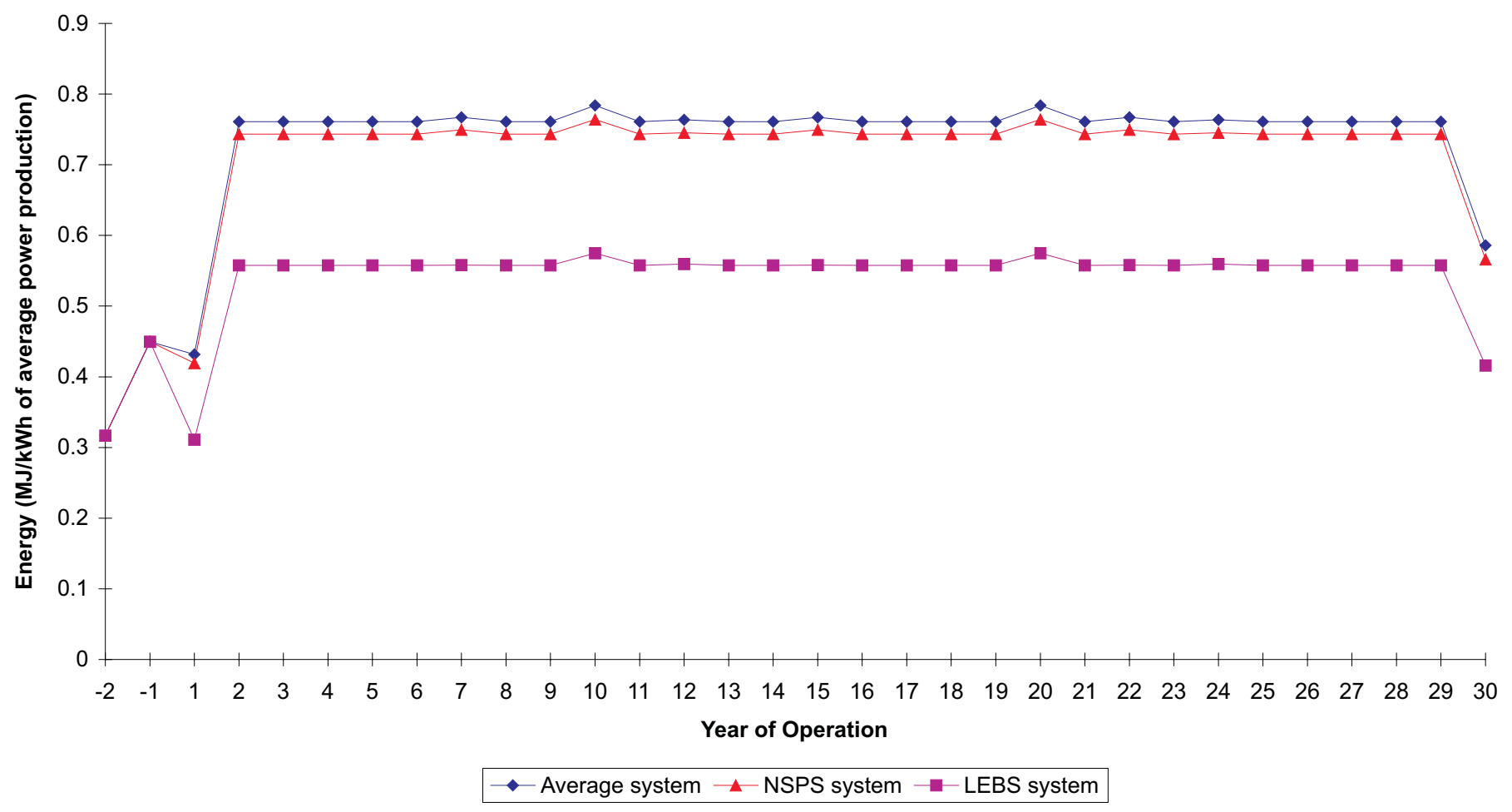


Table 37: Resource Consumption

\begin{tabular}{|l|c|c|c|c|c|c|}
\hline \multirow{2}{*}{ Resource } & \multicolumn{2}{|c|}{$\begin{array}{c}\text { Average } \\
(\mathrm{a}, \mathrm{b})\end{array}$} & \multicolumn{2}{c|}{$\begin{array}{c}\text { NSPS } \\
(\mathrm{a}, \mathrm{b})\end{array}$} & \multicolumn{2}{c|}{$\begin{array}{c}\text { LEBS } \\
(\mathrm{a}, \mathrm{b})\end{array}$} \\
\cline { 2 - 8 } & $\begin{array}{c}\% \text { by } \\
\text { wt (c) }\end{array}$ & $\begin{array}{c}\mathrm{g} / \mathrm{kWh} \\
(\mathrm{d})\end{array}$ & $\begin{array}{c}\% \text { by } \\
\text { wt }(\mathrm{c})\end{array}$ & $\begin{array}{c}\mathrm{g} / \mathrm{kWh} \\
(\mathrm{d})\end{array}$ & $\begin{array}{c}\% \text { by } \\
\text { wt (c) }\end{array}$ & $\begin{array}{c}\mathrm{g} / \mathrm{kWh} \\
(\mathrm{d})\end{array}$ \\
\hline Coal & 80.4 & 475.62 & 78.0 & 434.92 & 97.3 & 353.37 \\
\hline Limestone & 17.4 & 102.84 & 19.7 & 109.49 & 0.0 & 0.04 \\
\hline Oil & 1.9 & 11.48 & 2.0 & 11.32 & 1.3 & 4.88 \\
\hline Natural gas & 0.2 & 1.25 & 0.2 & 1.26 & 1.3 & 4.53 \\
\hline Iron ore & 0.0 & 0.11 & 0.0 & 0.11 & 0.0 & 0.095 \\
\hline Iron scrap & 0.0 & 0.12 & 0.0 & 0.12 & 0.0 & 0.10 \\
\hline
\end{tabular}

(a) Results are reported for the surface mining case. However, the underground mining numbers are similar to those listed here.

(b) Coal transportation $=$ average user by river.

(c) Percent of total resource consumption. Not all resources consumed by the system are shown; therefore the numbers do not add up to $100 \%$.

(d) Resource consumption per kWh of net electricity produced averaged over the life of the system.

Because of the different flue gas clean-up technologies, the amount of limestone used is significantly higher for the Average and NSPS systems, whereas the natural gas consumption is greater for the LEBS system. As noted previously, natural gas is used to regenerate the copper oxide sorbent. Using limestone scrubbing versus the copper oxide flue gas clean-up process also contributes to the larger oil consumption for the Average and NSPS systems. These systems require twice as much oil compared to the LEBS system due to the fuel oil usage during limestone quarrying (see section 10.1 for a detailed comparison).

Caution should be exercised when looking at the amounts of resources consumed by these systems, that inferences regarding the negative impact of such consumption not be made. In assessing resource depletion, the effects on society as a result of dwindling stock reserves were not assessed. Similarly, no estimations of the total reserve available were made. However, because each fossil resource, although finite, exists in different quantities, the impact of consuming a given quantity of one resource is not the same as the impact of consuming the same quantity of a different resource.

\subsection{Solid Waste}

The numbers in the following discussion are given for surface mining and transportation via the average user by river case. The majority of the solid waste in the Average and NSPS systems comes from the power plant in the form of flue gas clean-up waste and ash that must be landfilled: $58 \%-61 \%$ and $20 \%$ $23 \%$ of the total waste, respectively. For these two systems, non-hazardous solid waste makes up $18 \%$ $20 \%$ of the total waste, most of which is generated during limestone production. The bulk of the solid waste from the LEBS system is ash which accounts for $87 \%-93 \%$ of the total waste. The remaining waste for the LEBS system is non-hazardous solid waste which primarily comes from the mining operations. Table 28 and Tables B5, B10, B15, B20, and B25 in Appendix B contain detailed information about the wastes produced for each subsystem for both surface and underground mining and the average user by river transport case. 


\subsection{Results Specific to the Three Major Subsystems}

\subsection{Base Case Coal Mining Results}

Overall, the environmental impacts from surface and underground mining are essentially equal. Other than the mining methane emissions which will ultimately be site-specific, the main difference between the two techniques is that the surface mining subsystem results in a higher amount of airborne ammonia emissions due to the production of ammonium nitrate explosives used at the mine. For example, the average yearly airborne ammonia emissions for the Average system are $0.099 \mathrm{~g} / \mathrm{kWh}$ of net electricity produced for the surface mining case versus $0.00022 \mathrm{~g} / \mathrm{kWh}$ of net electricity produced for underground mining for the average user by river transport case. Another important difference between the two mining techniques is that underground mining requires limestone, which emits a large amount of particulates during its production. Therefore, the particulate emissions in systems using this mining method will be higher. For example, the average yearly particulate emissions for the Average system are $0.0092 \mathrm{~g} / \mathrm{kWh}$ of net electricity produced for the surface mining case versus $0.93 \mathrm{~g} / \mathrm{kWh}$ of net electricity produced for underground mining (average user by river transport).

In general, coal mining uses more electricity than the transportation and electricity generation subsystems. As expected, the majority of the overall methane emissions come from the mine itself. Also, about half of the water emissions come from the mining subsystem.

\subsection{Base Case Coal Transportation Results}

Of the three subsystems examined (coal mining, transportation, and electricity production), transportation required the least amount of resources and had the lowest air, water, and solid waste emissions even when considering the farthest user case (see Tables 24-28 and Tables B1-B25 in Appendix B for the average user by river numbers and percentages). However, the energy consumption for this subsystem was significant (excluding the mine mouth case). For mine mouth operation, all stressors are less than 3.5\% of the total over the life of the system, with the majority around $0.1 \%$. However, for the other three transportation cases (average user by river, average user by land, and farthest user) oil consumption as well as a few air and water emissions are high.

Regarding the average user by river and average user by land cases in the Average and NSPS systems, the oil consumption was about $45 \%$ of the total over the life of the system; this increased to $80 \%$ for the farthest user case. For the LEBS system, the oil consumption amounted to $85 \%$ for the average user by river and average user by land, increasing to $95 \%$ for the farthest user case.

For all three power plant systems (Average, NSPS, and LEBS), of the total non-coal energy consumed by the system the percent from transportation was about $33 \%$ for both the average user by river and average user by land cases. However, this percentage increased to approximately $67 \%$ for the farthest user case. Thus, the transportation distance was found to have a substantial effect on amount of oil consumed, a few of the system emissions, and the non-coal energy consumption, whereas the mode of transportation has virtually no effect on any major results. 


\subsection{Base Case Power Plant Construction \& Decommissioning Results}

The main emissions from cement manufacturing are particulate matter, $\mathrm{NO}_{\mathrm{x}}, \mathrm{SO}_{\mathrm{x}}, \mathrm{CO}_{2}$, and $\mathrm{CO}$. Small amounts of volatile organic compounds, ammonia, chlorine, and hydrogen chloride may also be emitted. Sources of particulates include quarrying and crushing, raw material storage, grinding and blending, clinker production, and packaging and loading. Fuel combustion required for these processing steps produces nitrogen oxides, sulfur dioxide, carbon monoxide, and carbon dioxide. Sulfur dioxide is also generated from the sulfur compounds in the raw materials. Substantial quantities of $\mathrm{CO}_{2}$ are produced through calcining of limestone through decomposition of $\mathrm{CaCO}_{3}$ to $\mathrm{CaO}$ and $\mathrm{CO}_{2} ; 64 \%$ of the $\mathrm{CO}_{2}$ emissions emitted during construction are attributed to the production of cement. This result is not unexpected since the material used in the largest quantity during construction is concrete (refer to Table 18). The second largest source of $\mathrm{CO}_{2}$ emissions (19\%) comes from combusting the fuel while transporting construction materials to the plant site. A large percentage of emissions comes from steel production from ore and aluminum production from ore. Aluminum production from ore is a very energy-intensive process, requiring more energy ( 2.7 times) than iron or steel production. The amount of aluminum used during plant construction is overshadowed by the steel requirement, however.

In general, the yearly trends for this LCA show that there are not significantly more air emissions in the two construction years than in the normal operating years (see Figures 8-13). This trend also holds true for the majority of the water emissions, wastes, and energy consumption. However, for all of the resources except coal, oil, natural gas, and limestone, the consumption in the two construction years is significantly greater than during the normal operating years. Figure 15 is an example of this, showing the iron ore consumption on a yearly basis over the life of the system. The consumption of these resources is overshadowed by the coal mining, transportation, and power plant operation resource requirements when summed over the life of the system. The average iron ore consumption over the life of the plant for all three power plant systems (Average NSPS, and LEBS) is about $0.11 \mathrm{~g} / \mathrm{kWh}$ of average power production. However, in years one and two the iron ore consumption for these three systems is approximately 3.5 and $3.2 \mathrm{~g} / \mathrm{kWh}$ of average power production, respectively. These numbers are factors of 32 and 29 times higher than the average resource consumption over the life of the plant.

\subsection{Base Case Power Generation Results}

For all three systems, coal is used at the highest rate. For the Average and NSPS systems, limestone and oil account for most of the remaining resources consumed. For the LEBS system, natural gas and oil account for the majority. In all three systems, the power plant produces most of the $\mathrm{CO}_{2}, \mathrm{SO}_{\mathrm{x}}, \mathrm{NO}_{\mathrm{x}}$, and CO. Excluding the $\mathrm{CO}_{2}$ from the combustion of the coal at the power plant, the process steps involved in manufacturing and transporting limestone and lime along with limestone use, account for 59\% and $62 \%$ of the system $\mathrm{CO}_{2}$ emissions for the Average and NSPS systems, respectively. For the LEBS system, $35 \%$ of the non-coal $\mathrm{CO}_{2}$ is due to natural gas production (3.2\%) and combustion (31.8\%) for copper oxide regeneration. Also, half of the water emissions occurred in the power generation subsystem. The majority of the solid waste in the Average and NSPS systems comes from the power plant in the form of flue gas clean-up waste that must be landfilled. There is also a high percentage of landfilled ash, plus a considerable amount of non-hazardous solid waste generated during limestone production. Because the copper oxide sorbent used in the LEBS system is regenerated rather than disposed, the primary waste from this system is ash. 
Figure 15: Yearly Iron Ore Consumption

(surface mining \& average user by river)

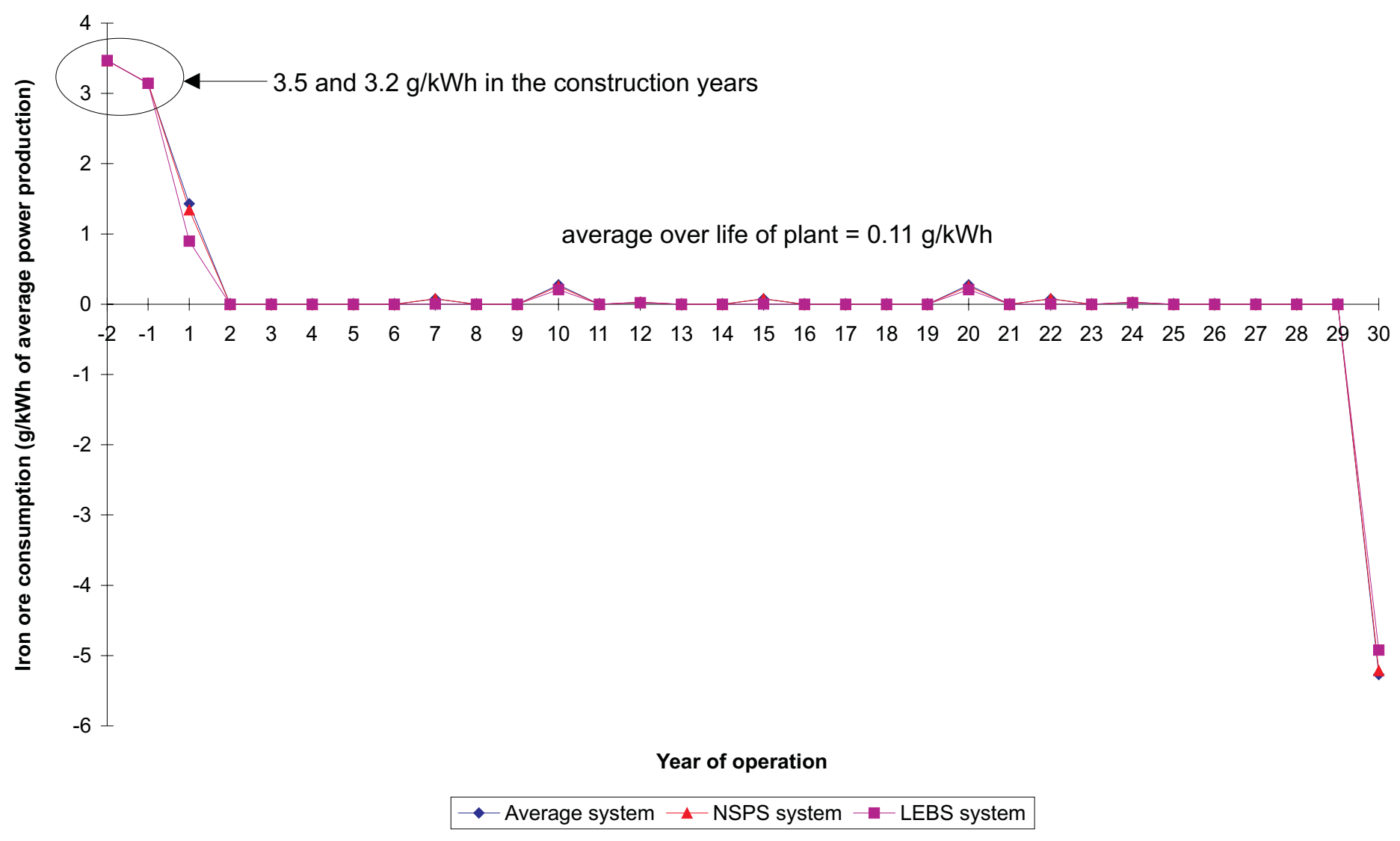


For the Average and NSPS systems, a large amount of the total non-coal energy requirement for the power generation subsystem comes from limestone production whereas for the LEBS system, the largest consumer of energy is in the production and consumption of natural gas. Limestone production accounts for $25 \%$ and $28 \%$ of the total non-coal system energy consumption for the Average and NSPS system, respectively. Natural gas production and use account for $37 \%$ of the total non-coal system energy for the LEBS system. As expected, the LEBS plant requires fewer resources and energy and produces fewer emissions and waste per unit of energy delivered to the utility grid than the Average or NSPS systems.

\subsection{Sensitivity Analysis}

A sensitivity analysis was conducted to determine the parameters that had the largest effects on the results and to determine the impact of estimated data as well as variations in data on the conclusions. Variables included in the sensitivity analysis were chosen to reflect system areas that had inherently more unknowns in the data in addition to areas where major assumptions were made. Each parameter was changed independently of all others so that the magnitude of its effect on the base case could be assessed. Therefore, no single sensitivity case represents the best or worst situation under which these systems might operate.

One variable may affect several factors and thus several process steps, or it may affect only one block in the overall life cycle assessment. For instance, changing the power plant efficiency affects the amount of coal required at the plant, which in turn affects the coal mining and transportation requirements. However, varying the amount of materials used to build the power plant affects only the emissions associated with plant construction and decommissioning. These effects were taken into account automatically in the LCA model.

The base case assumed transportation to the average user by river. Table 38 and Tables B26-B30 in Appendix B summarize the effects on the major emissions, energy use, and resource consumption relative to the base case for the parameters varied in the sensitivity analysis. Note that all resources and emissions are not shown in these tables. The percentages shown represent the deviation from the base case values when comparing the results on a per unit of energy produced (i.e., MWh) basis. The positive numbers indicate a percent increase; the negative numbers signify a decrease. Table 39 and Tables B31-B32 contain the sensitivity analysis results for the efficiencies and energy ratios. For easier interpretation, Figures 16-19 are graphical representations of these results for surface mining only for the Average power plant system (See Appendix C, Figures C6-C13, for the surface mining results of the LEBS and NSPS systems). The sensitivity cases that result in the largest change from the base case values are highlighted in these figures.

In general, the only way to appreciably reduce the emissions, resource consumption, and energy use of these systems, is to reduce the amount of coal being consumed. The vast majority of $\mathrm{CO}_{2}, \mathrm{SO}_{\mathrm{x}}, \mathrm{NO}_{\mathrm{x}}$, and $\mathrm{CO}$ air emissions result directly from coal combustion. Similarly, the energy consumed by the systems is due in large part to the consumption of the energy contained in the coal. Additionally, the best opportunity to reduce stressors associated with upstream processes is to reduce coal use at the power plant. For example, using less coal will result in lower limestone and transportation requirements. These in turn will reduce upstream $\mathrm{CO}_{2}$ and particulate emissions, resource consumption, and energy use. For these reasons, changing the power plant efficiency by $+/-5$ percentage points resulted in the largest change in emissions, resource consumption, and energy use. Increasing or decreasing the coal transportation distance had the next largest effect, although changing the mode of transportation (i.e., 
Table 38: Sensitivity Analysis Condensed Results - Average System (surface mining)

$\%$ change from the base case on a per unit of energy produced (i.e., MWh) basis

\begin{tabular}{|c|c|c|c|c|c|c|c|c|c|c|}
\hline & $\begin{array}{c}\text { A } \\
\text { surface }\end{array}$ & $\begin{array}{c}\mathrm{B} \\
\text { surface }\end{array}$ & $\begin{array}{c}C \\
\text { surface }\end{array}$ & $\begin{array}{c}\mathrm{D} \\
\text { surface }\end{array}$ & $\begin{array}{c}\mathrm{E} \\
\text { surface }\end{array}$ & $\begin{array}{c}\mathrm{F} \\
\text { surface }\end{array}$ & $\begin{array}{c}\mathrm{G} \\
\text { surface }\end{array}$ & $\begin{array}{c}\mathrm{H} \\
\text { surface }\end{array}$ & $\begin{array}{c}\mathrm{I} \\
\text { surface }\end{array}$ & $\begin{array}{c}\mathrm{J} \\
\text { surface }\end{array}$ \\
\hline (r) Coal (in ground) (including losses) & $-13.51 \%$ & $18.52 \%$ & $0.00 \%$ & $-0.05 \%$ & $0.00 \%$ & $-0.01 \%$ & $0.00 \%$ & $0.03 \%$ & $0.08 \%$ & $-0.10 \%$ \\
\hline (r) Limestone (CaCO3, in ground) & $-13.51 \%$ & $18.52 \%$ & $0.00 \%$ & $-0.01 \%$ & $0.00 \%$ & $0.00 \%$ & $0.00 \%$ & $0.00 \%$ & $0.00 \%$ & $0.00 \%$ \\
\hline (r) Natural Gas (in ground) & $-13.51 \%$ & $18.52 \%$ & $-0.03 \%$ & $-0.61 \%$ & $0.00 \%$ & $-1.71 \%$ & $0.03 \%$ & $5.65 \%$ & $0.72 \%$ & $-0.99 \%$ \\
\hline (r) Oil (in ground) & $-13.51 \%$ & $18.52 \%$ & $-0.93 \%$ & $-2.68 \%$ & $0.00 \%$ & $-47.87 \%$ & $1.20 \%$ & $159.09 \%$ & $0.17 \%$ & $-0.09 \%$ \\
\hline (a) total Carbon Dioxide (CO2) & $-13.51 \%$ & $18.52 \%$ & $-0.04 \%$ & $-0.42 \%$ & $0.00 \%$ & $-1.71 \%$ & $0.04 \%$ & $5.67 \%$ & $0.47 \%$ & $-0.64 \%$ \\
\hline (a) Carbon Monoxide (CO) & $-13.51 \%$ & $18.52 \%$ & $-0.73 \%$ & $-3.07 \%$ & $0.00 \%$ & $-37.89 \%$ & $1.56 \%$ & $127.56 \%$ & $1.09 \%$ & $-1.40 \%$ \\
\hline (a) total Hydrocarbons (except $\mathrm{CH} 4$, including VOCs) & $-13.51 \%$ & $18.52 \%$ & $-0.73 \%$ & $-3.62 \%$ & $0.00 \%$ & $-27.53 \%$ & $0.85 \%$ & $91.88 \%$ & $3.43 \%$ & $-4.62 \%$ \\
\hline (a) Methane $(\mathrm{CH} 4)$ & $-13.51 \%$ & $18.52 \%$ & $-0.01 \%$ & $-0.01 \%$ & $-55.12 \%$ & $-0.10 \%$ & $0.00 \%$ & $0.33 \%$ & $0.01 \%$ & $-0.01 \%$ \\
\hline (a) Nitrogen Oxides (NOx as NO2) & $-13.51 \%$ & $18.52 \%$ & $-0.15 \%$ & $-0.59 \%$ & $0.00 \%$ & $-5.48 \%$ & $0.24 \%$ & $18.52 \%$ & $0.47 \%$ & $-0.62 \%$ \\
\hline (a) total Particlulates (unspecified) & $-13.51 \%$ & $18.52 \%$ & $0.00 \%$ & $-0.13 \%$ & $0.00 \%$ & $-0.20 \%$ & $0.01 \%$ & $0.68 \%$ & $0.01 \%$ & $-0.02 \%$ \\
\hline (a) Sulfur Oxides (SOx as SO2) & $-13.51 \%$ & $18.52 \%$ & $-0.01 \%$ & $-0.20 \%$ & $0.00 \%$ & $-1.41 \%$ & $0.05 \%$ & $4.74 \%$ & $0.26 \%$ & $-0.35 \%$ \\
\hline Electricity & $-13.51 \%$ & $18.52 \%$ & $-0.05 \%$ & $-2.55 \%$ & $0.00 \%$ & $-2.05 \%$ & $-0.02 \%$ & $6.56 \%$ & $9.92 \%$ & $-13.69 \%$ \\
\hline total Non-Coal Energy & $-13.51 \%$ & $18.52 \%$ & $-0.64 \%$ & $-2.90 \%$ & $0.00 \%$ & $-31.94 \%$ & $1.74 \%$ & $109.04 \%$ & $2.16 \%$ & $-2.89 \%$ \\
\hline ash - landfilled (dry) & $-13.51 \%$ & $18.52 \%$ & $0.00 \%$ & $0.00 \%$ & $0.00 \%$ & $0.00 \%$ & $0.00 \%$ & $0.00 \%$ & $38.89 \%$ & $0.00 \%$ \\
\hline ash - total (dry) & $-13.51 \%$ & $18.52 \%$ & $0.00 \%$ & $0.00 \%$ & $0.00 \%$ & $0.00 \%$ & $0.00 \%$ & $0.00 \%$ & $0.00 \%$ & $0.00 \%$ \\
\hline FGC waste (dry) - landfilled & $-13.51 \%$ & $18.52 \%$ & $0.00 \%$ & $0.00 \%$ & $0.00 \%$ & $0.00 \%$ & $0.00 \%$ & $0.00 \%$ & $0.00 \%$ & $0.00 \%$ \\
\hline FGD waste (dry) - total & $-13.51 \%$ & $18.52 \%$ & $0.00 \%$ & $0.00 \%$ & $0.00 \%$ & $0.00 \%$ & $0.00 \%$ & $0.00 \%$ & $0.00 \%$ & $0.00 \%$ \\
\hline Waste (unspecified) & $-13.51 \%$ & $18.52 \%$ & $0.00 \%$ & $-0.63 \%$ & $0.00 \%$ & $-0.05 \%$ & $-0.01 \%$ & $0.13 \%$ & $0.92 \%$ & $-1.27 \%$ \\
\hline \multirow[t]{2}{*}{ Waste (total) } & $-13.51 \%$ & $18.52 \%$ & $0.00 \%$ & $-0.19 \%$ & $0.00 \%$ & $-0.01 \%$ & $0.00 \%$ & $0.02 \%$ & $9.21 \%$ & $-0.23 \%$ \\
\hline & $\begin{array}{c}\mathrm{K} \\
\text { surface }\end{array}$ & $\begin{array}{c}\mathrm{L} \\
\text { surface }\end{array}$ & $\begin{array}{c}M \\
\text { surface }\end{array}$ & $\underset{\text { surface }}{\mathrm{N}}$ & $\begin{array}{c}0 \\
\text { surface }\end{array}$ & $\begin{array}{c}P \\
\text { surface }\end{array}$ & $\begin{array}{c}Q \\
\text { surface }\end{array}$ & $\begin{array}{c}\mathrm{R} \\
\text { surface }\end{array}$ & $\begin{array}{c}\mathrm{S} \\
\text { surface }\end{array}$ & $\begin{array}{c}T \\
\text { surface }\end{array}$ \\
\hline (r) Coal (in ground) & $-0.06 \%$ & $-0.25 \%$ & $-0.01 \%$ & $0.01 \%$ & $-0.01 \%$ & $0.01 \%$ & $0.00 \%$ & $0.00 \%$ & $0.00 \%$ & $0.00 \%$ \\
\hline (r) Limestone (CaCO3, in ground) & $0.00 \%$ & $0.00 \%$ & $0.00 \%$ & $0.00 \%$ & $0.00 \%$ & $0.01 \%$ & $0.00 \%$ & $0.00 \%$ & $0.00 \%$ & $0.00 \%$ \\
\hline (r) Natural Gas (in ground) & $-0.57 \%$ & $-2.34 \%$ & $-0.19 \%$ & $0.08 \%$ & $-0.08 \%$ & $0.10 \%$ & $0.01 \%$ & $0.00 \%$ & $-0.01 \%$ & $-0.01 \%$ \\
\hline (r) Oil (in ground) & $-0.13 \%$ & $-0.29 \%$ & $-0.83 \%$ & $0.03 \%$ & $-0.03 \%$ & $0.01 \%$ & $0.22 \%$ & $0.00 \%$ & $-0.22 \%$ & $-0.22 \%$ \\
\hline (a) total Carbon Dioxide (CO2) & $-0.37 \%$ & $-1.52 \%$ & $-0.13 \%$ & $0.01 \%$ & $-0.01 \%$ & $0.01 \%$ & $0.01 \%$ & $-0.03 \%$ & $-0.01 \%$ & $-0.08 \%$ \\
\hline (a) Carbon Monoxide (CO) & $-0.86 \%$ & $-3.36 \%$ & $-0.95 \%$ & $0.04 \%$ & $-0.04 \%$ & $0.00 \%$ & $0.21 \%$ & $-0.46 \%$ & $-0.21 \%$ & $-1.15 \%$ \\
\hline (a) total Hydrocarbons (except $\mathrm{CH} 4$, including VOCs) & $-2.69 \%$ & $-10.95 \%$ & $-1.13 \%$ & $0.30 \%$ & $-0.30 \%$ & $0.36 \%$ & $0.19 \%$ & $-0.25 \%$ & $-0.20 \%$ & $-0.71 \%$ \\
\hline (a) Methane $(\mathrm{CH} 4)$ & $0.00 \%$ & $-0.02 \%$ & $0.00 \%$ & $0.00 \%$ & $0.00 \%$ & $0.00 \%$ & $0.00 \%$ & $-0.01 \%$ & $0.00 \%$ & $-0.03 \%$ \\
\hline (a) Nitrogen Oxides (NOx & $-0.37 \%$ & $-1.48 \%$ & $-0.18 \%$ & $0.01 \%$ & $-0.01 \%$ & $0.00 \%$ & $0.04 \%$ & $-0.02 \%$ & $-0.04 \%$ & $-0.08 \%$ \\
\hline (a) total Particlulates (unspecified) & $-0.01 \%$ & $-0.04 \%$ & $-0.04 \%$ & $0.00 \%$ & $0.00 \%$ & $0.01 \%$ & $0.00 \%$ & $-0.01 \%$ & $0.00 \%$ & $-0.01 \%$ \\
\hline (a) Sulfur Oxides (SOx as SO2) & $-0.20 \%$ & $-0.84 \%$ & $-0.06 \%$ & $0.01 \%$ & $-0.01 \%$ & $0.00 \%$ & $0.00 \%$ & $-0.01 \%$ & $0.00 \%$ & $-0.03 \%$ \\
\hline Electricity & $-7.80 \%$ & $-32.25 \%$ & $-0.80 \%$ & $0.53 \%$ & $-0.53 \%$ & $-0.12 \%$ & $0.01 \%$ & $0.00 \%$ & $-0.01 \%$ & $-0.01 \%$ \\
\hline total Non-Coal Energy & $-1.70 \%$ & $-6.86 \%$ & $-0.90 \%$ & $0.17 \%$ & $-0.17 \%$ & $0.13 \%$ & $0.15 \%$ & $0.00 \%$ & $-0.15 \%$ & $-0.15 \%$ \\
\hline FGC waste (dry) - landfilled & $0.00 \%$ & $0.00 \%$ & $0.00 \%$ & $0.00 \%$ & $0.00 \%$ & $0.00 \%$ & $32.80 \%$ & $0.00 \%$ & $-33.60 \%$ & $-33.60 \%$ \\
\hline FGD waste (dry) - total & $0.00 \%$ & $0.00 \%$ & $0.00 \%$ & $0.00 \%$ & $0.00 \%$ & $0.00 \%$ & $0.00 \%$ & $0.00 \%$ & $0.00 \%$ & $0.00 \%$ \\
\hline Waste (hazardous) & $-0.01 \%$ & $-0.01 \%$ & $-25.13 \%$ & $3.95 \%$ & $-3.95 \%$ & $35.24 \%$ & $0.01 \%$ & $0.00 \%$ & $-0.01 \%$ & $-0.01 \%$ \\
\hline Waste (municipal and industrial) & $-0.02 \%$ & $-0.02 \%$ & $-17.65 \%$ & $12.55 \%$ & $-12.55 \%$ & $94.45 \%$ & $0.04 \%$ & $0.00 \%$ & $-0.04 \%$ & $-0.04 \%$ \\
\hline Waste (unspecified) & $-0.72 \%$ & $-2.99 \%$ & $-0.20 \%$ & $0.09 \%$ & $-0.09 \%$ & $0.10 \%$ & $0.00 \%$ & $0.00 \%$ & $0.00 \%$ & $0.00 \%$ \\
\hline Waste (total) & $-7.24 \%$ & $-7.65 \%$ & $-0.06 \%$ & $0.03 \%$ & $-0.03 \%$ & $0.14 \%$ & $19.23 \%$ & $0.00 \%$ & $-19.69 \%$ & $-19.69 \%$ \\
\hline
\end{tabular}

SENSITIVITY CASE CASE LETTER

\begin{tabular}{|c|c|c|c|}
\hline \multicolumn{4}{|c|}{ SENSITIVITY CASE CASE LETTER } \\
\hline Increase plant efficiency by 5 points & A & Ish is recovered \& percent used in cement remains constant @ 42\% & $\mathrm{K}$ \\
\hline Decrease plant efficiency by 5 points & $\mathrm{B}$ & $50 \%$ of plant ash is recovered $\& 100 \%$ of this is used in cement & L \\
\hline Pond versus landfilling of ash from power plant & $\mathrm{C}$ & Plant operating capacity factor $=85 \%$ & $\mathrm{M}$ \\
\hline Construction materials low case & $\mathrm{D}$ & Increase mining equipment materials by $50 \%$ & $\mathrm{~N}$ \\
\hline ining methane emissions using EIA average U.S. numbers & $\mathrm{E}$ & Decrease mining equipment materials by $50 \%$ & $\mathrm{O}$ \\
\hline Mine mouth & $\mathrm{F}$ & Decrease in recycle of materials by $1 / 3$ & $P$ \\
\hline Average user by land & G & No FGC recovery - $100 \%$ is landfilled & $Q$ \\
\hline Farthest user & $\mathrm{H}$ & $100 \%$ of recovered FGC is used in asphalt & $\mathrm{R}$ \\
\hline No ash recovery $-100 \%$ of plant ash is landfilled & I & ;G is recovered \& percent used in asphalt remains constant @ 7.2\% & $\mathrm{S}$ \\
\hline $100 \%$ of recovered ash is used in cement & $\mathrm{J}$ & $50 \%$ of plant FCG is recovered \& $100 \%$ of this is used in asphalt & $\mathrm{T}$ \\
\hline
\end{tabular}


Table 39: Sensitivity Analysis Efficiencies and Energy Ratios - Average System

\begin{tabular}{|c|c|c|c|c|c|c|c|c|c|c|c|}
\hline & $\begin{array}{l}\text { avg - base } \\
\text { case }\end{array}$ & A & B & C & D & $\mathrm{E}$ & $\mathrm{F}$ & G & $\mathrm{H}$ & I & $\mathrm{J}$ \\
\hline power plant efficiency & $32 \%$ & $37 \%$ & $27 \%$ & $32 \%$ & $32 \%$ & $32 \%$ & $32 \%$ & $32 \%$ & $32 \%$ & $32 \%$ & $32 \%$ \\
\hline life cycle efficiency - surface mining & $-75.7 \%$ & $-70.9 \%$ & $-80.4 \%$ & $-75.6 \%$ & $-75.5 \%$ & $-75.7 \%$ & $-73.7 \%$ & $-75.8 \%$ & $-82.3 \%$ & $-75.8 \%$ & $-75.5 \%$ \\
\hline external energy efficiency - surface mining & $24.3 \%$ & $29.1 \%$ & $19.6 \%$ & $24.4 \%$ & $24.5 \%$ & $24.3 \%$ & $26.3 \%$ & $24.2 \%$ & $17.7 \%$ & $24.2 \%$ & $24.5 \%$ \\
\hline net energy ratio - surface mining & 0.29 & 0.33 & 0.24 & 0.29 & 0.29 & 0.29 & 0.29 & 0.29 & 0.27 & 0.29 & 0.29 \\
\hline external net energy ratio - surface mining & 4.97 & 5.75 & 4.20 & 5.00 & 5.12 & 4.97 & 7.31 & 4.89 & 2.38 & 4.87 & 5.12 \\
\hline life cycle efficiency - underground mining & $-75.5 \%$ & $-70.7 \%$ & $-80.2 \%$ & $-75.4 \%$ & $-75.3 \%$ & $-75.5 \%$ & $-73.5 \%$ & $-75.6 \%$ & $-82.1 \%$ & $-75.6 \%$ & $-75.3 \%$ \\
\hline external energy efficiency - underground mining & $24.5 \%$ & $29.3 \%$ & $19.8 \%$ & $24.6 \%$ & $24.7 \%$ & $24.5 \%$ & $26.5 \%$ & $24.4 \%$ & $17.9 \%$ & $24.4 \%$ & $24.7 \%$ \\
\hline net energy ratio - underground mining & 0.29 & 0.33 & 0.24 & 0.29 & 0.29 & 0.29 & 0.29 & 0.29 & 0.27 & 0.29 & 0.29 \\
\hline external net energy ratio - underground mining & 5.13 & 5.93 & 4.33 & 5.17 & 5.29 & 5.13 & 7.65 & 5.04 & 2.41 & 5.02 & 5.29 \\
\hline & avg - base & & & & & & & & & & \\
\hline & case & K & L & $\mathrm{M}$ & $\mathrm{N}$ & $\mathrm{O}$ & $\mathrm{P}$ & Q & $\mathrm{R}$ & $\mathrm{S}$ & $\mathrm{T}$ \\
\hline power plant efficiency & $32 \%$ & $32 \%$ & $32 \%$ & $32 \%$ & $32 \%$ & $32 \%$ & $32 \%$ & $32 \%$ & $32 \%$ & $32 \%$ & $32 \%$ \\
\hline life cycle efficiency - surface mining & $-75.7 \%$ & $-75.5 \%$ & $-75.2 \%$ & $-75.6 \%$ & $-75.7 \%$ & $-75.6 \%$ & $-75.7 \%$ & $-75.7 \%$ & $-75.7 \%$ & $-75.6 \%$ & $-75.6 \%$ \\
\hline external energy efficiency - surface mining & $24.3 \%$ & $24.5 \%$ & $24.8 \%$ & $24.4 \%$ & $24.3 \%$ & $24.4 \%$ & $24.3 \%$ & $24.3 \%$ & $24.3 \%$ & $24.4 \%$ & $24.4 \%$ \\
\hline net energy ratio - surface mining & 0.29 & 0.29 & 0.29 & 0.29 & 0.29 & 0.29 & 0.29 & 0.29 & 0.29 & 0.29 & 0.29 \\
\hline external net energy ratio - surface mining & 4.97 & 5.06 & 5.34 & 5.02 & 4.96 & 4.98 & 4.97 & 4.97 & 4.97 & 4.98 & 4.98 \\
\hline life cycle efficiency - underground mining & $-75.5 \%$ & $-75.4 \%$ & $-75.0 \%$ & $-75.4 \%$ & $-75.5 \%$ & $-75.5 \%$ & $-75.5 \%$ & $-75.5 \%$ & $-75.5 \%$ & $-75.5 \%$ & $-75.5 \%$ \\
\hline external energy efficiency - underground mining & $24.5 \%$ & $24.6 \%$ & $25.0 \%$ & $24.6 \%$ & $24.5 \%$ & $24.5 \%$ & $24.5 \%$ & $24.5 \%$ & $24.5 \%$ & $24.5 \%$ & $24.5 \%$ \\
\hline net energy ratio - underground mining & 0.29 & 0.29 & 0.29 & 0.29 & 0.29 & 0.29 & 0.29 & 0.29 & 0.29 & 0.29 & 0.29 \\
\hline external net energy ratio - underground mining & 5.13 & 5.22 & 5.52 & 5.18 & 5.13 & 5.14 & 5.13 & 5.12 & 5.13 & 5.14 & 5.14 \\
\hline
\end{tabular}

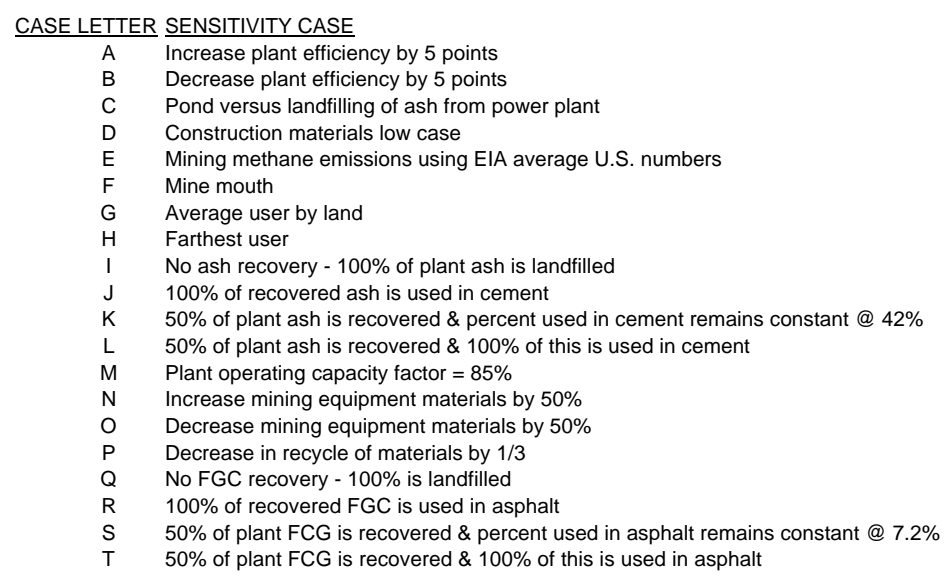


Figure 16: Sensitivity Results for Life Cycle Efficiency - Average System, Surface Mining Case

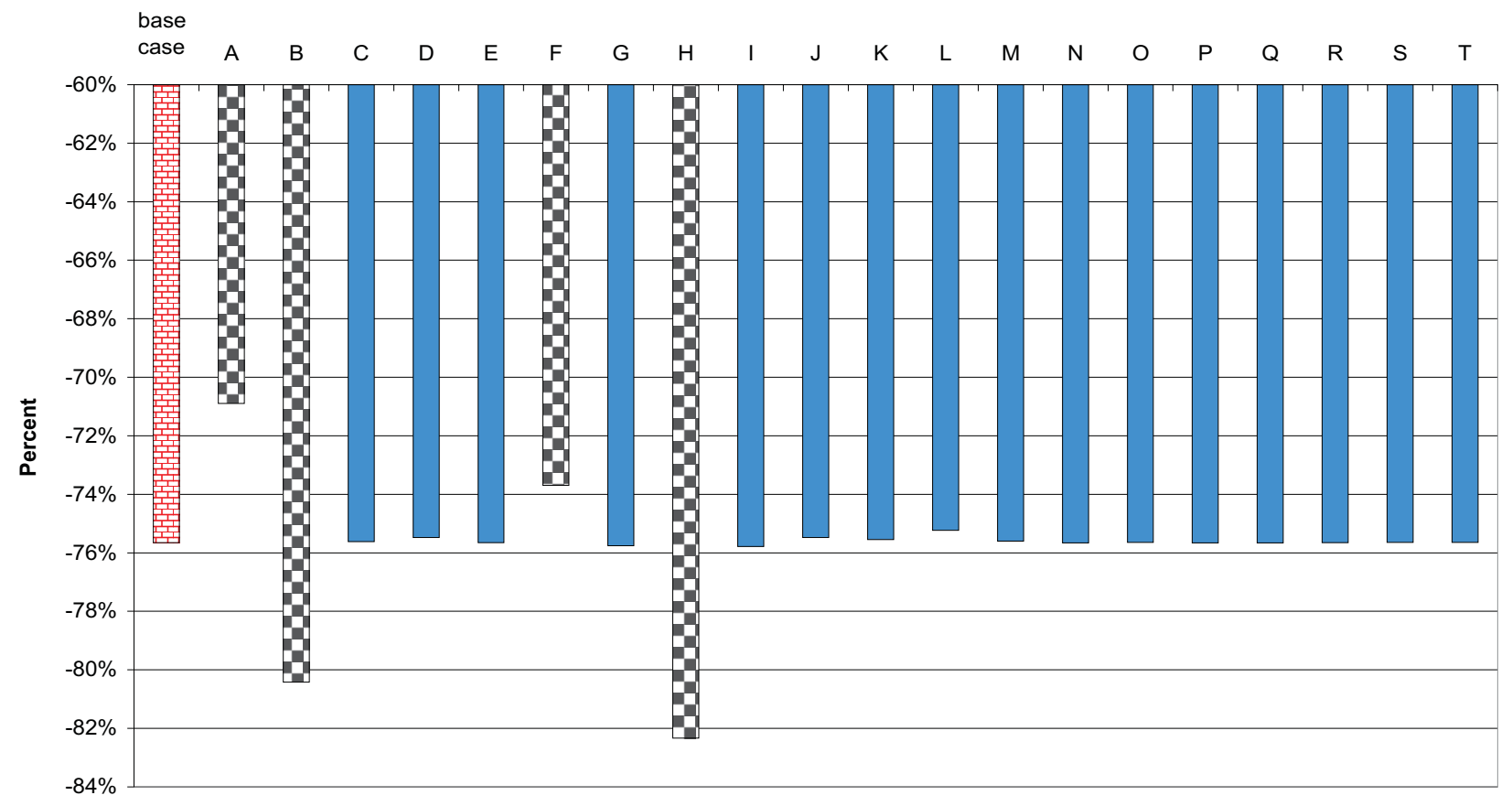

Sensitivity Case

Figure 17: Sensitivity Results for External Energy Efficiency - Average System, Surface Mining Case

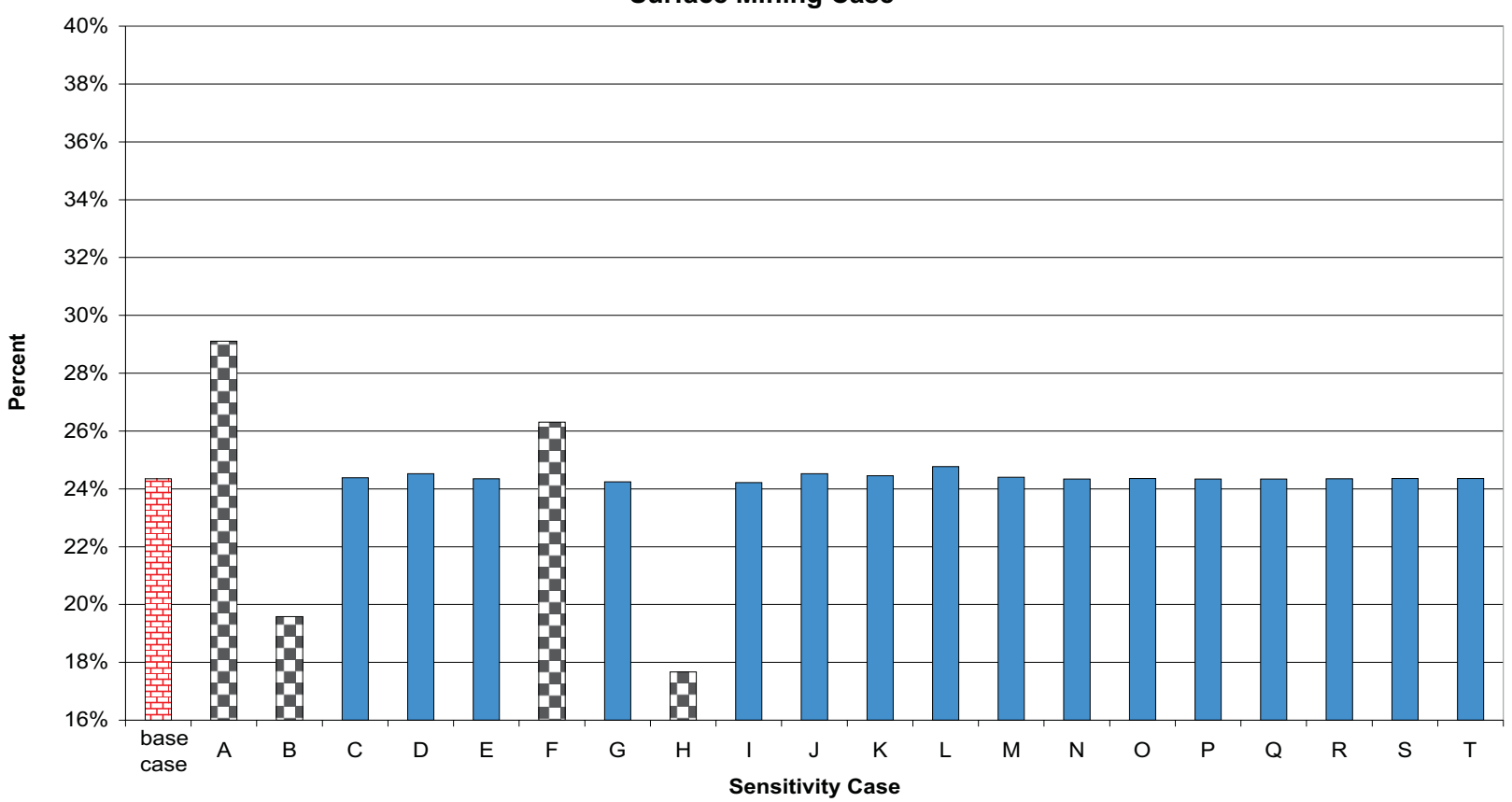

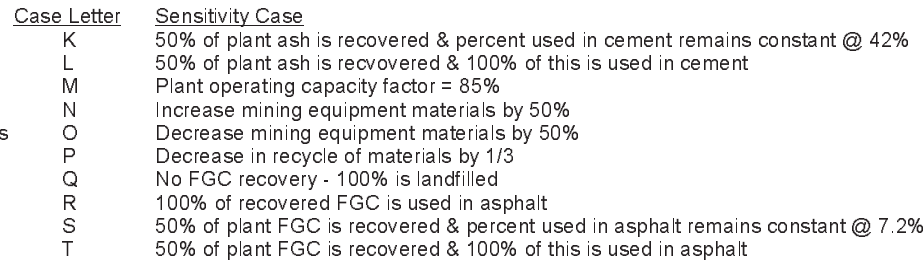
$50 \%$ of plant ash is recvovered $\& 100 \%$ of this is used in cement Plant operating capacity factor $=85 \%$

Increase mining equipment materials by $50 \%$

Decrease mining equipment materials by $50 \%$

Decrease in recycle of materials by $1 / 3$

No FGC recovery - $100 \%$ is landfilled

$100 \%$ of recovered FGC is used in asphalt

$50 \%$ of plant FGC is recovered \& percent used in asphalt remains constant $@ 7.2 \%$

$50 \%$ of plant FGC is recovered \& $100 \%$ of this is used in asphalt 
Figure 18: Sensitivity Results for Net Energy Ratio - Average System, Surface Mining Case

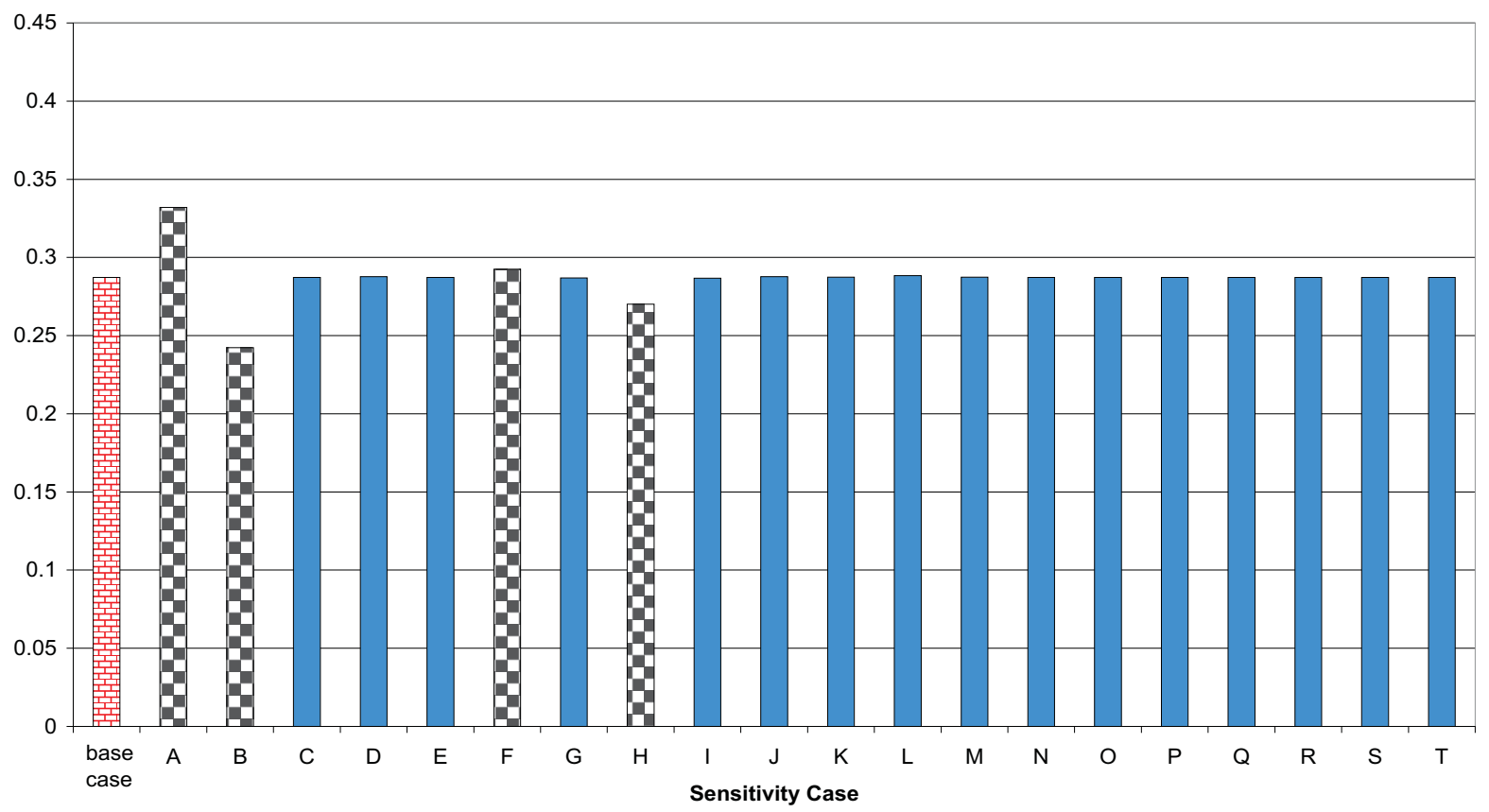

Figure 19: Sensitivity Results for External Net Energy Ratio - Average System, Surface Mining Case

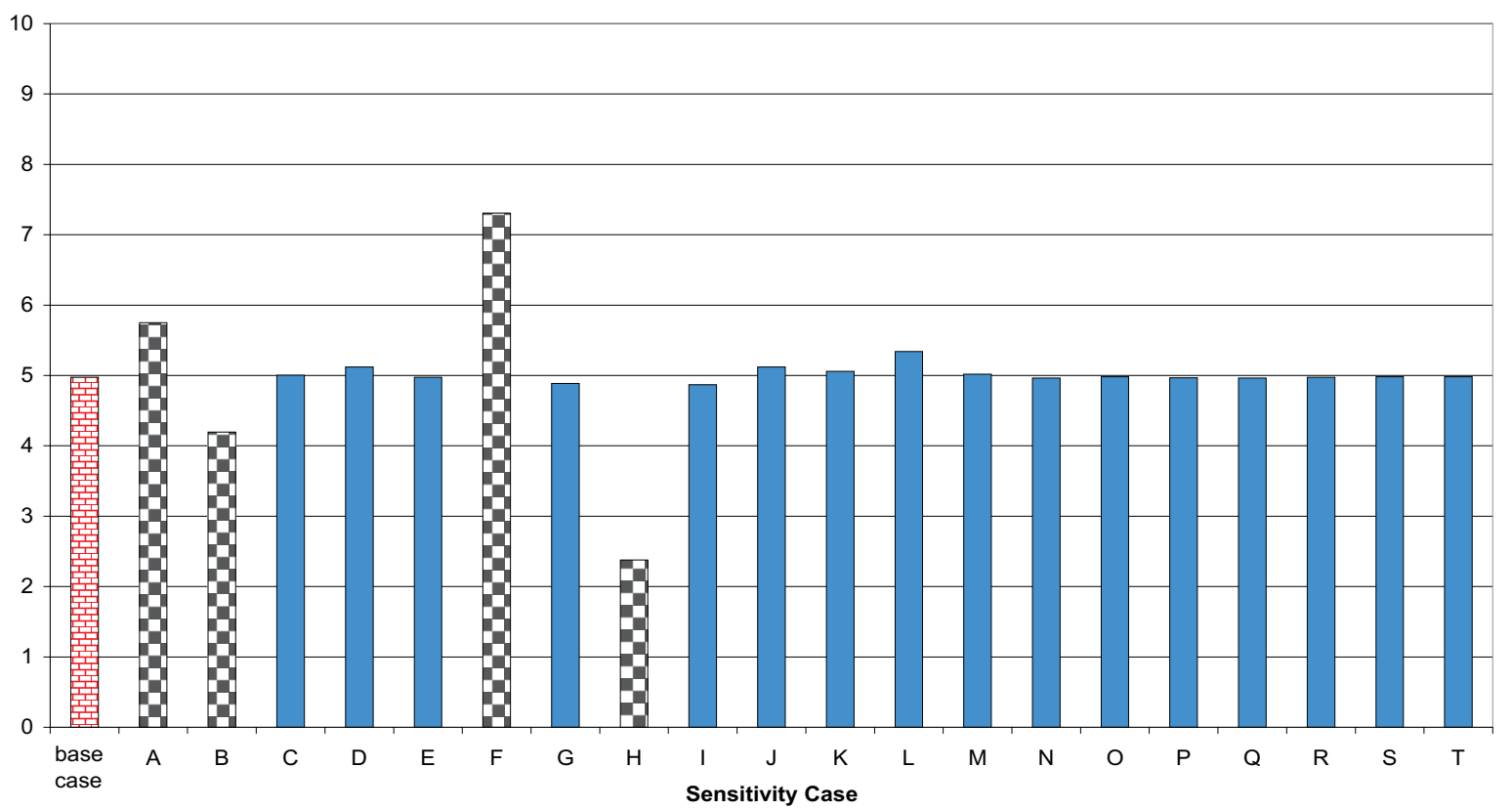

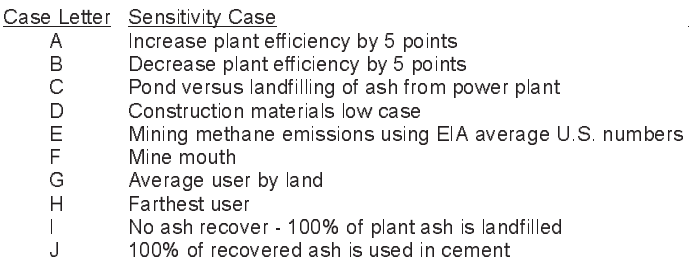

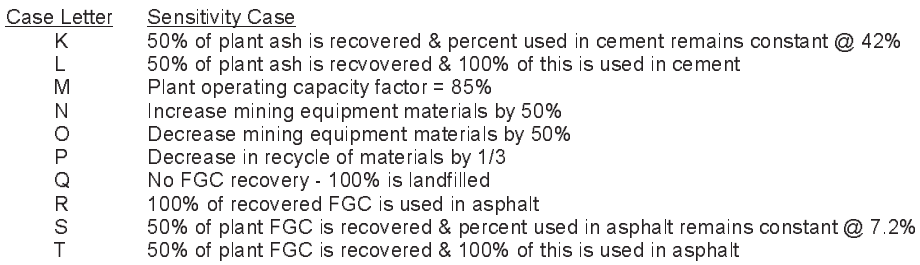


rail instead of barge) was not found to significantly affect the results. It is interesting to note that the energy results are strongly affected in the farthest user sensitivity case, and less so for the mine mouth case.

\subsection{Power Plant Efficiency Sensitivity Analysis (Case A-B)}

Both a decrease and an increase in the power plant efficiency were examined. The base case power plant efficiency on a higher heating value basis for the Average, NSPS, and LEBS system were 32\%, 35\%, and $42 \%$, respectively. This is defined as the energy delivered to the grid divided by the energy in the feedstock to the power plant (coal and natural gas in the LEBS system). The power plant efficiency was changed by plus and minus five percentage points for each system, i.e., $27 \%$ and $37 \%$ for the Average system. Table 40 gives the results per unit of energy produced (i.e., MWh) (also refer to Tables 38-39 and Tables B26-B30 in Appendix B).

Table 40: Sensitivity Results for Power Plant Efficiency - Percent Change

\begin{tabular}{|c|c|c|c|}
\hline \multirow{2}{*}{\begin{tabular}{c}
\multirow{2}{*}{ Efficiency change } \\
Enyy
\end{tabular}} & \multicolumn{3}{|c|}{$\begin{array}{c}\% \text { change in results from the base case } \\
\text { (on a per unit of energy produced (i.e., MWh) basis) }\end{array}$} \\
\cline { 2 - 4 } & Average (\% change) & NSPS (\% change) & LEBS (\% change) \\
\hline Increase plant efficiency by 5 points - case A & -13.5 & -12.5 & -10.6 \\
\hline Decrease plant efficiency by 5 points - case B & +18.5 & +16.7 & +13.6 \\
\hline
\end{tabular}

Changing the power plant efficiency had a large effect on the energy efficiency and energy ratios defined in section 6.4. Table 41 shows the energy results for increasing and decreasing the power plant efficiency as well as the base case numbers for surface mining (see Table 39 and Tables B31-B32 in Appendix B for the underground mining numbers which are similar to those listed here).

Table 41: Energy Efficiencies and Ratios - Sensitivity Results for Changes in Power Plant Efficiency

\begin{tabular}{|c|c|c|c|c|}
\hline \multicolumn{2}{|c|}{ Efficiency or energy ratio by efficiency change } & Average & NSPS & LEBS \\
\hline \multirow{3}{*}{$\begin{array}{l}\text { Life cycle } \\
\text { efficiency }(\%)\end{array}$} & Base case & -76 & -73 & -66 \\
\hline & Increase plant efficiency by 5 points - case $A$ & -71 & -69 & -61 \\
\hline & Decrease plant efficiency by 5 points - case B & -80 & -78 & -71 \\
\hline \multirow{3}{*}{$\begin{array}{l}\text { External energy } \\
\text { efficiency }(\%)\end{array}$} & Base case & 24 & 27 & 34 \\
\hline & Increase plant efficiency by 5 points - case $A$ & 29 & 32 & 39 \\
\hline & Decrease plant efficiency by 5 points - case B & 20 & 22 & 29 \\
\hline \multirow{3}{*}{$\begin{array}{l}\text { Net energy } \\
\text { ratio }\end{array}$} & Base case & 0.29 & 0.31 & 0.38 \\
\hline & Increase plant efficiency by 5 points - case $\mathrm{A}$ & 0.33 & 0.36 & 0.42 \\
\hline & Decrease plant efficiency by 5 points - case B & 0.24 & 0.27 & 0.33 \\
\hline
\end{tabular}




\begin{tabular}{|l|l|c|c|c|}
\hline \multicolumn{2}{|c|}{ Efficiency or energy ratio by efficiency change } & Average & NSPS & LEBS \\
\hline \multirow{2}{*}{$\begin{array}{l}\text { External energy } \\
\text { ratio }\end{array}$} & Base case & 5.0 & 5.1 & 6.7 \\
\cline { 2 - 5 } & Increase plant efficiency by 5 points - case A & 5.8 & 5.8 & 7.5 \\
\cline { 2 - 5 } & Decrease plant efficiency by 5 points - case B & 4.2 & 4.4 & 6.0 \\
\hline
\end{tabular}

\subsection{Pond Versus Landfilling of Power Plant Ash Sensitivity Analysis (Case C)}

Rather than landfilling the ash, some coal-fired power plants dispose of it in a settling pond. This method avoids the amount of diesel oil required for landfilling. Even though the amount of ash landfilled in the base case is $27 \%$ of the total amount of ash produced by the power plant, eliminating the landfilling of this ash had no noticeable effect on the resource consumption, emissions, or energy use.

\subsection{Power Plant Construction \& Decommissioning Sensitivity Analysis (Case D)}

Because there were two literature sources containing very different plant construction material requirements, the material requirements for concrete, steel, aluminum and iron were varied in one of the sensitivity analyses. The variation in these numbers can be seen in Table 42 (base case - DynCorp, 1995; sensitivity - Meridian, 1989). Both references based their study on a coal plant size of $500 \mathrm{MW}$. The larger numbers were used as the base case for this analysis to give more conservative results and because that study was conducted in a more rigorous fashion.

Table 42: Plant Material Requirements Used in Sensitivity Analysis

\begin{tabular}{|l|c|c|}
\hline \multicolumn{1}{|c|}{ Material } & $\begin{array}{c}\text { Base case } \\
\text { (kg/MW plant capacity) }\end{array}$ & $\begin{array}{c}\text { Sensitivity - case D } \\
\text { (kg/MW plant capacity) }\end{array}$ \\
\hline Concrete & 158,758 & 6,962 \\
\hline Steel & 50,721 & 1,764 \\
\hline Aluminum & 419 & 310 \\
\hline Iron & 619 & 622 \\
\hline
\end{tabular}

The amount of materials used affects the emissions for both construction and decommissioning. Decreasing the amount of materials used for construction had a large effect on the LCA. When comparing the results on a per unit of energy produced (i.e., MWh) basis, many of the resources decrease by $25 \%-30 \%$ causing many of the emissions to decrease by a similar amount. Two resources that decrease by as much as $70 \%$ are clay and iron ore. Most emissions, such as $\mathrm{CO}, \mathrm{CH}_{4}, \mathrm{SO}_{\mathrm{x}}$, and $\mathrm{NO}_{\mathrm{x}}$, are only slightly affected because the majority of these emissions come from the operation of the power plant, except in the case of methane which is produced primarily at the coal mine. The total non-coal energy requirement decreases by only $3 \%-4 \%$. 


\subsection{Coal Mining Methane Emissions Sensitivity Analysis (Case E)}

Because this LCA is only region-specific and not site-specific, and because two sources containing vastly different coal mining methane emissions were found, a sensitivity analysis was performed for the different methane emission numbers. The variation in these numbers can be seen in Table 43 for both surface and underground mining. The base case numbers are specific to the Illinois region; the sensitivity numbers are the average U.S. methane emissions from surface and underground coal mining and post-mining activities in 1996 (U.S. DOE, 1996). In this sensitivity case, the surface mining methane emissions decrease by $56 \%$ and the underground mining methane emissions increase by $54 \%$.

Table 43: Coal Mining Methane Emissions Used in Sensitivity

\begin{tabular}{|l|c|c|}
\hline Mining technique & $\begin{array}{c}\text { Base case } \\
\text { (g of } \mathrm{CH}_{4} / \mathrm{kg} \text { of } \\
\text { as-received coal) }\end{array}$ & $\begin{array}{c}\text { Sensitivity - case E } \\
\text { (g of } \mathrm{CH}_{4} / \mathrm{kg} \text { of } \\
\text { as-received coal) }\end{array}$ \\
\hline Surface & 1.91 & 0.84 \\
\hline Underground & 4.22 & 9.21 \\
\hline
\end{tabular}

Decreasing the surface mining methane emissions resulted in a decrease in the overall methane emissions of about $52 \%-55 \%$ on a per unit of energy produced basis. Increasing the underground mining methane emissions increased the overall methane emissions by $115 \%-117 \%$ on a per unit of energy produced basis. It is important to note that the amount of mining methane emissions will be site-specific and ultimately should be examined on a case-by-case basis. Although there may be opportunities for recovering coal bed methane (See section 10.0, Improvement), the amount of methane emitted, even in the high sensitivity cases, is three orders of magnitude lower than the $\mathrm{CO}_{2}$ emissions. Even with a GWP 21 times higher than $\mathrm{CO}_{2}$, the comparative effect on global climate change of methane from these systems is minute.

\subsection{Transportation Sensitivity Analysis (Case F-H)}

As discussed in section 5.2, Base Case Coal Transportation Assumptions, the following four transportation cases were examined for this study: 1) average user by land: railcar $=483 \mathrm{~km}, 2$ ) average user by river: railcar $=48 \mathrm{~km}$ plus barge $=434 \mathrm{~km}, 3$ ) farthest user: railcar $=1,538 \mathrm{~km}$ plus barge $=504$ $\mathrm{km}$, and 4) mine mouth: minimal truck transport $=2 \mathrm{~km}$. Of the three subsystems examined (coal mining, transportation, and electricity production), transportation required the least amount of resources and had the lowest air, water, and solid waste emissions even when considering the farthest user case (see Tables 24-28 and Tables B1-B25 in Appendix B for the average user by river numbers and percentages). However, the energy consumption for this subsystem is significant (excluding the mine mouth case).

Changing the transportation distance had a large effect on the energy efficiencies and ratios defined in section 6.4. Table 44 shows the energy results for the average user by river (base case), mine mouth, and farthest user transport cases for surface mining (see Table 39 and Tables B31-B32 in Appendix B for the underground mining numbers which are similar to those listed below). The numbers for the average user by land case were almost identical to the average user by river case and are therefore not listed in Table 44. 
Table 44: Energy Efficiencies and Ratios - Sensitivity Results for Changes in Transportation

\begin{tabular}{|l|l|c|c|c|}
\hline \multicolumn{2}{|c|}{ Efficiency or energy ratio by transport case } & Average & NSPS & LEBS \\
\hline \multirow{2}{*}{$\begin{array}{l}\text { Life cycle } \\
\text { efficiency (\%) }\end{array}$} & Average user by river - base case & -76 & -73 & -66 \\
\cline { 2 - 5 } & Mine mouth - case F & -74 & -71 & -64 \\
\cline { 2 - 5 } & Farthest user - case H & -82 & -80 & -72 \\
\hline \multirow{2}{*}{$\begin{array}{l}\text { External energy } \\
\text { efficiency (\%) }\end{array}$} & Average user by river - base case & 24 & 27 & 34 \\
\cline { 2 - 5 } & Mine mouth - case F & 26 & 29 & 36 \\
\cline { 2 - 5 } & Farthest user - case H & 18 & 20 & 28 \\
\hline \multirow{2}{*}{$\begin{array}{l}\text { Net energy } \\
\text { ratio }\end{array}$} & Average user by river - base case & 0.29 & 0.31 & 0.38 \\
\cline { 2 - 6 } & Mine mouth - case F & 0.29 & 0.32 & 0.38 \\
\cline { 2 - 6 } & Farthest user - case G & 0.27 & 0.29 & 0.36 \\
\hline \multirow{2}{*}{$\begin{array}{l}\text { External energy } \\
\text { ratio }\end{array}$} & Average user by river - base case & 5.0 & 5.1 & 6.7 \\
\cline { 2 - 6 } & Mine mouth - case F & 7.3 & 7.3 & 9.9 \\
\cline { 2 - 6 } & Farthest user - case H & 2.4 & 2.5 & 3.2 \\
\hline
\end{tabular}

The stressors that were affected significantly by changing the transportation distance include: oil, CO, NMHC (including VOCs), and energy. Table 45 shows the percentage of each of these stressors for the transportation subsystem. Again the numbers for the average user by land case are almost identical to the average user by river case.

Table 45: Most Significant Stressor Results for Changes in Transportation

\begin{tabular}{|c|c|c|c|c|c|c|c|c|c|c|c|c|}
\hline \multirow{3}{*}{$\begin{array}{l}\text { Stressor } \\
\text { (a) }\end{array}$} & \multicolumn{12}{|c|}{$\%$ of total from the transportation subsystem $(\%)$} \\
\hline & \multicolumn{3}{|c|}{$\begin{array}{l}\text { Average user by land } \\
\text { (base case } \mathrm{G} \text { ) }\end{array}$} & \multicolumn{3}{|c|}{$\begin{array}{l}\text { Mine mouth } \\
\quad(\text { case F) }\end{array}$} & \multicolumn{3}{|c|}{$\begin{array}{l}\text { Average user by river } \\
\text { (base case) }\end{array}$} & \multicolumn{3}{|c|}{$\begin{array}{l}\text { Farthest user } \\
\text { (case } \mathrm{H})\end{array}$} \\
\hline & Avg & NSPS & LEBS & Avg & NSPS & LEBS & Avg & NSPS & LEBS & Avg & NSPS & LEBS \\
\hline Oil & 48.1 & 44.6 & 84.2 & 0.5 & 0.4 & 2.6 & 48.7 & 45.2 & 84.5 & 80.0 & 77.6 & 95.8 \\
\hline $\mathrm{CO}$ & 38.0 & 37.5 & 39.5 & 0.2 & 0.2 & 0.2 & 39.0 & 38.4 & 56.0 & 72.8 & 72.3 & 74.0 \\
\hline NMHCs & 27.7 & 26.5 & 22.9 & 0.2 & 0.2 & 0.1 & 28.3 & 27.1 & 45.3 & 62.3 & 60.9 & 56.1 \\
\hline $\begin{array}{l}\text { Total non-coal } \\
\text { energy }\end{array}$ & 32.1 & 30.1 & 32.2 & 0.3 & 0.2 & 0.3 & 33.3 & 31.2 & 33.4 & 67.5 & 64.5 & 67.7 \\
\hline
\end{tabular}

(a) Results are reported for the surface mining case. However, the underground mining numbers are similar to those listed here. 


\subsubsection{Mine Mouth Case (Case F)}

For mine mouth operation, all stressors that result from transportation are minimal. Overall, any individual stressor for this subsystem amounts to less than $3.5 \%$ of the total over the life of the system, with the majority around $0.1 \%$. When examining differences between the average user by river transport case and having to transport the coal only a minimal distance, the only resource that decreases significantly is oil: $-48 \%,-44 \%$, and $-84 \%$ for the Average, NSPS, and LEBS system, respectively. Two air emissions that are reduced considerably are $\mathrm{CO}$ and total hydrocarbons (including VOCs, but excluding $\mathrm{CH} 4$ ). For each of the three power plant systems, the $\mathrm{CO}$ decreases by about $38 \%$ and the NMHCs by 23\%-30\%. Also, the non-coal energy consumption decreases by 30\%-32\% for each power plant system (Average, NSPS, and LEBS). For percentages and percent changes in the previously mentioned stressors see Table 45 and Table 38, respectively (also see Tables B26-B30 in Appendix B).

\subsubsection{Average User By Land (Case G)}

The stressors for the average user by land case are almost identical to the those from the average user by river case. The amount of oil consumed by transportation in each case represents $45 \%-48 \%$ of the total over the life of the system for both the Average and NSPS systems and $84 \%$ for the LEBS system (see Table 45). Of the total non-coal energy consumed by the system, the percent used in transportation was about $33 \%$ for both of these transportation cases for all three power plant systems (Average, NSPS, and LEBS) (see Table 45). The majority of any single air or water emission from these two transportation cases makes up only $4 \%-8 \%$ of the total system air or water emissions.

\subsubsection{Farthest User (Case H)}

As expected, the resources, emissions, and energy use due to transportation are highest for the farthest user case. Oil consumption was about $80 \%$ of the system total averaged over the life of the system for the Average and NSPS systems, and $95 \%$ for the LEBS system. Of the total non-coal energy consumed by the system, transportation accounted for approximately $67 \%$ in all three power plant systems (Average, NSPS, and LEBS) (see Table 45). When examining differences between farthest user and average user by river transport cases, the stressors that change significantly are oil consumption, $\mathrm{CO}$, total hydrocarbons (except $\mathrm{CH} 4$, including VOCs), and energy consumption. Oil increases by 159\%, 148\% , and $278 \%$ for the Average, NSPS, and LEBS system, respectively. The two air emissions increase by about $128 \%$ for $\mathrm{CO}$ and $92 \%$ for the NMHCs. The non-coal energy consumption decreases by $102 \%$ $110 \%$ for each of the three power plant systems. For percentages and percent changes in the previously mentioned stressors see Table 45 and Table 38, respectively (also see Tables B26-B30 in Appendix B).

\subsection{Flue Gas Clean-up Waste \& Ash Recovery and Disposal Sensitivity Analysis (Cases I-L \& Q-T)}

The base case numbers for FGC waste and ash recovery are based on U.S. averages. However, in general, the amount of either waste recovered and its end use will be site-specific and will depend on the composition of the waste. For example, the composition of fly ash varies greatly depending on the composition and volatility of the coal as well as the type of boiler at the plant (Ecobalance, Inc., 1997). Therefore, to determine the effects of these two variables on the results, the percentage of FGC waste recovered and the amount of recovered material credited to asphalt production were varied. The percentage of ash recovered and the amount of recovered material credited to cement production were 
also varied. Note that changes in the FGC waste recovery were made independently of changes in the ash recovery even though both topics are discussed in this section. Table 46 shows the numbers used for the FGC waste sensitivity analysis and Table 47 shows the numbers used for the ash sensitivity analysis.

Table 46: Recovered FGC Waste Sensitivity Numbers (Average and NSPS only)

\begin{tabular}{|l|c|c|}
\hline \multicolumn{1}{|c|}{ Case } & $\begin{array}{c}\% \text { recovered } \\
(\%)\end{array}$ & $\begin{array}{c}\text { \% of recovered FGC } \\
\text { waste used in asphalt (\%) }\end{array}$ \\
\hline Base case & 25 & 7 \\
\hline FGC sensitivity case Q - no recovery & 0 & N/A \\
\hline FGC sensitivity case R - 100\% utilization & 25 & 100 \\
\hline FGC sensitivity case S - 50\% recovery & 50 & 7 \\
\hline FGC sensitivity case T - 50\% recovery \& 100\% utilization & 50 & 100 \\
\hline
\end{tabular}

Changing the amount of FGC waste recovered and used for asphalt production had no noticeable effects on resource consumption, emissions, or energy use. Naturally, the amount of waste material from the system will decrease or increase because this is the largest waste generated in the Average and NSPS systems. In general, the resulting amount of FGC waste increased or decreased by as much as 34\%, causing the system waste production to increase or decrease by $19 \%-20 \%$.

Table 47: Recovered Ash Sensitivity Numbers (Average, NSPS, \& LEBS)

\begin{tabular}{|l|c|c|}
\hline \multicolumn{1}{|c|}{ Case } & $\begin{array}{c}\% \text { recovered } \\
(\%)\end{array}$ & $\begin{array}{c}\% \text { of recovered ash } \\
\text { used in cement }(\%)\end{array}$ \\
\hline Base case & 28 & 42 \\
\hline Ash sensitivity case I- no recovery & 0 & N/A \\
\hline Ash sensitivity case J - 100\% utilization & 28 & 100 \\
\hline Ash sensitivity case K - 50\% recovery & 50 & 42 \\
\hline Ash sensitivity case L - 50\% recovery \& $100 \%$ utilization & 50 & 100 \\
\hline
\end{tabular}

The amount of recovered ash was increased to $50 \%$ with $100 \%$ of the recovered ash being credited for cement production before there was a noticeable difference in any emissions or energy use. For this sensitivity case, the amount of ash landfilled decreases by $31 \%$ resulting in an overall waste reduction of $7 \%-8 \%$ from the Average and NSPS systems, and a reduction of 29\%-30\% from the LEBS system.

\subsection{Power Plant Operating Capacity Factor Sensitivity Analysis (Case M)}

The amount of time that the power plant operates was also varied in the sensitivity analysis. Because each power plant is assumed to operate at a $60 \%$ capacity factor for the base case, only a high case was examined. The operating capacity factor was increased from $60 \%$ to $85 \%$. Per unit of energy produced, the average decrease in resources, emissions, energy, and waste for all three systems was $8 \%$ to $9 \%$. The non-coal energy use decreased by about $1 \%$ for the Average, NSPS, and LEBS system. 


\subsection{Mining Equipment Materials Sensitivity Analysis (Case N-O)}

Another sensitivity analysis was performed to determine the effect of the mining materials on the outcome of this LCA. The amount of materials used was changed by $+/-50 \%$. This resulted in an average increase or decrease of $2 \%$ for the resources, emissions, energy, and waste. No single stressor changed by more than $13 \%$. Therefore, this variable has only a minor effect on the LCA.

\subsection{Landfilling versus Recycling Sensitivity Analysis (Case P)}

The amount of materials landfilled versus recycled after disassembly of the trucks, trains, mining equipment, and power plant was also varied. The base case assumes that $75 \%$ of all materials is recycled and that the remaining $25 \%$ is landfilled. These numbers were changed to $50 \%$ each. Reducing the amount of metals recycled results in large increases in some of the resources (50\%-65\% on a per unit of energy produced basis), but has a relatively minor effect on the energy requirements and on most emissions. Also, the municipal and industrial waste increases by almost a factor of two, but the overall amount of waste increases only slightly because the majority of the waste in all three systems (Average, NSPS, and LEBS) comes from the power plant.

\subsection{Impact Assessment}

Life cycle impact assessment examines the environmental and human health effects associated with the stressors quantified in the inventory stage. See section 2.0 for a discussion of the different methods available for conducting impact assessments. As explained in the methodology section, this LCA is not a comparative study, but a total examination of the stressors associated with the technologies studied. Therefore, although valuation is more detailed but controversial, it was felt that this method would not enhance the usefulness of the results for interpreting possible environmental effects. The methodologies used, less-is-better and categorization, highlight those areas of the systems that are responsible for the greatest potential for environmental damage, and provide enough information to identify design improvements (refer to section 10.0).

In classification, the inventory data that can be linked with potential ecological and human health effects, are placed into stressor categories. The association between the stressors and the categories results from previously identified consequences of environmental emissions. Many of the known effects of specific stressors have been summarized, although no attempt to define the full toxicological and environmental effects of each stressor has been made. It should be recognized that discovering and establishing a causal relationship between an emission identified in the inventory and an impact on the environment is not a component of this work or of life cycle assessment in general. The purpose of this report is only to inform the reader of known ecological and human health concerns associated with the emissions of a coal-fired power plant. Value judgements and opinions regarding the relative importance of the stressors, both environmental and economical, have been avoided. Table 48 contains a summary of the major stressors and stressor categories identified in this LCA. 
Table 48: Impacts Associated with Stressor Categories

\begin{tabular}{|c|c|c|c|c|}
\hline \multicolumn{2}{|c|}{ Stressor categories } & \multirow[t]{2}{*}{ Stressors } & \multirow{2}{*}{$\begin{array}{c}\text { Major impact } \\
\text { category (a) }\end{array}$} & \multirow{2}{*}{$\begin{array}{c}\text { Area } \\
\text { impacted (b) }\end{array}$} \\
\hline Major & Minor & & & \\
\hline $\begin{array}{l}\text { Ozone depletion } \\
\text { compounds }\end{array}$ & & $\begin{array}{l}\mathrm{Cl} \text { atom, } \mathrm{NO}, \mathrm{OH} \text { radical, } \\
\mathrm{H} \text { atom, } \mathrm{CFCs}\end{array}$ & $\mathrm{H}, \mathrm{E}$ & $\mathrm{R}, \mathrm{G}$ \\
\hline \multirow[t]{2}{*}{ Climate change } & Greenhouse gases & $\begin{array}{l}\mathrm{CO}_{2}, \mathrm{CH}_{4}, \mathrm{~N}_{2} \mathrm{O}, \mathrm{CFCs}, \mathrm{O}_{3} \text {, } \\
\mathrm{CO} \text { and } \mathrm{NO}_{\mathrm{x}} \text { (indirectly), water } \\
\text { vapor }\end{array}$ & $\mathrm{H}, \mathrm{E}$ & $\mathrm{R}, \mathrm{G}$ \\
\hline & Particulates & & $\mathrm{H}, \mathrm{E}$ & $\mathrm{L}, \mathrm{R}$ \\
\hline \multirow[t]{2}{*}{ Contributors to smog } & Photochemical & $\mathrm{NO}_{\mathrm{x}}, \mathrm{O}_{3}, \mathrm{VOCs}$ & $\mathrm{H}, \mathrm{E}$ & $\mathrm{L}, \mathrm{R}$ \\
\hline & London & Particulates, $\mathrm{SO}_{2}$ & $\mathrm{H}, \mathrm{E}$ & $\mathrm{L}, \mathrm{R}$ \\
\hline $\begin{array}{l}\text { Acidification } \\
\text { precursors }\end{array}$ & & $\begin{array}{l}\mathrm{SO}_{2}\left(\mathrm{H}_{2} \mathrm{SO}_{4}, \mathrm{H}_{2} \mathrm{SO}_{3}\right), \\
\mathrm{NO}_{\mathrm{x}}\left(\mathrm{HNO}_{3}\right), \mathrm{CO}_{2}\left(\mathrm{HCO}_{3}^{-}\right), \\
\mathrm{F}^{-}(\mathrm{HF}), \mathrm{CL}^{-}(\mathrm{HCl})\end{array}$ & $\mathrm{H}, \mathrm{E}$ & $\mathrm{L}, \mathrm{R}$ \\
\hline $\begin{array}{l}\text { Contributors to } \\
\text { corrosion }\end{array}$ & & $\begin{array}{l}\mathrm{NH}_{3}, \mathrm{NH}_{4}^{+} \text {salts, } \mathrm{SO}_{2}, \mathrm{H}_{2} \mathrm{~S}, \mathrm{O}_{3} \\
\mathrm{O}_{2}, \mathrm{H}_{2} \mathrm{O}, \mathrm{Cl}, \mathrm{HCl}, \mathrm{CL} \text { salts, } \\
\text { alkali metals }\end{array}$ & $\mathrm{E}$ & $\mathrm{L}$ \\
\hline Radionuclides & & Radon & $\mathrm{H}$ & $\mathrm{L}$ \\
\hline Trace elements & & $\begin{array}{l}\mathrm{Sb}, \mathrm{Ar}, \mathrm{Be}, \mathrm{B}, \mathrm{Cd}, \mathrm{Cr}, \mathrm{Co}, \mathrm{Cu} \\
\mathrm{Pb}, \mathrm{Mn}, \mathrm{Hg}, \mathrm{Mo}, \mathrm{Ni}, \mathrm{Se}, \mathrm{V}\end{array}$ & $\mathrm{H}, \mathrm{E}$ & $\mathrm{L}$ \\
\hline $\begin{array}{l}\text { Other stressors with } \\
\text { toxic effects }\end{array}$ & & NMHCs, $\mathrm{CN}^{-}$ & $\mathrm{H}, \mathrm{E}$ & $\mathrm{L}$ \\
\hline
\end{tabular}

(a) $\mathrm{H}=$ human health, $\mathrm{E}=$ ecological health.

(b) $\mathrm{L}=$ local (county), $\mathrm{R}=$ regional (state), $\mathrm{G}=$ global.

\subsection{Discussion of Stressor Categories}

In this section, the stressor categories into which various emissions were placed are discussed. The order in which the information is arranged does not imply that one stressor category is more important than any other.

\subsubsection{Atmospheric Concerns}

The earth's atmosphere is unique, as far as we know, in that its composition and structure make it capable of supporting life. The four major components of the atmosphere are nitrogen, oxygen, argon, and carbon dioxide. The atmosphere consists of four main regions based upon temperature variations. The troposphere is the region closest to the earth's surface. In this region, temperature decreases with altitude. At the tropopause the temperature scheme reverses so that within the next region, the stratosphere, the temperature increases with altitude. The mesosphere lies above the stratosphere, and the thermosphere lies above the mesosphere. 


\subsubsection{Climate Change}

The climate that a region experiences results from a complex set of chemical and physical phenomena in the atmosphere. Of particular concern is the possibility of upsetting the global response to energy from the sun. Energy from the sun enters the earth's atmosphere as radiation of varying wavelengths. Much of the ultraviolet portion of this radiation is absorbed by ozone in the stratosphere. The radiation that reaches the surface of the earth is absorbed as short-wave radiation and then emitted as long-wave, infrared radiation. Warming of the troposphere occurs as a result of the trapping of energy due to the absorption by trace atmospheric gases of the infrared radiation which would normally be radiated into space.

\subsubsection{Greenhouse Gases}

The gases responsible for the absorption of the infrared (long-wave) rays radiated by the earth have been coined "greenhouse gases." A growing number of scientists predict that an increase in the concentration of these gases will cause an increase in the mean global temperature. Carbon dioxide, in particular, has received most of the recent attention because of a 40 year trend showing increased atmospheric concentrations of $\mathrm{CO}_{2}$. Figure 20, which was taken from observations at the Mauna Loa Observatory in Hawaii, shows this increase (data taken from Keeling, 1998). Global mean temperatures have increased along with higher concentrations of atmospheric $\mathrm{CO}_{2}$, although the degree to which this increase is due to man-made greenhouse gases is still being debated.

A few other tropospheric gases capable of infrared absorption are methane, nitrous oxide, ozone, and chlorofluorocarbons (CFCs). Though most of these are present in the atmosphere at concentrations that are hundreds of times lower than the concentration of carbon dioxide, they are not insignificant. According to the Intergovernmental Panel on Climate Change (IPCC), the global warming potential (GWP) of methane and nitrous oxide are 21 and 310 times the GWP of carbon dioxide on a mass basis, respectively (Houghton et al, 1996). Not only are these gases more effective absorbers than $\mathrm{CO}_{2}$, some of them absorb in regions where $\mathrm{CO}_{2}$ is transparent. Figure 21 (Levi et al, 1992) shows the regions of absorptivity for a few atmospheric gases. Carbon dioxide can only absorb radiation with wavelengths that fall within the darkened regions on the figure. So, all other wavelengths of radiation would escape into space if the other greenhouse gases were not present or if they absorbed in the same regions of the spectrum as carbon dioxide. Since other greenhouse gases are present in the atmosphere and they do not absorb in the same regions as carbon dioxide, there are fewer wavelengths of radiation that will escape from the troposphere.

Carbon monoxide and nitrogen oxides (other than $\mathrm{N}_{2} \mathrm{O}$ ), although not typically referred to as greenhouse gases, are also included as climate change gases in Table 48. This is because they directly influence the atmospheric concentrations of actual greenhouse gases (IEA/OECD, 1991). For example, a molecule of carbon monoxide may react with a hydroxyl radical to form carbon dioxide. Also, both carbon monoxide and nitrogen oxides are involved in the production of tropospheric ozone.

\subsubsection{Particulate Matter and Climate}

Particulate matter is a general term that refers to a complex mixture of organic and inorganic substances present in the atmosphere as either liquids or solids. Fine particles in the atmosphere scatter solar radiation back into space. This process leads to climatic cooling. Locally, it is possible for the cooling 


\section{Figure 20: Concentration of Carbon Dioxide in the Earth's Atmosphere}

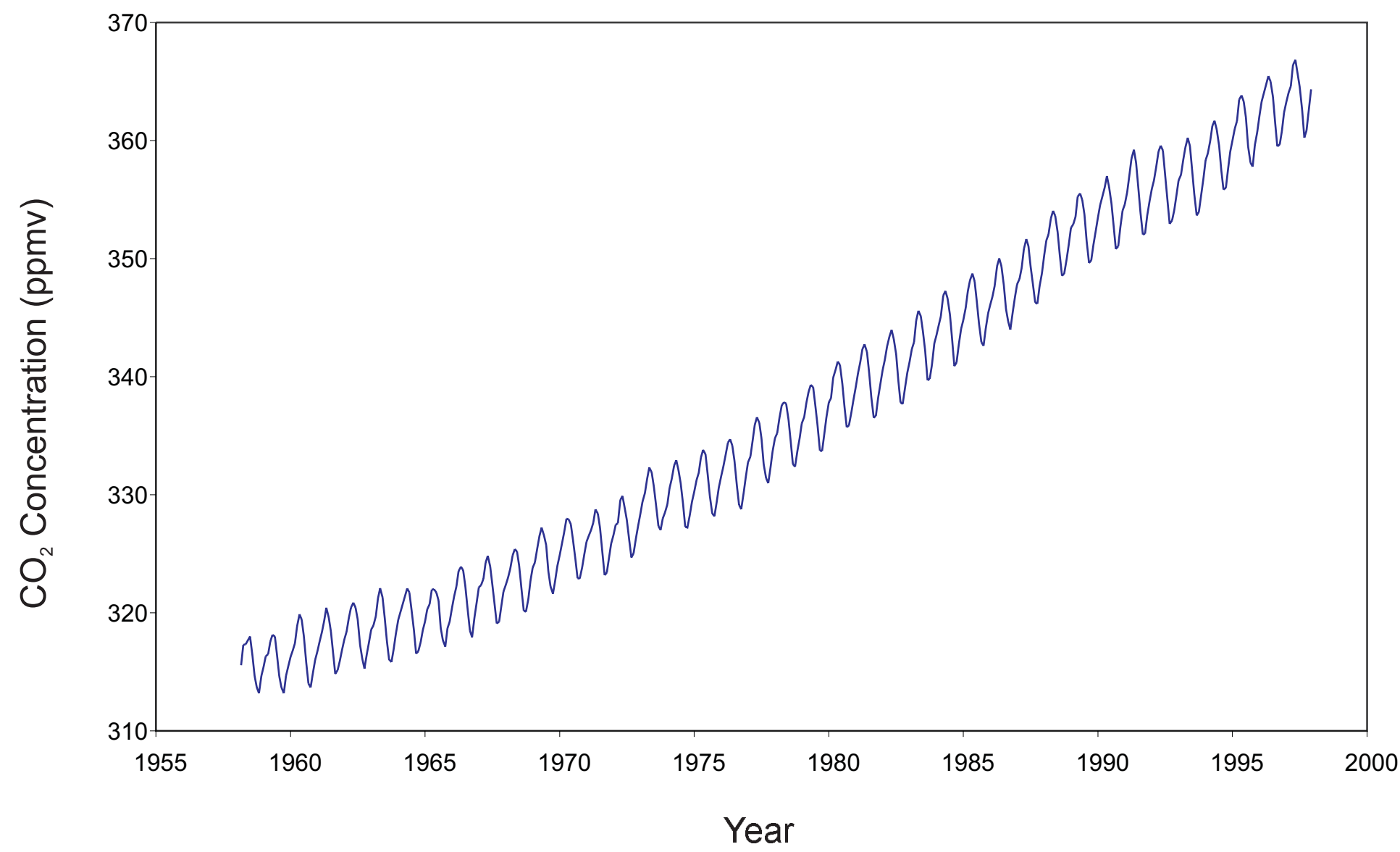

Graph produced from: Keeling, C.D.; Whorf, T.P. (August 1998). Scripps Institution of Oceanography (SIO). University of California. La Jolla, California. 92093-0220. Data from the Mauna Loa Observatory in Hawaii. 


\section{Figure 21: Absorptivity Spectrum for a Few Atmospheric Gases}

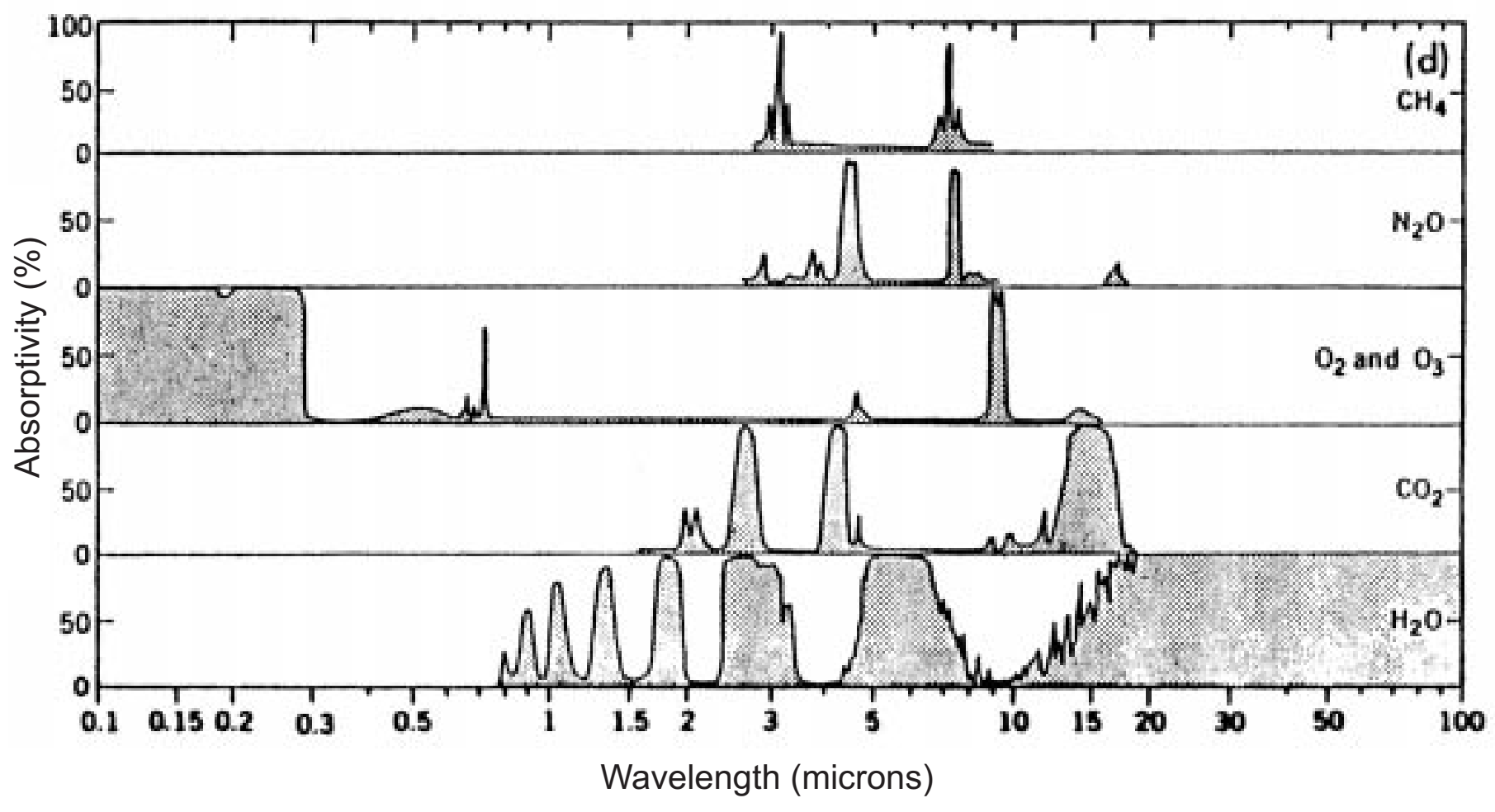

Reference: Levi, B.G.; Hafemeister, D.; Scribner, R. (1992). Global Warming: Physics and Facts. AIP Conference Proceedings No. 247; Washington, D.C. American Institute of Physics. 
effect to be large enough to offset the warming effect due to the greenhouse gases. However, particulate matter remains in the atmosphere for a much shorter period of time (days to months) in comparison to the long-lived greenhouse gases (decades to centuries). Therefore, the effect of particulates adjusts rapidly to increases or decreases in emissions (Watson et al, 1998).

\subsubsection{Ozone Depletion Compounds}

The term "ozone layer" is misleading, since it implies that there is a distinct region of the atmosphere in which ozone is a major atmospheric constituent. In reality, ozone is never more than a trace constituent. The concentration of ozone varies with latitude and season, but even at its maximum concentration, ozone is never present at more than $10 \mathrm{ppmv}$ (parts per million by volume). Ozone is an important greenhouse gas present in both the troposphere and stratosphere. Though it is only present in a trace concentration, ozone is a very important constituent of the stratosphere. Ozone shields the earth from short wavelength ultraviolet radiation. An increased presence in the stratosphere of man-made chemicals that act as catalysts for the destruction of ozone has raised a great deal of concern. A 5\% decrease in the amount of stratospheric ozone has been predicted to produce $20 \%$ more cases of skin cancer, mostly squamous cell carcinoma, per year in the United States (Bunce, 1994). A few of the "catalysts" of concern are the following species, which all have an unpaired valence electron: the chlorine atom $(\mathrm{Cl})$, nitric oxide (NO), the hydroxyl radical $(\mathrm{OH})$, and the hydrogen atom $(\mathrm{H})$. According to Bunce (1994), these catalysts all operate according to the following mechanism (where $\mathrm{X}$ equals the odd-electron species):

$$
\begin{aligned}
& \mathrm{X}+\mathrm{O}_{3} \rightarrow \mathrm{XO}+\mathrm{O}_{2} \\
& \frac{\mathrm{XO}+\mathrm{O} \rightarrow \mathrm{X}+\mathrm{O}_{2}-}{\mathrm{O}_{3}+\mathrm{O} \rightarrow 2 \mathrm{O}_{2}}
\end{aligned}
$$

Chlorofluorocarbons (CFCs), a heat transfer fluid introduced in the 1930s for use in refrigerators and air conditioning systems, are susceptible to gradual photolysis which produces more chlorine to participate in the above reactions:

$$
\mathrm{CF}_{2} \mathrm{Cl}_{2} \rightarrow h v, \lambda<250 \mathrm{~nm} \rightarrow \mathrm{CF}_{2} \mathrm{Cl}+\mathrm{Cl}
$$

\subsubsection{Smog: Photochemical and London}

There are two types of smog: photochemical smog and London smog. Photochemical smog (such as that in Los Angeles, California) consists of a yellow-brown haze, which reduces visibility, and consists of substances that both irritate the respiratory tract and cause eye-watering. Nitrogen dioxide is the chemical responsible for the color and opacity of the smog, while the irritant species include ozone, aliphatic aldehydes, and organic nitrates. The following four conditions must all be present simultaneously in order for photochemical smog development (Bunce, 1994):

- $\quad$ nitrogen oxides $\left(\mathrm{NO}_{\mathrm{x}}\right)$

- $\quad$ sunlight

- hydrocarbons

- temperatures higher than about $18^{\circ} \mathrm{C}$.

London smog is quite different from the Los Angeles-type photochemical smog. London smog results mainly from the burning of coal, which releases large amounts of particulates and sulfur dioxide gas. The most devastating occurrence of London smog occurred in London in 1952. Visibility in the center 
of the affected area was less than 22 yards. Sulfur dioxide concentrations were as high as $1.3 \mathrm{ppm}$, and total particles of $4.5 \mathrm{mg} \mathrm{m}^{-3}$ were recorded. These conditions caused over 4,000 fatalities (Finlayson-Pitts and Pitts, 1986). Comparisons of the two types of smog are shown in Table 49 (Bunce, 1994 and Finlayson-Pitts and Pitts, 1986).

Table 49: London versus Photochemical Smog

\begin{tabular}{|l|l|l|}
\hline \multirow{2}{*}{ Characteristics } & \multicolumn{2}{c|}{ Type of smog } \\
\cline { 2 - 3 } & \multicolumn{1}{|c|}{ Photochemical } & \multicolumn{1}{c|}{ London } \\
\hline Primary pollution source & Automobiles & $\begin{array}{l}\text { Coal burning without appropriate } \\
\text { clean-up technologies. }\end{array}$ \\
\hline Primary pollutants & $\mathrm{NO}_{x}$, organics & $\mathrm{SO}_{2}$, sooty particles \\
\hline Secondary pollutants & $\begin{array}{l}\mathrm{O}_{3}, \text { peroxyacetal nitrate }(\mathrm{PAN}), \mathrm{HNO}_{3}, \\
\text { aldehydes, sulfates, particulate nitrates, etc. }\end{array}$ & $\begin{array}{l}\mathrm{H}_{2} \mathrm{SO}_{4} \text {, aerosols, sulfonic acids, } \\
\text { sulfates, etc. }\end{array}$ \\
\hline Cause of reduced visibility & Liquid aerosol & Smoke, soot \\
\hline Chemistry of the atmosphere & Oxidizing $\left(\mathrm{O}_{3}, \mathrm{PAN}\right)$ & Reducing $\left(\mathrm{SO}_{3}\right)$ \\
\hline Temperature & Hot $\left(\geq 75^{\circ} \mathrm{F}\right)$ & Cool $\left(\leq 35^{\circ} \mathrm{F}\right)$ \\
\hline Relative humidity & Low, usually hot and dry & High, usually foggy \\
\hline Time air pollution peaks & Noon to evening & Early morning \\
\hline
\end{tabular}

When the impacts of emissions are being considered, it is important to account for effects of the chemistry in which the emissions participate, as well as the inherent toxic effects of each stressor and stressor category. A stressor may not be present at toxic concentrations, and yet it may be reacting to form toxic levels of another compound. The following information explains the complex chemistry for the formation of photochemical smog. The information given is based on the following sources: Bunce, 1994; Finlayson-Pitts \& Pitts, 1986; Warneck, 1988; and Wayne, 1991.

Spontaneous chemical reactions that occur when mixing two or more stable chemical reagents are quite rare. For the most part, a reaction will proceed only if stimulated by the addition of energy since most reactions must overcome an activation energy barrier. Heat is the common source of this energy in the laboratory; other forms of energy, such as visible or ultraviolet light, are used much less frequently. However, in the atmosphere, the heat content of ambient air is usually insufficient for thermal activation of a reaction. Therefore, solar radiation initiates most atmospheric reactions.

In a sense, the atmosphere is a giant photochemical reactor, in which the sun acts as the radiation source. The sun emits a wide range of radiation wavelengths, but only certain regions of the spectrum are important to the photochemistry of the troposphere. Light can become photochemically effective if the energy is absorbed into a molecule. The mere interaction of radiation with a molecule is insufficient; the energy must be incorporated into the molecule. Further, light radiation acts in a particulate manner. A ray of light is actually a flux of photons with each photon having a specific amount of energy. According to quantum mechanics, the energy of the photon must exactly correspond to the energy of a higher energy level in the molecule in order for the photon to be absorbed. 
Energy levels are customarily distinguished by rotational, vibrational, and electronic motions within a molecule. In general, the excitation of rotational and vibrational levels does not provide the energy necessary for photochemical reactions. In the troposphere, visible and near ultraviolet (1 400-200 nm) radiation is the major source of energy for photochemical reactions, since stratospheric ozone acts as a filter for shorter wavelengths. Radiation of longer wavelengths also reaches the earth's surface, but this radiation is too low in energy to cause electronic excitation of molecules. Longer wavelength radiation tends only to heat the atmosphere.

Once a molecule has been excited, the fate of the excitation energy depends on the nature of the molecule and the amount of energy received. If the excited molecule gives off the energy as radiation, the process is called fluorescence. The molecule may also undergo a process called quenching, in which the energy dissipates by collisions with other molecules. The energy may be used for chemical transformations such as isomerization, dissociation, or ionization. Sensitization, which involves the transfer of all or part of the energy to other molecules that can then react further, is a possibility, or the molecule can participate in chemical reactions directly.

One of the most important mechanisms of the atmospheric chemistry leading to photochemical or "Los Angeles" smog involves the photodissociation of ozone $\left(\mathrm{O}_{3}\right)$.

$$
\begin{gathered}
\mathrm{O}_{3}+h v, \lambda<400 \mathrm{~nm} \rightarrow \mathrm{O}_{2}^{*}+\mathrm{O}^{*} \\
\mathrm{O}^{*}+\mathrm{H}_{2} \mathrm{O} \rightarrow 2 \mathrm{OH}
\end{gathered}
$$

This reaction sequence is important because of the formation of the hydroxyl radical (OH). The hydroxyl radical is not to be confused with the hydroxide anion $\left(\mathrm{OH}^{-}\right)$. The hydroxyl radical has an unpaired electron and is neutral, which makes it chemically distinct from the hydroxide anion. The hydroxyl radical is the most powerful oxidant in the troposphere (Bunce, 1994).

\section{The Formation of Ozone, Aldehydes, and Peroxyacetal Nitrate}

Nitrogen dioxide is responsible for the brownish coloring of the haze associated with smog, but it also facilitates many of the reactions associated with smog formation. In the unpolluted atmosphere, carbon monoxide $(\mathrm{CO})$ and ozone $\left(\mathrm{O}_{3}\right)$ react to form carbon dioxide $\left(\mathrm{CO}_{2}\right)$ and molecular oxygen $\left(\mathrm{O}_{2}\right)$. However, in the presence of nitrogen oxides, carbon monoxide reacts to produce, rather than destroy, ozone. Because $\mathrm{NO}_{\mathrm{x}}$ and $\mathrm{CO}$ are produced during the combustion of fossil fuels, the ozone production reactions typically take place in the lower atmosphere, where the ozone is a pollutant rather than in the stratosphere where it absorbs incoming UV radiation.

Nitrogen oxides also participate in the oxidation reactions of hydrocarbons, which form ozone. When the formation of ozone from the oxidation of carbon monoxide is considered in conjunction with the formation of ozone from the oxidation of methane, the following overall reaction results:

$$
\mathrm{CH}_{4}+8 \mathrm{O}_{2}+4 h v \rightarrow \mathrm{CO}_{2}+2 \mathrm{H}_{2} \mathrm{O}+4 \mathrm{O}_{3}
$$

Thus, the oxidation of only one mole of methane can produce as many as four moles of ozone.

Aldehydes are produced similarly to the way methane is oxidized. An alkyl group undergoes hydrogen abstraction by the hydroxyl radical. The resulting alkyl radical then reacts with molecular oxygen to form 
an alkylperoxy radical. The peroxide radical then reacts with nitric oxide followed by molecular oxygen to form an aldehyde. The formation of organic nitrates also occurs by a free radical initiation and propagation type mechanism.

\subsubsection{Acid Deposition}

Usually, rainwater has a $\mathrm{pH}$ close to 5.6 because of the reaction between water and atmospheric carbon dioxide to form carbonic acid. However, the presence of sulfur oxides and nitrogen oxides (the precursors to sulfuric and nitric acid), as well as chlorides and fluorides (the precursors to hydrochloric and hydrofluoric acids), can lead to rainfall with a $\mathrm{pH}$ lower than 5.0. Rainwater with a $\mathrm{pH}$ of 4 to 4.5 is not uncommon, and pHs lower than 2 have been recorded (Bunce, 1994).

Excess acidity can be harmful to plants. The leaves of plants may be damaged when the pH of precipitation falls below 3.5, although changes in soil can occur at less acidic pHs. The changes in soil will be the most pronounced in poorly buffered soils. Though there are a few plants that can tolerate acidic soils, most plants prefer an alkaline environment. The acidity of the soil may inhibit seed germination and seedling growth in addition to other effects (Bunce, 1994). It is believed that calcium, magnesium, and potassium are leached out of the soil by acid rain. Though leaching may initially increase the availability of the cations for vegetation, nutrient deficiency may eventually occur. Also, acidic water may release sufficiently high concentrations of aluminum from minerals in the soil resulting in phytotoxic concentrations (Zakrzewski, 1991). High concentrations of aluminum may also reduce the uptake of nutrient cations such as $\mathrm{Ca}^{2+}$ (Levi et al, 1992).

Plant life is not the only ecological concern when acid rain is an issue. In areas where the underlying rocks have poor buffering capacity (e.g., granite), lakes and streams are sensitive to the addition of acid. The lower the $\mathrm{pH}$ becomes, the greater the losses of aquatic life. At a $\mathrm{pH}$ less than 4, lakes become suitable habitats for white moss. This moss forms a thick covering on the lake bottom preventing nutrient exchange between the water and lake sediments (Bunce, 1994). The Freshwater Institute of Manitoba performed a research project that involved the purposeful acidification of a small lake in Ontario. The $\mathrm{pH}$ of the lake was intentionally lowered from 6.8 to 5.0 over an eight-year period. The results of this study, as reported by Zakrzewski (1991), are as follows: "At the $\mathrm{pH} 5.9$ the population of a shrimp species decreased considerably, another species of crustacean disappeared, and fathead minnow stopped reproducing. At pH 5.4 all fish stopped reproducing."

According to Bunce (1994), lakes with a $\mathrm{pH}$ lower than 5 commonly do not contain fish. Table 50 gives further examples of aquatic organisms that are lost as a result of acidification of lakes and streams.

Table 50: Aquatic Organisms Lost - Due to Acidification of Lakes and Streams

\begin{tabular}{|c|l|}
\hline $\mathrm{pH}$ & \multicolumn{1}{|c|}{ Aquatic organism lost } \\
\hline 6.0 & Death of snails and crustaceans \\
\hline 5.5 & Death of salmon, rainbow trout, and whitefish \\
\hline 5.0 & Death of perch and pike \\
\hline 4.5 & Death of eel and brook trout \\
\hline
\end{tabular}


Structures may also incur damage due to acid rain. A commonly used building material is concrete. This material is attacked even under the normal conditions of slightly acidic rainwater. However, acid precipitation speeds up the chemical process of destruction. Iron and steel are also highly susceptible to corrosion. Acid rain promotes the corrosion process by providing hydrogen ions which catalyze the corrosion chemistry. Even galvanized steel (steel protected with zinc) may experience accelerated corrosion under acidic conditions.

\subsubsection{Contributors to Corrosion}

The stressors that contribute to the corrosion of metals are ammonia and ammonium salts, sulfur oxides, hydrogen sulfide, oxygen, ozone, water, chlorine, hydrochloric acid, chloride salts, and molten salts of alkali metals (Barton, 1976; Shreir, 1978; and Kofstad, 1988). Acid rain promotes corrosion of structures including concrete and metal as discussed above in the previous section. Additional information related to corrosion is discussed in section 9.2 for that specific stressor.

\subsubsection{Radionuclides}

Radionuclides are unstable elements that radioactively decay until a stable element is formed. When an element decays, it divides into two parts. The first is called a daughter (which may or may not be radioactive); the second is the radiation. The three possible types of radiation that may be emitted in the decay process are: alpha particles, beta particles, and gamma radiation. Alpha particles can travel only a short distance and cannot go through human skin. Beta particles may penetrate human skin, but they cannot travel completely through the body. Gamma radiation, however, can go all the way through the body. A few of the naturally occurring radioactive species are uranium, thorium, radium, and radon. Although natural, these sources of radiation are harmful to humans, and exposure to any radioactivity can cause cancer.

\subsection{Known Effects of Specific Stressors}

The previous section discussed the stressor categories into which various emissions were placed. In this section, the known ecological and human health effects caused by expected emissions are reported. The order in which the information is organized does not imply that one stressor is more harmful to the environment or human health than any other stressor.

\subsubsection{Nitrogen Compounds}

Five major gaseous forms of nitrogen compounds are released as a result of burning coal for electricity production. These include nitrogen gas $\left(\mathrm{N}_{2}\right)$, ammonia $\left(\mathrm{NH}_{3}\right)$, nitrous oxide $\left(\mathrm{N}_{2} \mathrm{O}\right)$, nitric oxide $(\mathrm{NO})$, and nitrogen dioxide $\left(\mathrm{NO}_{2}\right)$.

Nitrogen is an odorless gas that constitutes $75.5 \%$ by weight or $78.06 \%$ by volume of the earth's atmosphere. When a combustion source is applied, this gas combines with oxygen and hydrogen to form nitric oxide and ammonia, respectively (Budavari et al, 1996).

Ammonia is a colorless gas with a very pungent odor. The lower limit of human perception is $53 \mathrm{ppm}$ (Budavari et al, 1996). Ammonia is the only atmospheric gas capable of neutralizing the acids produced when $\mathrm{SO}_{2}$ and $\mathrm{NO}_{\mathrm{x}}$ are oxidized (Warneck, 1988 and Kirkwood and Longley, 1995). Because of this 
property, ammonia has been used as an agent for controlling $\mathrm{NO}_{\mathrm{x}}$ emissions (Bunce, 1994). Neutralization by ammonia leads to the formation of ammonium salt particulates of sulfuric and nitric acids (Warneck, 1988).

Ammonia and its compounds have been well documented for causing 'season cracking', a type of stresscorrosion cracking of cold-worked brass (Shreir, 1978). Corrosion can proceed all over the brass surface when ammonium salts are present because they have a low surface tension, which causes sheeting rather than drop formation condensation (Barton, 1976). Ammonia appears to be a contributor to the nitrogen loading of the Chesapeake Bay according to a study published by the Environmental Defense Fund (Zakrzewski, 1991) on the role of airborne nitrate deposition in eutrophication of the Chesapeake Bay.

Nitrous oxide, commonly known as laughing gas, is a colorless gas with a slightly sweetish odor and taste. It is very stable and chemically inert at room temperature but dissociates and becomes an oxidant at temperatures higher than $300^{\circ} \mathrm{C}\left(572^{\circ} \mathrm{F}\right)$ (Budavari et al, 1996). This gas absorbs infrared radiation; therefore, tropospheric $\mathrm{N}_{2} \mathrm{O}$ is considered a greenhouse gas with an estimated global warming potential 310 times (weight basis) that of carbon dioxide (Houghton et al, 1996). Due to its stability and chemical inertness, there are no known sinks, a chemical or physical process that removes a species from the "reservoir" of concern, for $\mathrm{N}_{2} \mathrm{O}$ in the troposphere other than migration to the stratosphere. In the stratosphere, nitrous oxide has two chemical sinks. The first sink is photochemical degradation.

$$
\mathrm{N}_{2} \mathrm{O}+h v \rightarrow \mathrm{N}_{2}+\mathrm{O}^{*} \text { (an excited oxygen atom) }
$$

Nitrous oxide may also undergo a reaction with an excited oxygen atom to produce nitric oxide, NO (Bunce, 1994). Information about the excitation of a species is given in section 9.1.6, Smog: Photochemical and London.

Nitric oxide (NO) and nitrogen dioxide $\left(\mathrm{NO}_{2}\right)$ are collectively known as $\mathrm{NO}_{\mathrm{x}}$ since they continuously cycle back and forth. Nitrogen oxides are produced when any fuel is combusted in air or oxygen (Bunce, 1994). $\mathrm{NO}_{\mathrm{x}}$ produced in this manner is often referred to as thermal $\mathrm{NO}_{\mathrm{x}}$. A second-type of $\mathrm{NO}_{\mathrm{x}}$, often referred to as fuel-bound $\mathrm{NO}_{x}$, is produced when nitrogen within a fuel (rather than from air) reacts with oxygen.

Nitric oxide is a colorless gas that contains an odd number of electrons (one of its valence electrons is unpaired) and is paramagnetic (Budavari et al, 1996). As an odd-electron species, NO acts as a catalyst for the depletion of stratospheric ozone.

Nitrogen dioxide is a reddish-brown gas with an irritating odor. This chemical species is responsible for the characteristic yellow-brown haze that exists in Los Angeles, California (Budavari et al, 1996). The coloration effect is a result of $\mathrm{NO}_{2}$ acting as a filter for blue light by strongly absorbing radiation with wavelengths less than $430 \mathrm{~nm}$ (Finlayson-Pitts and Pitts, 1986). Nitrogen oxides are contributors to acid deposition caused by the oxidation reaction of $\mathrm{NO}_{\mathrm{x}}$ to nitric acid.

The ingestion of nitrates $\left(\mathrm{NO}_{3}^{-}\right)$and nitrites $\left(\mathrm{NO}_{2}^{-}\right)$can cause relaxation of smooth muscle cells, which can be so drastic that the contractile system is totally inhibited. These compounds can cause blood to pool in the veins so that the heart is not completely filled. Therefore, the systolic blood pressure drops, and the pulse rate increases. Dilation of blood vessels in the brain leads to headaches. Additionally, 
acute circulatory collapse and fainting are also possible. Dilation of vessels in the retina leads to vision disorders (Ullmann, 1985).

The organic nitrate, peroxyacetyl nitrate (PAN), is often present in highly polluted areas because of the reaction between the peroxyacetyl radical and nitrogen dioxide. This species that is associated with photochemical smog irritates the mucous membranes, eyes, and skin.

\subsubsection{Sulfur Compounds}

The combustion of coal is the primary source of sulfur pollutants. The sulfur in the coal is oxidized to form sulfur dioxide gas when the coal is burned (Bunce, 1994). Sulfur dioxide is a colorless, nonflammable gas with a strong suffocating odor (Budavari et al, 1996). This gas is readily adsorbed onto the surface of particulate matter. The particulates act as a catalyst for the oxidation of $\mathrm{SO}_{2}$ to $\mathrm{SO}_{3}$ in the presence of moisture. The $\mathrm{SO}_{3}$ immediately combines with water to form sulfuric acid $\left(\mathrm{H}_{2} \mathrm{SO}_{4}\right)$. Many of these particles are removed from the atmosphere through acid deposition such as acid rain, acid snow, or acid fog. Inhaling these particles can damage the respiratory system (Zakrzewski, 1991). Sulfur oxides are also powerful stimulators of atmospheric corrosion because of their high solubility in water (Shreir, 1978 and Barton, 1976).

Another sulfur compound, hydrogen sulfide $\left(\mathrm{H}_{2} \mathrm{~S}\right)$, is emitted from each coal-to-electricity system. $\mathrm{H}_{2} \mathrm{~S}$ is a flammable, poisonous gas with a sweetish taste and the characteristic odor of rotten eggs, perceptible to the human nose when present in air at concentrations of 0.02-0.13 ppm (Budavari et al, 1996). At normal atmospheric concentrations, this gas is responsible for the tarnishing of copper, silver, and other metals with high energies of sulfide formation (Shreir, 1978 and Barton, 1976). $\mathrm{H}_{2} \mathrm{~S}$ can also lead to corrosion because it is readily oxidized to the powerful atmospheric corrosion stimulant $\mathrm{SO}_{2}($ Shreir, 1978). Sulfides, which are irritants, can emit hydrogen sulfide upon heating (Ullmann, 1985).

\subsubsection{Carbon Dioxide}

Carbon dioxide is produced from the burning of carbonaceous materials. It is a colorless, odorless, noncombustible gas that has a faint acid taste (Budavari et al, 1996). This gas is necessary for photosynthesis by plants. $\mathrm{CO}_{2}$ is the most publicized of the greenhouse gases due to its increasing rate of production and atmospheric concentration. Although the link between $\mathrm{CO}_{2}$ and higher global mean temperatures has not been fully established, many in the scientific community are beginning to think that the increase in atmospheric $\mathrm{CO}_{2}$ is likely to have some effect. Many efforts are under way to reduce greenhouse gas emissions, particularly $\mathrm{CO}_{2}$. For example, in December 1997, the nations attending the United Nations Convention on Climate Change agreed to the terms of the Kyoto Protocol, which obligates industrialized countries to meet legally binding greenhouse gas emission objectives over the 2008-2012 time frame. The International Energy Agency and IPCC are working to gather relevant scientific data and build international cooperation to achieve these objectives. Although the consequences of increased atmospheric $\mathrm{CO}_{2}$ and global mean temperatures are not known, a proactive approach to mitigation is seen by many to be the prudent course of action.

\subsubsection{Carbon Monoxide}

Carbon monoxide results from the incomplete combustion of hydrocarbons. It is a highly poisonous, odorless, colorless, tasteless, flammable gas (Budavari et al, 1996). Carbon monoxide is particularly 
dangerous because it cannot be detected by the natural senses of the body (Ullmann, 1985). CO is not itself a greenhouse gas, but it directly influences the concentrations of other greenhouse gases in the atmosphere by removing hydroxyl radicals that could otherwise react to destroy greenhouse gases (Zakrzewski, 1991). However, the primary reason CO is considered a pollutant results from its health implications. Carbon monoxide combines with the hemoglobin of the blood to form carboxyhemoglobin, which is useless as an oxygen carrier. At less than $2 \%$ carboxyhemoglobin, no health effects are seen in humans (Zakrzewski, 1991). However, at higher concentrations, toxic symptoms include headache, mental dullness, dizziness, weakness, nausea, vomiting, loss of muscular control, increased then decreased pulse and respiratory rates, collapse, unconsciousness, and death (Budavari et al, 1996). When a person is exposed to $\mathrm{CO}$ at a concentration of $100 \mathrm{ppmv}$, up to $15 \%$ of the person's hemoglobin has been converted to carboxyhemoglobin (Bunce, 1994). Physiological functions can be fully restored with the timely removal of $\mathrm{CO}$ from the blood stream. This can be achieved by administering oxygen to the affected individual. However, the time required for removing $50 \%$ of the carbon monoxide from the hemoglobin is 320 minutes or nearly 5.5 hours (Zakrzewski, 1991).

\subsubsection{Methane}

Methane, the simplest hydrocarbon, is a colorless, odorless, non-poisonous gas (Budavari et al, 1996). This gas has an estimated global warming potential of 21 times (weight basis) that of carbon dioxide (Houghton et al, 1996). Methane is also highly explosive in atmospheric concentrations of 5\%-15\%. As little as $0.5 \%-2 \% \mathrm{CH}_{4}$ may be dangerous, especially in the presence of coal dust. In coal mine entries used by personnel, methane levels cannot exceed $1 \%$, and in certain designated areas of the mine not frequented by mine personnel, methane levels cannot exceed $2 \%$ as regulated by the Mine Safety and Health Administration (IFC Resources Inc., 1990).

Acid rain may be contributing, in a minor way, to methane's atmospheric concentration and global warming potential. Many of the soil bacteria that consume atmospheric methane are less effective at this activity in response to acid precipitation. A less effective sink for methane leads to increased concentrations of atmospheric methane over time, which causes an increased global warming potential (Schlesinger, 1991).

Methane is also a contributor to photochemical smog. Four moles of ozone, one of the irritant species associated with photochemical smog, may be produced for every one mole of methane that is oxidized (Bunce, 1994). See section 9.1.6, Smog: Photochemical and London, under the heading, The Formation of Ozone, for the chemistry that leads to the net reaction shown below:

$$
\mathrm{CH}_{4}+8 \mathrm{O}_{2} \rightarrow \mathrm{CO}_{2}+2 \mathrm{H}_{2} \mathrm{O}+4 \mathrm{O}_{3}
$$

\subsubsection{Non-Methane Hydrocarbons (NMHCs)}

In general, alkanes have a narcotic effect; they diminish awareness of sensory impulses, especially pain, and, in large doses, can cause stupor, coma, and convulsions. However, n-hexane possesses a marked neurotoxic effect that distinguishes it from the other alkanes. It is also a skin irritant. The alkenes are toxicologically not very active, but higher molecular mass compounds possess narcotic properties. The alkylbenzenes tend to have low oral toxicity with $\mathrm{LD}_{50}>5000 \mathrm{mg} / \mathrm{kg}$ (Ullmann, 1985). $\mathrm{LD}_{50}$, which is also known as the median lethal concentration, is the concentration of a chemical that is estimated to be fatal to $50 \%$ of the organisms tested. 
When handling aldehydes, care must be taken to prevent either the liquids or their vapors from coming into contact with respiratory organs, eyes, and skin. Because of their health hazards, saturated and unsaturated aliphatic aldehydes, especially the lower members, should be handled only if special safety precautions are taken. Aldehydes are highly reactive and sometimes have a very unpleasant and intense odor (Ullmann, 1985).

Phenol is toxic in high concentrations. It can be absorbed through the skin, by inhalation, and swallowing. Possible results from inhaling phenol vapor or mist are shortness of breath, coughing, and lung edema. Swallowing phenol can lead to caustic burns on the mouth and esophagus and stomach pains. The effect of phenol on the central nervous system, sudden collapse and loss of consciousness, is the same for humans and animals. Historically, phenol was used as a very effective disinfectant because of its germicidal effect. However, because of its protein-degenerating effect, it often had a severely corrosive effect on the skin and mucous membranes (Ullmann, 1985).

Fuel oils, such as heavy and light diesel fuel, differ from one another by their hydrocarbon compositions, boiling point ranges, chemical additives, and uses. Breathing some fuel oils for short periods may cause nausea, eye irritation, increased blood pressure, headache, light-headedness, loss of appetite, poor coordination, and difficulty concentrating. Breathing diesel fuel vapors for long periods may cause kidney damage and lower the blood's ability to clot. Preliminary studies suggest that heavy fuel oils may cause cancer and that light fuel oils do not. However, further investigation is necessary.

In view of the high boiling range and low volatility of lubricants, the environment can be polluted only through seepage into the ground and contamination of surface and subsoil waters. This may happen because of careless handling, tank leakage, transport accidents, improper disposal of used oils, or inexpert draining of lubricant-containing industrial wastewater. The toxicology and occupational health concerns associated with lubricants vary with type and composition of the lubricant (Ullmann, 1985). However, common symptoms of exposure are skin irritation (resulting from skin contact) or stomach irritation (when ingested).

\subsubsection{Cyanides}

"Cyanides" is a collective term for the man-made and naturally occurring substances that are composed of the cyanide anion $\left(\mathrm{CN}^{-}\right)$and other elements. The single largest source of airborne cyanide emissions is vehicle exhaust. Cyanide in the form of vitamin $\mathrm{B}_{12}$ is needed as part of a healthy diet to prevent anemia. However, exposure to high levels of cyanide for a short period harms the central nervous, respiratory, and cardiovascular systems and may cause a coma or death. Brief exposures to lower levels result in rapid, deep breathing; shortness of breath; convulsions; and loss of consciousness. Skin contact with dust containing certain cyanides can cause skin irritation and ulceration. The U.S. EPA has not determined whether cyanides should be classified as human carcinogens (U.S. Department of Health and Human Services, 1993). 


\subsubsection{Ozone}

Ozone, a powerful oxidizing agent, is a bluish, explosive gas with a pleasant, characteristic odor at concentrations of less than $2 \mathrm{ppm}$ (Budavari et al, 1996). At higher concentrations, ozone is an irritating and injurious respiratory toxin. Acute exposure causes damage to and swelling of the respiratory tissue; chronic exposure may lead to emphysema (Zakrzewski, 1991). The presence of ozone is one cause for the irritating nature of photochemical smog and is one of the more active greenhouse gases (Bunce, 1994). Ozone also participates in corrosion processes by actively promoting the aging of elastomers and other organic substances that are commonly used as protective coatings (Barton, 1976).

Despite the ill effects of ozone in the troposphere, stratospheric ozone is a necessity because it reduces the penetration of ultraviolet light. UV-B light $(280-320 \mathrm{~nm})$ is particularly damaging to life because radiation in this region of the spectrum is strongly absorbed by proteins, nucleic acids, and other biological molecules (Macalady, 1998).

\subsubsection{Particulates}

Particulate matter is a general term for solid particles that are suspended in the atmosphere. These particles are made up of various compositions of organic and inorganic compounds. Air quality standards for particulate matter are now written in terms of total suspended particulate matter and are not classified according to size. However, the U.S. EPA may mandate a size restricted standard because of size-related health effects. If inhaled, large particles $(\geq 2.5 \mu \mathrm{m})$ are removed in the upper respiratory tract. On the other hand, particles that are typical of fossil fuel combustion are much smaller $(\leq 2.5 \mu \mathrm{m})$ and are respirable. They are not removed in the upper respiratory tract, but rather travel to the region of the lower respiratory tract where gas exchange occurs. In addition, they typically contain more toxic species than the large particles. Therefore, small particles are a greater health risk than large particles (Finlayson-Pitts and Pitts, 1986).

Particulates are not only a health risk, they also act as catalysts for the oxidation of sulfur dioxide which leads to acid precipitation. In addition, small particles are responsible for most light scattering and visibility reduction (Finlayson-Pitts and Pitts, 1986).

\subsubsection{Trace Elements and Their Compounds}

This section contains information about the trace elements included in the inventory analysis portion of the coal-fired power plant life cycle assessment. The toxicological effects of exposure by ingestion are given even though the primary means of exposure is inhalation for most of these trace elements. All information in this section, unless otherwise noted, has been taken from the Agency for Toxic Substances and Disease Registry (U.S. Department of Health and Human Services, 1993).

\section{$\underline{\text { Antimony }}$}

Antimony is a silvery-white metal that is released into the environment from natural sources and from industry. Mixed into alloys, it is used in lead acid batteries, solder, sheet and pipe metal, bearings, castings, and pewter. It is also used in paints, ceramics, and fireworks. In the air, antimony attaches to small particles that may stay airborne for many days. Eventually, most antimony ends up in the soil, where it adheres strongly to particles that contain iron, manganese, or aluminum. Breathing high levels of antimony for a long time can irritate the eyes and lungs as well as cause heart and lung problems, 
stomach pain, diarrhea, vomiting, and stomach ulcers. Ingesting large doses of antimony can cause vomiting. Limited information is available about the effects of antimony on humans. However, in shortterm studies, animals that were exposed to high levels of airborne antimony experienced lung, heart, liver, and kidney damage. Those exposed to very high levels died. In long-term studies, animals exposed to very low levels of antimony had eye irritation, hair loss, lung damage, heart problems, and fertility problems. As to its human carcinogenicity, antimony has not yet been classified by the U.S. EPA.

\section{$\underline{\text { Arsenic }}$}

Inorganic arsenic compounds are poisonous to humans. They are used to preserve wood and to make insecticides and weed killers. Organic forms of arsenic compounds are usually less harmful than inorganic forms. Fish and shellfish build up organic arsenic in their tissues, but most of the arsenic contained in fish is not toxic. High levels $(60 \mathrm{ppm})$ of inorganic arsenic can be fatal. Arsenic damages many tissues including nerves, stomach, intestines, and skin. Breathing high levels can cause a sore throat and irritated lungs. Lower levels of exposure to inorganic arsenic compounds may cause nausea, vomiting, and diarrhea, decreased production of red and white blood cells, abnormal heart rhythm, blood vessel damage, and a "pins and needles" sensation in the hands and feet. Long-term exposure to inorganic arsenic may lead to a darkening of the skin and the appearance of small corns or warts on the palms, soles, and torso. Direct skin contact may cause redness and swelling. Finally, arsenic is a known carcinogen.

\section{$\underline{\text { Barium }}$}

Insoluble barium compounds are not toxic. Soluble barium compounds, however, may cause harmful effects. Most barium poisoning is caused by mistaking soluble barium compounds, such as barium carbonate, for the insoluble and therefore nontoxic barium sulfate, which is used as a contrast agent in X-ray diagnosis (Ullmann, 1985). Barium compounds are used by oil and gas industries to make drilling muds, which make it easier to drill through rock by keeping the drill bit lubricated. These compounds are also used to make paint, bricks, tiles, glass, and rubber. Ingesting high levels of soluble barium compounds may cause difficulty in breathing, increased blood pressure, changes in heart rhythm, stomach irritation, brain swelling, muscle weakness, and damage to the liver, kidney, heart, and spleen. The U.S. Department of Health and Human Services has not classified barium as to its human carcinogenicity.

\section{Beryllium}

Pure beryllium is a hard, grayish metal that is used in electric parts, machine parts, ceramics, aircraft parts, nuclear weapons, and mirrors. Most of the beryllium that can be inhaled is released into the air by the burning of coal or fuel oil. Beryllium is a toxic substance that can be harmful, depending on the amount and duration of exposure to it. Not all of the effects of beryllium and its compounds are well understood, and not all forms of beryllium are equally toxic. Short term human and animal exposure to high levels of soluble beryllium compounds can lead to the development of inflammation or reddening and swelling of the lungs, a condition known as acute beryllium disease (similar to pneumonia). Removal from exposure leads to a reversal of symptoms. Long-term exposure to beryllium or beryllium oxide at much lower levels has been reported to cause chronic beryllium disease. This disease is characterized by shortness of breath, scarring of the lungs, and berylliosis (non-cancerous growths on the lungs of humans). Acute and chronic beryllium diseases can be fatal. Beryllium and its compounds may reasonably be anticipated to be carcinogens. 


\section{$\underline{\text { Boron }}$}

Boron is often found combined with other substances called borates such as boric acid, salts of borates, and boron oxide. Borates are used most widely to produce glass, but they are also used in fire retardants, leather tanning industries, cosmetics, photographic materials, soaps, and cleaners. Breathing moderate levels of molecular boron can irritate the nose, throat, and eyes. Reproductive effects have been observed in men exposed to boron over the long-term. Ingesting large amounts of boron over short periods of time can harm the stomach, intestines, liver, kidney, and brain. Boron has not been classified as to its carcinogenicity.

\section{Cadmium}

Since cadmium does not corrode easily, it has many industrial uses. It is used for batteries, pigments, metal coatings, and plastics. However, exposure to cadmium can cause a number of adverse health effects. Ingesting high doses severely irritates the stomach, which leads to vomiting and diarrhea; inhaling high doses severely irritates the lungs. However, these high doses are extremely rare. Some effects seen at more common excess levels are kidney and lung damage (such as emphysema), and lung cancer. Other tissues reported to be injured by cadmium exposure in animals or humans include the liver, the testes, the immune and nervous systems, and the blood. However, reproductive and developmental effects have been observed in animals only. In general, soluble cadmium compounds are more toxic than insoluble compounds.

\section{Chromium}

Chromium is considered to be an essential nutrient that helps to maintain normal metabolism of glucose, cholesterol, and fat in humans. Signs of chromium deficiency include weight loss and impairment of the body's ability to remove glucose from the blood. One form of chromium that is thought to be an essential nutrient is trivalent chromium (chromium [III]). Small doses of this substance are necessary, but large doses may be harmful. One of the major forms of chromium is hexavalent chromium (chromium [VI]). This substance can result in adverse effects such as ulcers of the skin, irritation of the nasal mucosa and perforation of the nasal septum, and irritation of the gastrointestinal tract. It may also cause harm to the liver and kidney. Also, chromium and certain chromium compounds are known carcinogens.

\section{Cobalt}

Industrially, cobalt is used as a drier for paint and porcelain enamel that is applied to steel bathroom fixtures, large appliances, and kitchen wares. This trace element has both beneficial and harmful effects on human health. Cobalt is beneficial because it causes red blood cells to be produced and this property makes it useful for treating anemia. Cobalt is part of Vitamin $\mathrm{B}_{12}$, which is essential for human health. However, inhaling high levels can be harmful resulting in asthma, pneumonia, or wheezing. Additionally, cobalt is a possible human carcinogen.

\section{Copper}

Copper is a reddish metal that occurs naturally in rock, soil, water, sediment, and air. It is primarily used as the metal or alloy in the manufacture of wire, sheet metal, pipe, and other metal products. It is an essential element for all known living organisms. Many copper compounds can be recognized by their blue-green color. Although copper is necessary for good health, very large single or daily intakes of copper can be harmful. Long-term exposure to copper dust can irritate the nose, mouth, and eyes and can cause headaches, dizziness, nausea, and diarrhea. High doses can cause liver and kidney damage and even death. Copper is not known to cause cancer. 


\section{$\underline{\text { Lead }}$}

Lead is a naturally occurring bluish-gray metal. Lead has many uses, but health concerns have caused the use of lead in gasoline, paints, caulking, and pipe solder to be dramatically reduced in recent years. Regardless of the manner in which lead enters the body, its effects are the same. If a pregnant woman is exposed to lead, it can be carried to the unborn child resulting in premature birth, low birth weight, or even miscarriage. For infants or young children, lead exposure has been shown to decrease intelligence (IQ) scores, slow growth, and cause hearing problems. Exposure to high levels of lead can damage the brain and kidneys of adults and children. Exposure to lead may increase blood pressure and damage the male reproductive system. There is insufficient information about whether or not lead is a carcinogen, but tumors have developed in rats and mice that were given large doses.

\section{Manganese}

Manganese is a naturally occurring, steel gray, lustrous, hard, brittle metal. Potential symptoms of overexposure to this metal are parkinsonism, asthenia, insomnia, mental confusion, metal fume fever (dry throat, coughing, tight chest, shortness of breath, rales, and flu-like fever), lower back pain, vomiting, malaise, and fatigue (Budavari et al, 1996).

\section{Mercury}

Mercury is used in thermometers, dental fillings, and batteries. Salts of mercury are used as antiseptic creams and ointments, as well as in skin lightening creams. One form of organic mercury, methylmercury, bioaccumulates in the environment; that is, it can build up in certain fish. Mercury can easily enter the body by breathing its vapors or by eating organic forms of it in contaminated fish or other foods. Once mercury has entered the body, it may be months before all traces leave. Long-term exposure to either organic or inorganic mercury compounds can permanently damage the brain, kidneys, and developing fetuses. In general, the toxicity of inorganic mercury compounds increases with increasing solubility; in most cases, organic mercury compounds are more toxic than the inorganic ones (Ullmann, 1985). Mercury has not been shown to cause cancer in humans.

\section{Molybdenum}

Molybdenum is an essential trace element. Leguminous plants require molybdenum for bacterial fixation of nitrogen. In animals and humans it serves as a cofactor for the enzymes xanthin oxidase and aldehyde oxidase. The relationship between molybdenum deficiency and esophageal cancer in humans was first reported in 1966. Information on the toxicity of molybdenum compounds is scarce. In general, molybdenum compounds are of low order of toxicity; any toxic effects are primarily associated with soluble molybdenum compounds (Ullmann, 1985).

\section{Nickel}

Nickel is commonly used for nickel plating, to color ceramics, and to make some batteries. The highest level of exposure to nickel commonly comes from dietary intake because it occurs in most food items. Nickel is required to maintain health in animals, but a lack of nickel has not been found to cause adverse effects to the health of humans. Compared to oral intake, the typical amount of inhaled nickel is small. The most common adverse effects of nickel exposure noted in the general population are skin allergies. However, the U.S. Department of Health and Human Services has determined that nickel and certain nickel compounds may reasonably be anticipated to be carcinogens. 


\section{$\underline{\text { Selenium }}$}

Humans are exposed daily to selenium in their food. Generally, the levels in food are large enough to prevent diseases that may result from too little selenium. Though necessary for human health, selenium compounds can be harmful if daily levels are only somewhat higher than needed. A large ingested dose of sodium selenate or sodium selenite could be life threatening. Long-term exposure to amounts greater than necessary may cause brittle hair, deformed nails, or loss of feeling and control of the arms and legs. Selenium sulfide may reasonably be anticipated to be a carcinogen.

\section{Vanadium}

Vanadium is a component in the steel used for automobile parts, springs, and ball bearings. Small amounts of this element are also used in making rubber, plastics, and ceramics. Vanadium mainly enters the environment from natural sources and from burning fuel oils. Inhaling high levels of vanadium mainly affects the lungs, throat, and eyes. Workers who breathed it for short or long periods sometimes experienced lung irritation, coughing, wheezing, chest pains, runny noses, and sore throats. These effects stopped soon after they stopped breathing the contaminated air. Vanadium has not been classified as to its human carcinogenicity.

\subsubsection{Alkali Metals}

The term alkali metals refers to the Group IA elements of the periodic table: lithium, sodium, potassium, rubidium, and cesium. Francium is also a group IA element, but it is radioactive and very rare. They are all very reactive due to the single, rather loosely held valence electron. Because of their high reactivity, the alkali metals can be caustic. They are called alkali metals because the oxides of these metals are quite soluble in water and produce very basic (alkaline) solutions (Brady and Humiston, 1982). Often the alkaline earth metals (Group IIA of the periodic table) are also included in this class of metals for reporting purposes. This group includes beryllium, magnesium, calcium, strontium, and barium. Radium, like francium, is a radioactive element that is not reported as an alkali metal. Like the Group IA elements, the Group IIA elements also produce basic solutions when added to water. The alkaline earth metals are somewhat less reactive than the alkali metals because they contain two valence electrons that fill the valence $s$ orbital, making them more stable. The reactivity, metallic properties, and solubility of hydroxides decrease from the bottom to the top of the periodic table (Brady and Humiston, 1982). At high temperatures, molten salts of these metals may cause accelerated corrosion and degradation (Kofstad, 1988).

\subsubsection{Fluorine, Fluorides, and Hydrogen Fluoride}

Fluorine is a by-product of coal combustion that is released entirely in the gas phase. Being a very reactive species, it combines readily with other atoms and molecules to form fluorides. Fluorides are respiratory irritants, but their main environmental impact is on plants. Fluorides are phytotoxins that can cause leaf damage and defoliation (Zakrzewski, 1991). At low levels, fluorides are not believed to be harmful to human health. At high levels, fluorine gas and hydrogen fluoride (HF) gas can harm the lungs and heart and can cause death. Even at low levels, these gases can irritate the eyes, skin, and lungs. Contact with hydrogen fluoride can burn the eyes and skin. In humans, hydrogen fluoride causes lesions of the respiratory system as a result of inhalation of HF vapors and of the skin as a result of direct contact. An environment containing $50 \mathrm{mg} / \mathrm{m}^{3}$ of air is dangerous. In fact, this concentration should be considered as an upper limit for a five minute exposure and may have fatal results if the exposure is continued for more than 30 minutes (Ullmann, 1985). Small amounts of sodium fluoride help reduce 
tooth cavities, but high levels can be harmful. In children whose teeth are forming, high fluoride exposure can cause dental fluorosis with visible changes in the teeth. In adults, high fluoride exposure over a long time can lead to skeletal fluorosis with denser bones, joint pain, and limited joint movement. Fluorine, hydrogen fluoride, and fluorides have not been classified as carcinogens (U.S. Department of Health and Human Services, 1993).

\subsubsection{Hydrogen Chloride}

Hydrogen chloride severely irritates the eye and respiratory tract and, to a lesser extent, the skin. Inhalation causes irritation and damage to mucous membranes. Prolonged occupational exposure to excessive $\mathrm{HCl}$ concentration causes increased incidence of chronic bronchitis or stomach and intestinal disorders due to abnormal acid levels. Phytotoxic investigation has shown that plants have differing tolerances but lettuce, strawberries, spruce, birch, and apple trees are more sensitive than others. These plants should not be exposed to concentrations greater than $0.8 \mathrm{mg} / \mathrm{m}^{3}$ as a daily average or greater than $0.1 \mathrm{mg} / \mathrm{m}^{3}$ as a monthly average (Ullmann, 1985).

\subsubsection{Radon}

Radon is a naturally occurring, colorless, odorless, radioactive gas that is formed from the normal radioactive decay of uranium which is present in coal, as well as in most rocks and soils. When uranium decays to radon, the radon gas can travel through cracks and fissures in the ground. The most common form of exposure to higher levels of radon occurs indoors, particularly in basements. Radon itself poses little threat to human health. Radon decays much slower than the breathing process so it is almost completely exhaled. The half-life of Radon-222 is 3.825 days (Budavari et al, 1996). However, its decay products (daughters) are solids that can be inhaled. These daughters do emit gamma radiation, and longterm exposure to gamma radiation can lead to lung cancer and other pulmonary diseases (Cothern and Smith, 1987 and U.S. Department of Health and Human Services, 1993).

\subsection{Improvement}

Life cycle assessment results can be used to identify opportunities to reduce the environmental burden of the system through design improvements. This study has highlighted several negative environmental aspects that are either direct or indirect results of the production of electricity from coal. The discussion in the following sections highlights changes that would reduce these effects. At this point, no attempt has been made to gather additional data and perform supplementary LCAs on alternative process designs that may result in more environmentally friendly systems.

\subsection{Flue Gas Clean-up}

Many of the environmental burdens of coal-fired power systems are due to the production and use of limestone for flue gas clean-up. In addition to requiring a considerable amount of oil and thus energy, limestone production is responsible for more particulate emissions than any other process step in the Average and NSPS systems. Additionally, a significant amount of $\mathrm{CO}_{2}$ is emitted during both production and use of the limestone. Since the ratification of the 1990 Clean Air Act, limestone consumption for gas clean-up has increased by a factor of 2.5 within 5 years: 1,051 Mg/year in 1989 to 2,630 Mg/yr in 1994 (SRI International, 1996). 
Because of well-documented health effects, particulate emissions from coal-fired power plants are being regulated. Ironically, however, the amount of particulates emitted from producing the limestone required to operate the Average and NSPS plants is significantly higher than the regulated amount. For new plants built after 1978, the amount of allowable particulates emitted from the power plant is equivalent to 0.12 $\mathrm{g} / \mathrm{kWh}$ of net electricity produced (calculation made from regulation in 40 CFR 60.42a; Office of the Federal Register National Archives and Records Administration, 1996). By comparison, the particulate emissions for limestone production alone are 8.2 and $8.6 \mathrm{~g} / \mathrm{kWh}$ of net electricity produced averaged over the life of the system for the Average and NSPS system, respectively. These numbers are 68 and 72 times higher than the regulated amount. The particulate removal efficiency is $99.53 \%$ for the Average and NSPS plants and $99.75 \%$ for the LEBS plant. Therefore, it is also important to note that if the particulate emissions were not regulated, the emissions from these power plants could be 213 times higher for the Average and NSPS plants (29 g/kWh and $26 \mathrm{~g} / \mathrm{kWh}$, respectively) and 400 times higher for the LEBS plant $(21 \mathrm{~g} / \mathrm{kWh})$.

One of the best ways to improve the environmental impacts of electricity production from coal-fired boilers is through alternative means of gas clean-up. One example of a different technology is the LEBS plant, which eliminates the conventional limestone flue gas clean-up system and replaces it with a regenerable copper oxide scrubbing process. Table 51 compares the particulate and $\mathrm{CO}_{2}$ emissions as well as the energy and oil requirements for limestone FGC versus the copper oxide process. To make a fair comparison, all process steps required for each clean-up technology are included. The numbers for the limestone FGC include those resulting from the production and transportation of lime and limestone as well as the $\mathrm{CO}_{2}$ emissions from the limestone scrubbing reaction. Limestone is used for gas clean-up and lime is mixed with the FGC waste before landfilling. The numbers for the copper oxide process include those generated from the production and transportation of ammonia, copper oxide, and natural gas along with the $\mathrm{CO}_{2}$ emitted from combusting the natural gas at the power plant. The copper oxide is the main component of the flue gas clean-up catalyst, ammonia is injected for $\mathrm{NO}_{\mathrm{x}}$ reduction, and natural gas is used to regenerate the sorbent.

Thus for flue gas clean-up, the numbers in the Table 51 show that per unit of electricity produced, the LEBS system produces significantly fewer particulates, requires somewhat less energy, consumes a much smaller amount of oil, and emits considerably less $\mathrm{CO}_{2}$ than the Average and NSPS systems for the process steps associated with the flue gas clean-up technology. The particulates resulting from the operations required for clean-up for the Average and NSPS systems are 361 and 385 times higher than those from the LEBS system. The non-coal energy requirement associated with flue gas clean-up is only reduced from $0.26-0.27 \mathrm{MJ} / \mathrm{kWh}$ for the Average and NSPS systems to $0.21 \mathrm{MJ} / \mathrm{kWh}$ for the LEBS system which is roughly $38 \%-39 \%$ of the total system energy requirement for each of the three systems. Because a large amount of fuel oil is consumed during limestone quarrying, the oil resource consumption for the Average and NSPS plants are 27 and 29 times higher than that for the LEBS system for the process steps associated with flue gas clean-up. Additionally, since the majority of the $\mathrm{CO}_{2}$ emissions are emitted from the combustion of the coal the total $\mathrm{CO}_{2}$ emissions for each system is high. However, the $\mathrm{CO}_{2}$ emissions associated with the clean-up technology are 28-30 g/kWh lower for the LEBS system.

Limestone requirements at coal-fired power plants can also be reduced through the use of lower-sulfur coal. Coal production in the west, particularly in Wyoming and Montana, has increased several-fold during the past twenty years in response to tighter $\mathrm{SO}_{\mathrm{x}}$ regulations. However, the use of mid- and highsulfur coals is still commonplace. 
Table 51: Comparison of Limestone FGC versus Copper Oxide Process

\begin{tabular}{|c|c|c|c|c|c|c|c|c|}
\hline \multirow[t]{3}{*}{ System } & \multicolumn{8}{|c|}{ Stressor (a) } \\
\hline & \multicolumn{2}{|c|}{$\begin{array}{l}\text { Particulates } \\
(\mathrm{g} / \mathrm{kWh})\end{array}$} & \multicolumn{2}{|c|}{$\begin{array}{c}\mathrm{CO}_{2} \\
(\mathrm{~g} / \mathrm{kWh})\end{array}$} & \multicolumn{2}{|c|}{$\begin{array}{l}\text { non-coal energy consumption } \\
(\mathrm{MJ} / \mathrm{kWh})\end{array}$} & \multicolumn{2}{|c|}{$\begin{array}{l}\text { oil consumption } \\
(\mathrm{g} / \mathrm{kWh})\end{array}$} \\
\hline & $\begin{array}{l}\text { Associated with } \\
\text { gas clean-up } \\
\text { (b), (c) }\end{array}$ & $\begin{array}{l}\text { System } \\
\text { total } \\
\text { (d), (e) }\end{array}$ & $\begin{array}{l}\text { Associated with } \\
\text { gas clean-up } \\
\text { (b), (c), (f) }\end{array}$ & $\begin{array}{l}\text { System } \\
\text { total } \\
\text { (d), (e) }\end{array}$ & $\begin{array}{l}\text { Associated with } \\
\text { gas clean-up } \\
\text { (b), (c) }\end{array}$ & $\begin{array}{l}\text { System } \\
\text { total } \\
\text { (d), (e) }\end{array}$ & $\begin{array}{l}\text { Associated with } \\
\text { gas clean-up } \\
\text { (b), (c) }\end{array}$ & $\begin{array}{l}\text { System } \\
\text { total } \\
\text { (d), (e) }\end{array}$ \\
\hline Average & 9.03 & 9.21 & 40 & 1,022 & 0.26 & 0.72 & 5.2 & 11.5 \\
\hline NSPS & 9.62 & 9.78 & 42 & 941 & 0.27 & 0.71 & 5.5 & 11.3 \\
\hline LEBS & 0.025 & 0.11 & 12 & 741 & 0.21 & 0.54 & 0.19 & 4.9 \\
\hline
\end{tabular}

(a) Numbers are per $\mathrm{kWh}$ of net electricity produced averaged over the life of the system.

(b) For Average \& NSPS, this column includes only the process steps for limestone FGC which are: production, transportation, and use of lime and limestone.

(c) For LEBS, this column includes only the process steps for the copper oxide process which are: production, transportation, and use of ammonia, copper oxide, and natural gas.

(d) Coal transportation $=$ average user by river.

(e) Results are reported for the surface mining case. However, the underground mining numbers are similar to those listed here.

(f) Includes the $\mathrm{CO}_{2}$ emissions from the limestone scrubbing process (Average \& NSPS) or $\mathrm{CO}_{2}$ emissions from combustion of natural gas at the power plant (LEBS). 
It is not enough to simply improve the limestone scrubbing process because the impacts are primarily due to the production of limestone, not its use. The majority, $89 \%$, of the total system particulate emissions, and $25 \%-28 \%$ of the non-coal system energy consumption, come from limestone production. Unless technologies can be developed that reduce the impact of this clean-up process, the overall environmental impacts of power plants using limestone FGC will remain unchanged. Another option that will be compared to these technologies in a future LCA is an IGCC plant which utilizes gas cooling, scrubbing, acid gas removal, and sulfur recovery instead of limestone FGC. Scrubbing would be done with water, which can be treated and recycled, but some solid waste requiring disposal will be created. The acid gas removal system that removes sulfur compounds would consist of a solvent flowing between an absorber and stripper column. The hydrogen sulfide and sulfur dioxide would then be reacted via the Claus reaction $\left(2 \mathrm{H}_{2} \mathrm{~S}+\mathrm{SO}_{2} \rightarrow 3 \mathrm{~S}+2 \mathrm{H}_{2} \mathrm{O}\right)$ to produce elemental sulfur. However, no assumptions should be made regarding the environmental burdens from this technology relative to the three coal-fired power plants presented in this report. Predicting the outcome of the IGCC technology is not possible without looking at each process step in detail. It should not be assumed that the effects on the environment will be less than the Average and NSPS systems, only that a possibility exists due to the different gas clean-up technology.

\subsection{Methane from Coal Mining}

Coal mining is the major contributor in the overall system to methane emissions; greater than $99 \%$ of the total methane emissions come from coal mining for the Average and NSPS systems and greater than 94\% for the LEBS system. Higher rank coals, those containing more carbon, tend to contain more methane within the structure of the coal and in coalbed fractures. In general, the amount of methane released from a specific mine is a result of the temperature and pressure of the coal seam. Additionally, underground mines tend to emit higher amounts of methane than surface mines because the coal beds are deeper and therefore under greater pressure. The option of capturing some of the methane from underground mines for an alternative use was not explored in this LCA because the majority of U.S. coal mines vent methane to the atmosphere. In 1996, the total amount of methane emissions from coal mining in the U.S. were estimated to be 3.3 million $\mathrm{Mg}$ (U.S. EPA, 1998). Of this amount, 67\% came from underground mines, $13 \%$ was emitted from surface mines, and $20 \%$ resulted from post-mining activities. See Table 52, below, for a breakdown of the methane generated from each source (U.S. EPA, 1998). The amount of methane recovered and used from underground mines was equivalent to 0.7 million $\mathrm{Mg}$. This large amount is the result of 15 coal mines residing primarily in the states of Alabama, New Mexico, and Wyoming that have developed coalbed methane projects (U.S. EPA, 1998 and U.S. DOE, February 1995).

Table 52: Coal Mining Methane Emissions for 1996

\begin{tabular}{|c|l|c|}
\hline Mining type & \multicolumn{1}{|c|}{ Mining activity } & Methane generated (million Mg) \\
\hline \multirow{4}{*}{ Underground } & Post-mining & 0.6 \\
\cline { 2 - 3 } & Underground mining & 2.9 \\
\cline { 2 - 3 } & Recovered and used & 0.7 \\
\cline { 2 - 3 } & Total $=$ & 2.8 \\
\hline \multirow{3}{*}{ Surface } & Post-mining & 0.1 \\
\cline { 2 - 3 } & Surface mining & 0.4 \\
\cline { 2 - 3 } & Total $=$ & 0.5 \\
\hline
\end{tabular}


Underground mines can capture methane via their ventilation system or through a degasification system. All underground mines require a ventilation system, however, the methane will be contaminated with the air from the mined area. Thus, not only will the gas stream be diluted (typically $<1$ vol\% $\mathrm{CH}_{4}$ (U.S. EPA, February 1996)), it will also contain impurities such as dust, water vapor, $\mathrm{CO}, \mathrm{CO}_{2}$ and other gaseous compounds emitted during the mining process. Therefore, for most mines, economical recovery and use of methane gas from the ventilation system is unlikely. Currently, degasification systems are primarily installed in "gassy" mines to aid in the removal of methane for safety reasons. The following five degasification methods are used to extract methane gas from active coal mines: vertical wells, short horizontal boreholes, longhole horizontal boreholes, gob wells, and cross measure boreholes (U.S. EPA, February 1996). The first three types remove methane prior to mining whereas gob wells and cross measure boreholes recover methane from areas that have already been mined. Generally, methane removal from unmined areas results in a gas stream containing greater than $95 \%$ methane, however, the percent of methane recovered by the three different methods varies from $20 \%-70 \%$ of the amount that would normally be emitted to the atmosphere. The other two techniques, gob wells and cross measure boreholes, are used to recover methane from an area known as a "gob" which is the region of layers surrounding the coal seam that has collapsed after mining (U.S. EPA, February 1996). The methane recovery efficiency for these two methods ranges from $20 \%-50 \%$ and the initial gas composition may be nearly $100 \%$ methane but over time the purity decreases due to infiltration of the mine air and can be reduced to a concentration of only $30 \%$ methane. It should be noted that geologic conditions may restrict the type of drilling technology and thus may prohibit the use of one or more of the degasification techniques. Also when utilizing vertical wells, they must be drilled from the surface to the coal seam several years before mining.

The methane from an underground mine can be recovered for a variety of applications. The feasibility of economically recovering methane will depend on several factors including the amount of methane produced from the mine, purity of the gas stream, and mine location. Table 53 summarizes the potential applications for recovered methane along with some requirements for consideration.

Table 53: Applications and Requirements for Recovered Methane

\begin{tabular}{|c|c|c|}
\hline Application & Use & Requirements \\
\hline $\begin{array}{l}\text { Power } \\
\text { production }\end{array}$ & $\begin{array}{l}\text { - Used on-site and/or sold to the grid } \\
\text { (size range is typically below } 30 \mathrm{MW} \text { ) }\end{array}$ & $\begin{array}{l}\text { - Gas heating value must be high enough to operate a gas } \\
\text { turbine }\left(>13,000 \mathrm{KJ} / \mathrm{m}^{3} \text {; U.S. EPA February 1996) }\right. \\
\text { - For off-site, must have transmission or distribution } \\
\text { system in close proximity to the mine }\end{array}$ \\
\hline Fuel & $\begin{array}{l}\text { - Thermal dryers for coal preparation } \\
\text { - Boilers for space and water heating } \\
\text { - Stoves at mine site kitchens } \\
\text { - Water treatment }\end{array}$ & $\begin{array}{l}\text { - Gas quantity and quality must meet that required for } \\
\text { the on-site equipment }\end{array}$ \\
\hline Natural gas & - Sold to off-site natural gas operator & $\begin{array}{l}\text { - Must have high methane concentration; gas enrichment } \\
\text { if costly (methane content of a typical natural gas } \\
\text { stream in U.S. = 95.3\% but can range from } 81.3 \% \text { - } \\
97.5 \% \text {; World LNG Source Book, 1998) } \\
\text { - Must be processed to meet specifications of the } \\
\text { pipeline gas } \\
\text { - Transport distance to an existing pipeline system } \\
\text { should be minimized }\end{array}$ \\
\hline
\end{tabular}




\begin{tabular}{|l|l|l|}
\hline Application & \multicolumn{1}{|c|}{ Use } & \multicolumn{1}{c|}{ Requirements } \\
\hline $\begin{array}{l}\text { Chemical } \\
\text { feedstock }\end{array}$ & • Sold to off-site chemical manufacturer & $\begin{array}{l}\text { - Quantity must be large; usually only suitable for very } \\
\text { "gassy" mines } \\
\text { Must have high methane concentration; gas enrichment } \\
\text { is costly } \\
\text { Transport distance to the chemical manufacturer should } \\
\text { be minimized }\end{array}$ \\
\hline
\end{tabular}

Recovering some of the methane from underground mines is one design change that would reduce the amount of methane emitted to the atmosphere, possibly improving the environmental consequences from the coal-to-electricity system. Naturally, methane recovery for alternative uses would not be applicable to the surface mining case. The feasibility of each application listed above will be site specific. To incorporate these options into this LCA the trade-off of additional stressors associated with recovering the methane and its use in an alternative service compared to emitting methane to the atmosphere needs to be explored. For each option the stressors associated with the material and energy requirements for drilling and operating the wells or boreholes must be included. For power production some additional stressors will result from the manufacture and construction of equipment but a credit will be given for displacing power production. For the fuel, natural gas, and chemical feedstock options a credit would be given for displacing natural gas production. However, as described in section 6.2, methane emissions are extremely small compared to $\mathrm{CO}_{2}$ emissions, and essentially do not increase the GWP of the system. Therefore, efforts to reduce methane emissions from the mine will not greatly reduce the impact of coalfired power systems on the climate.

\subsection{Flue Gas Clean-up Waste \& Ash}

One highly publicized topic is waste resulting from coal-fired power plants. Two types of waste are produced by pulverized coal boilers: flue gas clean-up waste and ash. Statistically, about 3/4 of each waste stream is landfilled based on U.S. averages (American Coal Ash Association, 1996). The quantity of additional stressors, other than the waste itself, associated with the process of landfilling is small compared to the resource consumption, emissions, and energy use for the overall coal-to-electricity system. The real concern is the generation of a significant amount of waste material. Table 54 gives the amount of FGC waste and ash produced for each system examined in this LCA as well as the total amount of waste generated by the overall system. The LEBS plant uses a regenerable sorbent thus producing sulfuric acid or sulfur as a by-product instead of generating a solid waste. The majority of the waste produced by the Average and NSPS plants, over 55\%, is FGC waste and approximately $22 \%$ of the remaining waste is ash. The LEBS system reduces the total amount of waste generated by about $81 \%$.

Table 54: Power Plant FGC Waste and Ash

\begin{tabular}{|l|l|l|l|}
\hline \multicolumn{1}{|c|}{ Solid waste } & \multicolumn{2}{c|}{ Emission amount (g/kWh) (a) } \\
\cline { 2 - 4 } \multicolumn{1}{|c|}{} & Average & NSPS & \multicolumn{2}{c|}{ LEBS } \\
\hline FGC waste - dry total & $86.0(\mathrm{~b})$ & $91.5(\mathrm{~b})$ & $34.2(\mathrm{c})$ \\
FGC waste - dry landfilled & 64.7 & 68.9 & 0 \\
\hline Ash - moisture free total & 35.7 (d) & $32.6(\mathrm{~d})$ & $26.6(\mathrm{~d})$ \\
Ash - moisture free landfilled & 25.7 & 23.5 & 19.1 \\
\hline Total waste produced from the system (mining, & 110.4 & 113.4 & 20.7 \\
transportation, and power generation subsystems) (e), (f), (g) & & & \\
\hline
\end{tabular}


(a) Numbers are per kWh of net electricity produced averaged over the life of the system.

(b) For the base case $75.3 \%$ of FGC waste is landfilled.

(c) Used in the production of elemental sulfur, sulfuric acid, or phosphate fertilizer. Thus ultimately this stream is not a waste.

(d) For the base case $72.0 \%$ of ash is landfilled.

(e) Coal transportation $=$ average user by river.

(f) Results are reported for the surface mining case. However, the underground mining numbers are similar to those listed here.

(g) The amount of FGC waste and ash used in an alternative service is not included in this total.

A sensitivity analysis was performed on the amounts of FGC waste and ash recovered and used in alternative processes rather than landfilling (see section 8.4 for details). Obviously utilizing more of either the FGC waste or ash for an alternative service will reduce the total amount of waste produced from the system. However, the feasibility of utilizing either waste stream for another useful product depends on many factors, including the composition of the waste stream and the location of the coal-fired plant in relation to the processing plant or point of use for the alternative service.

\subsection{Summary of Results and Discussion}

Combustion of coal accounts for the majority of utility power generation in the United States; as a result, the additive environmental consequences of these systems can be quite large. Examining the resource consumption, energy requirements, and emissions from a life cycle point of view, including coal mining, transportation, and power production, can help to determine which areas have the greatest environmental burdens. It may then be possible to focus on improving process steps that have a large impact on the environment and human health. The following text summarizes the major findings from this coal-toelectricity LCA.

\section{1 $\mathrm{CO}_{2}$ Emissions}

In terms of total air emissions, $\mathrm{CO}_{2}$ is emitted in the greatest quantity, accounting for $98-99 \mathrm{wt} \%$ of the total air emissions for all systems examined. The majority, greater than $93 \%$, of the $\mathrm{CO}_{2}$ is emitted from the power generation subsystem during coal combustion. Because this amount is so large, it overshadows the $\mathrm{CO}_{2}$ from the other process steps within the life cycle assessment. In the Average and NSPS systems, a very significant portion of the $\mathrm{CO}_{2}$ not produced by the combustion of coal is generated while manufacturing the limestone and during the limestone scrubbing reaction. For these two systems, another major source of $\mathrm{CO}_{2}$ is coal transportation. For the LEBS system a significant amount of $\mathrm{CO}_{2}$ also comes from the transportation subsystem. However, because the traditional limestone scrubbing system is replaced with the copper oxide process, a large portion of the non-coal $\mathrm{CO}_{2}$ generated from this system is due to natural gas production and combustion for sorbent regeneration. 

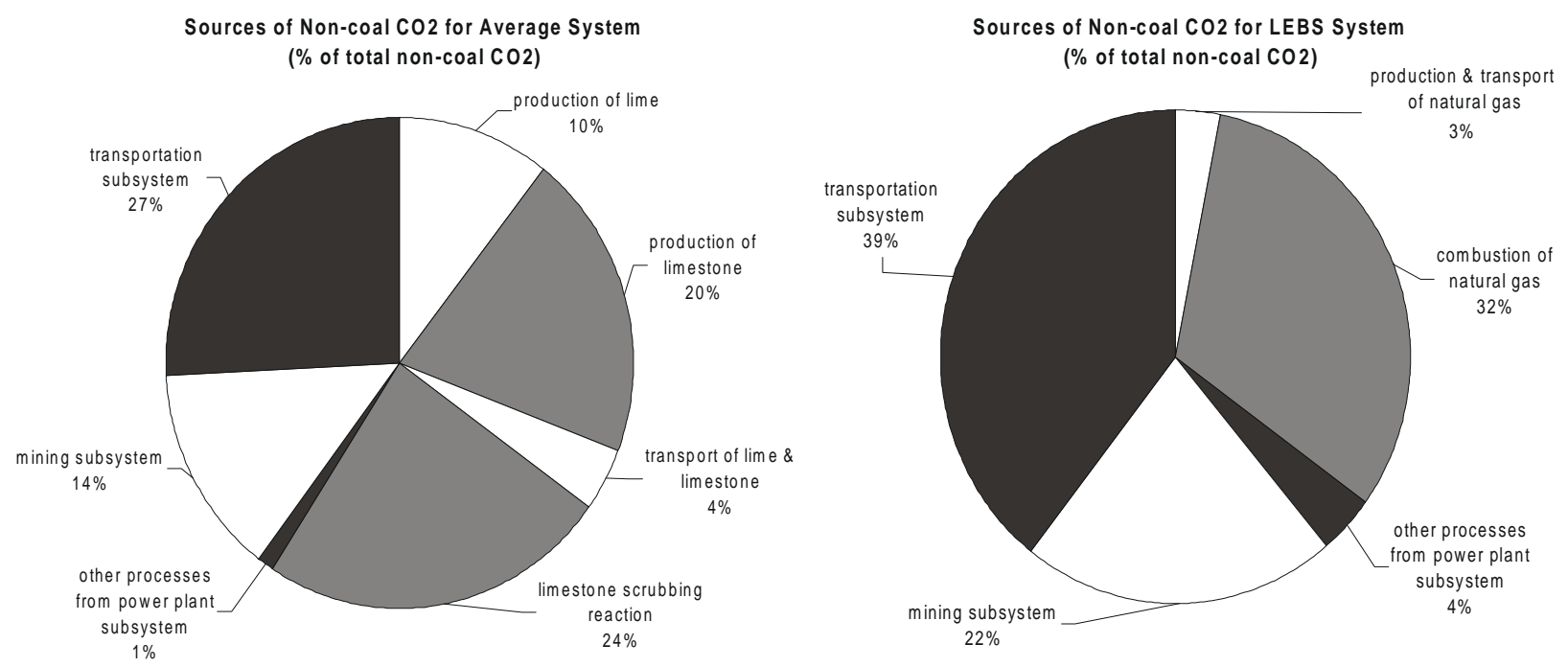

\subsection{Non- $\mathrm{CO}_{2}$ Air Emissions}

Aside from $\mathrm{CO}_{2}$, the next highest air emissions include particulates, $\mathrm{SO}_{\mathrm{x}}$, $\mathrm{NO}_{x}, \quad \mathrm{CH}_{4}, \mathrm{CO}, \quad$ and NMHCs. In all three systems, the power plant produces most of the $\mathrm{SO}_{x}$, $\mathrm{NO}_{\mathrm{x}}$, and $\mathrm{CO}$; nearly all of the methane comes from the coal mine. For the Average and NSPS systems, the majority (89\%) of the particulates come from the production of limestone. $\varangle$ For the LEBS system, the power plant is the largest single source of particulate emissions, generating $47 \%$ of all system particulates; at

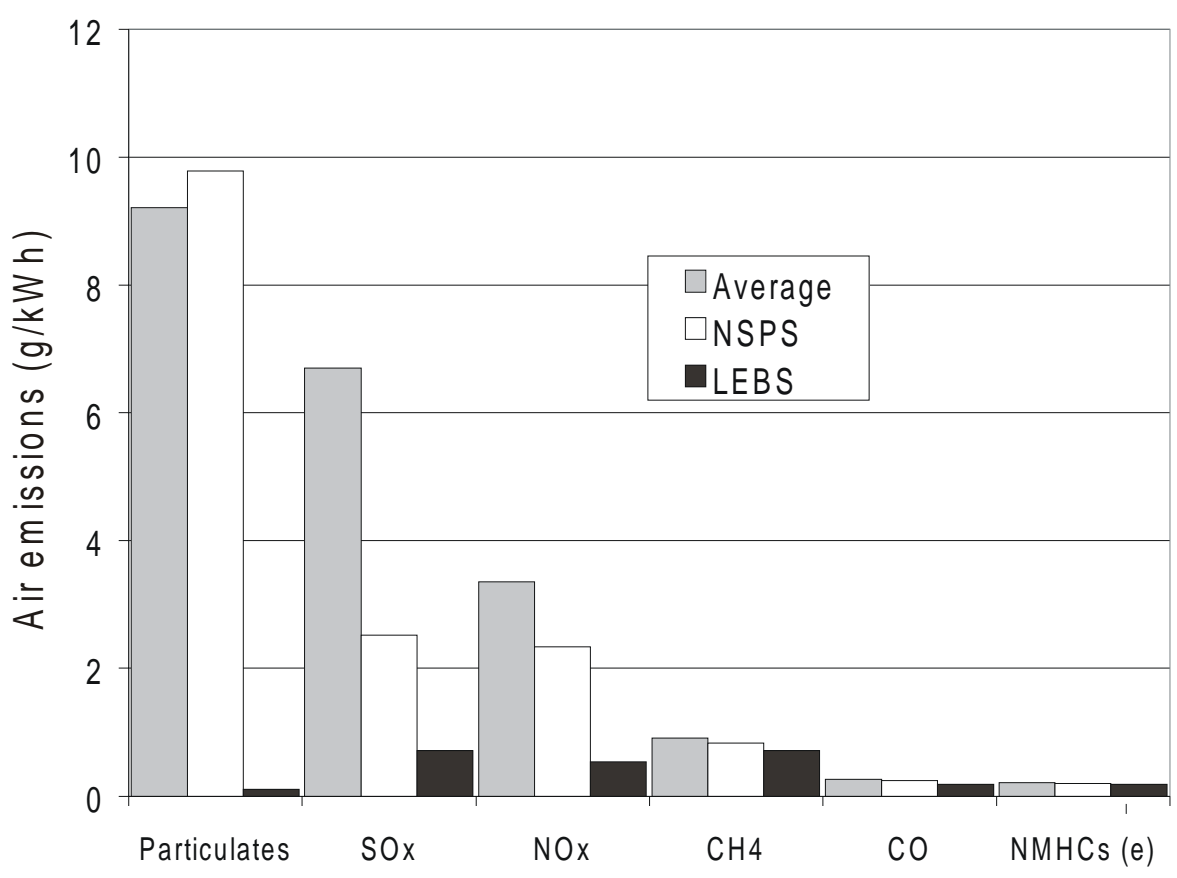
22\%, copper oxide production is responsible for the next highest rate of particulate emissions from this system. For all three systems, the NMHC emissions are evenly distributed among the mining, transportation, and power generation subsystems. However, for the LEBS system, it should be noted that a significant amount of the total NMHCs are emitted during natural gas production. 


\subsection{Flue Gas Clean-up}

The most significant finding of this study is that many of the environmental burdens of coal-fired power systems are due to the production and use of limestone for flue gas clean-up. In addition to requiring a considerable amount of oil and energy, limestone production is responsible for more particulate emissions than any other process step in the Average and NSPS systems. In fact, the amount of particulates from limestone production is greater than the limits set by federal air regulations for coal-fired power plants. Additionally, a significant amount of $\mathrm{CO}_{2}$ is emitted during both production and use of the limestone. Partly because of the use of a different gas clean-up technology, the total amount of particulates, oil, energy, and $\mathrm{CO}_{2}$ is less from the LEBS system.

\subsection{Transportation Subsystem}

Of the three subsystems examined (coal mining, transportation, and electricity production), transportation required the fewest resources and had the lowest air, water, and solid waste emissions even when considering the farthest user case. However, the energy consumption for this subsystem was significant (excluding the mine mouth case) because of the energy required to extract crude oil, distill it, produce a usable transportation fuel, and distribute it to refueling stations. For mine mouth operation, all resource consumption, emissions, and energy use constitute a small percentage of the total over the life of the system. However, for the other three transportation cases (average user by river, average user by land, and farthest user), oil consumption, as well as a few air and water emissions, are high. The transportation distance was found to have a substantial effect on the oil consumption, a few of the system's emissions, and the energy consumption whereas the mode of transportation has virtually no effect on the results.

\subsection{Energy}

Another import result of this study is that large amounts of energy are consumed in upstream processes. For all three power plant systems, the energy consumed to transport the coal by a combination of train and barge accounts for 30\%-33\% of the total non-coal system energy consumption (average user by river). For the Average and NSPS systems, limestone production accounts for a very significant portion of the non-coal system energy consumption. For the LEBS plant, the largest consumer of energy is the production and use of natural gas used to regenerate the flue gas clean-up sorbent. Overall, as expected, the largest amount of energy consumed in each system is the energy contained in the coal fed to the power plant. The coal energy is about $94 \%$ of the total system energy for each of the three power systems. 
Sources of Non-coal Energy for Average System (\% of total non-coal energy)

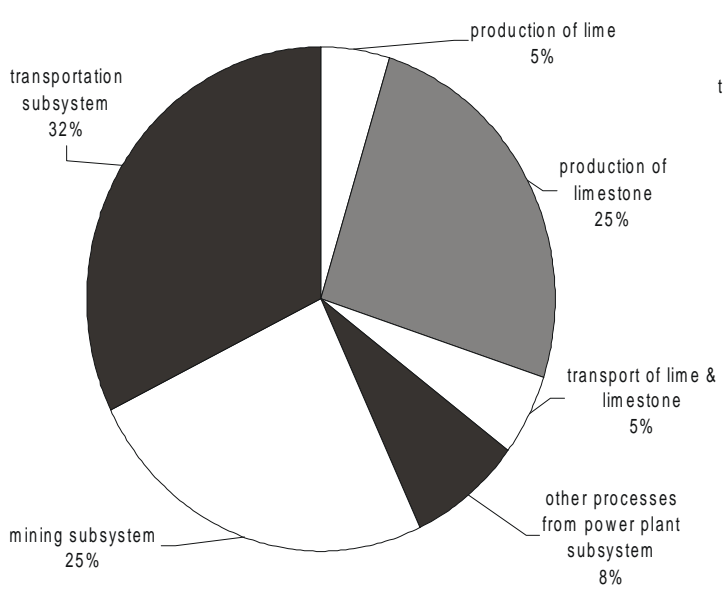

Sources of Non-coal Energy for LEBS System (\% of total non-coal energy)

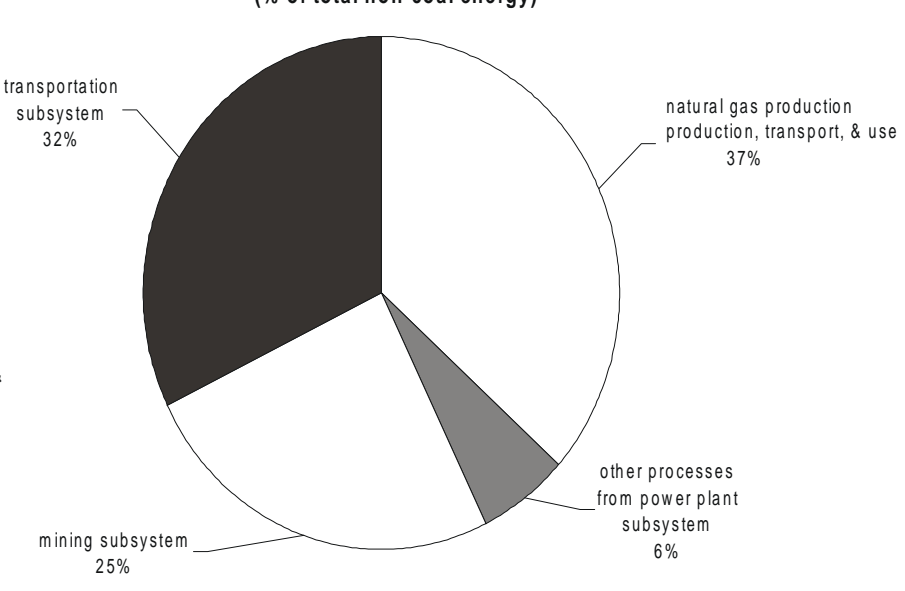

\subsection{Water Emissions, Wastes and Resources}

For all three systems, the majority of the water emissions occurred in the mining and power generation subsystems. The water emissions were evenly distributed between these two subsystems. In general, though, the total amount of water pollutants was found to be small compared to other emissions.

The majority of the solid waste in the Average and NSPS systems comes from the power plant in the form of flue gas clean-up waste (over 55\%) and ash (approximately 22\%) that must be landfilled. For these two systems, non-hazardous solid waste accounts for the balance of the total waste (about 19\%) most of which is generated during limestone production. The flue gas clean-up process for the LEBS system utilizes a regenerable sorbent; therefore, the bulk (87\%-93\%) of the waste from this system is ash. The remaining waste for the LEBS system is non-hazardous solid waste which primarily comes from the mining operations.

In terms of resource consumption, as expected, coal is used at the highest rate for all three systems. For the Average and NSPS systems, limestone and oil account for the majority of the remaining resources consumed. For the LEBS system, natural gas and oil account for the majority of the remaining resources consumed.

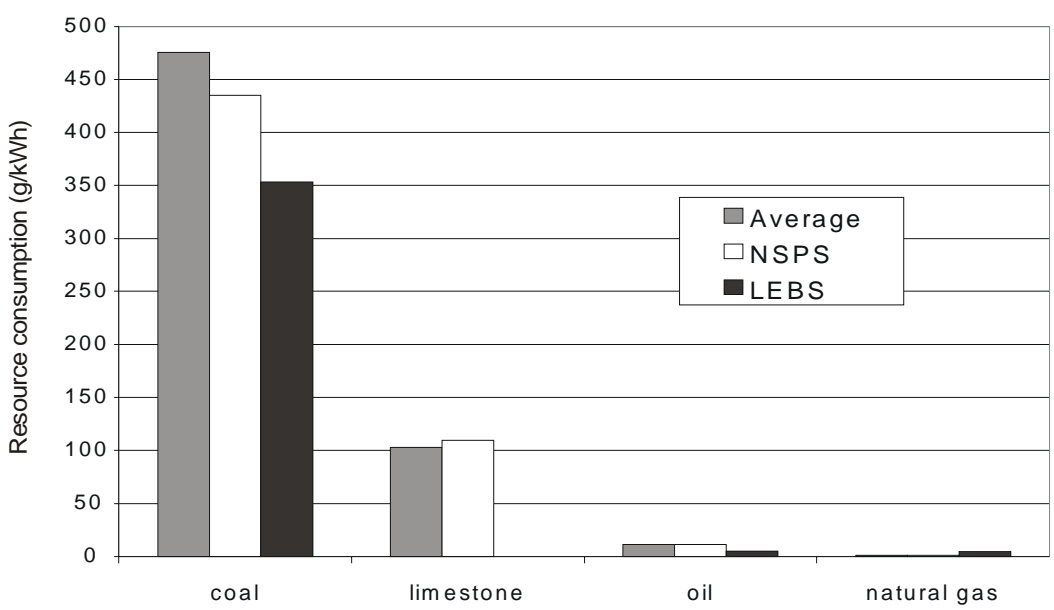




\subsection{Surface versus Underground Mining}

Overall, the environmental impacts from surface and underground mining are not significantly different in any of the three power plant systems examined. The main difference between these two mining techniques is that the surface mining subsystem results in a higher amount of airborne ammonia emissions due to the production of ammonium nitrate explosives which are used at the mine. Another important difference is that underground mining requires limestone which emits a large amount of particulates during its production. Therefore the particulate emissions will be higher for underground mining than for surface mining.

\subsection{Sensitivity Analysis Findings}

The sensitivity analysis identified the parameters that most affect the stressors produced by these systems. Overall, parameters that appreciably decrease the amount of coal consumed will impact the results of the study. In the case of coal consumption, the direct use of coal and the indirect requirements (e.g., transportation, limestone) related to the use of coal, are responsible for the vast majority of all emissions, resource consumption, and energy use.

\subsection{Improvement Opportunities}

Design changes can be made in several areas to improve the environmental impact of coal-fired power plants. Any parameter that reduces the coal consumption will have the largest effect on decreasing the systems resource consumption, energy usage, air and water emissions, and waste. Because the largest portion of several stressors comes from limestone production and use, changing the type of gas clean-up will affect the oil usage, energy consumption, particulate and $\mathrm{CO}_{2}$ emissions, and waste. Likewise, using the flue gas clean-up waste and ash in an alternative service can significantly reduce the total amount of waste from the system. However, factors such as the location of the power plant, waste composition, and economics play a large role in the plant's ability to incorporate the waste into a useful product. Additionally, the majority of the methane emissions come from the coal mine, therefore capturing the methane for uses such as power production, fuel use at the mine site (for water treatment or coal preparation), or additional natural gas supply may improve the environmental consequences of coal-fired power systems.

\subsection{Future Work}

The primary goal of this life cycle assessment is to assess the environmental aspects of producing electricity from a coal-fired power system. The focus of this initial work was on an inventory of all resources, environmental emissions, and energy flows of the system, studied in a cradle-to-grave manner. Ultimately, the resulting stressors will be compared to a previously completed LCA of electricity production from a biomass IGCC power plant (Mann and Spath, 1997). The next step will be to examine another power generation option of co-firing biomass in a coal-fired boiler. Additionally, LCA studies will be conducted on direct-fired biomass combustion and biomass gasification cofiring systems. Another coal technology, IGCC, using coal gasification, cold gas clean up, a gas turbine and a steam cycle will

be investigated. Also, a natural gas system will be studied for comparison to the biomass and coal systems. 


\subsection{Related Studies}

The following is a brief summary of publications related to this LCA. This list was generated from literature found while performing this assessment and therefore is not all inclusive of the previously published studies related to life cycle assessment of coal-to-electricity systems. In the past, much has been reported on the emissions and wastes from coal-fired power plants; however, little has been done from a life cycle point of view. Data from some of these sources were used in this LCA, as documented in the main body of this report.

\section{DynCorp EENSP, Inc. (1995).}

A life cycle assessment of $\mathrm{CO}_{2}$ and methane emissions from various renewable and non-renewable electricity production technologies was performed. The coal technology examined was a $500 \mathrm{MW}$ pulverized coal steam boiler system and the assessment included surface mining and transportation. Additional air emissions as well as resource consumption, energy use, water emissions and waste were not evaluated. Emissions factors from a modified version of the TEMIS model were used.

Nieuwlaar et al. (1996).

The article briefly describes LCA and the methodology they used in evaluating energy production systems. The following case studies were examined with their streamlined LCA method: gas engine cogeneration of heat and power, photovoltaic solar cell systems, and coal IGCC. The article stated that coal mining, treatment, and transport, were included in the IGCC study in addition to power plant construction, operation, and decommissioning. No details were given in this article; however, a document titled "Life Cycle Assessment of Integrated Coal Gasification Combined Cycle" is referenced and this report is discussed below. The results are categorized into energy use, waste production, exhaustion of raw materials, global warming, and acidification. A summary of some of the results for the six impact categories is given for each system examined.

\section{Nieuwlaar and Smit (November 1994).}

This report gives the results of a life cycle assessment for a $600 \mathrm{MW}$ coal IGCC system. The following power plant sections were included: an oxygen blown Shell gasifier, cyclone particulate removal, a selective absorbent (Slufinol) desulfurization section, a Claus unit, a Scot unit, a gas turbine, a HRSG, and a steam turbine. Coal mining and transport were also assessed. $50 \%$ of the coal is assumed to come from surface mining and the other half from underground mining. Since this study was done for a site located in the Netherlands, transportation of coal was assumed to be primarily from foreign sources in the U.S., Australia, Columbia, India, and Poland. Although detailed results are not given in the report, many of the conclusions are consistent with those obtained in the present study. The power plant is the major source of environmental impacts, a conclusion that corroborates our findings. Additionally, they found that recovering methane from the coal mine will not have a large impact on the total global warming value of the system. We found this to be true because even though the GWP of methane is 21 times higher than $\mathrm{CO}_{2}$, the amount of methane emitted is much smaller and therefore does not significantly change the GWP of the overall system. In contrast to our findings, their study shows no waste from the power plant, at a minimum, there is ash removed from the cyclone separators. They do not state what they do with the ash but it would not be reasonable to assume that $100 \%$ of the ash is used in some alternative source. Some portion of the ash must be landfilled. Like Nieuwlaar's 1996 article, listed above, the results are categorized into energy use, waste production, exhaustion of raw materials, global warming, and acidification. Exhaust of raw materials is shown to come solely from constructing the power plant. Because coal transport occurs over such long distances there should be a significant 
amount of oil consumed by this subsection. It is not clear why this does not show up in the exhaustion of raw materials category. This study includes the materials for constructing the power plant and the transportation vessels. It also includes the chemicals required in the gas clean-up and waste water treatment; however, it does not include any of the upstream process required for producing the chemicals and transporting them to the power plant. Overall, the study summarizes many important aspects of electricity production from coal using IGCC technology, however, a few details are lacking making some of their conclusions incomplete.

Oak Ridge National Laboratory and Resources for the Future. (September 1994).

Rather than a life cycle assessment, this study was primarily a methodology for estimating externalities of a coal fuel cycle including mining, transportation, and electricity generation as well as construction of the power plant. The technology examined is a pulverized fuel plant. Two specific cites are evaluated: east Tennessee and the Four Corners Region of New Mexico. The study considers health (employees and the public), environmental (ecosystem impacts), and non-environmental impacts (road damage, employment benefits, energy security, etc.).

Swiss Agency for the Environment, Forests and Landscape. (1998).

This is a study of cradle-to-grave inventories for aluminum, glass, plastics, paper, cardboard, and corrugated board, and steel sheets. The inventories include the following stressors: resources, energy, air emissions, water pollutants, and wastes. This two-volume report also gives the resource requirements and air and water emissions for six different electricity production systems: natural gas, oil, brown coal, hard coal, nuclear, and hydroelectric. However, details regarding resource extraction methods, modes of transportation, and power plant design/parameters are not included.

Vattenfall. (1996).

This document outlines the LCA work that Vattenfall has done for the following electricity generation systems: hydro, nuclear, oil condensing, natural gas combined-cycle, gas turbine, wind, and biofueled combined heat and power. The assessments are cradle-to-grave, incorporating aspects such as construction, demolition, and transportation, but only a select number of stressors were examined. Eleven resources were inventoried in these LCAs, the water emissions were recorded as the total amount of nitrogen, and the waste was categorized into radioactive, demolition and other. The only air emissions examined were $\mathrm{NO}_{x}, \mathrm{SO}_{2}, \mathrm{CO}$, dust, $\mathrm{HC}$, and $\mathrm{CO}_{2}$. It is not clear what is included in the $\mathrm{HC}$ category but since $\mathrm{CH}_{4}$ is one greenhouse gas that contributes to climate change it should probably be spelled out separately. The results of the life-cycle studies are being reviewed by Chalmers Contract Research Organization and the Swedish Environmental Research Institute.

Waku et al. (1995).

Energy and $\mathrm{CO}_{2}$ emissions were examined in a cradle-to-grave LCA for LNG combined cycle and coal IGCC systems incorporating $\mathrm{CO}_{2}$ recovery and sequestration. This paper briefly summarizes these results which come from on going research activities sponsored by New Energy and Industrial Technology Development Organization. They define net energy ratio to be the total energy produced by the system divided by the total energy required for construction, operation, and maintenance of the system. This number does not include the energy in the natural gas or coal and therefore can only be compared to our external energy ratio. It appears that no other stressors have been examined but that their next step is to include inventories of air emissions such as $\mathrm{NO}_{\mathrm{x}}$ and $\mathrm{SO}_{\mathrm{x}}$. 


\subsection{Acknowledgments}

We would like to acknowledge the U.S. Department of Energy's Biomass Power Program for funding this work, and John Marano and Massood Ramezan for providing the power plant operating data. Dr. Richard Bain, Dr. Ralph Overend, and Kevin Craig also provided extensive technical guidance and review. Additionally, our thanks to the many people outside of NREL who have contributed their time and effort in assisting us, specifically, Dr. Matt Hrebar from the Colorado School of Mines Mining Department for providing ideas on how to find the best references and data for the coal mining subsystem, and Vince Camobreco of Ecobalance for his technical support for the TEAM ${ }^{\circledR}$ and TEAM Plus ${ }^{\circledR}$ software. 


\subsection{References and Pertinent Literature}

U.S. Department of Health and Human Services. (1993). Agency for Toxic Substances and Disease Registry (ATSDR). Atlanta, Georgia.

American Coal Ash Association. (1996). Annual Coal Combustion Product (CCP) Survey Report. 1996 Coal Combustion Product (CCP)- Production and Use (Short Tons). 2760 Eisenhower Avenue, Suite 304, Alexandria, VA 22314-4553.

Barry Lawson Associates. (1997). Co-Firing II - Cofiring Coal and Biomass in Utility Boilers. Report of a One-Day Forum. Sponsored by U.S. DOE - Office of Utility Technologies, Northeast Regional Biomass Program, Southeast Regional Biomass Program, and Great Lakes Regional Biomass Program, January.

Barton, K. (1976). Protection Against Atmospheric Corrosion. London: John Wiley \& Sons, Inc.

Bechtel; Amoco. (March 1993). Direct Coal Liquefaction Baseline Design and System Analysis. Final Report on Baseline and Improved Baseline. Volume III Options to Baseline Design. Worked performed for the U.S. Department of Energy under contract \#DEAC22 90PC89857.

Benson, S.A.; Steadman, E.N.; Mehta, A.K.; Schmidt, C.E. (1994). Trace Element Transformations in Coal-Fired Power Systems. Amsterdam: Elsevier.

Brady, J.E.; Humiston, G.E. (1982). General Chemistry: Principles and Structure. New York: John Wiley \& Sons, Inc.

Boustead, I.; Hancock, G.F. (1979). Handbook of Industrial Energy Analysis. New York: John Wiley \& Sons, pp. 120-146.

Budavari, S.; O’Neil, M.J.; Smith, A.; Heckelman, P.E; Kinneary, J.F. (1996). The Merck Index: An Encyclopedia of Chemicals, Drugs, and Biologicals. Twelfth Edition. Whitehouse Station, NJ: Merck \& Co.

Bunce, N. (1994). Environmental Chemistry. Second Edition. Winnepeg: Wuerz Publishing.

Chameides, W.L.; Perdue, E.M. (1997). Biogeochemical Cycles. New York: Oxford University Press.

Coal Age Equipment Guide. (1982). McGraw-Hill, Inc., New York, New York.

Collins, S. (June 1994). “Gas Turbine Power Plants - Special Report.” Power. Vol. 138. No. 6.

Colorado Energy Research Institute. (April 1976). Summary Report. Net Energy Analysis: An Energy Balance Study of Fossil Fuel Resources. Golden, CO.

Combustion Engineering, Inc. (1981). Combustion, Fossil Power Systems: A Reference Book on Fuel Burning and Steam Generation. 3rd Edition. 
Cothern, C.R.; Smith, J.E., Jr. (1987). Environmental Radon. New York: Plenum Press.

Damberger, H.; Stiff, B.; Hines, J. (1997). Coal Industry in Illinois. Illinois State Geological Survey. Champaign, IL.

Damberger, H. (1998). Personal correspondence. Illinois State Geological Survey. Champaign, IL.

Darguzas, J.N.; Giermak, E.A.; Gielda, G.S.; Litka, A.F. (1997). "Engineering Development of Advanced Coal-Fired Low Emission Boiler Systems (LEBS). Phase III Report, Volume II - Revised Commercial Generating Unit Design," submitted by DB Riley, Inc., Worchester, Massachusetts. Prepared for the U.S. Department of Energy. Federal Energy Technology Center. DOE contract no. DE-AC22-92PC92158.

Duda, J.R.; Hemingway, E.L. (1976). Basic Estimated Capital Investment and Operating Costs for Underground Bituminous Coal Mines Developed for Longwall Mining. U.S. Department of the Interior. Bureau of Mined Information Circular 8715.

DynCorp EENSP, Inc. (1995). Assessment of the Environmental Benefits of Renewables Deployment: A Total Fuel Cycle Analysis of the Greenhouse Gas Impacts of Renewable Generation Technologies in Regional Utility Systems. Prepared for the National Renewable Energy Laboratory, contract no. DE-AC02-83CH10093, May.

Ecobalance, Inc. (1997). Comparison of Coal Combustion Products (CCPs) Used as Structural Fill Material vs. Disposal in a Landfill Using the Life Cycle Assessment Framework. Prepared for the American Coal Ash Association, 2760 Eisenhower Avenue, Suite 304, Alexandria, VA 22314-4553, September.

Encyclopedia Americana, Intl. Ed. (1986). Danbury, CT: Grolier Inc.

Evans, R.J.; Bitler, J.R. (1977). Coal Surface Mining Reclamation Costs. U.S. Department of the Interior. Bureau of Mines Information Circular 8695.

Finlayson-Pitts, B.J; Pitts, J.N., Jr. (1986). Atmospheric Chemistry: Fundamentals and Experimental Techniques. New York: John Wiley \& Sons, Inc.

GAI Consultants, Inc. (1995). Coal Ash Disposal Manual: Third Edition. Prepared for the Electric Power Research Institute, report no. EPRI TR-104137, research project no. 3176-7, January.

Green, L.E.; Palowitch, E.R. (1977). Comparative Shortwall and Room-and-Pillar Mining Costs. U.S. Department of the Interior. Bureau of Mines Information Circular 8757.

Hinser, D. (1998). Personal correspondence. Joy Mining Machinery Products. Franklin, PA.

Houghton, J.T.; Meira Filho, L.G.; Callander, B.A.; Harris, N.; Kattenberg, A.; Maskell, K., eds. (1996). Climate Change 1995. The Science of Climate Change. Published for the Intergovernmental Panel on Climate Change. New York: Cambridge University Press. 
IFC Resources Incorporated. (1990). Methane Emissions From Coal Mining. Prepared for the United States Environmental Protection Agency. Office of Air and Radiation. EPA-400/9-90/008. Washington, D.C.

Illinois Coal Development Board. (1996). Outlook for the Illinois Coal Industry. October.

Illinois State Department of Natural Resources. Office of Mines and Minerals. (1996). Annual Coal Mine Operator Report. Year ending 1996.

Inland Waterways Mileage Guide. (1980). Jeffersonville, IN: American Commercial Barge Line Company.

Keeling, C.D.; Whorf, T.P. (August 1998). Scripps Institution of Oceanography (SIO). University of California. La Jolla, California. 92093-0220.

Keeth, R.J.; Miranda, J.E.; Reisdorf, J.B.; Scheck,R.W. (1983). Economic Evaluation of FGD Systems. Volume 1: Throwaway FGD Processes, High- and Low-Sulfur Coal. EPRI CS-3342. Research Project 1610-1. Denver, CO: Stearns-Roger Engineering Corporation, December.

Keolian, G.A.; Lewis, G. (1997). Application of Life-cycle Energy Analysis to Photovoltaic Module Design. Progress in Photovoltaics: Research and Application. Vol. 5, pp. 287-300.

Kerr, R. (1998). Personal correspondence. Earthmoving Machinery Inc. Denver, CO.

Kirk-Othmer's Encyclopedia of Chemical Technology. (1993). 4th Edition, Vol. 1, pp. 764; Vol. 2, pp. 693-694; Vol. 5, pp. 40; Vol. 23, pp. 446-447.

Kirkwood, R.C.; Longley, A.J. (1995). Clean Technology and the Environment. London: Chapman \& Hall.

Kofstad, P. (1988). High Temperature Corrosion. London: Elsevier Applied Science.

Ladino, R.H.; Miller E.H.; Waltz, R.J.; Leaver, D.E.; Brown R.G. (1982). Engineering Assessment of an Advanced Pulverized-Coal Power Plant. Westinghouse Electric Corporation. Final Report. EPRI CS-2223.

Laidler, K.J.; Meiser, J.H. (1995). Physical Chemistry. Second Edition. Boston: Houghton Mifflin Company.

Larinoff, M. (October, 1994). Specifying Better-Performing Air Cooled Condensers. Power Engineering. Vol. 98. No. 10. pg 37.

Levi, B.G.; Hafemeister, D.; Scribner, R. (1992). "Global Warming: Physics and Facts." AIP Conference Proceedings No. 247; Washington, D.C. American Institute of Physics.

Lucas, Criss. (1998). Personal correspondence. Norberg Sales Corp., Western Region. Englewood, CO. 
Macalady, D.L. (1998). Perspectives in Environmental Chemistry. New York: Oxford University Press.

Mann, M.K.; Spath, P.L. (1997). Life Cycle Assessment of a Biomass Gasification Combined-Cycle Power System. National Renewable Energy Laboratory, Golden, CO, TP-430-23076.

Martin, P. (1998). Personal correspondence. Martin Consultants, Inc. Golden, CO.

Martin, J.W.; Martin, T.J.; Bennett, T.P.; Martin, K.M. (1982). Surface Mining Equipment. First Edition. Martin Consultants, Inc., Golden, CO.

Meridian Corporation. (1989). Energy System Emissions and Material Requirements, for the U.S. Department of Energy, Deputy Assistant Secretary for Renewable Energy, Washington, D.C., February.

Moran, M.J. (1989). Availability Analysis - A Guide to Efficient Energy Use. Corrected Edition. American Society of Mechanical Engineers Press. New York.

National Research Council. (1991). Rethinking the Ozone Problem in Urban and Regional Air Pollution. National Academy Press, Washington, D.C.

Nieuwlaar, E.; Alsema, E.; Van Engelenburg, B. (1996). "Using Life-Cycle Assessments for the Environmental Evaluation of Greenhouse Gas Mitigation Options." Energy Conversion Management. Vol. 37, No. 6-8, pp. 831-836.

Nieuwlaar, E.; Smit, R. (November 1994). Life Cycle Assessment of Integrated Coal Gasification Combined Cycle. Utrecht University. Department of Science, Technology and Society. Report No. 94021.

Oak Ridge National Laboratory and Resources for the Future. (September 1994). Estimating Externalities of Coal Fuel Cycles. Report No. 3 on the External Costs and Benefits of Fuel Cycles. Work performed for the U.S. Department of Energy and the Commission of the European Communities. Published by Utility Data Institute and Integrated Resource Planning Report. McGraw Hill, Inc.

Office of the Federal Register National Archives and Records Administration. (October 1998) Code of Federal Regulations. Protection of Environment. Title 40. Part II. Finding of Significant Contributions and Rulemaking for Certain States in the Ozone Transport Assessment Group Region for Purposes of Reducing regional Transport of Ozone; Rule. Parts 51, 72, 75, and $96 .$.

Office of the Federal Register National Archives and Records Administration. (July 1996) Code of Federal Regulations. Protection of Environment. Title 40. Part 60.

International Energy Agency, Organization for Economic Co-operation and Development (IEA/OECD). (1991). Greenhouse Gas Emissions: The Energy Dimension. Paris, France: OECD.

Peele, R. (1927). Mining Engineers' Handbook. Second Edition. John Wiley \& Sons, Inc. 
Persse, F.H.; Lockhard, D.W.; Lindquist, A.E. (1977). Coal Surface Mining Reclamation Costs in the Western United States. U.S. Department of the Interior. Bureau of Mines Information Circular 8737.

Pimentel, D. (1980). Handbook of Energy Utilization in Agriculture. Boca Raton, Florida: CRC Press, Inc.

Radziwon, A.; Winter, E. (1996). Summary of Air Toxics Emissions Testing at Sixteen Utility Power Plants. Prepared for the U.S. Department of Energy by Burns and Roe Services Corporation, contract no. DE-AC22-94PC92100, July.

Rand McNally Commercial Atlas and Marketing Guide. (1994). 125th ed. Chicago, IL: Rand McNally \& Co.

Ruth, L.A. (1997). “The U.S. Department of Energy's Combustion 2000 Program: Clean, Efficient Electricity from Coal.” Energy Conversion Management. Vol. 38, No. 10-13, pp. 1249-1257.

Schultz, S.C.; Kitto, J.B. (1992). STEAM Its Generation and Use. Barberton, Ohio: Babcock \& Wilcox.

Schlesinger, W.H. (1991). Biogeochemistry: An Analysis of Global Change. San Diego: Academic Press.

SETAC Foundation. (1991). A Technical Framework for Life-Cycle Assessment. Society of Environmental Toxicology and Chemistry and SETAC Foundation for Environmental Education, Inc., Washington, D.C.

Shreir, L.L. (1978). Corrosion, Vol. 1: Metal/Environment Reactions. London: Newnes-Butterworths.

Sidney, K.; Hemingway, E.L.; Berkshire, L.H. (1976). Basic Estimated Capital Investment and Operating Costs for Coal Strip Mines. U.S. Department of the Interior. Bureau of Mined Information Circular 8703.

Society for Environmental Toxicology and Chemistry. (1997). "Life-Cycle Impact Assessment: The State-of-the-Art." Report of the SETAC LCA Impact Assessment Workgroup, SETAC LCA Advisory Group.

Spindler, D. (1998). Personal correspondence and reclamation plan. State of Illinois. Illinois Department of Natural Resources. 524 South Second Street, Springfield, IL.

SRI International. (1996). Chemical Economics Handbook. Limestone. 214.1000A.

Swiss Agency for the Environment, Forests and Landscape. (1998). Life Cycle Inventories for Packagings. Volume I \& II. Environmental Series No. 250/I \& II. Berne Swiss Packaging Institute, Berne. 
The American Institute of Mining, Metallurgical, and Petroleum Engineers, Inc. (1968). Coal Preparation. Third edition. Baltimore, Maryland: Port City Press, Inc.

The American Institute of Mining, Metallurgical, and Petroleum Engineers, Inc. (1968). Surface Mining. First Edition. York, Pennsylvania: The Maple Press Company.

Tyson, P.E.; Blackstock, T. (March 1995). "Coal Combustion Byproducts (CCBs)--Overview of Applications and Opportunities in the U.S.A." Society of Mining Engineers Annual Meeting. Denver, Colorado.

Ullmann's Encyclopedia of Industrial Chemistry. (1986). Vol. A2, pp. 261-263; Vol. A5, pp. 172-173; Vol. A7, pp. 570-571, Weinheim (Federal Replublic of Germany): VCH.

Ullmann's Encyclopedia of Industrial Chemistry. (1985). Fifth Edition. Weinheim (Federal Republic of Germany): VCH.

U.S. Department of Energy. (July 1998). Annual Energy Review 1997. Energy Information Administration, Office of Energy Markets and End Use. DOE/EIA-0384(97). Washington, D.C.

U.S. Department of Energy. (September 1996). A Comprehensive Assessment of Toxic Emissions from Coal-Fired Power Plants: Phase I Results from the U.S. Department of Energy Study. Work performed by Energy \& Environment Research Center. Prepared for the U.S. Department of Energy, Pittsburgh Energy Technology Center and Morgantown Energy Technology Center, contract no. DE-FC21-93MC30097.

U.S. Department of Energy. (1996). Methane Emissions from Coal Mining and Post-Mining Activities, 1989-1996. Revision of data from Emissions of Greenhouse Gases in the United States 1995. Energy Information Administration. DOE/EIA-0573(95). Washington, D.C.

U.S. Department of Energy. (February 1995). Coal Data: A Reference. Energy Information Administration, Office of Coal, Nuclear, Electric and Alternative Fuels. DOE/EIA-0064(93). Washington, D.C.

U.S. Department of Energy, Assistant Secretary for Environmental Protection, Safety, and Emergency Preparedness. (1983). Energy Technology Characterizations Handbook, Environmental Pollution and Control Factors. Third edition, DOE/EP-0093, Washington, D.C.

U.S. Environmental Protection Agency. (March 1998). Inventory of U.S. Greenhouse Gas Emissions and Sinks: 1990-1996. EPA-236-R-98-006. Office of Policy, Planning, and Evaluation. Washington, D.C.

U.S. Environmental Protection Agency. (February 1996). A Guide for Methane Mitigation Projects. Gas-to-Energy at Coal Mines. Draft (6202 J). Office of Air \& Radiation. Developed for the Coalbed Methane Outreach Program. Edited by D. Kruger and C. Schultz. 
U.S. Environmental Protection Agency. (1995). Compilation of Air Pollutant Emission Factors. United States Environmental Protection Agency. AP-42. Vol. 1, parts 1, 2, and 3; Stationary Point and Area Sources. Ann Arbor, MI.

U.S. Environmental Protection Agency. (1995). Toxics Release Inventory. Office of Pollution Prevention. Washington, D.C.

U.S. Environmental Protection Agency. (September 1991). Toxics in the Community: National and Local Perspectives. EPA Office of Toxic Substances. Washington, D.C.

U.S. Environmental Protection Agency. (1985). Compilation of Air Pollutant Emission Factors. United States Environmental Protection Agency. AP-42. Vol. 1, parts 1, 2, and 3; Stationary Point and Area Sources. Ann Arbor, MI.

Utility Data Institute. (1993). Scrubber Database, cost and performance. Utility Data Institute, $1700 \mathrm{~K}$ Street N.W., Suite 400, Washington, D.C., 20006.

Utility Data Institute. (1993). U.S. Coal Plant Statistics, UDI-022-93, April. Utility Data Institute, 1700 K Street N.W., Suite 400, Washington, D.C., 20006.

Utility Data Institute. (1996). UDI Environmental Database. Utility Data Institute, 1700 K Street N.W., Suite 400, Washington, D.C., 20006.

Vattenfall. (1996). Life Cycle Assessment for Vattenfall's Electricity Generation. Summary Report. S16287 Stockholm, Sweden.

Waku, H.; Tamura, I.; Inque, M.; Akai, M. (1995). "Life Cycle Analysis of Fossil Power Plant with $\mathrm{CO}_{2}$ Recovery and Sequestering System.” Energy Conversion Management. Vol. 36, No. 6-9, pp. 877-880.

Walas, S.M. (1988). Chemical Processes and Equipment: Selection and Design. Butterworths Monographs in Chemical Engineering. Butterworth-Heinmann.

Warneck, P. (1988). Chemistry of the Natural Atmosphere. San Diego: Academic Press.

Watson, R.T.; Zinyowera, M.C.; Moss, R.H.; Dokken, D.J., ed. (1998). The Regional Impacts of Climate Change: An Assessment of Vulnerability. Published for the Intergovernmental Panel on Climate Change. New York: Cambridge University Press.

Wayne, R.P. (1991). Chemistry of Atmospheres. Oxford: Oxford University Press.

World LNG Source Book. (1998). Zeus Development Corporation. Houston, Texas.

Zakrzewski, S.F. (1991). Principles of Environmental Toxicology. Washington, D.C.: American Chemical Society. 
Appendix A: Graphical Representation of the LCA System in TEAM ${ }^{\circledR}$ 


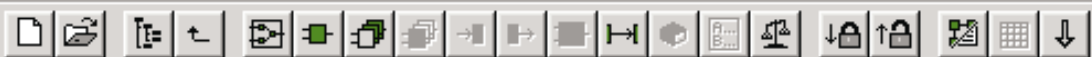

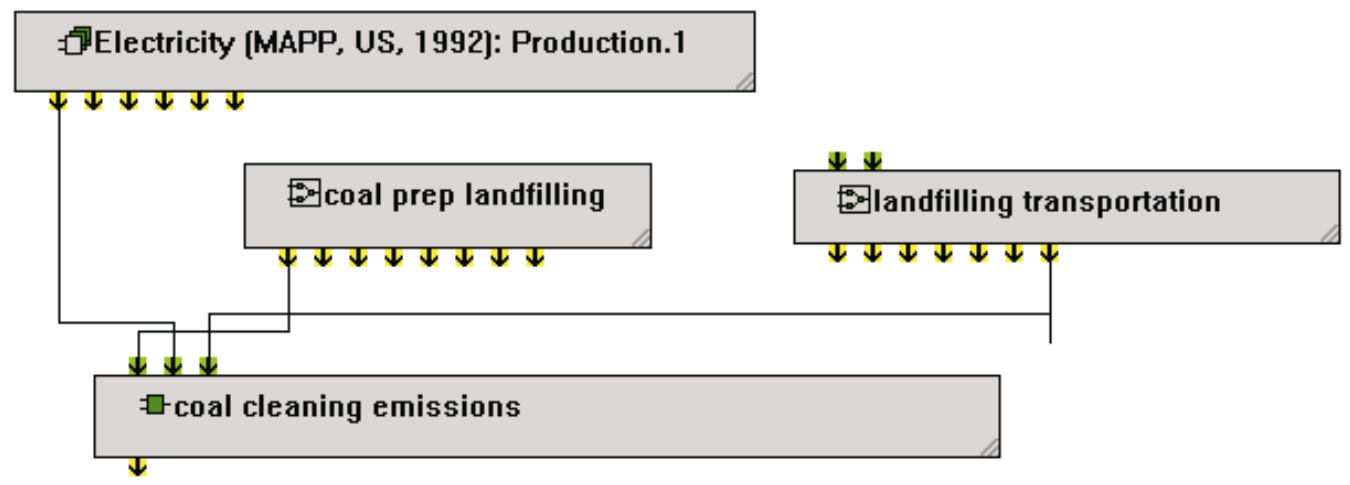

1

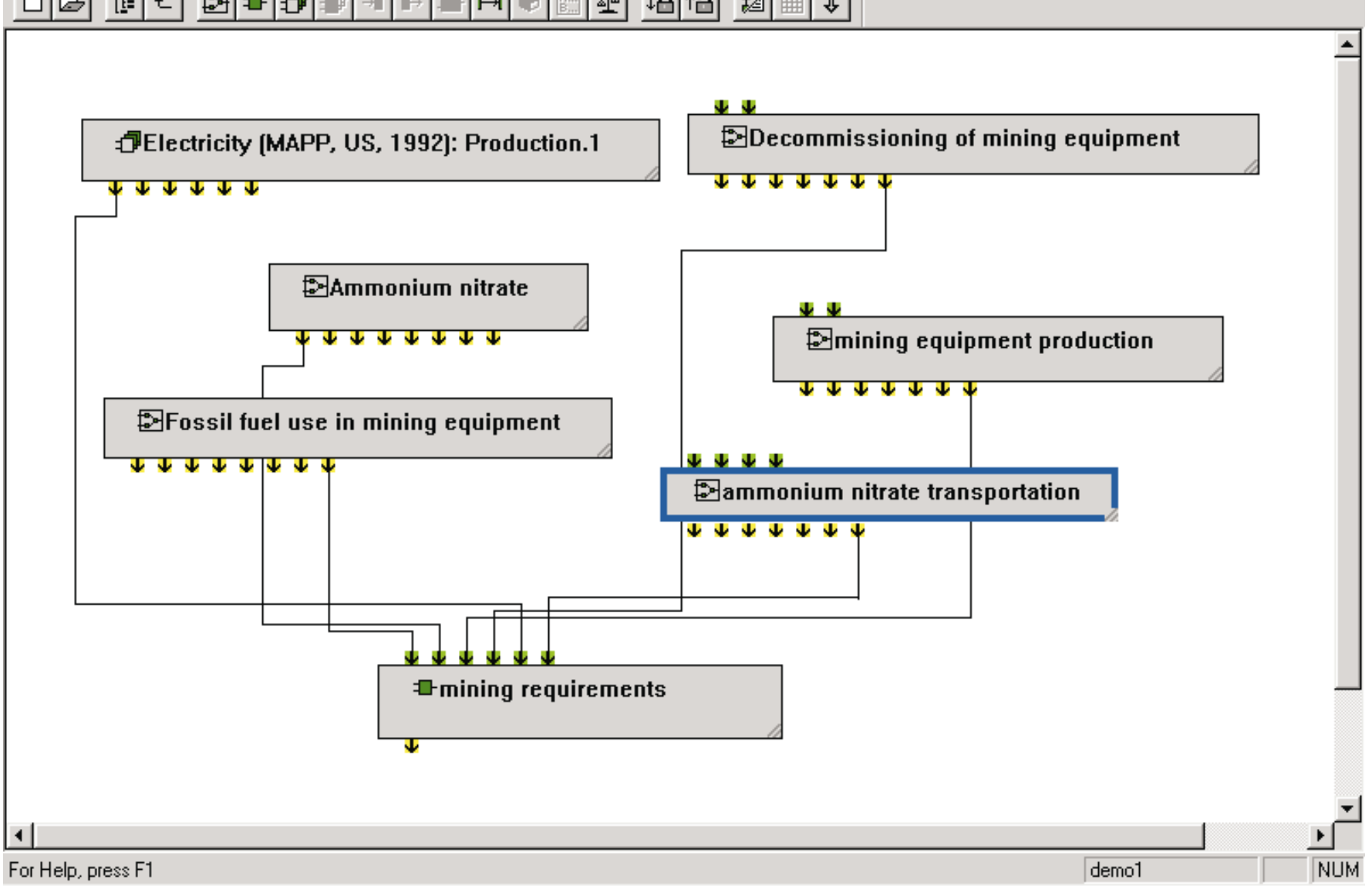




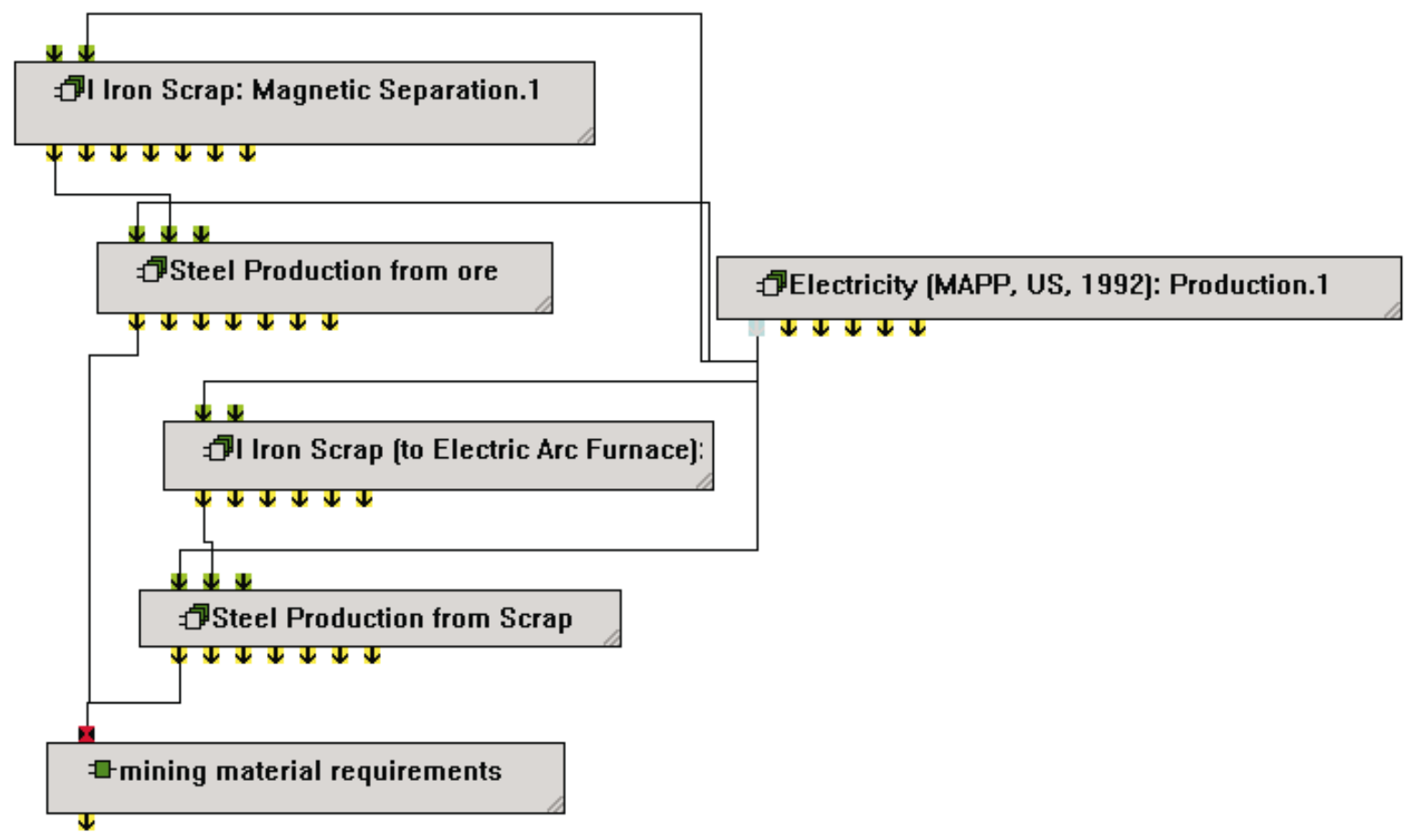

1

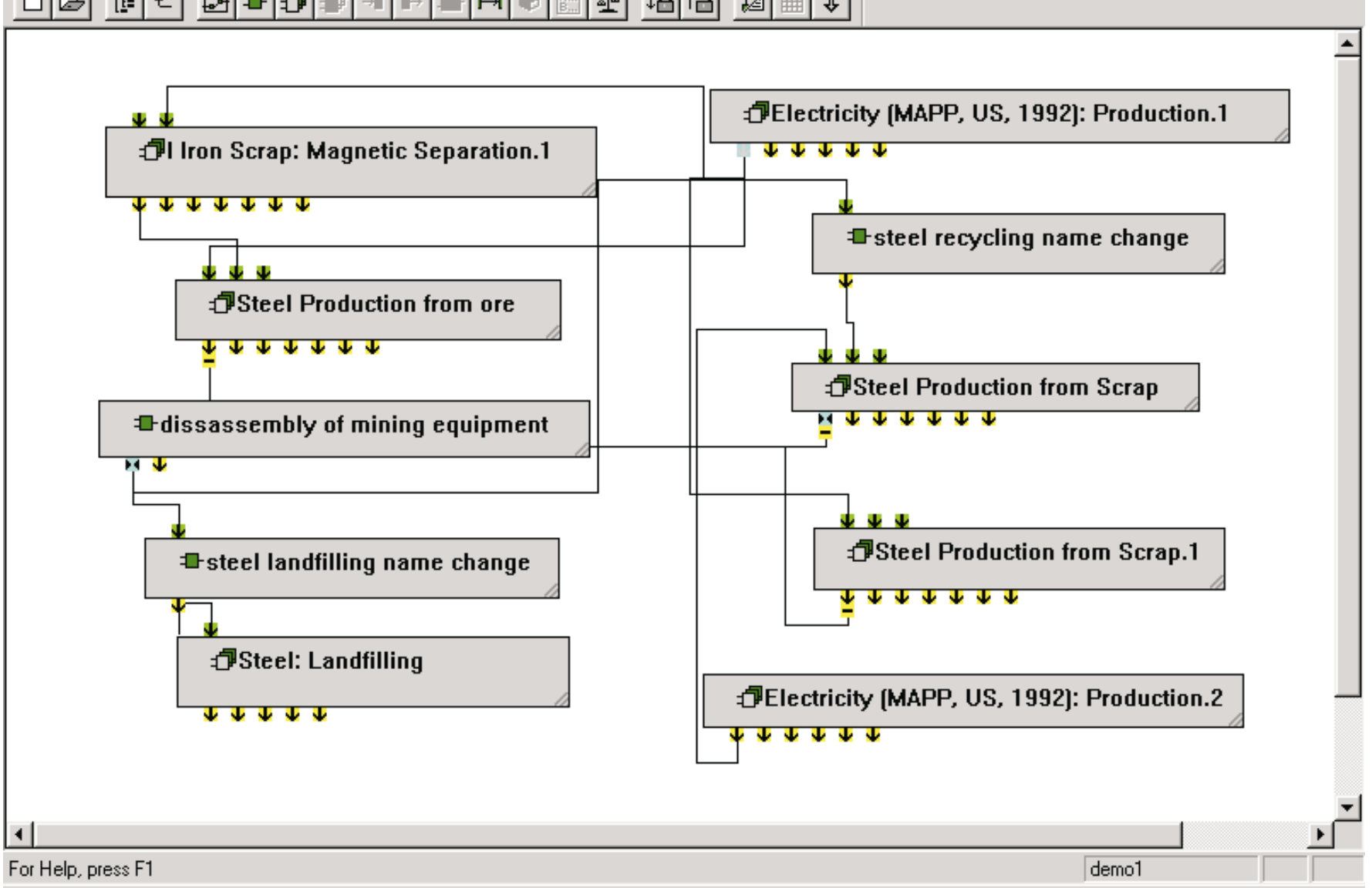




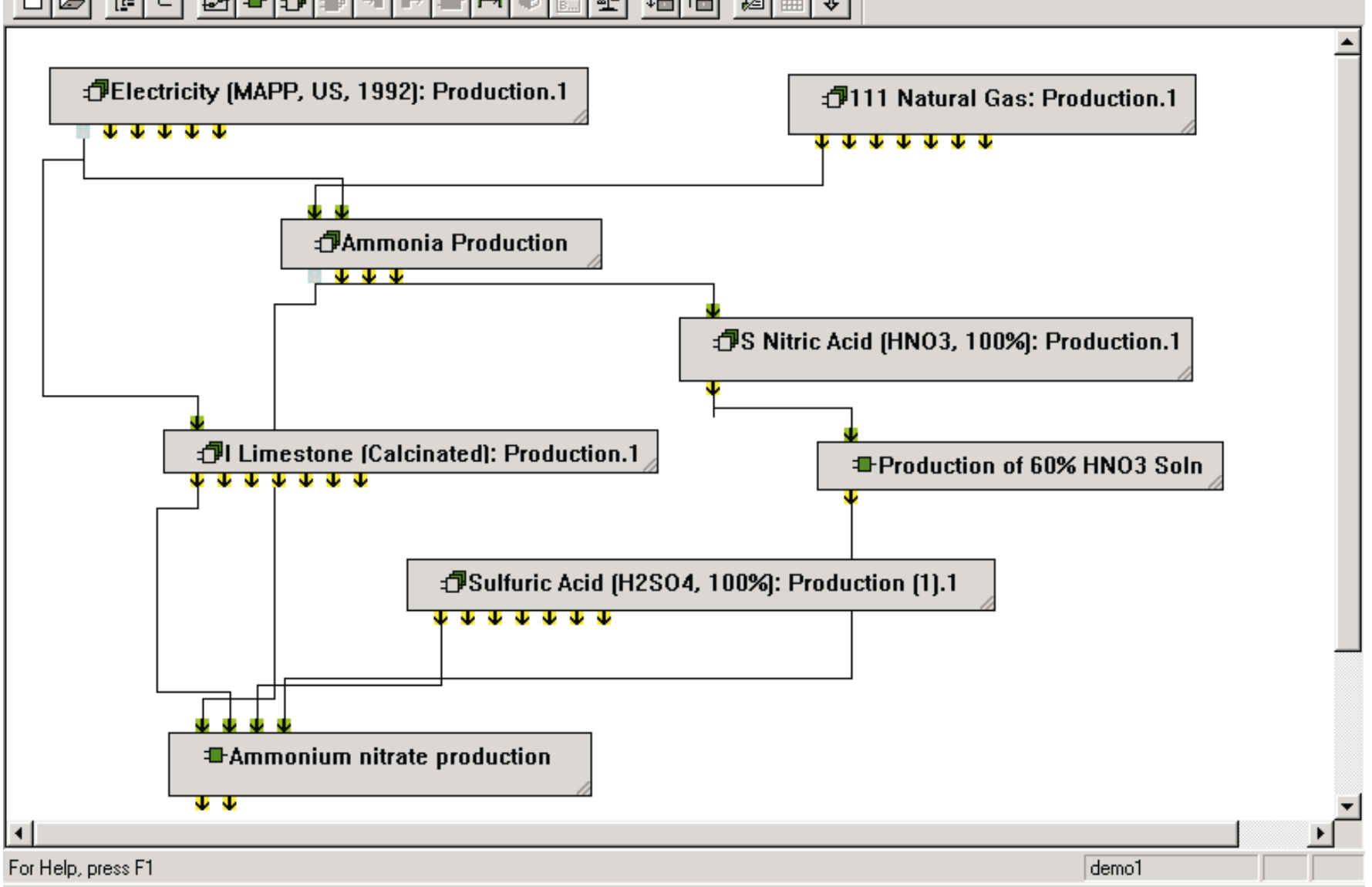

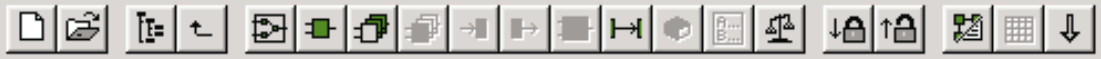

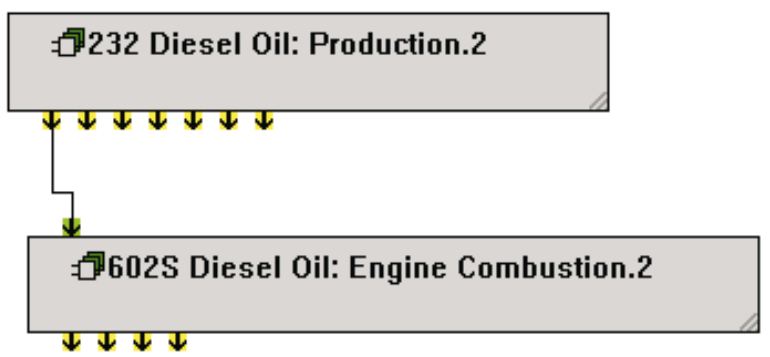


1

Decommissioning of additional equipment

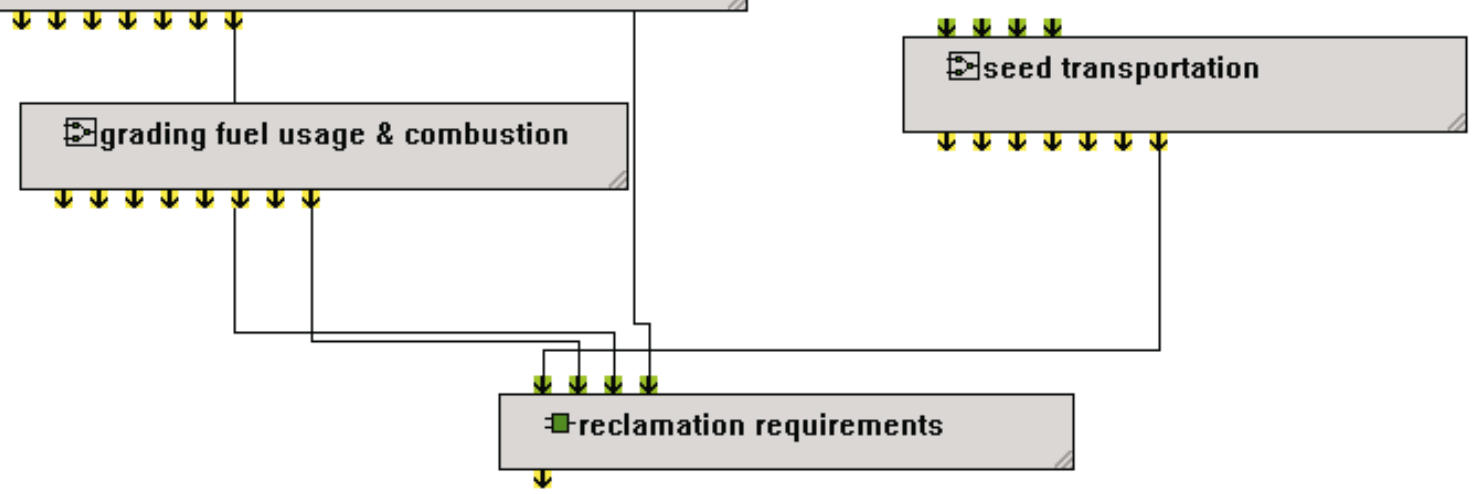

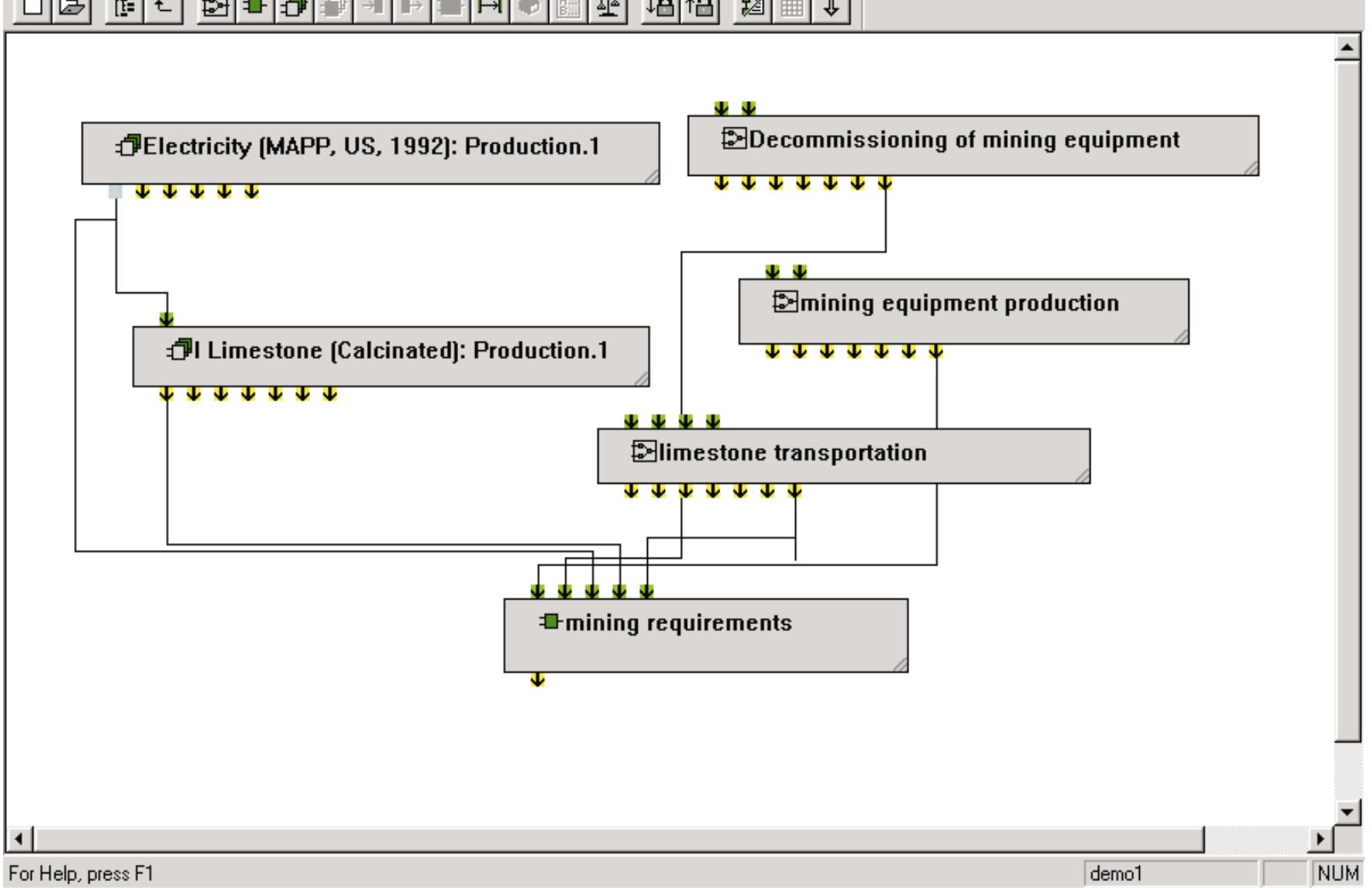




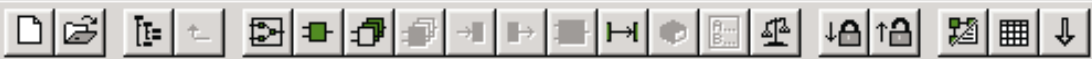
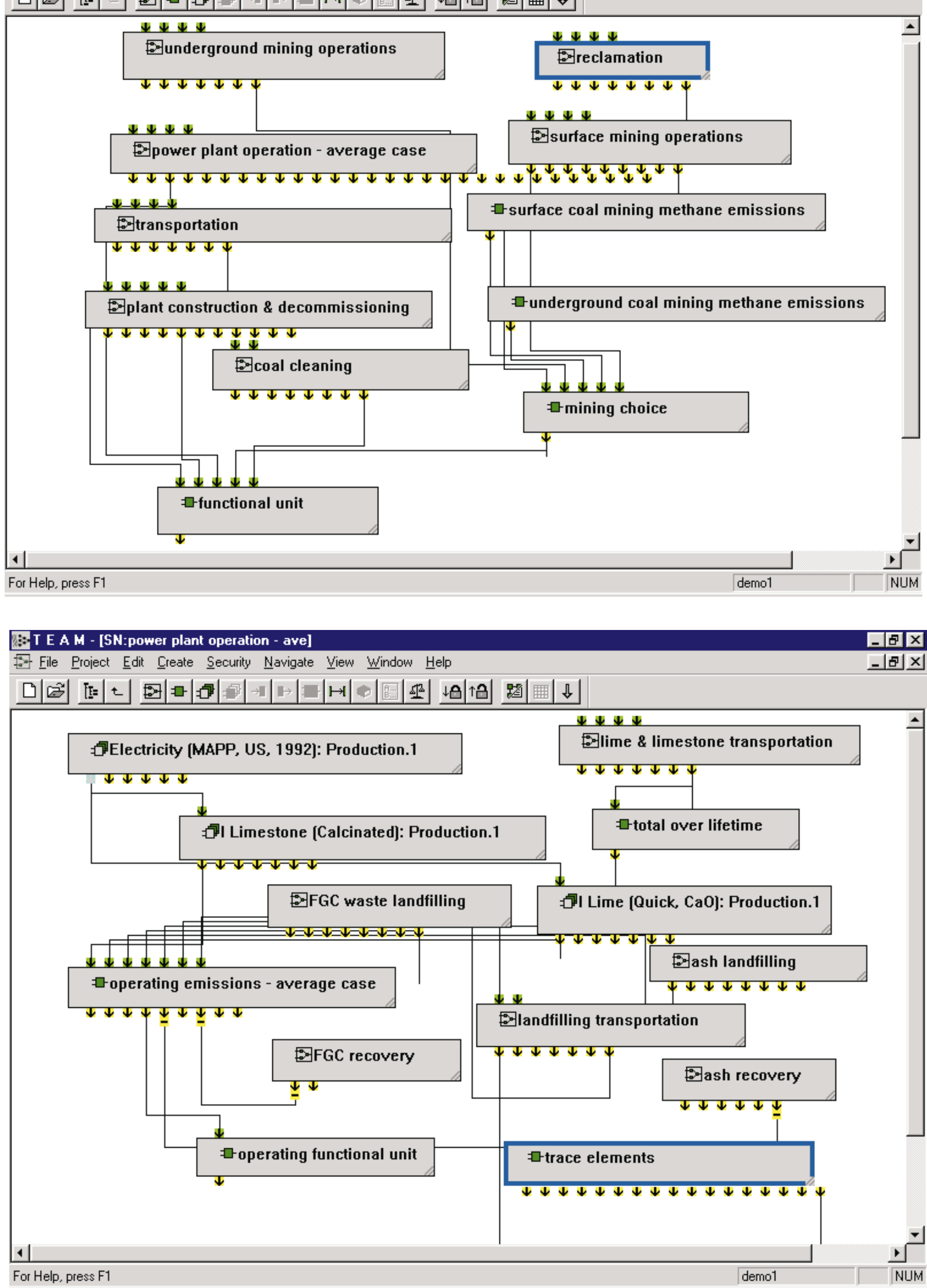


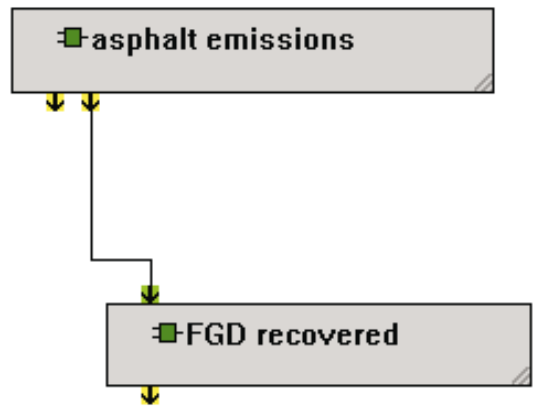

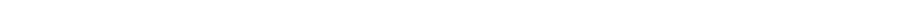

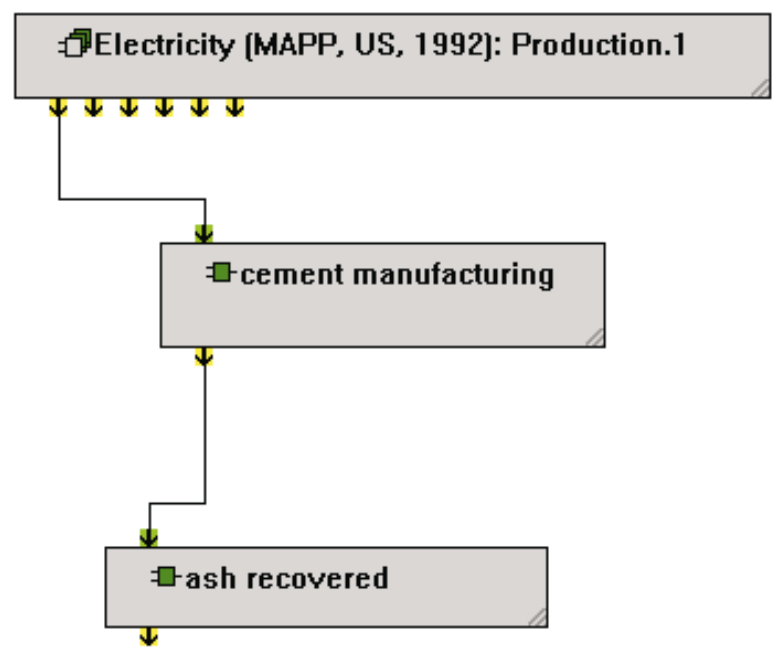




\section{미영 [E:}
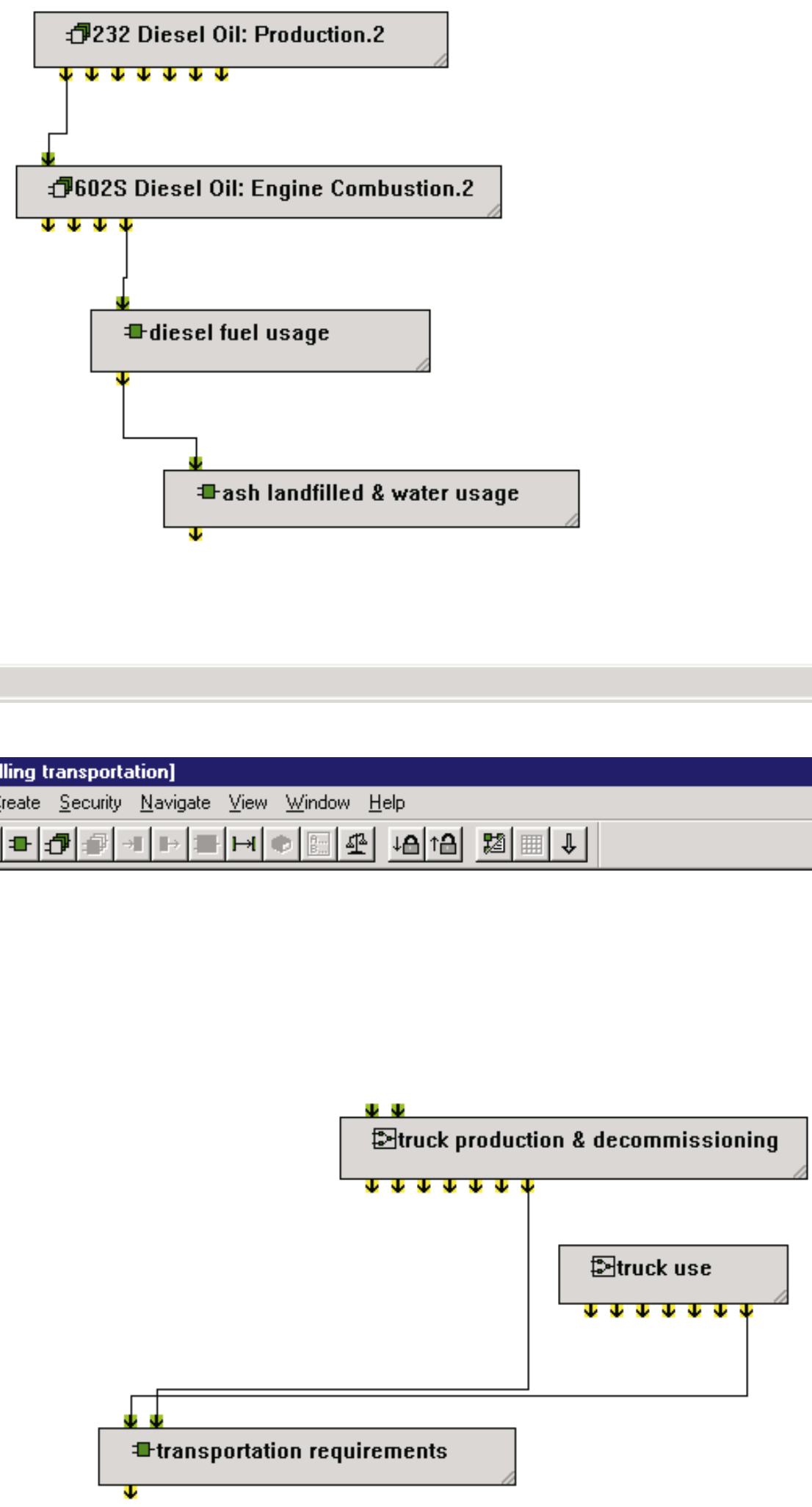

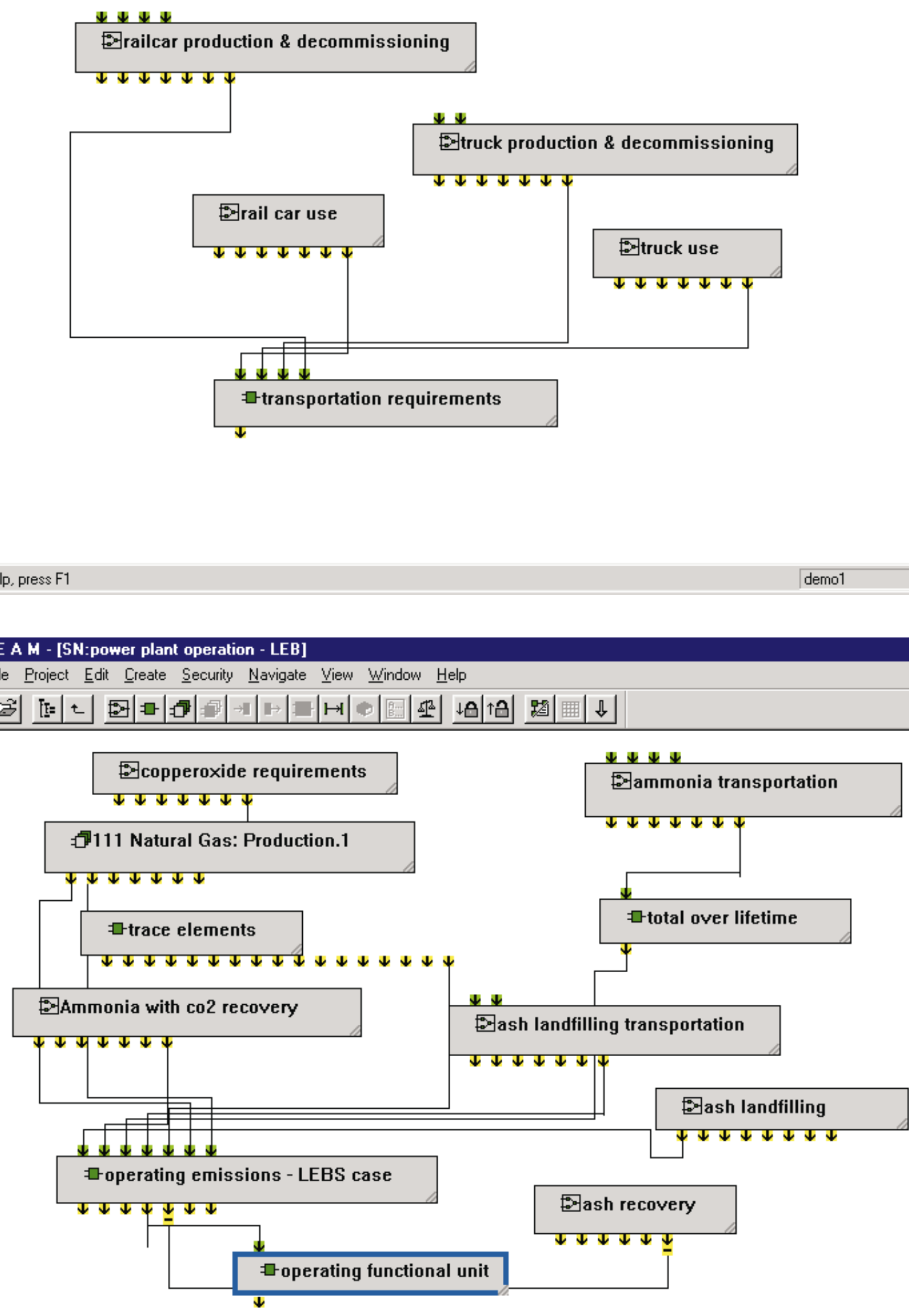


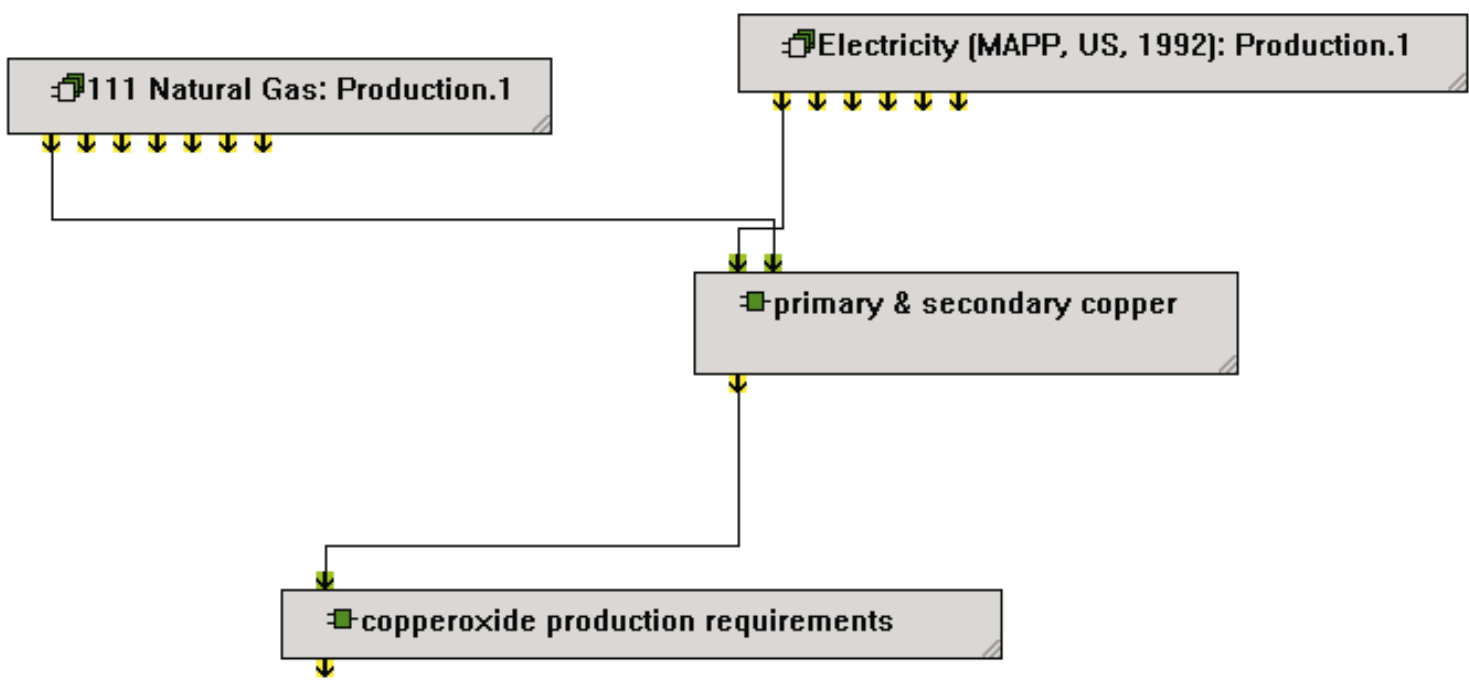

4

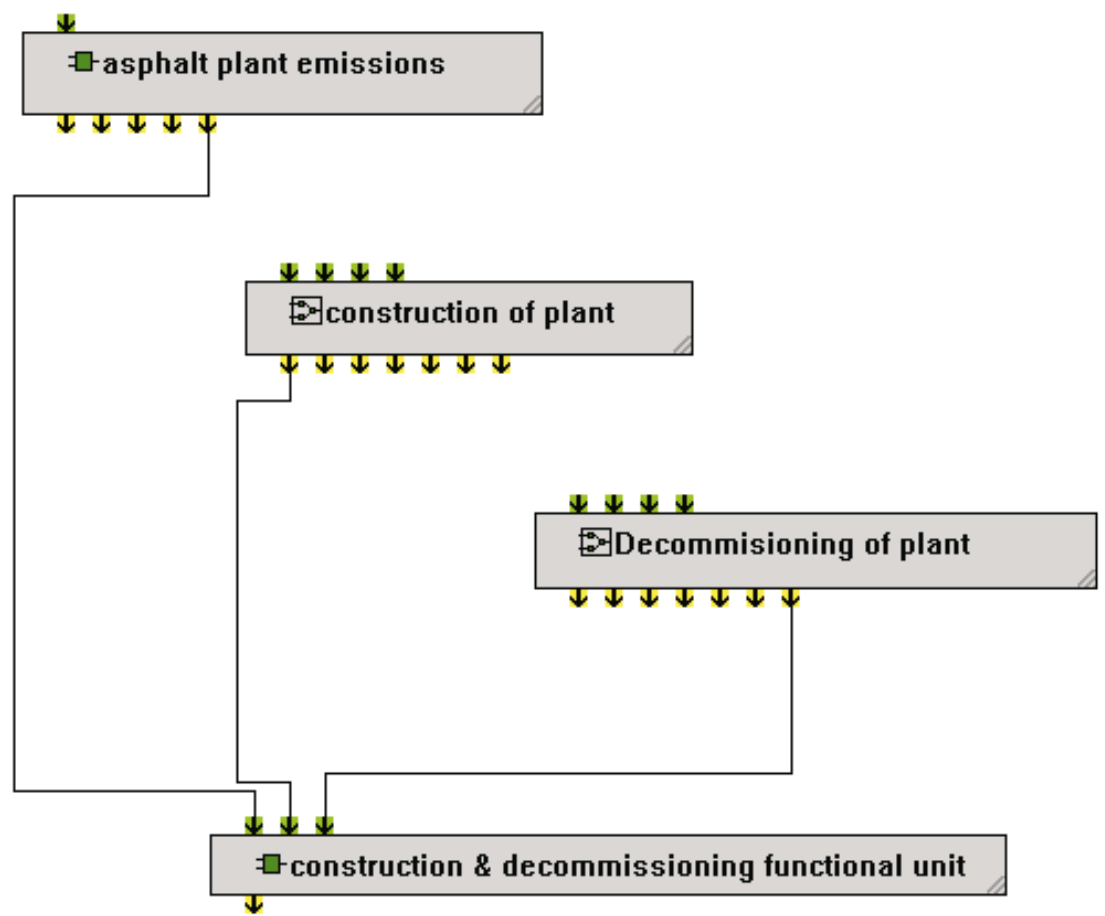




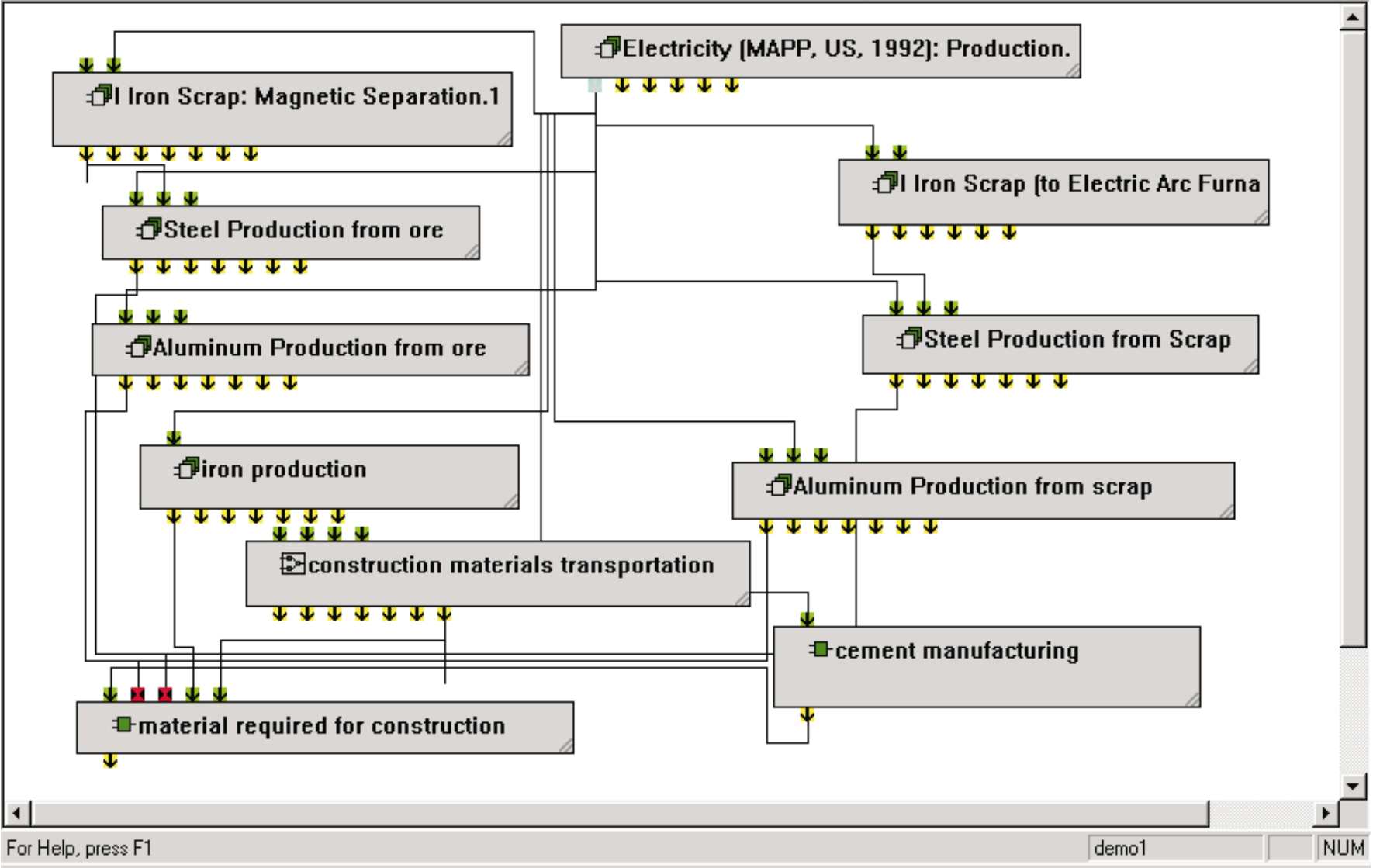

\section{:-T E A M - [SN:construction materials tran]}

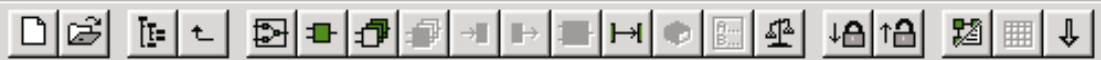

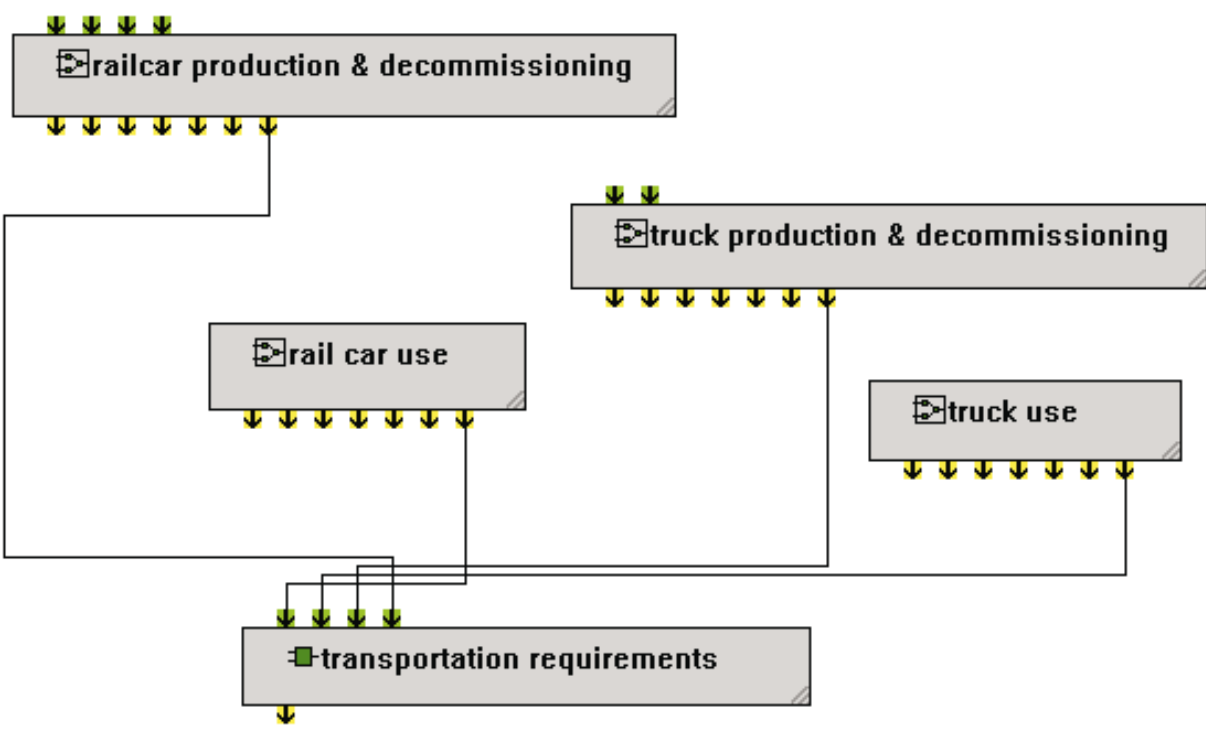




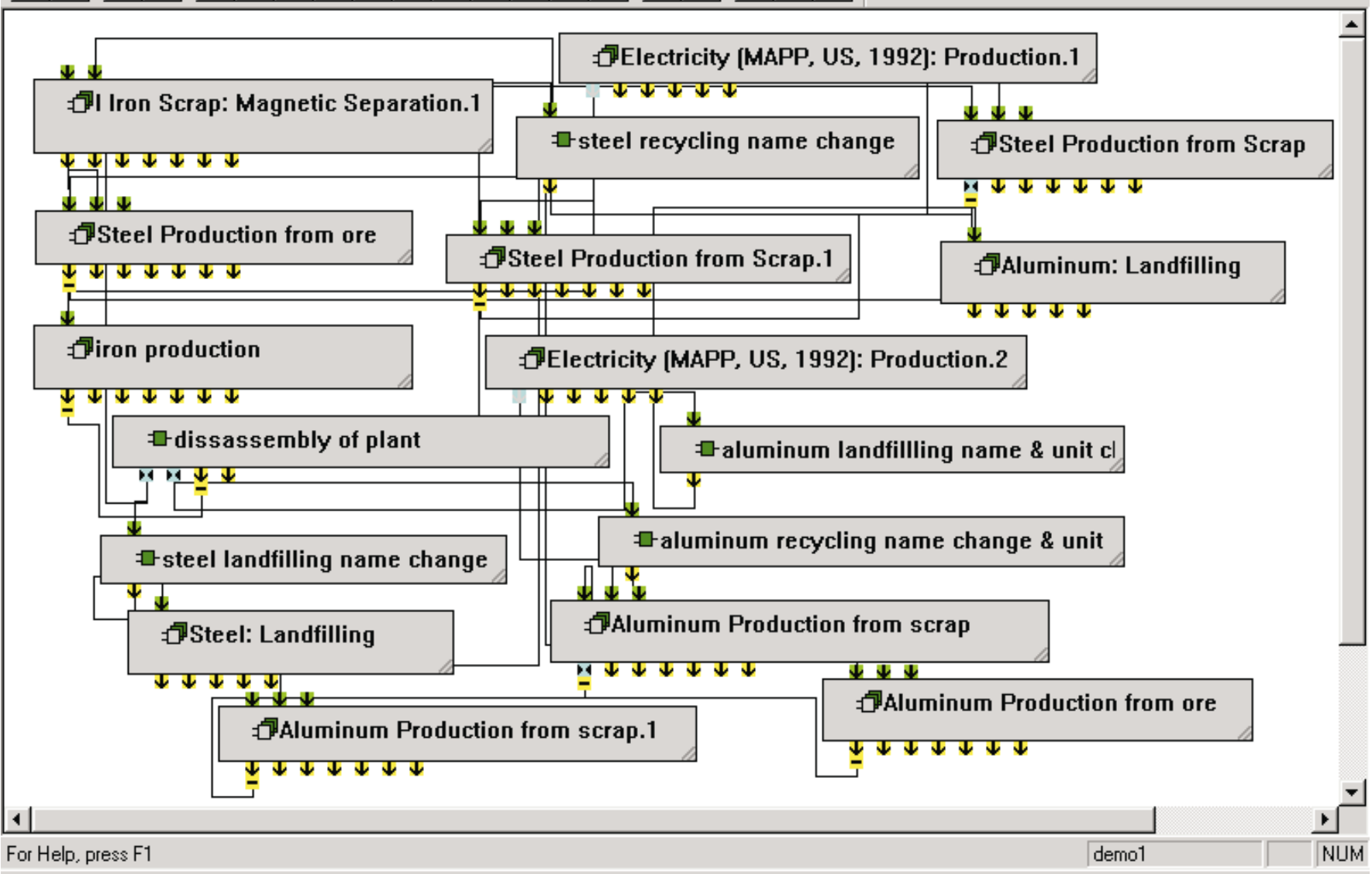

\section{8:-T E A M - [SN:transportation]}

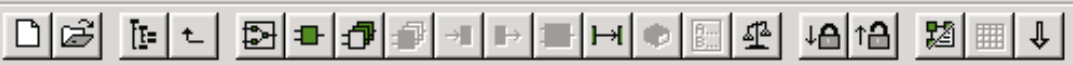

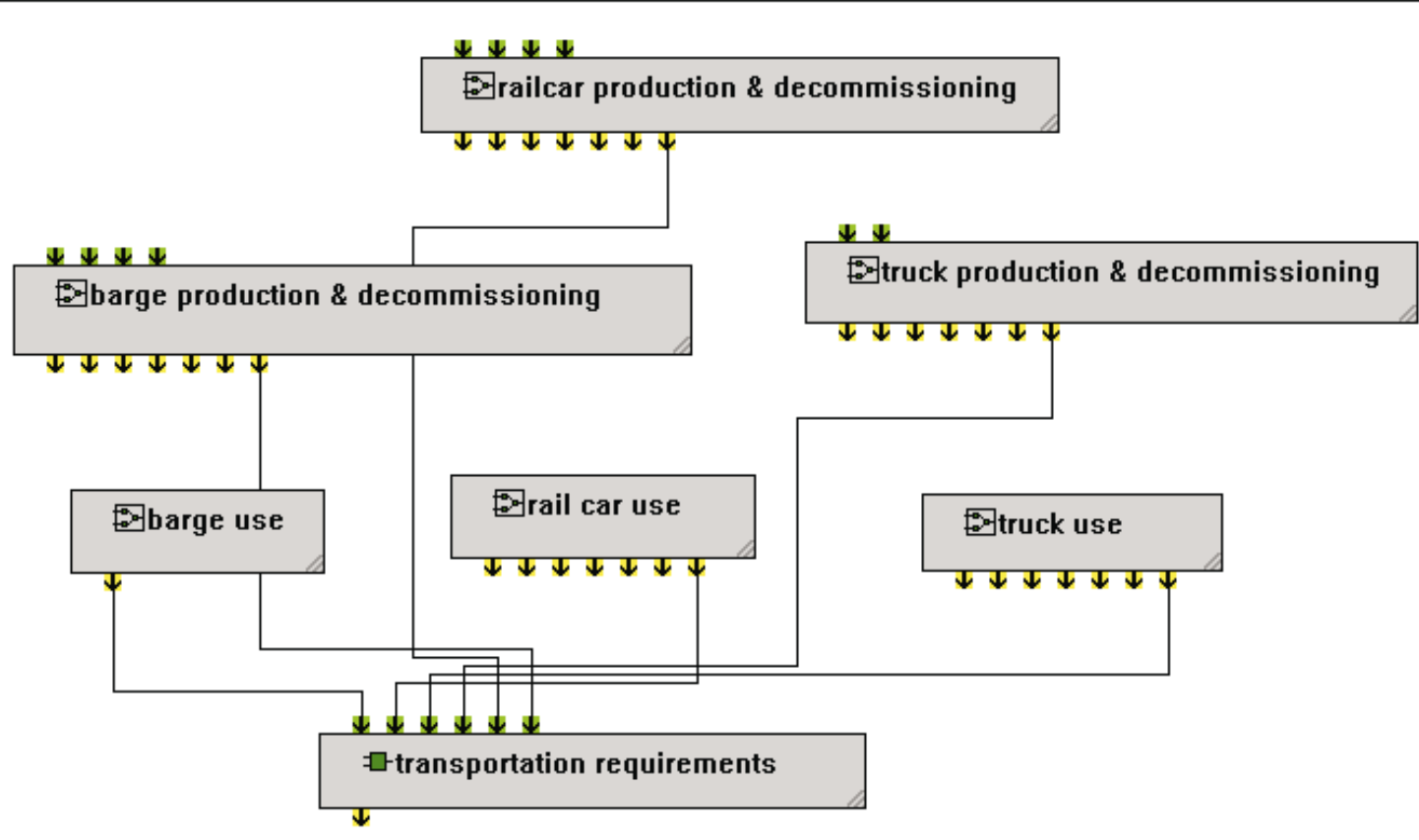




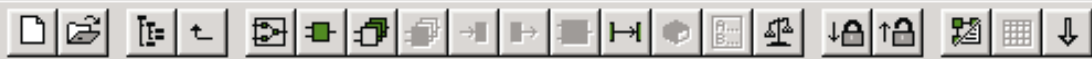
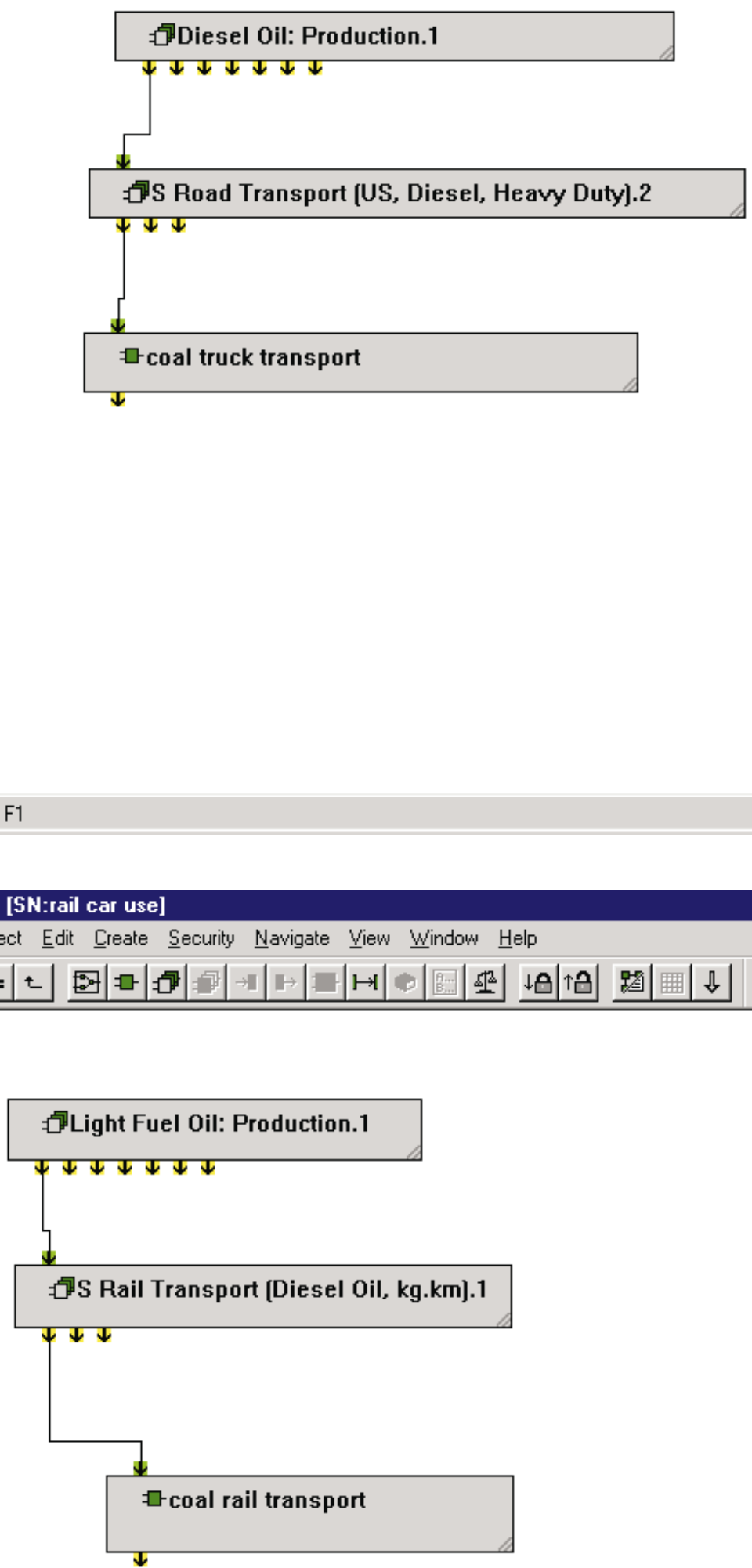


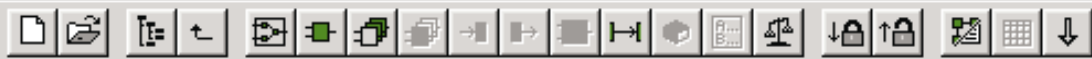

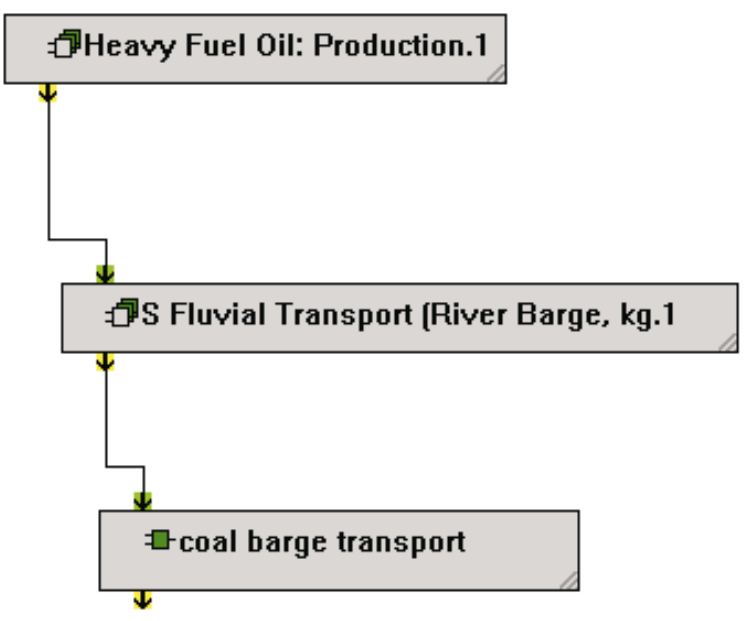

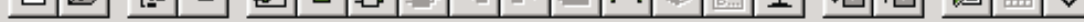

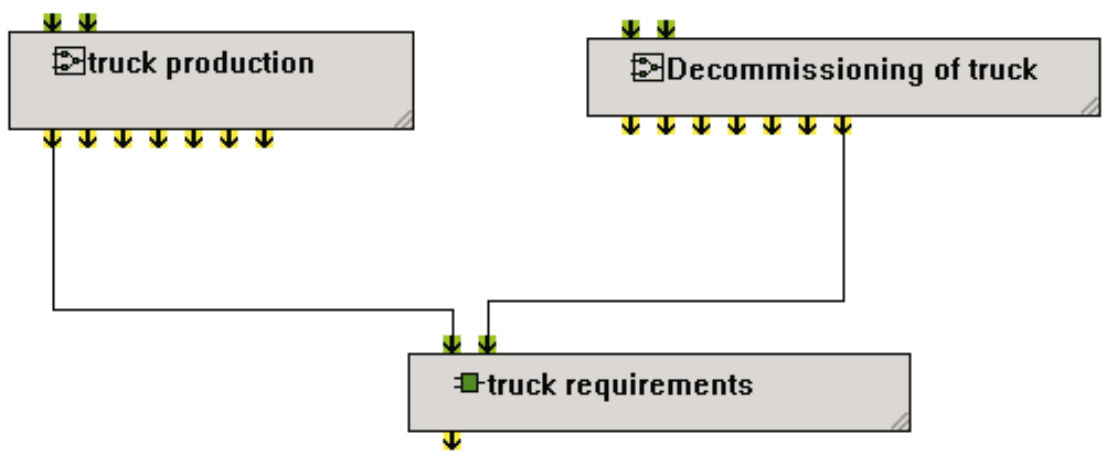




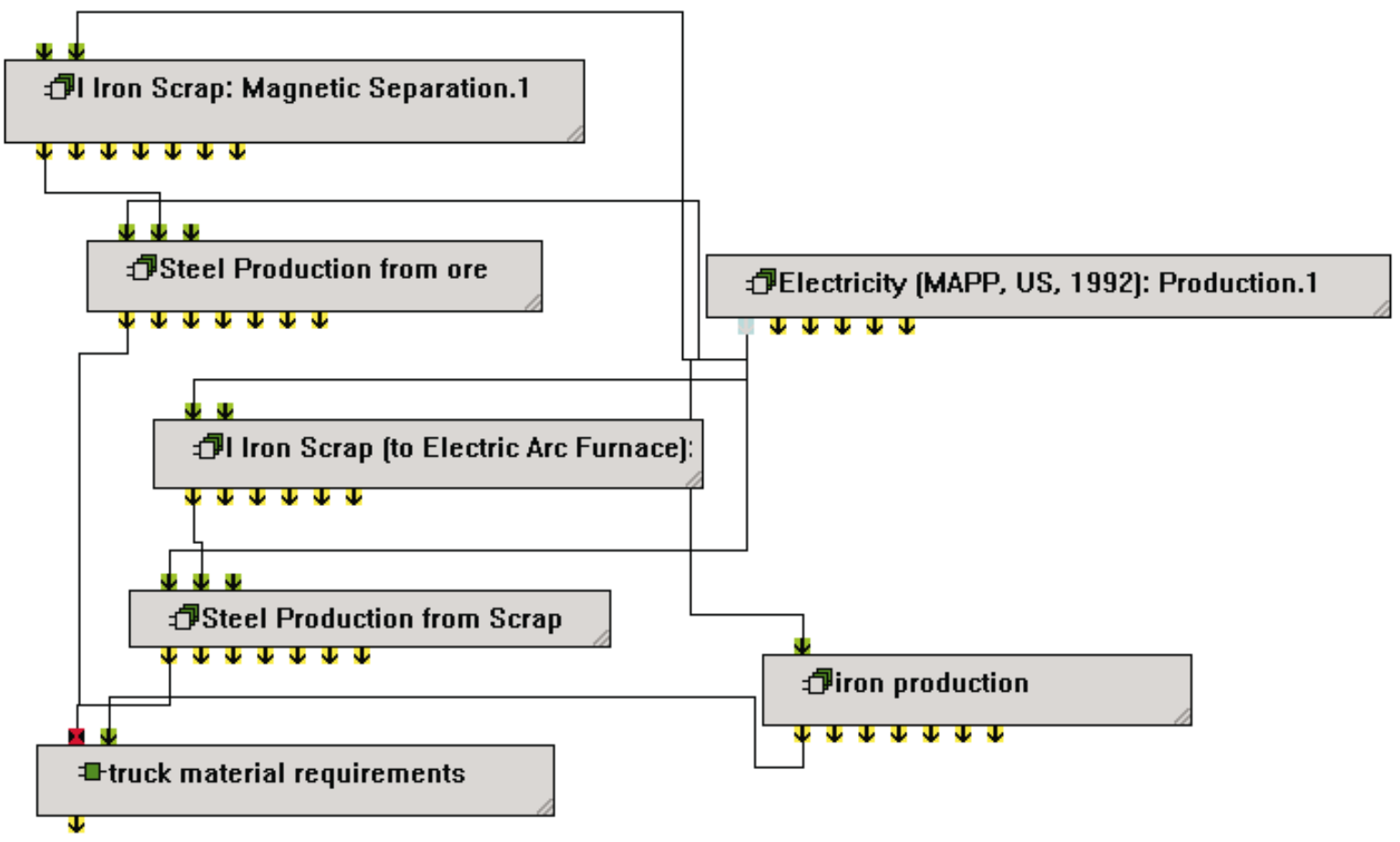

1

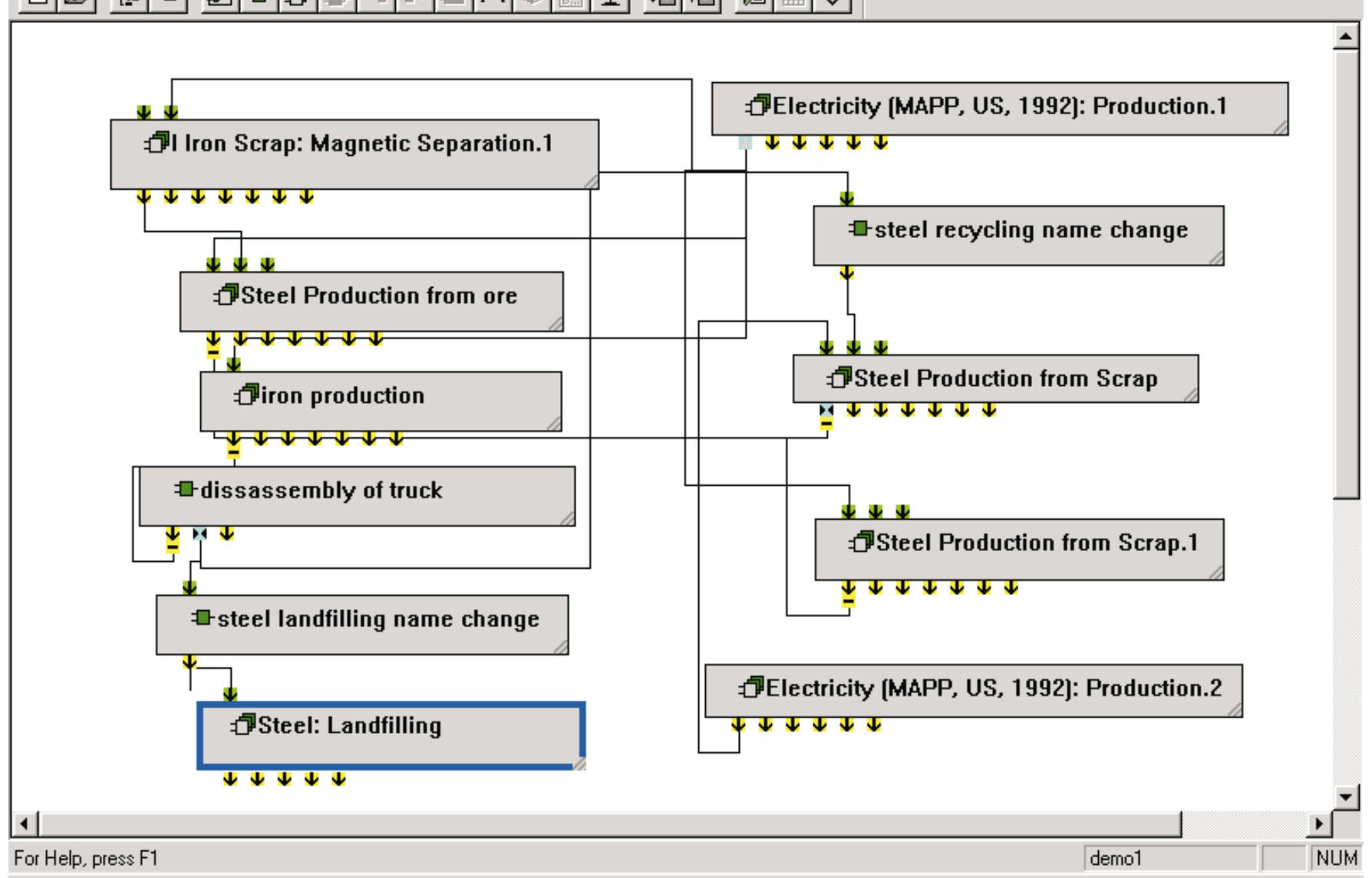



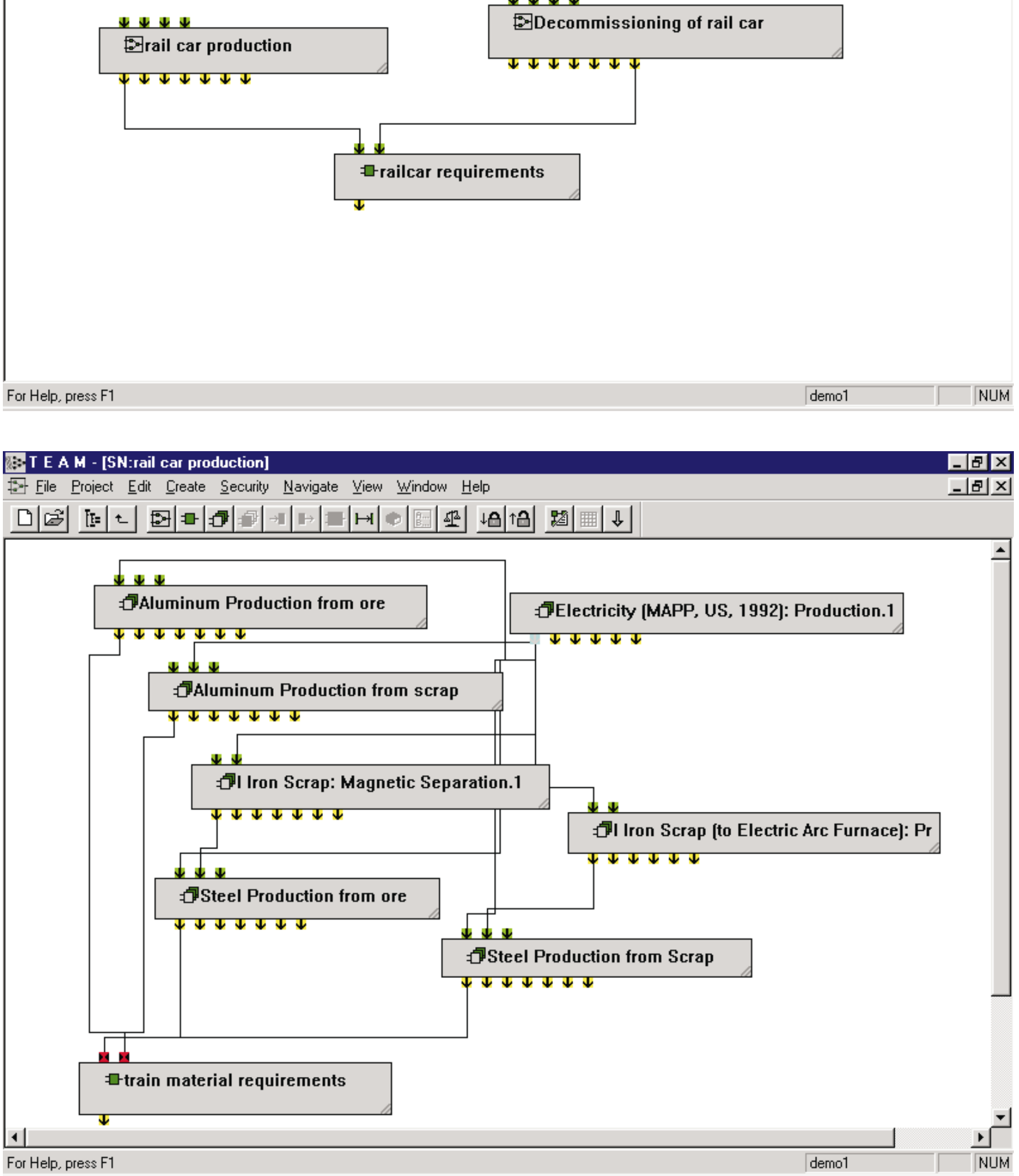


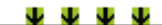

Oarge production

$\downarrow \downarrow \downarrow \downarrow \downarrow \downarrow$

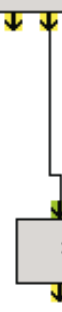

$\boldsymbol{\Psi} \boldsymbol{\Psi} \boldsymbol{\Psi}$

decommissioning of barge

$\downarrow \downarrow \downarrow \downarrow \downarrow \downarrow \downarrow$ 


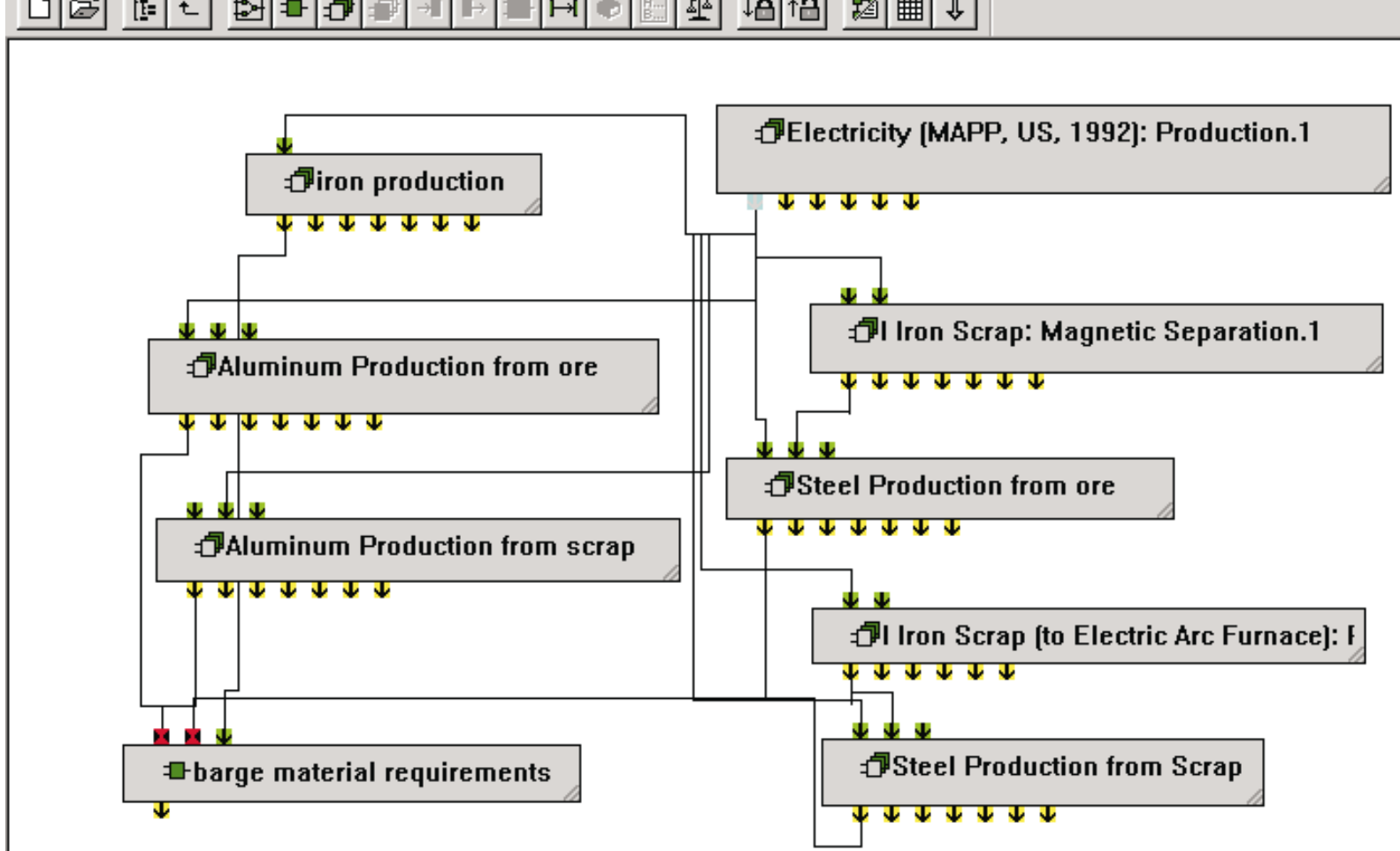

1 
Appendix B: Additional Tables 
Table B1: Average Resource Consumption per kWh of Net Electricity Produced - Average System (underground mining \& average user by river)

\begin{tabular}{|c|c|c|c|c|c|}
\hline & $\begin{array}{l}\% \text { of Total in } \\
\text { this Table }\end{array}$ & Total (g/kWh) & $\begin{array}{l}\begin{array}{l}\% \text { of Total } \\
\text { from }\end{array} \\
\text { Underground } \\
\text { Coal Mining }\end{array}$ & $\begin{array}{l}\% \text { of Total from } \\
\text { Transportation }\end{array}$ & $\begin{array}{c}\% \text { of Total from } \\
\text { Electricity } \\
\text { Generation }\end{array}$ \\
\hline (r) Bauxite (Al2O3, ore) & $0.00 \%$ & $2.54 \mathrm{E}-03$ & $0.01 \%$ & $4.90 \%$ & $95.09 \%$ \\
\hline (r) Clay (in ground) & $0.00 \%$ & $2.08 \mathrm{E}-08$ & $11.81 \%$ & $2.94 \%$ & $85.25 \%$ \\
\hline (r) Coal (in ground) & $79.05 \%$ & $4.75 \mathrm{E}+02$ & $0.67 \%$ & $0.01 \%$ & $99.33 \%$ \\
\hline (r) Iron (Fe, ore) & $0.02 \%$ & $9.62 \mathrm{E}-02$ & $13.76 \%$ & $2.61 \%$ & $83.63 \%$ \\
\hline (r) Limestone (CaCO3, in ground) & $18.82 \%$ & $1.13 \mathrm{E}+02$ & $9.12 \%$ & $0.00 \%$ & $90.88 \%$ \\
\hline (r) Natural Gas (in ground) & $0.14 \%$ & 8.53E-01 & $9.79 \%$ & $2.53 \%$ & $87.68 \%$ \\
\hline (r) Oil (in ground) & $1.96 \%$ & $1.18 \mathrm{E}+01$ & $5.47 \%$ & $46.80 \%$ & $47.73 \%$ \\
\hline (r) Sand (in ground) & $0.00 \%$ & 2.27E-08 & $0.01 \%$ & $4.90 \%$ & $95.09 \%$ \\
\hline (r) Sodium Chloride ( $\mathrm{NaCl}$, in ground or in sea) & $0.00 \%$ & $7.26 \mathrm{E}-05$ & $0.92 \%$ & $4.75 \%$ & $94.33 \%$ \\
\hline (r) Uranium (U, ore) & $0.00 \%$ & 4.02E-05 & $96.35 \%$ & $0.10 \%$ & $3.55 \%$ \\
\hline Aluminum Scrap & $0.00 \%$ & $6.22 \mathrm{E}-04$ & $0.01 \%$ & $4.90 \%$ & $95.09 \%$ \\
\hline Iron Scrap & $0.02 \%$ & 1.02E-01 & $13.99 \%$ & $2.58 \%$ & $83.43 \%$ \\
\hline Lubricant & $0.00 \%$ & 1.74E-03 & $13.77 \%$ & $2.60 \%$ & $83.64 \%$ \\
\hline Trinitrotoluene (C6H3(NO2)3) & $0.00 \%$ & 4.53E-06 & $0.01 \%$ & $4.90 \%$ & $95.09 \%$ \\
\hline
\end{tabular}

Table B2: Average Air Emissions per kWh of Net Electricity Produced - Average System (underground mining \& average user by river)

\begin{tabular}{|c|c|c|c|c|c|c|}
\hline & $\begin{array}{c}\% \text { of Total in } \\
\text { this Table }\end{array}$ & $\begin{array}{c}\% \text { of Total in } \\
\text { this Table } \\
\text { except CO2 }\end{array}$ & Total (g/kWh) & $\begin{array}{l}\text { \% of Total from } \\
\text { Underground } \\
\text { Coal Mining }\end{array}$ & $\begin{array}{l}\% \text { of Total from } \\
\text { Transportation }\end{array}$ & $\begin{array}{c}\begin{array}{c}\% \text { of Total } \\
\text { from }\end{array} \\
\text { Electricity } \\
\text { Generation }\end{array}$ \\
\hline (a) Aldehydes & $0.00 \%$ & $0.00 \%$ & 4.64E-04 & $11.28 \%$ & $43.89 \%$ & $44.84 \%$ \\
\hline (a) Ammonia (NH3) & $0.00 \%$ & $0.00 \%$ & 2.22E-04 & $5.23 \%$ & $46.03 \%$ & $48.79 \%$ \\
\hline (a) antimony & $0.00 \%$ & $0.00 \%$ & 4.11E-06 & $0.00 \%$ & $0.00 \%$ & $100.00 \%$ \\
\hline (a) arsenic & $0.00 \%$ & $0.00 \%$ & 4.95E-05 & $0.00 \%$ & $0.00 \%$ & $100.00 \%$ \\
\hline (a) barium & $0.00 \%$ & $0.00 \%$ & $1.28 \mathrm{E}-05$ & $0.00 \%$ & $0.00 \%$ & $100.00 \%$ \\
\hline (a) beryllium & $0.00 \%$ & $0.00 \%$ & $1.60 \mathrm{E}-06$ & $0.00 \%$ & $0.00 \%$ & $100.00 \%$ \\
\hline (a) boron & $0.00 \%$ & $0.07 \%$ & $1.70 \mathrm{E}-02$ & $0.00 \%$ & $0.00 \%$ & $100.00 \%$ \\
\hline (a) cadmium & $0.00 \%$ & $0.00 \%$ & 4.07E-06 & $0.00 \%$ & $0.00 \%$ & $100.00 \%$ \\
\hline (a) total Carbon Dioxide (CO2) & $97.83 \%$ & & $1.02 \mathrm{E}+03$ & $0.85 \%$ & $1.72 \%$ & $97.43 \%$ \\
\hline (a) Carbon Monoxide (CO) & $0.02 \%$ & $1.15 \%$ & $2.61 \mathrm{E}-01$ & $1.03 \%$ & $38.96 \%$ & $60.01 \%$ \\
\hline (a) Chlorides (Cl-) & $0.00 \%$ & $0.00 \%$ & 5.70E-07 & $0.01 \%$ & $3.48 \%$ & $96.52 \%$ \\
\hline (a) chromium & $0.00 \%$ & $0.00 \%$ & 5.92E-05 & $0.00 \%$ & $0.00 \%$ & $100.00 \%$ \\
\hline (a) cobalt & $0.00 \%$ & $0.00 \%$ & $6.87 \mathrm{E}-06$ & $0.00 \%$ & $0.00 \%$ & $100.00 \%$ \\
\hline (a) copper & $0.00 \%$ & $0.00 \%$ & $2.34 \mathrm{E}-05$ & $0.00 \%$ & $0.00 \%$ & $100.00 \%$ \\
\hline (a) Fluorides (F-) & $0.00 \%$ & $0.00 \%$ & 2.66E-07 & $17.12 \%$ & $3.40 \%$ & $79.48 \%$ \\
\hline (a) non-methane Hydrocarbons (including VOCs) & $0.02 \%$ & $0.87 \%$ & $1.98 \mathrm{E}-01$ & $33.63 \%$ & $29.67 \%$ & $36.69 \%$ \\
\hline (a) Hydrogen Chloride $(\mathrm{HCl})$ & $0.00 \%$ & $0.00 \%$ & $1.83 \mathrm{E}-06$ & $0.14 \%$ & $3.19 \%$ & $96.67 \%$ \\
\hline (a) Hydrogen Fluoride (HF) & $0.00 \%$ & $0.00 \%$ & $1.65 \mathrm{E}-07$ & $2.62 \%$ & $4.47 \%$ & $92.91 \%$ \\
\hline (a) Hydrogen Sulfide (H2S) & $0.00 \%$ & $0.00 \%$ & $1.04 \mathrm{E}-08$ & $11.81 \%$ & $2.94 \%$ & $85.25 \%$ \\
\hline (a) lead & $0.00 \%$ & $0.00 \%$ & $3.00 \mathrm{E}-05$ & $0.00 \%$ & $0.00 \%$ & $100.00 \%$ \\
\hline (a) manganese & $0.00 \%$ & $0.00 \%$ & 4.30E-05 & $0.00 \%$ & $0.00 \%$ & $100.00 \%$ \\
\hline (a) mercury & $0.00 \%$ & $0.00 \%$ & 3.66E-05 & $0.00 \%$ & $0.00 \%$ & $100.00 \%$ \\
\hline (a) Metals (unspecified) & $0.00 \%$ & $0.00 \%$ & 1.27E-09 & $9.69 \%$ & $3.29 \%$ & $87.01 \%$ \\
\hline (a) Methane $(\mathrm{CH} 4)$ & $0.19 \%$ & $8.82 \%$ & $2.00 \mathrm{E}+00$ & $99.53 \%$ & $0.05 \%$ & $0.43 \%$ \\
\hline (a) molybdenum & $0.00 \%$ & $0.00 \%$ & 3.81E-05 & $0.00 \%$ & $0.00 \%$ & $100.00 \%$ \\
\hline (a) nickel & $0.00 \%$ & $0.00 \%$ & $5.79 \mathrm{E}-05$ & $0.00 \%$ & $0.00 \%$ & $100.00 \%$ \\
\hline (a) Nitrogen Oxides (NOx as NO2) & $0.32 \%$ & $14.75 \%$ & $3.34 \mathrm{E}+00$ & $1.10 \%$ & $5.53 \%$ & $93.37 \%$ \\
\hline (a) Nitrous Oxide (N2O) & $0.00 \%$ & $0.02 \%$ & 4.30E-03 & $20.36 \%$ & $5.72 \%$ & $73.92 \%$ \\
\hline (a) Organic Matter (unspecified) & $0.00 \%$ & $0.00 \%$ & $6.95 \mathrm{E}-04$ & $13.51 \%$ & $43.96 \%$ & $42.53 \%$ \\
\hline (a) total Particulates (unspecified) & $0.97 \%$ & $44.72 \%$ & $1.01 \mathrm{E}+01$ & $9.22 \%$ & $0.18 \%$ & $90.60 \%$ \\
\hline (a) selenium & $0.00 \%$ & $0.00 \%$ & 4.06E-04 & $0.00 \%$ & $0.00 \%$ & $100.00 \%$ \\
\hline (a) Sulfur Oxides (SOx as SO2) & $0.64 \%$ & $29.59 \%$ & $6.70 \mathrm{E}+00$ & $1.12 \%$ & $1.42 \%$ & $97.46 \%$ \\
\hline (a) Tars (unspecified) & $0.00 \%$ & $0.00 \%$ & $3.65 \mathrm{E}-07$ & $11.56 \%$ & $2.98 \%$ & $85.46 \%$ \\
\hline (a) vanadium & $0.00 \%$ & $0.00 \%$ & $8.80 \mathrm{E}-05$ & $0.00 \%$ & $0.00 \%$ & $100.00 \%$ \\
\hline
\end{tabular}


Table B3: Average Water Emissions per kWh of Net Electricity Produced - Average System (underground mining \& avg user by river)

(w) Acids $(\mathrm{H}+)$

(w) Ammonia $(\mathrm{NH} 4+)$

(w) Ammonia (NH4+, $\mathrm{NH} 3$, as $\mathrm{N}$ )

(w) TOTAL BOD5 (Biological Oxygen Demand)

(w) Chlorides (Cl-)

(w) COD (Chemical Oxygen Demand)

(w) Cyanides (CN-)

(w) Dissolved Matter (unspecified)

(w) Fluorides (F-)

(w) Inorganic Dissolved Matter (unspecified)

(w) Iron $(\mathrm{Fe}++, \mathrm{Fe} 3+)$

(w) Metals (unspecified)

(w) Nitrates (NO3-)

(w) Nitric acid

(w) Nitrogenous Matter (unspecified, as N)

(w) Oils

(w) Oils (unspecified)

(w) Organic Dissolved Matter (unspecified)

(w) Phenol $(\mathrm{C} 6 \mathrm{H} 6 \mathrm{O})$

(w) Sodium $(\mathrm{Na}+)$

(w) Sulfates (SO4--)

(w) Sulfides (S--)

(w) Suspended Matter (unspecified)

(w) Tars (unspecified)

(w) Water: Chemically Polluted

(w) = water emission

\begin{tabular}{|c|c|c|c|c|}
\hline & & $\begin{array}{l}\% \text { of Total } \\
\text { from }\end{array}$ & & $\%$ of Total from \\
\hline$\%$ of Total in & & Underground & $\%$ of Total from & Electricity \\
\hline this Table & Total ( $\mathrm{g} / \mathrm{kWh})$ & Coal Mining & Transportation & Generation \\
\hline $0.00 \%$ & 9.32E-08 & $7.91 \%$ & $3.58 \%$ & $88.37 \%$ \\
\hline $0.00 \%$ & $0.00 \mathrm{E}+00$ & $0.00 \%$ & $0.00 \%$ & $0.00 \%$ \\
\hline $0.00 \%$ & 3.31E-06 & $83.99 \%$ & $0.48 \%$ & $15.54 \%$ \\
\hline $0.04 \%$ & $6.52 \mathrm{E}-05$ & $5.05 \%$ & $46.90 \%$ & $48.05 \%$ \\
\hline $0.00 \%$ & $3.42 \mathrm{E}-06$ & $2.36 \%$ & $4.76 \%$ & $92.88 \%$ \\
\hline $0.12 \%$ & $1.94 \mathrm{E}-04$ & $5.00 \%$ & $47.15 \%$ & $47.85 \%$ \\
\hline $0.00 \%$ & 7.29E-09 & $13.76 \%$ & $2.61 \%$ & $83.63 \%$ \\
\hline $98.49 \%$ & 1.57E-01 & $5.65 \%$ & $41.23 \%$ & $53.12 \%$ \\
\hline $0.00 \%$ & 7.07E-06 & $84.69 \%$ & $0.45 \%$ & $14.85 \%$ \\
\hline $0.00 \%$ & $5.26 \mathrm{E}-07$ & $11.68 \%$ & $2.96 \%$ & $85.35 \%$ \\
\hline $0.00 \%$ & $1.17 \mathrm{E}-08$ & $96.35 \%$ & $0.10 \%$ & $3.55 \%$ \\
\hline $0.00 \%$ & 3.20E-07 & $11.52 \%$ & $2.99 \%$ & $85.49 \%$ \\
\hline $0.00 \%$ & $1.44 \mathrm{E}-06$ & $96.35 \%$ & $0.10 \%$ & $3.55 \%$ \\
\hline $0.00 \%$ & $0.00 \mathrm{E}+00$ & $0.00 \%$ & $0.00 \%$ & $0.00 \%$ \\
\hline $0.00 \%$ & $1.04 \mathrm{E}-08$ & $11.81 \%$ & $2.94 \%$ & $85.25 \%$ \\
\hline $1.17 \%$ & $1.87 \mathrm{E}-03$ & $5.59 \%$ & $44.53 \%$ & $49.88 \%$ \\
\hline $0.02 \%$ & 2.63E-05 & $0.00 \%$ & $0.00 \%$ & $100.00 \%$ \\
\hline $0.00 \%$ & $2.08 \mathrm{E}-08$ & $11.81 \%$ & $2.94 \%$ & $85.25 \%$ \\
\hline $0.00 \%$ & 2.29E-08 & $13.67 \%$ & $2.62 \%$ & $83.70 \%$ \\
\hline $0.00 \%$ & 1.46E-06 & $65.65 \%$ & $1.63 \%$ & $32.72 \%$ \\
\hline $0.00 \%$ & 1.73E-06 & $71.61 \%$ & $1.33 \%$ & $27.05 \%$ \\
\hline $0.00 \%$ & 1.46E-08 & $13.76 \%$ & $2.61 \%$ & $83.63 \%$ \\
\hline $0.12 \%$ & $1.91 \mathrm{E}-04$ & $7.94 \%$ & $16.98 \%$ & $75.08 \%$ \\
\hline $0.00 \%$ & 5.22E-09 & $11.56 \%$ & $2.98 \%$ & $85.46 \%$ \\
\hline $0.02 \%$ & 3.11E-05 & $0.01 \%$ & $3.79 \%$ & $96.20 \%$ \\
\hline
\end{tabular}

Table B4: Average Energy Requirements per kWh of Net Electricity Produced - Average System (underground mining \& avg user by river)

\begin{tabular}{|c|c|c|c|c|}
\hline $\begin{array}{l}\text { Non-electric Energy Consumed by System (excluding coal energy) } \\
\text { Electricity Consumed by System } \\
\text { Total Non-coal Energy Consumed by System } \\
\text { Energy in Coal to Power Plant } \\
\text { Total Energy Consumed by System }\end{array}$ & $\begin{array}{c}\text { Total }(\mathrm{MJ} / \mathrm{kWh}) \\
0.6715 \\
0.0300 \\
0.7015 \\
11.8508 \\
12.5523\end{array}$ & $\begin{array}{c}\begin{array}{c}\% \text { of Total } \\
\text { from }\end{array} \\
\text { Underground } \\
\text { Coal Mining } \\
19.10 \% \\
98.49 \% \\
22.49 \% \\
\text { N/A } \\
1.26 \%\end{array}$ & $\begin{array}{c}\text { \% of Total from } \\
\text { Transportation } \\
34.51 \% \\
2.35 \% \\
33.14 \% \\
\mathrm{~N} / \mathrm{A} \\
1.85 \%\end{array}$ & $\begin{array}{c}\text { \% of Total from } \\
\text { Electricity } \\
\text { Generation } \\
46.39 \% \\
-0.84 \% \\
44.38 \% \\
\text { N/A } \\
96.89 \%\end{array}$ \\
\hline
\end{tabular}

Note: The electricity produced and consumed by the power plant is not included in this table.

The power plant energy and electricty requirements are from upstream processes, construction, and decommissioning. 
Table B5: Average Solid Waste Generation per kWh of Net Electricity Produced - Average System (underground mining \& avg user by river)

\author{
(s) antimony \\ (s) arsenic \\ (s) barium \\ (s) beryllium \\ (s) boron \\ (s) cadmium \\ (s) chromium \\ (s) cobalt \\ (s) copper \\ (s) lead \\ (s) manganese \\ (s) mercury \\ (s) molybdenum \\ (s) nickel \\ (s) selenium \\ (s) vanadium \\ ash - landfilled (dry) \\ FGC waste (dry) - landfilled \\ Waste (hazardous) \\ Waste (municipal and industrial) \\ Waste (unspecified)
}

(s) = solid emission

\begin{tabular}{|c|c|c|}
\hline $\begin{array}{l}\% \text { of Total } \\
\text { from }\end{array}$ & & $\%$ of Total from \\
\hline Underground & $\%$ of Total from & Electricity \\
\hline Coal Mining & Transportation & Generation \\
\hline $0.00 \%$ & $0.00 \%$ & $100.00 \%$ \\
\hline $0.00 \%$ & $0.00 \%$ & $100.00 \%$ \\
\hline $0.00 \%$ & $0.00 \%$ & $100.00 \%$ \\
\hline $0.00 \%$ & $0.00 \%$ & $100.00 \%$ \\
\hline $0.00 \%$ & $0.00 \%$ & $100.00 \%$ \\
\hline $0.00 \%$ & $0.00 \%$ & $100.00 \%$ \\
\hline $0.00 \%$ & $0.00 \%$ & $100.00 \%$ \\
\hline $0.00 \%$ & $0.00 \%$ & $100.00 \%$ \\
\hline $0.00 \%$ & $0.00 \%$ & $100.00 \%$ \\
\hline $0.00 \%$ & $0.00 \%$ & $100.00 \%$ \\
\hline $0.00 \%$ & $0.00 \%$ & $100.00 \%$ \\
\hline $0.00 \%$ & $0.00 \%$ & $100.00 \%$ \\
\hline $0.00 \%$ & $0.00 \%$ & $100.00 \%$ \\
\hline $0.00 \%$ & $0.00 \%$ & $100.00 \%$ \\
\hline $0.00 \%$ & $0.00 \%$ & $100.00 \%$ \\
\hline $0.00 \%$ & $0.00 \%$ & $100.00 \%$ \\
\hline $0.00 \%$ & $0.00 \%$ & $100.00 \%$ \\
\hline $0.00 \%$ & $0.00 \%$ & $100.00 \%$ \\
\hline $3.72 \%$ & $4.29 \%$ & $92.00 \%$ \\
\hline $13.67 \%$ & $2.44 \%$ & $83.89 \%$ \\
\hline $16.29 \%$ & $0.05 \%$ & $83.66 \%$ \\
\hline
\end{tabular}


Table B6: Average Resource Consumption per kWh of Net Electricity Produced - NSPS Case (surface mining \& average user by river)

\begin{tabular}{|c|c|c|c|c|c|}
\hline & $\begin{array}{l}\% \text { of Total in } \\
\text { this Table }\end{array}$ & Total $(\mathrm{g} / \mathrm{kWh})$ & $\begin{array}{c}\% \text { of Total } \\
\text { from Surface } \\
\text { Coal Mining }\end{array}$ & $\begin{array}{l}\% \text { of Total from } \\
\text { Transportation }\end{array}$ & $\begin{array}{c}\% \text { of Total from } \\
\text { Electricity } \\
\text { Generation }\end{array}$ \\
\hline (r) Bauxite (Al2O3, ore) & $0.00 \%$ & $2.53 \mathrm{E}-03$ & $0.00 \%$ & $4.50 \%$ & $95.49 \%$ \\
\hline (r) Clay (in ground) & $0.00 \%$ & 2.35E-08 & $21.65 \%$ & $2.39 \%$ & $75.97 \%$ \\
\hline (r) Coal (in ground) & $78.05 \%$ & 4.35E+02 & $0.75 \%$ & $0.01 \%$ & $99.24 \%$ \\
\hline (r) Iron (Fe, ore) & $0.02 \%$ & $1.11 \mathrm{E}-01$ & $24.70 \%$ & $2.07 \%$ & $73.22 \%$ \\
\hline (r) Limestone (CaCO3, in ground) & $19.65 \%$ & $1.09 \mathrm{E}+02$ & $0.04 \%$ & $0.00 \%$ & $99.96 \%$ \\
\hline (r) Natural Gas (in ground) & $0.23 \%$ & $1.26 \mathrm{E}+00$ & $35.07 \%$ & $1.57 \%$ & $63.37 \%$ \\
\hline (r) Oil (in ground) & $2.03 \%$ & $1.13 \mathrm{E}+01$ & $2.62 \%$ & $44.62 \%$ & $52.76 \%$ \\
\hline (r) Sand (in ground) & $0.00 \%$ & $2.26 \mathrm{E}-08$ & $0.00 \%$ & $4.50 \%$ & $95.50 \%$ \\
\hline (r) Sodium Chloride ( $\mathrm{NaCl}$, in ground or in sea) & $0.00 \%$ & 7.30E-05 & $1.88 \%$ & $4.32 \%$ & $93.80 \%$ \\
\hline (r) Uranium (U, ore) & $0.00 \%$ & 4.22E-05 & $95.07 \%$ & $0.09 \%$ & $4.84 \%$ \\
\hline Aluminum Scrap & $0.00 \%$ & 6.19E-04 & $0.00 \%$ & $4.50 \%$ & $95.50 \%$ \\
\hline Iron Scrap & $0.02 \%$ & $1.18 \mathrm{E}-01$ & $25.10 \%$ & $2.05 \%$ & $72.86 \%$ \\
\hline Lubricant & $0.00 \%$ & 2.01E-03 & $24.75 \%$ & $2.06 \%$ & $73.18 \%$ \\
\hline Trinitrotoluene (C6H3(NO2)3) & $0.00 \%$ & 4.51E-06 & $0.00 \%$ & $4.50 \%$ & $95.49 \%$ \\
\hline
\end{tabular}

$(r)=$ resource

Table B7: Average Air Emissions per kWh of Net Electricity Produced - NSPS Case (surface mining \& average user by river)

\begin{tabular}{|c|c|c|c|c|c|c|}
\hline & $\begin{array}{l}\% \text { of Total in } \\
\text { this Table }\end{array}$ & $\begin{array}{c}\% \text { of Total in } \\
\text { this Table } \\
\text { except CO2 }\end{array}$ & Total (g/kWh) & $\begin{array}{c}\% \text { of Total from } \\
\text { Surface Coal } \\
\text { Mining }\end{array}$ & $\begin{array}{l}\% \text { of Total from } \\
\text { Transportation }\end{array}$ & $\begin{array}{l}\% \text { of Total } \\
\text { from } \\
\text { Electricity } \\
\text { Generation }\end{array}$ \\
\hline (a) Aldehydes & $0.00 \%$ & $0.00 \%$ & 4.47E-04 & $8.93 \%$ & $41.65 \%$ & $49.42 \%$ \\
\hline (a) Ammonia (NH3) & $0.01 \%$ & $0.56 \%$ & $9.04 \mathrm{E}-02$ & $99.77 \%$ & $0.10 \%$ & $0.13 \%$ \\
\hline (a) antimony & $0.00 \%$ & $0.00 \%$ & $3.76 \mathrm{E}-06$ & $0.00 \%$ & $0.00 \%$ & $100.00 \%$ \\
\hline (a) arsenic & $0.00 \%$ & $0.00 \%$ & 4.52E-05 & $0.00 \%$ & $0.00 \%$ & $100.00 \%$ \\
\hline (a) barium & $0.00 \%$ & $0.00 \%$ & 1.17E-05 & $0.00 \%$ & $0.00 \%$ & $100.00 \%$ \\
\hline (a) beryllium & $0.00 \%$ & $0.00 \%$ & $1.46 \mathrm{E}-06$ & $0.00 \%$ & $0.00 \%$ & $100.00 \%$ \\
\hline (a) boron & $0.00 \%$ & $0.10 \%$ & $1.55 \mathrm{E}-02$ & $0.00 \%$ & $0.00 \%$ & $100.00 \%$ \\
\hline (a) cadmium & $0.00 \%$ & $0.00 \%$ & $3.72 \mathrm{E}-06$ & $0.00 \%$ & $0.00 \%$ & $100.00 \%$ \\
\hline (a) total Carbon Dioxide (CO2) & $98.32 \%$ & & $9.41 \mathrm{E}+02$ & $0.93 \%$ & $1.71 \%$ & $97.36 \%$ \\
\hline (a) Carbon Monoxide (CO) & $0.03 \%$ & $1.54 \%$ & $2.48 \mathrm{E}-01$ & $3.40 \%$ & $37.46 \%$ & $59.14 \%$ \\
\hline (a) Chlorides (Cl-) & $0.00 \%$ & $0.00 \%$ & $5.68 \mathrm{E}-07$ & $0.00 \%$ & $3.19 \%$ & $96.81 \%$ \\
\hline (a) chromium & $0.00 \%$ & $0.00 \%$ & $5.41 \mathrm{E}-05$ & $0.00 \%$ & $0.00 \%$ & $100.00 \%$ \\
\hline (a) cobalt & $0.00 \%$ & $0.00 \%$ & $6.28 \mathrm{E}-06$ & $0.00 \%$ & $0.00 \%$ & $100.00 \%$ \\
\hline (a) copper & $0.00 \%$ & $0.00 \%$ & $2.14 \mathrm{E}-05$ & $0.00 \%$ & $0.00 \%$ & $100.00 \%$ \\
\hline (a) Fluorides (F-) & $0.00 \%$ & $0.00 \%$ & 2.83E-07 & $22.06 \%$ & $2.92 \%$ & $75.02 \%$ \\
\hline (a) non-methane Hydrocarbons (including VOCs) & $0.02 \%$ & $1.26 \%$ & 2.03E-01 & $36.58 \%$ & $26.51 \%$ & $36.91 \%$ \\
\hline (a) Hydrogen Chloride ( $\mathrm{HCl})$ & $0.00 \%$ & $0.00 \%$ & $1.83 \mathrm{E}-06$ & $0.28 \%$ & $2.92 \%$ & $96.80 \%$ \\
\hline (a) Hydrogen Fluoride (HF) & $0.00 \%$ & $0.00 \%$ & 1.69E-07 & $5.27 \%$ & $3.99 \%$ & $90.75 \%$ \\
\hline (a) Hydrogen Sulfide (H2S) & $0.00 \%$ & $0.00 \%$ & 1.17E-08 & $21.65 \%$ & $2.39 \%$ & $75.97 \%$ \\
\hline (a) lead & $0.00 \%$ & $0.00 \%$ & 2.74E-05 & $0.00 \%$ & $0.00 \%$ & $100.00 \%$ \\
\hline (a) manganese & $0.00 \%$ & $0.00 \%$ & 3.93E-05 & $0.00 \%$ & $0.00 \%$ & $100.00 \%$ \\
\hline (a) mercury & $0.00 \%$ & $0.00 \%$ & 3.35E-05 & $0.00 \%$ & $0.00 \%$ & $100.00 \%$ \\
\hline (a) Metals (unspecified) & $0.00 \%$ & $0.00 \%$ & $1.40 \mathrm{E}-09$ & $18.15 \%$ & $2.73 \%$ & $79.12 \%$ \\
\hline (a) Methane $(\mathrm{CH} 4)$ & $0.09 \%$ & $5.21 \%$ & 8.36E-01 & $98.81 \%$ & $0.10 \%$ & $1.09 \%$ \\
\hline (a) molybdenum & $0.00 \%$ & $0.00 \%$ & $3.48 \mathrm{E}-05$ & $0.00 \%$ & $0.00 \%$ & $100.00 \%$ \\
\hline (a) nickel & $0.00 \%$ & $0.00 \%$ & $5.29 \mathrm{E}-05$ & $0.00 \%$ & $0.00 \%$ & $100.00 \%$ \\
\hline (a) Nitrogen Oxides (NOx as NO2) & $0.24 \%$ & $14.58 \%$ & $2.34 \mathrm{E}+00$ & $1.87 \%$ & $7.22 \%$ & $90.92 \%$ \\
\hline (a) Nitrous Oxide (N2O) & $0.00 \%$ & $0.03 \%$ & $4.52 \mathrm{E}-03$ & $20.25 \%$ & $4.97 \%$ & $74.78 \%$ \\
\hline (a) Organic Matter (unspecified) & $0.00 \%$ & $0.02 \%$ & $2.56 \mathrm{E}-03$ & $76.13 \%$ & $10.92 \%$ & $12.95 \%$ \\
\hline (a) total Particulates (unspecified) & $1.02 \%$ & $60.96 \%$ & $9.78 \mathrm{E}+00$ & $0.12 \%$ & $0.17 \%$ & $99.70 \%$ \\
\hline (a) selenium & $0.00 \%$ & $0.00 \%$ & 3.71E-04 & $0.00 \%$ & $0.00 \%$ & $100.00 \%$ \\
\hline (a) Sulfur Oxides (SOx as SO2) & $0.26 \%$ & $15.74 \%$ & $2.53 \mathrm{E}+00$ & $2.58 \%$ & $3.44 \%$ & $93.98 \%$ \\
\hline (a) Tars (unspecified) & $0.00 \%$ & $0.00 \%$ & 4.11E-07 & $21.24 \%$ & $2.42 \%$ & $76.33 \%$ \\
\hline (a) vanadium & $0.00 \%$ & $0.00 \%$ & 8.05E-05 & $0.00 \%$ & $0.00 \%$ & $100.00 \%$ \\
\hline
\end{tabular}

(a) = air emission 
Table B8: Average Water Emissions per kWh of Net Electricity Produced - NSPS Case (surface mining \& average user by river)

\begin{tabular}{|c|c|c|c|c|c|}
\hline & $\begin{array}{c}\% \text { of Total in } \\
\text { this Table }\end{array}$ & Total (g/kWh) & $\begin{array}{c}\% \text { of Total } \\
\text { from Surface } \\
\text { Coal Mining }\end{array}$ & $\begin{array}{l}\% \text { of Total from } \\
\text { Transportation }\end{array}$ & $\begin{array}{c}\% \text { of Total from } \\
\text { Electricity } \\
\text { Generation }\end{array}$ \\
\hline (w) Acids $(\mathrm{H}+)$ & $0.01 \%$ & 2.35E-05 & $99.63 \%$ & $0.01 \%$ & $0.35 \%$ \\
\hline (w) Ammonia (NH4+) & $12.10 \%$ & 2.14E-02 & $100.00 \%$ & $0.00 \%$ & $0.00 \%$ \\
\hline (w) Ammonia (NH4+, $\mathrm{NH} 3$, as $\mathrm{N}$ ) & $0.00 \%$ & $3.52 \mathrm{E}-06$ & $83.69 \%$ & $0.41 \%$ & $15.90 \%$ \\
\hline (w) TOTAL BOD5 (Biological Oxygen Demand) & $0.31 \%$ & 5.49E-04 & $88.87 \%$ & $5.09 \%$ & $6.04 \%$ \\
\hline (w) Chlorides (Cl-) & $0.00 \%$ & 3.42E-06 & $2.62 \%$ & $4.36 \%$ & $93.01 \%$ \\
\hline (w) COD (Chemical Oxygen Demand) & $0.93 \%$ & 1.65E-03 & $88.95 \%$ & $5.08 \%$ & $5.98 \%$ \\
\hline (w) Cyanides (CN-) & $0.00 \%$ & 8.38E-09 & $24.70 \%$ & $2.07 \%$ & $73.22 \%$ \\
\hline (w) Dissolved Matter (unspecified) & $84.76 \%$ & $1.50 \mathrm{E}-01$ & $1.74 \%$ & $39.37 \%$ & $58.89 \%$ \\
\hline (w) Fluorides (F-) & $0.00 \%$ & 7.51E-06 & $84.34 \%$ & $0.39 \%$ & $15.27 \%$ \\
\hline (w) Inorganic Dissolved Matter (unspecified) & $0.00 \%$ & 5.93E-07 & $21.44 \%$ & $2.41 \%$ & $76.15 \%$ \\
\hline (w) Iron $(\mathrm{Fe}++, \mathrm{Fe} 3+)$ & $0.00 \%$ & 1.23E-08 & $95.07 \%$ & $0.09 \%$ & $4.84 \%$ \\
\hline (w) Metals (unspecified) & $0.00 \%$ & 3.60E-07 & $21.17 \%$ & $2.43 \%$ & $76.40 \%$ \\
\hline (w) Nitrates (NO3-) & $0.00 \%$ & $1.50 \mathrm{E}-06$ & $95.07 \%$ & $0.09 \%$ & $4.84 \%$ \\
\hline (w) Nitric acid & $0.67 \%$ & 1.19E-03 & $100.00 \%$ & $0.00 \%$ & $0.00 \%$ \\
\hline (w) Nitrogenous Matter (unspecified, as N) & $0.00 \%$ & 1.17E-08 & $21.65 \%$ & $2.39 \%$ & $75.97 \%$ \\
\hline (w) Oils & $1.03 \%$ & 1.82E-03 & $4.31 \%$ & $41.74 \%$ & $53.95 \%$ \\
\hline (w) Oils (unspecified) & $0.02 \%$ & 2.80E-05 & $0.00 \%$ & $0.00 \%$ & $100.00 \%$ \\
\hline (w) Organic Dissolved Matter (unspecified) & $0.00 \%$ & 2.35E-08 & $21.65 \%$ & $2.39 \%$ & $75.97 \%$ \\
\hline (w) Phenol (C6H6O) & $0.00 \%$ & 2.63E-08 & $24.57 \%$ & $2.09 \%$ & $73.35 \%$ \\
\hline (w) Sodium $(\mathrm{Na}+)$ & $0.00 \%$ & $1.51 \mathrm{E}-06$ & $65.85 \%$ & $1.44 \%$ & $32.70 \%$ \\
\hline (w) Sulfates (SO4--) & $0.00 \%$ & 1.79E-06 & $71.61 \%$ & $1.18 \%$ & $27.22 \%$ \\
\hline (w) Sulfides (S--) & $0.00 \%$ & $1.68 \mathrm{E}-08$ & $24.70 \%$ & $2.07 \%$ & $73.22 \%$ \\
\hline (w) Suspended Matter (unspecified) & $0.13 \%$ & 2.29E-04 & $22.03 \%$ & $12.93 \%$ & $65.05 \%$ \\
\hline (w) Tars (unspecified) & $0.00 \%$ & 5.87E-09 & $21.24 \%$ & $2.42 \%$ & $76.33 \%$ \\
\hline (w) Water: Chemically Polluted & $0.02 \%$ & 3.09E-05 & $0.00 \%$ & $3.48 \%$ & $96.52 \%$ \\
\hline
\end{tabular}

(w) = water emission

Table B9: Average Energy Requirements per kWh of Net Electricity Produced - NSPS Case (surface mining \& average user by river)

\begin{tabular}{|c|c|c|c|c|}
\hline & & $\begin{array}{c}\% \text { of Total } \\
\text { from Surface }\end{array}$ & $\%$ of Total from & $\begin{array}{l}\% \text { of Total from } \\
\text { Electricity }\end{array}$ \\
\hline & Total (MJ/kWh) & Coal Mining & Transportation & Generation \\
\hline Non-electric Energy Consumed by System (excluding coal energy) & 0.6757 & $19.86 \%$ & $31.36 \%$ & $48.78 \%$ \\
\hline Electricity Consumed by System & 0.0314 & $97.39 \%$ & $2.05 \%$ & $0.56 \%$ \\
\hline Total Non-coal Energy Consumed by System & 0.7071 & $23.30 \%$ & $30.06 \%$ & $46.65 \%$ \\
\hline Energy in Coal to Power Plant & 10.8350 & N/A & N/A & N/A \\
\hline Total Energy Consumed by System & 11.5421 & $1.43 \%$ & $1.84 \%$ & $96.73 \%$ \\
\hline
\end{tabular}

Note: The electricity produced and consumed by the power plant is not included in this table.

The power plant energy and electricty requirements are from upstream processes, construction, and decommissioning. 
Table B10: Average Solid Waste Generation per kWh of Net Electricity Produced - NSPS Case (surface mining \& average user by river)

\begin{tabular}{|c|c|c|c|c|c|}
\hline & $\begin{array}{c}\% \text { of Total in } \\
\text { this Table }\end{array}$ & Total (g/kWh) & $\begin{array}{l}\% \text { of Total } \\
\text { from Surface } \\
\text { Coal Mining }\end{array}$ & $\begin{array}{l}\% \text { of Total from } \\
\text { Transportation }\end{array}$ & $\begin{array}{c}\text { \% of Total from } \\
\text { Electricity } \\
\text { Generation }\end{array}$ \\
\hline (s) antimony & $0.00 \%$ & 1.36E-05 & $0.00 \%$ & $0.00 \%$ & $100.00 \%$ \\
\hline (s) arsenic & $0.00 \%$ & 1.19E-04 & $0.00 \%$ & $0.00 \%$ & $100.00 \%$ \\
\hline (s) barium & $0.00 \%$ & 4.00E-04 & $0.00 \%$ & $0.00 \%$ & $100.00 \%$ \\
\hline (s) beryllium & $0.00 \%$ & $1.29 \mathrm{E}-05$ & $0.00 \%$ & $0.00 \%$ & $100.00 \%$ \\
\hline (s) boron & $0.00 \%$ & 6.57E-04 & $0.00 \%$ & $0.00 \%$ & $100.00 \%$ \\
\hline (s) cadmium & $0.00 \%$ & 8.99E-06 & $0.00 \%$ & $0.00 \%$ & $100.00 \%$ \\
\hline (s) chromium & $0.00 \%$ & 2.03E-04 & $0.00 \%$ & $0.00 \%$ & $100.00 \%$ \\
\hline (s) cobalt & $0.00 \%$ & 4.25E-05 & $0.00 \%$ & $0.00 \%$ & $100.00 \%$ \\
\hline (s) copper & $0.00 \%$ & $1.05 E-04$ & $0.00 \%$ & $0.00 \%$ & $100.00 \%$ \\
\hline (s) lead & $0.00 \%$ & 9.15E-05 & $0.00 \%$ & $0.00 \%$ & $100.00 \%$ \\
\hline (s) manganese & $0.00 \%$ & 2.49E-04 & $0.00 \%$ & $0.00 \%$ & $100.00 \%$ \\
\hline (s) mercury & $0.00 \%$ & $1.52 \mathrm{E}-07$ & $0.00 \%$ & $0.00 \%$ & $100.00 \%$ \\
\hline (s) molybdenum & $0.00 \%$ & 3.56E-05 & $0.00 \%$ & $0.00 \%$ & $100.00 \%$ \\
\hline (s) nickel & $0.00 \%$ & $1.43 \mathrm{E}-04$ & $0.00 \%$ & $0.00 \%$ & $100.00 \%$ \\
\hline (s) selenium & $0.00 \%$ & $9.40 \mathrm{E}-06$ & $0.00 \%$ & $0.00 \%$ & $100.00 \%$ \\
\hline (s) vanadium & $0.00 \%$ & 2.90E-04 & $0.00 \%$ & $0.00 \%$ & $100.00 \%$ \\
\hline ash - landfilled (dry) & $20.71 \%$ & $2.35 \mathrm{E}+01$ & $0.00 \%$ & $0.00 \%$ & $100.00 \%$ \\
\hline FGC waste (dry) - landfilled & $60.75 \%$ & $6.89 \mathrm{E}+01$ & $0.00 \%$ & $0.00 \%$ & $100.00 \%$ \\
\hline Waste (hazardous) & $0.00 \%$ & 3.43E-09 & $7.40 \%$ & $3.78 \%$ & $88.82 \%$ \\
\hline Waste (municipal and industrial) & $0.12 \%$ & $1.42 \mathrm{E}-01$ & $23.66 \%$ & $1.96 \%$ & $74.38 \%$ \\
\hline Waste (unspecified) & $18.42 \%$ & $2.09 E+01$ & $8.05 \%$ & $0.05 \%$ & $91.90 \%$ \\
\hline
\end{tabular}

(s) = solid emission 
Table B11: Average Resource Consumption per kWh of Net Electricity Produced - NSPS Case (underground mining \& average user by river)

\begin{tabular}{|c|c|c|c|c|c|}
\hline & $\begin{array}{l}\% \text { of Total in } \\
\text { this Table }\end{array}$ & Total (g/kWh) & $\begin{array}{l}\text { \% of Total } \\
\text { from } \\
\text { Underground } \\
\text { Coal Mining }\end{array}$ & $\begin{array}{l}\% \text { of Total from } \\
\text { Transportation }\end{array}$ & $\begin{array}{c}\% \text { of Total from } \\
\text { Electricity } \\
\text { Generation }\end{array}$ \\
\hline (r) Bauxite (Al2O3, ore) & $0.00 \%$ & 2.53E-03 & $0.01 \%$ & $4.50 \%$ & $95.49 \%$ \\
\hline (r) Clay (in ground) & $0.00 \%$ & 2.06E-08 & $10.89 \%$ & $2.71 \%$ & $86.40 \%$ \\
\hline (r) Coal (in ground) & $76.76 \%$ & $4.35 \mathrm{E}+02$ & $0.67 \%$ & $0.01 \%$ & $99.33 \%$ \\
\hline (r) Iron (Fe, ore) & $0.02 \%$ & 9.54E-02 & $12.69 \%$ & $2.41 \%$ & $84.90 \%$ \\
\hline (r) Limestone ( $\mathrm{CaCO} 3$, in ground) & $21.00 \%$ & $1.19 \mathrm{E}+02$ & $7.93 \%$ & $0.00 \%$ & $92.07 \%$ \\
\hline (r) Natural Gas (in ground) & $0.16 \%$ & 8.93E-01 & $8.55 \%$ & $2.21 \%$ & $89.24 \%$ \\
\hline (r) Oil (in ground) & $2.05 \%$ & $1.16 \mathrm{E}+01$ & $5.08 \%$ & $43.49 \%$ & $51.43 \%$ \\
\hline (r) Sand (in ground) & $0.00 \%$ & $2.26 \mathrm{E}-08$ & $0.01 \%$ & $4.50 \%$ & $95.49 \%$ \\
\hline (r) Sodium Chloride ( $\mathrm{NaCl}$, in ground or in sea) & $0.00 \%$ & 7.23E-05 & $0.85 \%$ & $4.37 \%$ & $94.79 \%$ \\
\hline (r) Uranium (U, ore) & $0.00 \%$ & 3.75E-05 & $94.46 \%$ & $0.10 \%$ & $5.44 \%$ \\
\hline Aluminum Scrap & $0.00 \%$ & $6.19 \mathrm{E}-04$ & $0.01 \%$ & $4.50 \%$ & $95.49 \%$ \\
\hline Iron Scrap & $0.02 \%$ & $1.01 \mathrm{E}-01$ & $12.90 \%$ & $2.38 \%$ & $84.72 \%$ \\
\hline Lubricant & $0.00 \%$ & $1.73 \mathrm{E}-03$ & $12.70 \%$ & $2.39 \%$ & $84.91 \%$ \\
\hline Trinitrotoluene (C6H3(NO2)3) & $0.00 \%$ & 4.51E-06 & $0.01 \%$ & $4.50 \%$ & $95.49 \%$ \\
\hline
\end{tabular}

$(r)=$ resource

Table B12: Average Air Emissions per kWh of Net Electricity Produced - NSPS Case (underground mining \& average user by river)

\begin{tabular}{|c|c|c|c|c|c|c|}
\hline & $\begin{array}{c}\% \text { of Total in } \\
\text { this Table }\end{array}$ & $\begin{array}{c}\% \text { of Total in } \\
\text { this Table } \\
\text { except CO2 }\end{array}$ & Total (g/kWh) & $\begin{array}{c}\% \text { of Total from } \\
\text { Underground } \\
\text { Coal Mining }\end{array}$ & $\begin{array}{l}\% \text { of Total from } \\
\text { Transportation }\end{array}$ & $\begin{array}{c}\% \text { of Total } \\
\text { from } \\
\text { Electricity } \\
\text { Generation }\end{array}$ \\
\hline (a) Aldehydes & $0.00 \%$ & $0.00 \%$ & 4.55E-04 & $10.52 \%$ & $40.92 \%$ & $48.56 \%$ \\
\hline (a) Ammonia (NH3) & $0.00 \%$ & $0.00 \%$ & $2.18 \mathrm{E}-04$ & $4.86 \%$ & $42.73 \%$ & $52.40 \%$ \\
\hline (a) antimony & $0.00 \%$ & $0.00 \%$ & 3.76E-06 & $0.00 \%$ & $0.00 \%$ & $100.00 \%$ \\
\hline (a) arsenic & $0.00 \%$ & $0.00 \%$ & 4.52E-05 & $0.00 \%$ & $0.00 \%$ & $100.00 \%$ \\
\hline (a) barium & $0.00 \%$ & $0.00 \%$ & 1.17E-05 & $0.00 \%$ & $0.00 \%$ & $100.00 \%$ \\
\hline (a) beryllium & $0.00 \%$ & $0.00 \%$ & $1.46 \mathrm{E}-06$ & $0.00 \%$ & $0.00 \%$ & $100.00 \%$ \\
\hline (a) boron & $0.00 \%$ & $0.09 \%$ & $1.55 \mathrm{E}-02$ & $0.00 \%$ & $0.00 \%$ & $100.00 \%$ \\
\hline (a) cadmium & $0.00 \%$ & $0.00 \%$ & $3.72 \mathrm{E}-06$ & $0.00 \%$ & $0.00 \%$ & $100.00 \%$ \\
\hline (a) total Carbon Dioxide (CO2) & $98.14 \%$ & & $9.40 \mathrm{E}+02$ & $0.85 \%$ & $1.71 \%$ & $97.45 \%$ \\
\hline (a) Carbon Monoxide (CO) & $0.03 \%$ & $1.36 \%$ & $2.42 \mathrm{E}-01$ & $1.01 \%$ & $38.38 \%$ & $60.60 \%$ \\
\hline (a) Chlorides (Cl-) & $0.00 \%$ & $0.00 \%$ & 5.68E-07 & $0.01 \%$ & $3.19 \%$ & $96.80 \%$ \\
\hline (a) chromium & $0.00 \%$ & $0.00 \%$ & $5.41 \mathrm{E}-05$ & $0.00 \%$ & $0.00 \%$ & $100.00 \%$ \\
\hline (a) cobalt & $0.00 \%$ & $0.00 \%$ & $6.28 \mathrm{E}-06$ & $0.00 \%$ & $0.00 \%$ & $100.00 \%$ \\
\hline (a) copper & $0.00 \%$ & $0.00 \%$ & $2.14 \mathrm{E}-05$ & $0.00 \%$ & $0.00 \%$ & $100.00 \%$ \\
\hline (a) Fluorides (F-) & $0.00 \%$ & $0.00 \%$ & $2.62 \mathrm{E}-07$ & $15.88 \%$ & $3.15 \%$ & $80.97 \%$ \\
\hline (a) non-methane Hydrocarbons (including VOCs) & $0.02 \%$ & $1.07 \%$ & $1.90 \mathrm{E}-01$ & $32.15 \%$ & $28.36 \%$ & $39.49 \%$ \\
\hline (a) Hydrogen Chloride $(\mathrm{HCl})$ & $0.00 \%$ & $0.00 \%$ & $1.82 \mathrm{E}-06$ & $0.13 \%$ & $2.93 \%$ & $96.94 \%$ \\
\hline (a) Hydrogen Fluoride (HF) & $0.00 \%$ & $0.00 \%$ & $1.64 \mathrm{E}-07$ & $2.41 \%$ & $4.11 \%$ & $93.48 \%$ \\
\hline (a) Hydrogen Sulfide (H2S) & $0.00 \%$ & $0.00 \%$ & $1.03 \mathrm{E}-08$ & $10.89 \%$ & $2.71 \%$ & $86.40 \%$ \\
\hline (a) lead & $0.00 \%$ & $0.00 \%$ & 2.74E-05 & $0.00 \%$ & $0.00 \%$ & $100.00 \%$ \\
\hline (a) manganese & $0.00 \%$ & $0.00 \%$ & 3.93E-05 & $0.00 \%$ & $0.00 \%$ & $100.00 \%$ \\
\hline (a) mercury & $0.00 \%$ & $0.00 \%$ & 3.35E-05 & $0.00 \%$ & $0.00 \%$ & $100.00 \%$ \\
\hline (a) Metals (unspecified) & $0.00 \%$ & $0.00 \%$ & $1.26 \mathrm{E}-09$ & $8.93 \%$ & $3.03 \%$ & $88.03 \%$ \\
\hline (a) Methane $(\mathrm{CH} 4)$ & $0.19 \%$ & $10.29 \%$ & $1.83 \mathrm{E}+00$ & $99.46 \%$ & $0.05 \%$ & $0.50 \%$ \\
\hline (a) molybdenum & $0.00 \%$ & $0.00 \%$ & $3.48 \mathrm{E}-05$ & $0.00 \%$ & $0.00 \%$ & $100.00 \%$ \\
\hline (a) nickel & $0.00 \%$ & $0.00 \%$ & $5.29 \mathrm{E}-05$ & $0.00 \%$ & $0.00 \%$ & $100.00 \%$ \\
\hline (a) Nitrogen Oxides (NOx as NO2) & $0.24 \%$ & $13.12 \%$ & $2.33 E+00$ & $1.45 \%$ & $7.25 \%$ & $91.30 \%$ \\
\hline (a) Nitrous Oxide (N2O) & $0.00 \%$ & $0.02 \%$ & $4.41 \mathrm{E}-03$ & $18.16 \%$ & $5.10 \%$ & $76.74 \%$ \\
\hline (a) Organic Matter (unspecified) & $0.00 \%$ & $0.00 \%$ & $6.97 \mathrm{E}-04$ & $12.33 \%$ & $40.12 \%$ & $47.56 \%$ \\
\hline (a) total Particulates (unspecified) & $1.11 \%$ & $59.81 \%$ & $1.06 \mathrm{E}+01$ & $8.04 \%$ & $0.16 \%$ & $91.80 \%$ \\
\hline (a) selenium & $0.00 \%$ & $0.00 \%$ & $3.71 \mathrm{E}-04$ & $0.00 \%$ & $0.00 \%$ & $100.00 \%$ \\
\hline (a) Sulfur Oxides (SOx as SO2) & $0.26 \%$ & $14.24 \%$ & $2.53 E+00$ & $2.72 \%$ & $3.43 \%$ & $93.84 \%$ \\
\hline (a) Tars (unspecified) & $0.00 \%$ & $0.00 \%$ & $3.62 \mathrm{E}-07$ & $10.66 \%$ & $2.75 \%$ & $86.59 \%$ \\
\hline (a) vanadium & $0.00 \%$ & $0.00 \%$ & $8.05 \mathrm{E}-05$ & $0.00 \%$ & $0.00 \%$ & $100.00 \%$ \\
\hline
\end{tabular}


Table B13: Average Water Emissions per kWh of Net Electricity Produced - NSPS Case (underground mining \& avg user by river)

(w) Acids $(\mathrm{H}+)$

(w) Ammonia (NH4+)

(w) Ammonia $(\mathrm{NH} 4+, \mathrm{NH} 3$, as $\mathrm{N}$ )

(w) TOTAL BOD5 (Biological Oxygen Demand)

(w) Chlorides (Cl-)

(w) COD (Chemical Oxygen Demand)

(w) Cyanides (CN-)

(w) Dissolved Matter (unspecified)

(w) Fluorides (F-)

(w) Inorganic Dissolved Matter (unspecified)

(w) Iron (Fe++, $\mathrm{Fe} 3+$ )

(w) Metals (unspecified)

(w) Nitrates (NO3-)

(w) Nitric acid

(w) Nitrogenous Matter (unspecified, as N)

(w) Oils

(w) Oils (unspecified)

(w) Organic Dissolved Matter (unspecified)

(w) Phenol (C6H6O)

(w) Sodium ( $\mathrm{Na}+)$

(w) Sulfates (SO4--)

(w) Sulfides (S--)

(w) Suspended Matter (unspecified)

(w) Tars (unspecified)

(w) Water: Chemically Polluted

(w) = water emission
$\%$ of Total

from

$\%$ of Total in

this Table Total $(\mathrm{g} / \mathrm{kWh})$

$0.00 \% \quad 9.24 \mathrm{E}-08$

$0.00 \% \quad 0.00 \mathrm{E}+00$

$0.00 \% \quad 3.12 \mathrm{E}-06$

$0.04 \% \quad 6.42 \mathrm{E}-05$

$0.00 \% \quad 3.40 \mathrm{E}-06$

$0.12 \% \quad 1.91 \mathrm{E}-04$

$0.00 \% \quad 7.23 \mathrm{E}-09$

$98.50 \% \quad 1.56 \mathrm{E}-01$

$0.00 \% \quad 6.65 \mathrm{E}-06$

$0.00 \% \quad 5.22 \mathrm{E}-07$

$0.00 \%$

$0.00 \%$

$0.00 \%$

$0.00 \%$

$0.00 \%$

$1.17 \%$

$0.02 \%$

$0.00 \%$

$0.00 \%$

$0.00 \%$

$0.00 \%$

$0.00 \%$

$0.12 \%$

$0.00 \%$

$0.02 \%$
$1.09 \mathrm{E}-08$

3.18E-07

1.34E-06

$0.00 \mathrm{E}+00$

1.03E-08

$1.84 \mathrm{E}-03$

2.80E-05

2.06E-08

2.27E-08

1.39E-06

$1.64 \mathrm{E}-06$

$1.45 \mathrm{E}-08$

1.92E-04

5.18E-09

3.09E-05
Underground \% of Total from

Coal Mining Transportation

$\begin{array}{ll}7.30 \% & 3.30 \%\end{array}$

$0.00 \%$

$81.57 \%$

$4.69 \%$

$2.17 \%$

$4.65 \%$

$12.69 \%$

$5.21 \%$

$82.30 \%$

$10.77 \%$

$94.46 \%$

$10.62 \%$

$94.46 \%$

$0.00 \%$

$10.89 \%$

$5.19 \%$

$0.00 \%$

$10.89 \%$

$12.61 \%$

$63.02 \%$

$69.02 \%$

$12.69 \%$

$7.20 \%$

$10.66 \%$

$0.01 \%$
$0.00 \%$

$0.46 \%$

$43.57 \%$

$4.38 \%$

$43.80 \%$

$2.41 \%$

$37.98 \%$

$0.44 \%$

$2.73 \%$

$0.10 \%$

$2.76 \%$

$0.10 \%$

$0.00 \%$

$2.71 \%$

$41.35 \%$

$0.00 \%$

$2.71 \%$

$2.42 \%$

$1.56 \%$

$1.28 \%$

$2.41 \%$

$15.38 \%$

$2.75 \%$

$3.48 \%$
$\%$ of Total from

Electricity

Generation

$89.41 \%$

$0.00 \%$

$17.97 \%$

$51.73 \%$

$93.45 \%$

$51.55 \%$

$84.90 \%$

$56.81 \%$

$17.26 \%$

$86.50 \%$

$5.44 \%$

$86.63 \%$

$5.44 \%$

$0.00 \%$

$86.40 \%$

$53.45 \%$

$100.00 \%$

$86.40 \%$

$84.97 \%$

$35.42 \%$

$29.69 \%$

$84.90 \%$

$77.42 \%$

$86.59 \%$

$96.51 \%$

Table B14: Average Energy Requirements per kWh of Net Electricity Produced - NSPS Case (underground mining \& avg user by river)

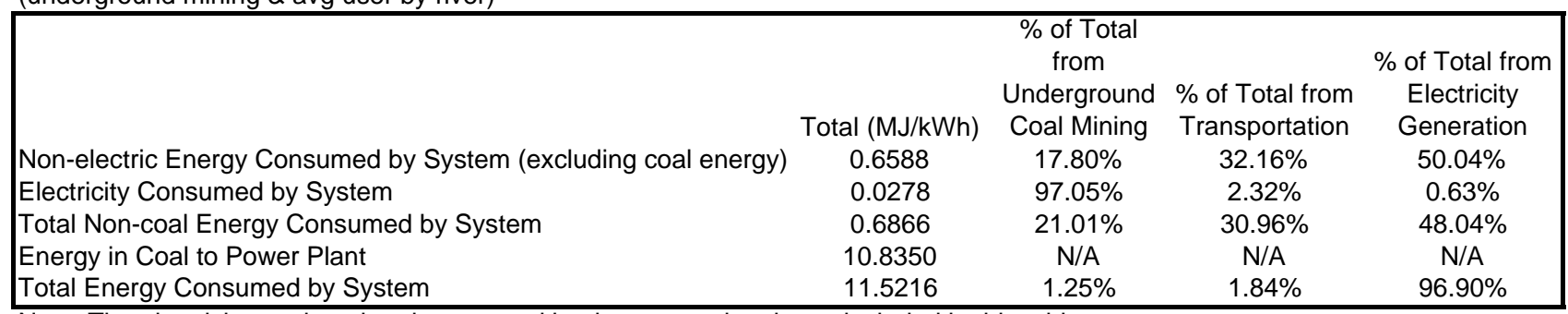

Note: The electricity produced and consumed by the power plant is not included in this table.

The power plant energy and electricty requirements are from upstream processes, construction, and decommissioning. 
Table B15: Average Solid Waste Generation per kWh of Net Electricity Produced - NSPS Case (underground mining \& avg user by river)

(s) antimony

(s) arsenic

(s) barium

(s) beryllium

(s) boron

(s) cadmium

(s) chromium

(s) cobalt

(s) copper

(s) lead

(s) manganese

(s) mercury

(s) molybdenum

(s) nickel

(s) selenium

(s) vanadium

ash - landfilled (dry)

FGC waste (dry) - landfilled

Waste (hazardous)

Waste (municipal and industrial)

Waste (unspecified)

(s) = solid emission
$\%$ of Total

from

$\%$ of Total in

this Table Total $(\mathrm{g} / \mathrm{kWh})$

$0.00 \%$

1.36E-05

Underground \% of Total from

Coal Mining Transportation

$0.00 \% \quad 0.00 \%$

$0.00 \% \quad 0.00 \%$

$0.00 \% \quad 0.00 \%$

$0.00 \% \quad 0.00 \%$

$0.00 \% \quad 0.00 \%$

$0.00 \%$

$0.00 \%$

$0.00 \%$

$0.00 \%$

$0.00 \%$

$0.00 \%$

$0.00 \%$

$0.00 \%$

$0.00 \%$

$0.00 \%$

$0.00 \%$

$0.00 \%$

$0.00 \%$

$0.00 \%$

$0.00 \%$

$0.00 \%$

$0.00 \%$

$0.00 \%$

$0.00 \%$

$0.00 \%$

$0.00 \%$

$0.00 \%$

$0.00 \%$

$0.00 \%$

$0.00 \%$

$3.94 \%$

$3.42 \%$

$2.24 \%$

$0.11 \%$

3.29E-09

$12.56 \%$

$2.24 \mathrm{E}+01$
$\%$ of Total from Electricity

Generation $100.00 \%$

$100.00 \%$

$100.00 \%$

$100.00 \%$

$100.00 \%$

$100.00 \%$

$100.00 \%$

$100.00 \%$

$100.00 \%$

$100.00 \%$

$100.00 \%$

$100.00 \%$

$100.00 \%$

$100.00 \%$

$100.00 \%$

$100.00 \%$

$100.00 \%$

$100.00 \%$

$92.64 \%$

$85.19 \%$

$85.65 \%$ 
Table B16: Average Resource Consumption per kWh of Net Electricity Produced - LEBS Case (surface mining \& average user by river)

\begin{tabular}{|c|c|c|c|c|c|}
\hline & $\begin{array}{l}\% \text { of Total in } \\
\text { this Table }\end{array}$ & Total (g/kWh) & $\begin{array}{l}\% \text { of Total } \\
\text { from Surface } \\
\text { Coal Mining }\end{array}$ & $\begin{array}{l}\% \text { of Total from } \\
\text { Transportation }\end{array}$ & $\begin{array}{c}\% \text { of Total from } \\
\text { Electricity } \\
\text { Generation }\end{array}$ \\
\hline (r) Bauxite (Al2O3, ore) & $0.00 \%$ & $2.50 \mathrm{E}-03$ & $0.00 \%$ & $3.69 \%$ & $96.30 \%$ \\
\hline (r) Clay (in ground) & $0.00 \%$ & 2.07E-08 & $19.99 \%$ & $2.20 \%$ & $77.81 \%$ \\
\hline (r) Coal (in ground) & $97.34 \%$ & $3.53 \mathrm{E}+02$ & $0.75 \%$ & $0.01 \%$ & $99.24 \%$ \\
\hline (r) Iron (Fe, ore) & $0.03 \%$ & 9.54E-02 & $23.29 \%$ & $1.96 \%$ & $74.75 \%$ \\
\hline (r) Limestone (CaCO3, in ground) & $0.01 \%$ & 3.96E-02 & $81.38 \%$ & $0.48 \%$ & $18.14 \%$ \\
\hline (r) Natural Gas (in ground) & $1.25 \%$ & $4.53 \mathrm{E}+00$ & $7.91 \%$ & $0.35 \%$ & $91.74 \%$ \\
\hline (r) Oil (in ground) & $1.34 \%$ & $4.88 \mathrm{E}+00$ & $4.94 \%$ & $84.18 \%$ & $10.88 \%$ \\
\hline (r) Sand (in ground) & $0.00 \%$ & 2.24E-08 & $0.00 \%$ & $3.69 \%$ & $96.30 \%$ \\
\hline (r) Sodium Chloride ( $\mathrm{NaCl}$, in ground or in sea) & $0.00 \%$ & 7.17E-05 & $1.56 \%$ & $3.58 \%$ & $94.86 \%$ \\
\hline (r) Uranium (U, ore) & $0.00 \%$ & 3.23E-05 & $100.89 \%$ & $0.09 \%$ & $-0.98 \%$ \\
\hline Aluminum Scrap & $0.00 \%$ & 6.13E-04 & $0.00 \%$ & $3.69 \%$ & $96.30 \%$ \\
\hline Iron Scrap & $0.03 \%$ & 1.02E-01 & $23.65 \%$ & $1.93 \%$ & $74.42 \%$ \\
\hline Lubricant & $0.00 \%$ & 1.73E-03 & $23.28 \%$ & $1.94 \%$ & $74.78 \%$ \\
\hline Trinitrotoluene (C6H3(NO2)3) & $0.00 \%$ & 4.47E-06 & $0.00 \%$ & $3.69 \%$ & $96.30 \%$ \\
\hline
\end{tabular}

$(r)=$ resource

Table B17: Average Air Emissions per kWh of Net Electricity Produced - LEBS Case (surface mining \& average user by river)

\begin{tabular}{|c|c|c|c|c|c|c|}
\hline & $\begin{array}{l}\% \text { of Total in } \\
\text { this Table }\end{array}$ & $\begin{array}{c}\% \text { of Total in } \\
\text { this Table } \\
\text { except CO2 }\end{array}$ & Total (g/kWh) & $\begin{array}{c}\% \text { of Total from } \\
\text { Surface Coal } \\
\text { Mining }\end{array}$ & $\begin{array}{l}\% \text { of Total from } \\
\text { Transportation }\end{array}$ & $\begin{array}{c}\% \text { of Total } \\
\text { from } \\
\text { Electricity } \\
\text { Generation }\end{array}$ \\
\hline (a) Aldehydes & $0.00 \%$ & $0.01 \%$ & $1.97 \mathrm{E}-04$ & $16.50 \%$ & $76.96 \%$ & $6.54 \%$ \\
\hline (a) Ammonia (NH3) & $0.01 \%$ & $2.87 \%$ & 7.34E-02 & $99.88 \%$ & $0.10 \%$ & $0.01 \%$ \\
\hline (a) antimony & $0.00 \%$ & $0.00 \%$ & 3.06E-06 & $0.00 \%$ & $0.00 \%$ & $100.00 \%$ \\
\hline (a) arsenic & $0.00 \%$ & $0.00 \%$ & $3.68 \mathrm{E}-05$ & $0.00 \%$ & $0.00 \%$ & $100.00 \%$ \\
\hline (a) barium & $0.00 \%$ & $0.00 \%$ & $9.50 \mathrm{E}-06$ & $0.00 \%$ & $0.00 \%$ & $100.00 \%$ \\
\hline (a) beryllium & $0.00 \%$ & $0.00 \%$ & 1.19E-06 & $0.00 \%$ & $0.00 \%$ & $100.00 \%$ \\
\hline (a) boron & $0.00 \%$ & $0.49 \%$ & $1.26 \mathrm{E}-02$ & $0.00 \%$ & $0.00 \%$ & $100.00 \%$ \\
\hline (a) cadmium & $0.00 \%$ & $0.00 \%$ & $3.02 \mathrm{E}-06$ & $0.00 \%$ & $0.00 \%$ & $100.00 \%$ \\
\hline (a) total Carbon Dioxide (CO2) & $99.66 \%$ & & $7.41 \mathrm{E}+02$ & $0.96 \%$ & $1.76 \%$ & $97.28 \%$ \\
\hline (a) Carbon Monoxide (CO) & $0.03 \%$ & $7.47 \%$ & $1.91 \mathrm{E}-01$ & $3.58 \%$ & $39.52 \%$ & $56.89 \%$ \\
\hline (a) Chlorides (Cl-) & $0.00 \%$ & $0.00 \%$ & $5.64 \mathrm{E}-07$ & $0.00 \%$ & $2.61 \%$ & $97.39 \%$ \\
\hline (a) chromium & $0.00 \%$ & $0.00 \%$ & 4.40E-05 & $0.00 \%$ & $0.00 \%$ & $100.00 \%$ \\
\hline (a) cobalt & $0.00 \%$ & $0.00 \%$ & 5.11E-06 & $0.00 \%$ & $0.00 \%$ & $100.00 \%$ \\
\hline (a) copper & $0.00 \%$ & $0.00 \%$ & $1.74 \mathrm{E}-05$ & $0.00 \%$ & $0.00 \%$ & $100.00 \%$ \\
\hline (a) Fluorides (F-) & $0.00 \%$ & $0.00 \%$ & 2.57E-07 & $19.72 \%$ & $2.61 \%$ & $77.66 \%$ \\
\hline (a) non-methane Hydrocarbons (including VOCs) & $0.03 \%$ & $7.48 \%$ & $1.91 \mathrm{E}-01$ & $31.53 \%$ & $22.85 \%$ & $45.62 \%$ \\
\hline (a) Hydrogen Chloride $(\mathrm{HCl})$ & $0.00 \%$ & $0.00 \%$ & $1.81 \mathrm{E}-06$ & $0.23 \%$ & $2.40 \%$ & $97.38 \%$ \\
\hline (a) Hydrogen Fluoride (HF) & $0.00 \%$ & $0.00 \%$ & 1.63E-07 & $4.44 \%$ & $3.36 \%$ & $92.19 \%$ \\
\hline (a) Hydrogen Sulfide (H2S) & $0.00 \%$ & $0.00 \%$ & 1.03E-08 & $19.99 \%$ & $2.20 \%$ & $77.81 \%$ \\
\hline (a) lead & $0.00 \%$ & $0.00 \%$ & 2.23E-05 & $0.00 \%$ & $0.00 \%$ & $100.00 \%$ \\
\hline (a) manganese & $0.00 \%$ & $0.00 \%$ & 3.19E-05 & $0.00 \%$ & $0.00 \%$ & $100.00 \%$ \\
\hline (a) mercury & $0.00 \%$ & $0.00 \%$ & $2.72 \mathrm{E}-05$ & $0.00 \%$ & $0.00 \%$ & $100.00 \%$ \\
\hline (a) Metals (unspecified) & $0.00 \%$ & $0.00 \%$ & 1.26E-09 & $16.43 \%$ & $2.47 \%$ & $81.10 \%$ \\
\hline (a) Methane $(\mathrm{CH} 4)$ & $0.10 \%$ & $27.91 \%$ & 7.14E-01 & $94.07 \%$ & $0.10 \%$ & $5.84 \%$ \\
\hline (a) molybdenum & $0.00 \%$ & $0.00 \%$ & 2.83E-05 & $0.00 \%$ & $0.00 \%$ & $100.00 \%$ \\
\hline (a) nickel & $0.00 \%$ & $0.00 \%$ & 4.30E-05 & $0.00 \%$ & $0.00 \%$ & $100.00 \%$ \\
\hline (a) Nitrogen Oxides (NOx as NO2) & $0.07 \%$ & $21.27 \%$ & $5.44 \mathrm{E}-01$ & $6.53 \%$ & $25.24 \%$ & $68.23 \%$ \\
\hline (a) Nitrous Oxide (N2O) & $0.00 \%$ & $0.05 \%$ & 1.19E-03 & $62.34 \%$ & $15.29 \%$ & $22.38 \%$ \\
\hline (a) Organic Matter (unspecified) & $0.00 \%$ & $0.07 \%$ & $1.86 \mathrm{E}-03$ & $85.13 \%$ & $12.21 \%$ & $2.65 \%$ \\
\hline (a) total Particulates (unspecified) & $0.02 \%$ & $4.39 \%$ & $1.12 \mathrm{E}-01$ & $8.66 \%$ & $12.24 \%$ & $79.11 \%$ \\
\hline (a) selenium & $0.00 \%$ & $0.01 \%$ & $3.01 \mathrm{E}-04$ & $0.00 \%$ & $0.00 \%$ & $100.00 \%$ \\
\hline (a) Sulfur Oxides (SOx as SO2) & $0.10 \%$ & $27.97 \%$ & 7.15E-01 & $7.41 \%$ & $9.86 \%$ & $82.72 \%$ \\
\hline (a) Tars (unspecified) & $0.00 \%$ & $0.00 \%$ & 3.63E-07 & $19.57 \%$ & $2.23 \%$ & $78.19 \%$ \\
\hline (a) vanadium & $0.00 \%$ & $0.00 \%$ & $6.54 \mathrm{E}-05$ & $0.00 \%$ & $0.00 \%$ & $100.00 \%$ \\
\hline
\end{tabular}


Table B18: Average Water Emissions per kWh of Net Electricity Produced - LEBS Case (surface mining \& average user by river)

(w) Acids $(\mathrm{H}+)$

(w) Ammonia $(\mathrm{NH} 4+)$

(w) Ammonia (NH4+, $\mathrm{NH} 3$, as $\mathrm{N}$ )

(w) TOTAL BOD5 (Biological Oxygen Demand)

(w) Chlorides (Cl-)

(w) COD (Chemical Oxygen Demand)

(w) Cyanides (CN-)

(w) Dissolved Matter (unspecified)

(w) Fluorides (F-)

(w) Inorganic Dissolved Matter (unspecified)

(w) Iron $(\mathrm{Fe}++, \mathrm{Fe} 3+)$

(w) Metals (unspecified)

(w) Nitrates (NO3-)

(w) Nitric acid

(w) Nitrogenous Matter (unspecified, as N)

(w) Oils

(w) Oils (unspecified)

(w) Organic Dissolved Matter (unspecified)

(w) Phenol $(\mathrm{C} 6 \mathrm{H} 6 \mathrm{O})$

(w) Sodium $(\mathrm{Na}+)$

(w) Sulfates (SO4--)

(w) Sulfides (S--)

(w) Suspended Matter (unspecified)

(w) Tars (unspecified)

(w) Water: Chemically Polluted

(w) = water emission
$\%$ of Total in this Table

$0.03 \%$

$22.72 \%$

$0.01 \%$

$0.66 \%$

$0.00 \%$

$1.98 \%$

$0.00 \%$

$71.46 \%$

$0.01 \%$

$0.00 \%$

$0.00 \%$

$0.00 \%$

$0.00 \%$

$1.26 \%$

$0.00 \%$

$1.26 \%$

$0.00 \%$

$0.00 \%$

$0.00 \%$

$0.00 \%$

$0.00 \%$

$0.00 \%$

$0.56 \%$

$0.00 \%$

$0.04 \%$
$\%$ of Total

from Surface

Coal Mining

$82.11 \%$

$100.00 \%$

$43.53 \%$

$78.36 \%$

$2.17 \%$

$78.41 \%$

$23.29 \%$

$3.87 \%$

$87.81 \%$

$19.78 \%$

$100.89 \%$

$19.50 \%$

$100.89 \%$

$100.00 \%$

$19.99 \%$

$6.63 \%$

$0.00 \%$

$19.99 \%$

$23.14 \%$

$64.10 \%$

$70.85 \%$

$23.29 \%$

$9.47 \%$

$19.57 \%$

$0.00 \%$
$\%$ of Total from

Transportation

$0.01 \%$

$0.00 \%$

$0.21 \%$

$4.49 \%$

$3.61 \%$

$4.48 \%$

$1.96 \%$

$87.68 \%$

$0.41 \%$

$2.22 \%$

$0.09 \%$

$2.24 \%$

$0.09 \%$

$0.00 \%$

$2.20 \%$

$64.29 \%$

$0.00 \%$

$2.20 \%$

$1.97 \%$

$1.41 \%$

$1.17 \%$

$1.96 \%$

$5.56 \%$

$2.23 \%$

$2.85 \%$
$\%$ of Total from

Electricity

Generation

$17.88 \%$

$0.00 \%$

$56.26 \%$

$17.15 \%$

$94.23 \%$

$17.11 \%$

$74.75 \%$

$8.45 \%$

$11.78 \%$

$78.01 \%$

$-0.98 \%$

$78.26 \%$

$-0.98 \%$

$0.00 \%$

$77.81 \%$

$29.07 \%$

$0.00 \%$

$77.81 \%$

$74.89 \%$

$34.50 \%$

$27.98 \%$

$74.75 \%$

$84.98 \%$

$78.19 \%$

$97.15 \%$

Table B19: Average Energy Requirements per kWh of Net Electricity Produced - LEBS Case (surface mining \& average user by river)

\begin{tabular}{|c|c|c|c|c|}
\hline & Total (MJ/kWh) & $\begin{array}{c}\% \text { of Total } \\
\text { from Surface } \\
\text { Coal Mining }\end{array}$ & $\begin{array}{l}\% \text { of Total from } \\
\text { Transportation }\end{array}$ & $\begin{array}{c}\% \text { of Total from } \\
\text { Electricity } \\
\text { Generation }\end{array}$ \\
\hline Non-electric Energy Consumed by System (excluding coal energy) & 0.5109 & $21.35 \%$ & $33.71 \%$ & $44.94 \%$ \\
\hline Electricity Consumed by System & 0.0250 & $99.23 \%$ & $2.09 \%$ & $-1.32 \%$ \\
\hline Total Non-coal Energy Consumed by System & 0.5359 & $24.98 \%$ & $32.24 \%$ & $42.78 \%$ \\
\hline Energy in Coal to Power Plant & 8.8075 & $\mathrm{~N} / \mathrm{A}$ & $\mathrm{N} / \mathrm{A}$ & $\mathrm{N} / \mathrm{A}$ \\
\hline Total Energy Consumed by System & 9.3434 & $1.43 \%$ & $1.85 \%$ & $96.72 \%$ \\
\hline
\end{tabular}

Note: The electricity produced and consumed by the power plant is not included in this table.

The power plant energy and electricty requirements are from upstream processes, construction, and decommissioning. 
Table B20: Average Solid Waste Generation per kWh of Net Electricity Produced - LEBS Case (surface mining \& average user by river)
(s) antimony
(s) arsenic
(s) barium
(s) beryllium
(s) boron
(s) cadmium
(s) chromium
(s) cobalt
(s) copper
(s) lead
(s) manganese
(s) mercury
(s) molybdenum
(s) nickel
(s) selenium
(s) vanadium ash - landfilled (dry)

FGC waste (dry) - landfilled

Waste (hazardous)

Waste (municipal and industrial)

Waste (unspecified)

$\%$ of Total
from Surface
Coal Mining
$0.00 \%$
$0.00 \%$
$0.00 \%$
$0.00 \%$
$0.00 \%$
$0.00 \%$
$0.00 \%$
$0.00 \%$
$0.00 \%$
$0.00 \%$
$0.00 \%$
$0.00 \%$
$0.00 \%$
$0.00 \%$
$0.00 \%$
$0.00 \%$
$0.00 \%$
$0.00 \%$
$6.31 \%$
$23.50 \%$
$96.48 \%$

\begin{tabular}{c} 
\% of Total from \\
Transportation \\
$0.00 \%$ \\
$0.00 \%$ \\
$0.00 \%$ \\
$0.00 \%$ \\
$0.00 \%$ \\
$0.00 \%$ \\
$0.00 \%$ \\
$0.00 \%$ \\
$0.00 \%$ \\
$0.00 \%$ \\
$0.00 \%$ \\
$0.00 \%$ \\
$0.00 \%$ \\
$0.00 \%$ \\
$0.00 \%$ \\
$0.00 \%$ \\
$0.00 \%$ \\
$0.00 \%$ \\
$3.22 \%$ \\
$1.95 \%$ \\
$0.58 \%$ \\
\hline
\end{tabular}

$\%$ of Total from Electricity

Generation $100.00 \%$ $100.00 \%$ $100.00 \%$ $100.00 \%$ $100.00 \%$ $100.00 \%$ $100.00 \%$ $100.00 \%$ $100.00 \%$ $100.00 \%$ $100.00 \%$ $100.00 \%$ $100.00 \%$ $100.00 \%$ $100.00 \%$ $100.00 \%$ $100.00 \%$ $0.00 \%$ $90.47 \%$ $74.55 \%$ $2.94 \%$

(s) = solid emission 
Table B21: Average Resource Consumption per kWh of Net Electricity Produced - LEBS Case (underground mining \& average user by river)

\begin{tabular}{|c|c|c|c|c|c|}
\hline & $\begin{array}{l}\% \text { of Total in } \\
\text { this Table }\end{array}$ & Total (g/kWh) & $\begin{array}{c}\% \text { of Total } \\
\text { from } \\
\text { Underground } \\
\text { Coal Mining }\end{array}$ & $\begin{array}{l}\% \text { of Total from } \\
\text { Transportation }\end{array}$ & $\begin{array}{c}\% \text { of Total from } \\
\text { Electricity } \\
\text { Generation }\end{array}$ \\
\hline (r) Bauxite (Al2O3, ore) & $0.00 \%$ & $2.50 \mathrm{E}-03$ & $0.01 \%$ & $3.69 \%$ & $96.30 \%$ \\
\hline (r) Clay (in ground) & $0.00 \%$ & $1.84 \mathrm{E}-08$ & $9.95 \%$ & $2.48 \%$ & $87.57 \%$ \\
\hline (r) Coal (in ground) & $95.36 \%$ & $3.53 \mathrm{E}+02$ & $0.67 \%$ & $0.01 \%$ & $99.33 \%$ \\
\hline (r) Iron (Fe, ore) & $0.02 \%$ & 8.30E-02 & $11.86 \%$ & $2.25 \%$ & $85.89 \%$ \\
\hline (r) Limestone (CaCO3, in ground) & $2.07 \%$ & $7.67 \mathrm{E}+00$ & $99.90 \%$ & $0.00 \%$ & $0.09 \%$ \\
\hline (r) Natural Gas (in ground) & $1.14 \%$ & $4.24 \mathrm{E}+00$ & $1.47 \%$ & $0.38 \%$ & $98.16 \%$ \\
\hline (r) Oil (in ground) & $1.38 \%$ & $5.11 \mathrm{E}+00$ & $9.38 \%$ & $80.25 \%$ & $10.37 \%$ \\
\hline (r) Sand (in ground) & $0.00 \%$ & $2.24 \mathrm{E}-08$ & $0.01 \%$ & $3.69 \%$ & $96.30 \%$ \\
\hline (r) Sodium Chloride ( $\mathrm{NaCl}$, in ground or in sea) & $0.00 \%$ & 7.10E-05 & $0.70 \%$ & $3.61 \%$ & $95.69 \%$ \\
\hline (r) Uranium (U, ore) & $0.00 \%$ & 2.85E-05 & $101.01 \%$ & $0.11 \%$ & $-1.11 \%$ \\
\hline Aluminum Scrap & $0.00 \%$ & $6.13 E-04$ & $0.01 \%$ & $3.69 \%$ & $96.30 \%$ \\
\hline Iron Scrap & $0.02 \%$ & 8.83E-02 & $12.04 \%$ & $2.22 \%$ & $85.73 \%$ \\
\hline Lubricant & $0.00 \%$ & $1.51 \mathrm{E}-03$ & $11.83 \%$ & $2.23 \%$ & $85.94 \%$ \\
\hline Trinitrotoluene (C6H3(NO2)3) & $0.00 \%$ & 4.47E-06 & $0.01 \%$ & $3.69 \%$ & $96.30 \%$ \\
\hline
\end{tabular}

$(r)=$ resource

Table B22: Average Air Emissions per kWh of Net Electricity Produced - LEBS Case (underground mining \& average user by river)

\begin{tabular}{|c|c|c|c|c|c|c|}
\hline & $\begin{array}{l}\% \text { of Total in } \\
\text { this Table }\end{array}$ & $\begin{array}{l}\% \text { of Total in } \\
\text { this Table } \\
\text { except CO2 }\end{array}$ & Total (g/kWh) & $\begin{array}{l}\% \text { of Total from } \\
\text { Underground } \\
\text { Coal Mining }\end{array}$ & $\begin{array}{l}\% \text { of Total from } \\
\text { Transportation }\end{array}$ & $\begin{array}{l}\% \text { of Total } \\
\text { from } \\
\text { Electricity } \\
\text { Generation }\end{array}$ \\
\hline (a) Aldehydes & $0.00 \%$ & $0.01 \%$ & 2.03E-04 & $19.15 \%$ & $74.52 \%$ & $6.33 \%$ \\
\hline (a) Ammonia (NH3) & $0.00 \%$ & $0.00 \%$ & 9.52E-05 & $9.06 \%$ & $79.68 \%$ & $11.27 \%$ \\
\hline (a) antimony & $0.00 \%$ & $0.00 \%$ & 3.06E-06 & $0.00 \%$ & $0.00 \%$ & $100.00 \%$ \\
\hline (a) arsenic & $0.00 \%$ & $0.00 \%$ & 3.68E-05 & $0.00 \%$ & $0.00 \%$ & $100.00 \%$ \\
\hline (a) barium & $0.00 \%$ & $0.00 \%$ & $9.50 \mathrm{E}-06$ & $0.00 \%$ & $0.00 \%$ & $100.00 \%$ \\
\hline (a) beryllium & $0.00 \%$ & $0.00 \%$ & 1.19E-06 & $0.00 \%$ & $0.00 \%$ & $100.00 \%$ \\
\hline (a) boron & $0.00 \%$ & $0.32 \%$ & $1.26 \mathrm{E}-02$ & $0.00 \%$ & $0.00 \%$ & $100.00 \%$ \\
\hline (a) cadmium & $0.00 \%$ & $0.00 \%$ & 3.02E-06 & $0.00 \%$ & $0.00 \%$ & $100.00 \%$ \\
\hline (a) total Carbon Dioxide (CO2) & $99.47 \%$ & & $7.41 \mathrm{E}+02$ & $0.87 \%$ & $1.76 \%$ & $97.37 \%$ \\
\hline (a) Carbon Monoxide (CO) & $0.02 \%$ & $4.71 \%$ & $1.86 \mathrm{E}-01$ & $1.07 \%$ & $40.55 \%$ & $58.38 \%$ \\
\hline (a) Chlorides (Cl-) & $0.00 \%$ & $0.00 \%$ & $5.64 \mathrm{E}-07$ & $0.01 \%$ & $2.61 \%$ & $97.38 \%$ \\
\hline (a) chromium & $0.00 \%$ & $0.00 \%$ & 4.40E-05 & $0.00 \%$ & $0.00 \%$ & $100.00 \%$ \\
\hline (a) cobalt & $0.00 \%$ & $0.00 \%$ & 5.11E-06 & $0.00 \%$ & $0.00 \%$ & $100.00 \%$ \\
\hline (a) copper & $0.00 \%$ & $0.00 \%$ & 1.74E-05 & $0.00 \%$ & $0.00 \%$ & $100.00 \%$ \\
\hline (a) Fluorides (F-) & $0.00 \%$ & $0.00 \%$ & 2.40E-07 & $14.08 \%$ & $2.80 \%$ & $83.12 \%$ \\
\hline (a) non-methane Hydrocarbons (including VOCs) & $0.02 \%$ & $4.57 \%$ & $1.80 \mathrm{E}-01$ & $27.45 \%$ & $24.21 \%$ & $48.34 \%$ \\
\hline (a) Hydrogen Chloride ( $\mathrm{HCl})$ & $0.00 \%$ & $0.00 \%$ & $1.81 \mathrm{E}-06$ & $0.11 \%$ & $2.40 \%$ & $97.50 \%$ \\
\hline (a) Hydrogen Fluoride (HF) & $0.00 \%$ & $0.00 \%$ & $1.59 \mathrm{E}-07$ & $2.02 \%$ & $3.45 \%$ & $94.53 \%$ \\
\hline (a) Hydrogen Sulfide (H2S) & $0.00 \%$ & $0.00 \%$ & 9.18E-09 & $9.95 \%$ & $2.48 \%$ & $87.57 \%$ \\
\hline (a) lead & $0.00 \%$ & $0.00 \%$ & 2.23E-05 & $0.00 \%$ & $0.00 \%$ & $100.00 \%$ \\
\hline (a) manganese & $0.00 \%$ & $0.00 \%$ & 3.19E-05 & $0.00 \%$ & $0.00 \%$ & $100.00 \%$ \\
\hline (a) mercury & $0.00 \%$ & $0.00 \%$ & $2.72 \mathrm{E}-05$ & $0.00 \%$ & $0.00 \%$ & $100.00 \%$ \\
\hline (a) Metals (unspecified) & $0.00 \%$ & $0.00 \%$ & 1.14E-09 & $8.00 \%$ & $2.72 \%$ & $89.28 \%$ \\
\hline (a) Methane $(\mathrm{CH} 4)$ & $0.20 \%$ & $38.47 \%$ & $1.52 \mathrm{E}+00$ & $97.21 \%$ & $0.05 \%$ & $2.74 \%$ \\
\hline (a) molybdenum & $0.00 \%$ & $0.00 \%$ & 2.83E-05 & $0.00 \%$ & $0.00 \%$ & $100.00 \%$ \\
\hline (a) nickel & $0.00 \%$ & $0.00 \%$ & 4.30E-05 & $0.00 \%$ & $0.00 \%$ & $100.00 \%$ \\
\hline (a) Nitrogen Oxides (NOx as NO2) & $0.07 \%$ & $13.56 \%$ & 5.36E-01 & $5.12 \%$ & $25.62 \%$ & $69.26 \%$ \\
\hline (a) Nitrous Oxide (N2O) & $0.00 \%$ & $0.03 \%$ & $1.10 \mathrm{E}-03$ & $59.12 \%$ & $16.59 \%$ & $24.29 \%$ \\
\hline (a) Organic Matter (unspecified) & $0.00 \%$ & $0.01 \%$ & 3.46E-04 & $20.16 \%$ & $65.59 \%$ & $14.25 \%$ \\
\hline (a) total Particulates (unspecified) & $0.11 \%$ & $20.16 \%$ & 7.97E-01 & $87.12 \%$ & $1.73 \%$ & $11.16 \%$ \\
\hline (a) selenium & $0.00 \%$ & $0.01 \%$ & 3.01E-04 & $0.00 \%$ & $0.00 \%$ & $100.00 \%$ \\
\hline (a) Sulfur Oxides (SOx as SO2) & $0.10 \%$ & $18.17 \%$ & 7.18E-01 & $7.79 \%$ & $9.82 \%$ & $82.38 \%$ \\
\hline (a) Tars (unspecified) & $0.00 \%$ & $0.00 \%$ & 3.23E-07 & $9.71 \%$ & $2.51 \%$ & $87.78 \%$ \\
\hline (a) vanadium & $0.00 \%$ & $0.00 \%$ & $6.54 \mathrm{E}-05$ & $0.00 \%$ & $0.00 \%$ & $100.00 \%$ \\
\hline
\end{tabular}

(a) = air emission 
Table B23: Average Water Emissions per kWh of Net Electricity Produced - LEBS Case (underground mining \& avg user by river)

(w) Acids $(\mathrm{H}+)$

(w) Ammonia (NH4+)

(w) Ammonia ( $\mathrm{NH} 4+, \mathrm{NH} 3$, as $\mathrm{N}$ )

(w) TOTAL BOD5 (Biological Oxygen Demand)

(w) Chlorides (Cl-)

(w) COD (Chemical Oxygen Demand)

(w) Cyanides (CN-)

(w) Dissolved Matter (unspecified)

(w) Fluorides (F-)

(w) Inorganic Dissolved Matter (unspecified)

(w) Iron (Fe++, $\mathrm{Fe} 3+)$

(w) Metals (unspecified)

(w) Nitrates (NO3-)

(w) Nitric acid

(w) Nitrogenous Matter (unspecified, as N)

(w) Oils

(w) Oils (unspecified)

(w) Organic Dissolved Matter (unspecified)

(w) Phenol (C6H6O)

(w) Sodium $(\mathrm{Na}+)$

(w) Sulfates (SO4--)

(w) Sulfides (S--)

(w) Suspended Matter (unspecified)

(w) Tars (unspecified)

(w) Water: Chemically Polluted

$(w)$ = water emission
$\%$ of Total

from

$\%$ of Total in

this Table Total $(\mathrm{g} / \mathrm{kWh})$

$0.01 \%$

$0.00 \%$

$0.01 \%$

$0.18 \%$

$0.01 \%$

$0.55 \%$

$0.00 \%$

$96.93 \%$

$0.01 \%$

$0.00 \%$

$0.00 \%$

$0.00 \%$

$0.00 \%$

$0.00 \%$

$0.00 \%$

$1.60 \%$

$0.00 \%$

$0.00 \%$

$0.00 \%$

$0.00 \%$

$0.00 \%$

$0.00 \%$

$0.66 \%$

$0.00 \%$

$0.05 \%$

\subsection{E-06}

$0.00 \mathrm{E}+00$

5.18E-06

1.12E-04

3.35E-06

3.36E-04

6.29E-09

5.93E-02

5.16E-06

4.65E-07

8.32E-09

2.83E-07

$1.02 \mathrm{E}-06$

$0.00 \mathrm{E}+00$

9.18E-09

9.77E-04

$0.00 \mathrm{E}+00$

$1.84 \mathrm{E}-08$

1.98E-08

1.17E-06

1.35E-06

1.26E-08

4.03E-04

4.62E-09

3.07E-05
Underground \% of Total from

Coal Mining Transportation

$0.13 \% \quad 0.06 \%$

$0.00 \%$

$39.93 \%$

$2.19 \%$

$1.79 \%$

$2.15 \%$

$11.86 \%$

$11.11 \%$

$86.15 \%$

$9.83 \%$

$101.01 \%$

$9.67 \%$

$101.01 \%$

$0.00 \%$

$9.95 \%$

$7.96 \%$

$0.00 \%$

$9.95 \%$

$11.77 \%$

$61.20 \%$

$68.23 \%$

$11.86 \%$

$2.79 \%$

$9.71 \%$ $0.01 \%$
$\%$ of Total from

Electricity

Generation

$99.81 \%$

$0.00 \%$

$59.84 \%$

$77.54 \%$

$94.59 \%$

$77.56 \%$

$85.89 \%$

$7.81 \%$

$13.39 \%$

$87.68 \%$

$-1.11 \%$

$87.81 \%$

$-1.11 \%$

$0.00 \%$

$87.57 \%$

$28.66 \%$

$0.00 \%$

$87.57 \%$

$85.97 \%$

$37.28 \%$

$30.50 \%$

$85.89 \%$

$91.24 \%$

$87.78 \%$

$97.15 \%$

Table B24: Average Energy Requirements per kWh of Net Electricity Produced - LEBS Case (underground mining $\&$ avg user by river)

\begin{tabular}{|c|c|c|c|c|}
\hline & Total (MJ/kWh) & $\begin{array}{l}\text { \% of Total } \\
\text { from } \\
\text { Underground } \\
\text { Coal Mining }\end{array}$ & $\begin{array}{l}\% \text { of Total from } \\
\text { Transportation }\end{array}$ & $\begin{array}{c}\% \text { of Total from } \\
\text { Electricity } \\
\text { Generation }\end{array}$ \\
\hline by System ( & 0.4971 & $19.17 \%$ & $34.65 \%$ & $46.18 \%$ \\
\hline Elec & 0.0 & 99 & 2. & $\%$ \\
\hline Total Non-coal Energy Consumed by System & 0.5193 & $22.58 \%$ & $33.27 \%$ & $44.15 \%$ \\
\hline Energy in Coal to Power Plant & 8.8075 & $\mathrm{~N} / \mathrm{A}$ & $\mathrm{N} / \mathrm{A}$ & $\mathrm{N} / \mathrm{A}$ \\
\hline Total Energy Consumed by System & 9.3268 & $1.26 \%$ & $1.85 \%$ & $96.89 \%$ \\
\hline
\end{tabular}

Note: The electricity produced and consumed by the power plant is not included in this table.

The power plant energy and electricty requirements are from upstream processes, construction, and decommissioning. 
Table B25: Average Solid Waste Generation per kWh of Net Electricity Produced - LEBS Case (underground mining \& avg user by river)

\begin{tabular}{|c|c|c|c|c|c|}
\hline & $\begin{array}{c}\% \text { of Total in } \\
\text { this Table }\end{array}$ & Total ( $\mathrm{g} / \mathrm{kWh})$ & $\begin{array}{l}\begin{array}{c}\% \text { of Total } \\
\text { from }\end{array} \\
\text { Underground } \\
\text { Coal Mining }\end{array}$ & $\begin{array}{l}\% \text { of Total from } \\
\text { Transportation }\end{array}$ & $\begin{array}{c}\% \text { of Total from } \\
\text { Electricity } \\
\text { Generation }\end{array}$ \\
\hline (s) antimony & $0.00 \%$ & $1.11 \mathrm{E}-05$ & $0.00 \%$ & $0.00 \%$ & $100.00 \%$ \\
\hline (s) arsenic & $0.00 \%$ & $9.68 \mathrm{E}-05$ & $0.00 \%$ & $0.00 \%$ & $100.00 \%$ \\
\hline (s) barium & $0.00 \%$ & $3.25 E-04$ & $0.00 \%$ & $0.00 \%$ & $100.00 \%$ \\
\hline (s) beryllium & $0.00 \%$ & 1.05E-05 & $0.00 \%$ & $0.00 \%$ & $100.00 \%$ \\
\hline (s) boron & $0.00 \%$ & 5.34E-04 & $0.00 \%$ & $0.00 \%$ & $100.00 \%$ \\
\hline (s) cadmium & $0.00 \%$ & 7.31E-06 & $0.00 \%$ & $0.00 \%$ & $100.00 \%$ \\
\hline (s) chromium & $0.00 \%$ & 1.65E-04 & $0.00 \%$ & $0.00 \%$ & $100.00 \%$ \\
\hline (s) cobalt & $0.00 \%$ & 3.46E-05 & $0.00 \%$ & $0.00 \%$ & $100.00 \%$ \\
\hline (s) copper & $0.00 \%$ & 8.50E-05 & $0.00 \%$ & $0.00 \%$ & $100.00 \%$ \\
\hline (s) lead & $0.00 \%$ & 7.43E-05 & $0.00 \%$ & $0.00 \%$ & $100.00 \%$ \\
\hline (s) manganese & $0.00 \%$ & 2.03E-04 & $0.00 \%$ & $0.00 \%$ & $100.00 \%$ \\
\hline (s) mercury & $0.00 \%$ & 1.23E-07 & $0.00 \%$ & $0.00 \%$ & $100.00 \%$ \\
\hline (s) molybdenum & $0.00 \%$ & 2.89E-05 & $0.00 \%$ & $0.00 \%$ & $100.00 \%$ \\
\hline (s) nickel & $0.00 \%$ & 1.16E-04 & $0.00 \%$ & $0.00 \%$ & $100.00 \%$ \\
\hline (s) selenium & $0.00 \%$ & 7.64E-06 & $0.00 \%$ & $0.00 \%$ & $100.00 \%$ \\
\hline (s) vanadium & $0.00 \%$ & 2.36E-04 & $0.00 \%$ & $0.00 \%$ & $100.00 \%$ \\
\hline ash - landfilled (dry) & $87.39 \%$ & $1.91 \mathrm{E}+01$ & $0.00 \%$ & $0.00 \%$ & $100.00 \%$ \\
\hline FGC waste (dry) - landfilled & $0.00 \%$ & $0.00 \mathrm{E}+00$ & $0.00 \%$ & $0.00 \%$ & $0.00 \%$ \\
\hline Waste (hazardous) & $0.00 \%$ & 3.16E-09 & $2.90 \%$ & $3.34 \%$ & $93.76 \%$ \\
\hline Waste (municipal and industrial) & $0.46 \%$ & $1.01 \mathrm{E}-01$ & $12.47 \%$ & $2.23 \%$ & $85.31 \%$ \\
\hline Waste (unspecified) & $12.13 \%$ & $2.66 \mathrm{E}+00$ & $98.12 \%$ & $0.31 \%$ & $1.57 \%$ \\
\hline
\end{tabular}

(s) = solid emission 
Table B26: Sensitivity Analysis Condensed Results - Average System (underground mining)

\begin{tabular}{|c|c|c|c|c|c|c|c|c|c|c|}
\hline & $\begin{array}{c}\mathrm{A} \\
\text { underground }\end{array}$ & $\begin{array}{c}\mathrm{B} \\
\text { underground }\end{array}$ & $\begin{array}{c}\mathrm{C} \\
\text { underground }\end{array}$ & $\begin{array}{c}\mathrm{D} \\
\text { underground }\end{array}$ & $\begin{array}{c}\mathrm{E} \\
\text { underground }\end{array}$ & $\begin{array}{c}\mathrm{F} \\
\text { underground }\end{array}$ & $\begin{array}{c}\mathrm{G} \\
\text { underground }\end{array}$ & $\begin{array}{c}\mathrm{H} \\
\text { underground }\end{array}$ & $\begin{array}{c}1 \\
\text { underground }\end{array}$ & $\begin{array}{c}\mathrm{J} \\
\text { underground }\end{array}$ \\
\hline (r) Coal (in ground) (including losses) & $-13.51 \%$ & $18.52 \%$ & $0.00 \%$ & $-0.05 \%$ & $0.00 \%$ & $-0.01 \%$ & $0.00 \%$ & $0.03 \%$ & $0.08 \%$ & $-0.10 \%$ \\
\hline (r) Limestone ( $\mathrm{CaCO} 3$, in ground) & $-13.51 \%$ & $18.52 \%$ & $0.00 \%$ & $-0.01 \%$ & $0.00 \%$ & $0.00 \%$ & $0.00 \%$ & $0.00 \%$ & $0.00 \%$ & $0.00 \%$ \\
\hline (r) Natural Gas (in ground) & $-13.51 \%$ & $18.52 \%$ & $-0.05 \%$ & $-0.90 \%$ & $0.00 \%$ & $-2.51 \%$ & $0.05 \%$ & $8.29 \%$ & $1.06 \%$ & $-1.46 \%$ \\
\hline (r) Oil (in ground) & $-13.51 \%$ & $18.52 \%$ & $-0.91 \%$ & $-2.61 \%$ & $0.00 \%$ & $-46.57 \%$ & $1.17 \%$ & $154.76 \%$ & $0.16 \%$ & $-0.08 \%$ \\
\hline (a) total Carbon Dioxide (CO2) & $-13.51 \%$ & $18.52 \%$ & $-0.04 \%$ & $-0.42 \%$ & $0.00 \%$ & $-1.71 \%$ & $0.04 \%$ & $5.68 \%$ & $0.47 \%$ & $-0.64 \%$ \\
\hline (a) Carbon Monoxide (CO) & $-13.51 \%$ & $18.52 \%$ & $-0.75 \%$ & $-3.15 \%$ & $0.00 \%$ & $-38.84 \%$ & $1.60 \%$ & $130.75 \%$ & $1.12 \%$ & $-1.43 \%$ \\
\hline (a) total Hydrocarbons (except $\mathrm{CH} 4$, including VOCs) & $-13.51 \%$ & $18.52 \%$ & $-0.79 \%$ & $-3.89 \%$ & $0.00 \%$ & $-29.55 \%$ & $0.91 \%$ & $98.59 \%$ & $3.68 \%$ & $-4.96 \%$ \\
\hline (a) Methane $(\mathrm{CH} 4)$ & $-13.51 \%$ & $18.52 \%$ & $0.00 \%$ & $0.00 \%$ & $117.34 \%$ & $-0.05 \%$ & $0.00 \%$ & $0.15 \%$ & $0.00 \%$ & $0.00 \%$ \\
\hline (a) Nitrogen Oxides ( $\mathrm{NOx}$ as $\mathrm{NO} 2$ ) & $-13.51 \%$ & $18.52 \%$ & $-0.15 \%$ & $-0.59 \%$ & $0.00 \%$ & $-5.50 \%$ & $0.24 \%$ & $18.58 \%$ & $0.47 \%$ & $-0.63 \%$ \\
\hline (a) total Particlulates (unspecified) & $-13.51 \%$ & $18.52 \%$ & $0.00 \%$ & $-0.11 \%$ & $0.00 \%$ & $-0.18 \%$ & $0.01 \%$ & $0.62 \%$ & $0.01 \%$ & $-0.02 \%$ \\
\hline (a) Sulfur Oxides (SOx as SO2) & $-13.51 \%$ & $18.52 \%$ & $-0.01 \%$ & $-0.20 \%$ & $0.00 \%$ & $-1.41 \%$ & $0.05 \%$ & $4.73 \%$ & $0.26 \%$ & $-0.35 \%$ \\
\hline Electricity & $-13.51 \%$ & $18.52 \%$ & $-0.05 \%$ & $-2.88 \%$ & $0.00 \%$ & $-2.32 \%$ & $-0.02 \%$ & $7.42 \%$ & $11.22 \%$ & $-15.48 \%$ \\
\hline total Non-Coal Energy & $-13.51 \%$ & $18.52 \%$ & $-0.66 \%$ & $-2.99 \%$ & $0.00 \%$ & $-32.96 \%$ & $1.80 \%$ & $112.53 \%$ & $2.23 \%$ & $-2.98 \%$ \\
\hline ash - landfilled (dry) & $-13.51 \%$ & $18.52 \%$ & $0.00 \%$ & $0.00 \%$ & $0.00 \%$ & $0.00 \%$ & $0.00 \%$ & $0.00 \%$ & $38.89 \%$ & $0.00 \%$ \\
\hline ash - total (dry) & $-13.51 \%$ & $18.52 \%$ & $0.00 \%$ & $0.00 \%$ & $0.00 \%$ & $0.00 \%$ & $0.00 \%$ & $0.00 \%$ & $0.00 \%$ & $0.00 \%$ \\
\hline FGC waste (dry) - landfilled & $-13.51 \%$ & $18.52 \%$ & $0.00 \%$ & $0.00 \%$ & $0.00 \%$ & $0.00 \%$ & $0.00 \%$ & $0.00 \%$ & $0.00 \%$ & $0.00 \%$ \\
\hline FGD waste (dry) - total & $-13.51 \%$ & $18.52 \%$ & $0.00 \%$ & $0.00 \%$ & $0.00 \%$ & $0.00 \%$ & $0.00 \%$ & $0.00 \%$ & $0.00 \%$ & $0.00 \%$ \\
\hline Waste (hazardous) & $-13.51 \%$ & $18.52 \%$ & $-0.06 \%$ & $-38.08 \%$ & $0.00 \%$ & $-4.16 \%$ & $-3.41 \%$ & $0.00 \%$ & $0.01 \%$ & $0.00 \%$ \\
\hline Waste (municipal and industrial) & $-13.51 \%$ & $18.52 \%$ & $-0.21 \%$ & $-66.67 \%$ & $0.00 \%$ & $-2.01 \%$ & $-1.66 \%$ & $0.00 \%$ & $0.02 \%$ & $0.00 \%$ \\
\hline Waste (unspecified) & $-13.51 \%$ & $18.52 \%$ & $0.00 \%$ & $-0.58 \%$ & $0.00 \%$ & $-0.05 \%$ & $-0.01 \%$ & $0.12 \%$ & $0.85 \%$ & $-1.17 \%$ \\
\hline \multirow[t]{2}{*}{ Waste (total) } & $-13.51 \%$ & $18.52 \%$ & $0.00 \%$ & $-0.19 \%$ & $0.00 \%$ & $-0.01 \%$ & $0.00 \%$ & $0.02 \%$ & $9.08 \%$ & $-0.23 \%$ \\
\hline & $\begin{array}{c}\mathrm{K} \\
\text { underground }\end{array}$ & $\begin{array}{c}\mathrm{L} \\
\text { underground }\end{array}$ & $\begin{array}{c}M \\
\text { underground }\end{array}$ & $\begin{array}{c}\mathrm{N} \\
\text { underground }\end{array}$ & $\begin{array}{c}\mathrm{O} \\
\text { underground }\end{array}$ & $\begin{array}{c}\mathrm{P} \\
\text { underground }\end{array}$ & $\begin{array}{c}\mathrm{Q} \\
\text { underground }\end{array}$ & $\begin{array}{c}\mathrm{R} \\
\text { underground }\end{array}$ & $\begin{array}{c}\mathrm{S} \\
\text { underground }\end{array}$ & $\begin{array}{c}T \\
\text { underground }\end{array}$ \\
\hline (r) Coal (in ground) (including losses) & $-0.06 \%$ & $-0.25 \%$ & $-0.01 \%$ & $0.00 \%$ & $0.00 \%$ & $0.01 \%$ & $0.00 \%$ & $0.00 \%$ & $0.00 \%$ & $0.00 \%$ \\
\hline (r) Limestone ( $\mathrm{CaCO} 3$, in ground) & $0.00 \%$ & $0.00 \%$ & $0.00 \%$ & $0.00 \%$ & $0.00 \%$ & $0.01 \%$ & $0.00 \%$ & $0.00 \%$ & $0.00 \%$ & $0.00 \%$ \\
\hline (r) Natural Gas (in ground) & $-0.83 \%$ & $-3.44 \%$ & $-0.28 \%$ & $0.05 \%$ & $-0.05 \%$ & $0.12 \%$ & $0.01 \%$ & $0.00 \%$ & $-0.01 \%$ & $-0.01 \%$ \\
\hline (r) Oil (in ground) & $-0.13 \%$ & $-0.28 \%$ & $-0.81 \%$ & $0.01 \%$ & $-0.01 \%$ & $0.00 \%$ & $0.21 \%$ & $0.00 \%$ & $-0.22 \%$ & $-0.22 \%$ \\
\hline (a) total Carbon Dioxide (CO2) & $-0.37 \%$ & $-1.52 \%$ & $-0.13 \%$ & $0.00 \%$ & $0.00 \%$ & $0.01 \%$ & $0.01 \%$ & $-0.03 \%$ & $-0.01 \%$ & $-0.08 \%$ \\
\hline (a) Carbon Monoxide (CO) & $-0.88 \%$ & $-3.44 \%$ & $-0.97 \%$ & $0.02 \%$ & $-0.02 \%$ & $0.00 \%$ & $0.21 \%$ & $-0.47 \%$ & $-0.22 \%$ & $-1.18 \%$ \\
\hline (a) total Hydrocarbons (except $\mathrm{CH} 4$, including VOCs) & $-2.89 \%$ & $-11.75 \%$ & $-1.21 \%$ & $0.13 \%$ & $-0.13 \%$ & $0.33 \%$ & $0.21 \%$ & $-0.27 \%$ & $-0.21 \%$ & $-0.76 \%$ \\
\hline (a) Methane $(\mathrm{CH} 4)$ & $0.00 \%$ & $-0.01 \%$ & $0.00 \%$ & $0.00 \%$ & $0.00 \%$ & $0.00 \%$ & $0.00 \%$ & $-0.01 \%$ & $0.00 \%$ & $-0.01 \%$ \\
\hline (a) Nitrogen Oxides ( $\mathrm{NOx}$ as $\mathrm{NO} 2$ ) & $-0.37 \%$ & $-1.49 \%$ & $-0.18 \%$ & $0.00 \%$ & $0.00 \%$ & $0.00 \%$ & $0.04 \%$ & $-0.02 \%$ & $-0.04 \%$ & $-0.08 \%$ \\
\hline (a) total Particlulates (unspecified) & $-0.01 \%$ & $-0.04 \%$ & $-0.04 \%$ & $0.00 \%$ & $0.00 \%$ & $0.01 \%$ & $0.00 \%$ & $0.00 \%$ & $0.00 \%$ & $-0.01 \%$ \\
\hline (a) Sulfur Oxides (SOx as SO2) & $-0.20 \%$ & $-0.84 \%$ & $-0.06 \%$ & $0.00 \%$ & $0.00 \%$ & $0.00 \%$ & $0.00 \%$ & $-0.01 \%$ & $0.00 \%$ & $-0.03 \%$ \\
\hline Electricity & $-8.81 \%$ & $-36.45 \%$ & $-0.91 \%$ & $0.25 \%$ & $-0.25 \%$ & $-0.10 \%$ & $0.01 \%$ & $0.00 \%$ & $-0.01 \%$ & $-0.01 \%$ \\
\hline total Non-Coal Energy & $-1.75 \%$ & $-7.08 \%$ & $-0.93 \%$ & $0.07 \%$ & $-0.07 \%$ & $0.12 \%$ & $0.16 \%$ & $0.00 \%$ & $-0.16 \%$ & $-0.16 \%$ \\
\hline ash - landfilled (dry) & $-30.56 \%$ & $-30.56 \%$ & $0.00 \%$ & $0.00 \%$ & $0.00 \%$ & $0.00 \%$ & $0.00 \%$ & $0.00 \%$ & $0.00 \%$ & $0.00 \%$ \\
\hline ash - total (dry) & $0.00 \%$ & $0.00 \%$ & $0.00 \%$ & $0.00 \%$ & $0.00 \%$ & $0.00 \%$ & $0.00 \%$ & $0.00 \%$ & $0.00 \%$ & $0.00 \%$ \\
\hline FGC waste (dry) - landfilled & $0.00 \%$ & $0.00 \%$ & $0.00 \%$ & $0.00 \%$ & $0.00 \%$ & $0.00 \%$ & $32.80 \%$ & $0.00 \%$ & $-33.60 \%$ & $-33.60 \%$ \\
\hline FGD waste (dry) - total & $0.00 \%$ & $0.00 \%$ & $0.00 \%$ & $0.00 \%$ & $0.00 \%$ & $0.00 \%$ & $0.00 \%$ & $0.00 \%$ & $0.00 \%$ & $0.00 \%$ \\
\hline Waste (hazardous) & $-0.01 \%$ & $-0.01 \%$ & $-26.30 \%$ & $1.73 \%$ & $-1.73 \%$ & $37.51 \%$ & $0.01 \%$ & $0.00 \%$ & $-0.01 \%$ & $-0.01 \%$ \\
\hline Waste (municipal and industrial) & $-0.02 \%$ & $-0.02 \%$ & $-20.44 \%$ & $6.06 \%$ & $-6.06 \%$ & $93.06 \%$ & $0.05 \%$ & $0.00 \%$ & $-0.05 \%$ & $-0.05 \%$ \\
\hline Waste (unspecified) & $-0.67 \%$ & $-2.76 \%$ & $-0.18 \%$ & $0.03 \%$ & $-0.03 \%$ & $0.08 \%$ & $0.00 \%$ & $0.00 \%$ & $0.00 \%$ & $0.00 \%$ \\
\hline Waste (total) & $-7.13 \%$ & $-7.54 \%$ & $-0.06 \%$ & $0.01 \%$ & $-0.01 \%$ & $0.12 \%$ & $18.94 \%$ & $0.00 \%$ & $-19.40 \%$ & $-19.40 \%$ \\
\hline
\end{tabular}

SENSITIVITY CASE CASE LETTER Increase plant efficiency by 5 points Pond versus landfilling of ash from power plant Construction mom power plant Mining methane emissions using EIA average U.S. numbers Mine mouth Farthest user No ash recovery - $100 \%$ of plant ash is landfilled $100 \%$ of recovered ash is used in cement

A
$B$
$C$
$D$
$E$
$F$
$G$
$H$
$I$
$J$

$50 \%$ of plant ash is recovered $\&$ percent used in Plant operating capacity factor $=85 \%$ Increase mining equipment materials by $50 \%$ Decrease mining equipment materials by $50 \%$ Decrease in recycle of materials by $1 / 3$ No FGC recovery - $100 \%$ is landfilled $100 \%$ of recovered FGC is used in asphalt $50 \%$ of plant $\mathrm{FCG}$ is recovered \& percent used in asphalt remains constant @ $7.2 \%$ $50 \%$ of plant FCG is recovered \& $100 \%$ of this is used in asphalt

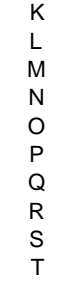


Table B27: Sensitivity Analysis Condensed Results - NSPS System (surface mining) $\%$ change from the base case on a per unit of energy produced (i.e., MWh) basis

\begin{tabular}{|c|c|c|c|c|c|c|c|c|c|c|}
\hline & $\begin{array}{c}\text { A } \\
\text { surface }\end{array}$ & $\begin{array}{c}\mathrm{B} \\
\text { surface }\end{array}$ & $\begin{array}{c}\mathrm{C} \\
\text { surface }\end{array}$ & $\begin{array}{c}\mathrm{D} \\
\text { surface }\end{array}$ & $\begin{array}{c}E \\
\text { surface }\end{array}$ & $\begin{array}{c}\mathrm{F} \\
\text { surface }\end{array}$ & $\begin{array}{c}\mathrm{G} \\
\text { surface }\end{array}$ & $\begin{array}{c}\mathrm{H} \\
\text { surface }\end{array}$ & $\begin{array}{c}1 \\
\text { surface }\end{array}$ & $\begin{array}{c}\mathrm{J} \\
\text { surface }\end{array}$ \\
\hline (r) Coal (in ground) (including losses) & $-12.50 \%$ & $16.67 \%$ & $0.00 \%$ & $-0.05 \%$ & $0.00 \%$ & $-0.01 \%$ & $0.00 \%$ & $0.03 \%$ & $0.08 \%$ & $-0.10 \%$ \\
\hline (r) Limestone ( $\mathrm{CaCO} 3$, in ground) & $-12.50 \%$ & $16.67 \%$ & $0.00 \%$ & $-0.01 \%$ & $0.00 \%$ & $0.00 \%$ & $0.00 \%$ & $0.00 \%$ & $0.00 \%$ & $0.00 \%$ \\
\hline (r) Natural Gas (in ground) & $-12.50 \%$ & $16.67 \%$ & $-0.03 \%$ & $-0.61 \%$ & $0.00 \%$ & $-1.56 \%$ & $0.03 \%$ & $5.14 \%$ & $0.66 \%$ & $-0.90 \%$ \\
\hline (r) Oil (in ground) & $-12.50 \%$ & $16.67 \%$ & $-0.97 \%$ & $-2.72 \%$ & $0.00 \%$ & $-44.39 \%$ & $1.11 \%$ & $147.53 \%$ & $0.15 \%$ & $-0.08 \%$ \\
\hline (a) total Carbon Dioxide (CO2) & $-12.50 \%$ & $16.67 \%$ & $-0.04 \%$ & $-0.46 \%$ & $0.00 \%$ & $-1.70 \%$ & $0.04 \%$ & $5.63 \%$ & $0.47 \%$ & $-0.64 \%$ \\
\hline (a) Carbon Monoxide (CO) & $-12.50 \%$ & $16.67 \%$ & $-0.81 \%$ & $-3.31 \%$ & $0.00 \%$ & $-37.34 \%$ & $1.53 \%$ & $125.70 \%$ & $1.08 \%$ & $-1.38 \%$ \\
\hline (a) total Hydrocarbons (except $\mathrm{CH} 4$, including VOCs) & $-12.50 \%$ & $16.67 \%$ & $-0.79 \%$ & $-3.80 \%$ & $0.00 \%$ & $-26.40 \%$ & $0.82 \%$ & $88.08 \%$ & $3.29 \%$ & $-4.43 \%$ \\
\hline (a) Methane $(\mathrm{CH} 4)$ & $-12.50 \%$ & $16.67 \%$ & $-0.01 \%$ & $-0.01 \%$ & $-55.01 \%$ & $-0.10 \%$ & $0.00 \%$ & $0.33 \%$ & $0.01 \%$ & $-0.01 \%$ \\
\hline (a) Nitrogen Oxides ( $\mathrm{NOx}$ as $\mathrm{NO}$ ) & $-12.50 \%$ & $16.67 \%$ & $-0.22 \%$ & $-0.85 \%$ & $0.00 \%$ & $-7.18 \%$ & $0.31 \%$ & $24.26 \%$ & $0.61 \%$ & $-0.82 \%$ \\
\hline (a) total Particlulates (unspecified) & $-12.50 \%$ & $16.67 \%$ & $0.00 \%$ & $-0.12 \%$ & $0.00 \%$ & $-0.17 \%$ & $0.01 \%$ & $0.58 \%$ & $0.01 \%$ & $-0.02 \%$ \\
\hline (a) Sulfur Oxides ( $\mathrm{SO} x$ as SO2) & $-12.50 \%$ & $16.67 \%$ & $-0.03 \%$ & $-0.54 \%$ & $0.00 \%$ & $-3.43 \%$ & $0.13 \%$ & $11.49 \%$ & $0.63 \%$ & $-0.86 \%$ \\
\hline Electricity & $-12.50 \%$ & $16.67 \%$ & $-0.05 \%$ & $-2.75 \%$ & $0.00 \%$ & $-2.03 \%$ & $-0.02 \%$ & $6.48 \%$ & $9.79 \%$ & $-13.52 \%$ \\
\hline total Non-Coal Energy & $-12.50 \%$ & $16.67 \%$ & $-0.67 \%$ & $-2.96 \%$ & $0.00 \%$ & $-29.90 \%$ & $1.63 \%$ & $102.07 \%$ & $2.03 \%$ & $-2.71 \%$ \\
\hline ash - landfilled (dry) & $-12.50 \%$ & $16.67 \%$ & $0.00 \%$ & $0.00 \%$ & $0.00 \%$ & $0.00 \%$ & $0.00 \%$ & $0.00 \%$ & $38.89 \%$ & $0.00 \%$ \\
\hline ash - total (dry) & $-12.50 \%$ & $16.67 \%$ & $0.00 \%$ & $0.00 \%$ & $0.00 \%$ & $0.00 \%$ & $0.00 \%$ & $0.00 \%$ & $0.00 \%$ & $0.00 \%$ \\
\hline FGC waste (dry) - landfilled & $-12.50 \%$ & $16.67 \%$ & $0.00 \%$ & $0.00 \%$ & $0.00 \%$ & $0.00 \%$ & $0.00 \%$ & $0.00 \%$ & $0.00 \%$ & $0.00 \%$ \\
\hline FGD waste (dry) - total & $-12.50 \%$ & $16.67 \%$ & $0.00 \%$ & $0.00 \%$ & $0.00 \%$ & $0.00 \%$ & $0.00 \%$ & $0.00 \%$ & $0.00 \%$ & $0.00 \%$ \\
\hline Waste (hazardous) & $-12.50 \%$ & $16.67 \%$ & $-0.06 \%$ & $-36.66 \%$ & $0.00 \%$ & $-3.67 \%$ & $-3.01 \%$ & $0.00 \%$ & $0.01 \%$ & $0.00 \%$ \\
\hline Waste (municipal and industrial) & $-12.50 \%$ & $16.67 \%$ & $-0.18 \%$ & $-58.46 \%$ & $0.00 \%$ & $-1.61 \%$ & $-1.33 \%$ & $0.00 \%$ & $0.02 \%$ & $0.00 \%$ \\
\hline Waste (unspecified) & $-12.50 \%$ & $16.67 \%$ & $0.00 \%$ & $-0.60 \%$ & $0.00 \%$ & $-0.05 \%$ & $-0.01 \%$ & $0.11 \%$ & $0.80 \%$ & $-1.11 \%$ \\
\hline \multirow[t]{2}{*}{ Waste (total) } & $-12.50 \%$ & $16.67 \%$ & $0.00 \%$ & $-0.18 \%$ & $0.00 \%$ & $-0.01 \%$ & $0.00 \%$ & $0.02 \%$ & $8.20 \%$ & $-0.20 \%$ \\
\hline & $\begin{array}{c}\mathrm{K} \\
\text { surface }\end{array}$ & $\begin{array}{c}\mathrm{L} \\
\text { surface }\end{array}$ & $\stackrel{N}{N}$ & $\begin{array}{c}\text { O } \\
\text { surface }\end{array}$ & $\begin{array}{c}P \\
\text { surface }\end{array}$ & $\begin{array}{c}\mathrm{Q} \\
\text { surface }\end{array}$ & $\begin{array}{c}R \\
\text { surface }\end{array}$ & $\underset{\text { surface }}{\mathrm{S}}$ & $\begin{array}{c}T \\
\text { surface }\end{array}$ & $\underset{\text { surface }}{U}$ \\
\hline (r) Coal (in ground) (including losses) & $-0.06 \%$ & $-0.25 \%$ & $-0.02 \%$ & $0.01 \%$ & $-0.01 \%$ & $0.01 \%$ & $0.00 \%$ & $0.00 \%$ & $0.00 \%$ & $0.00 \%$ \\
\hline (r) Limestone ( $\mathrm{CaCO} 3$, in ground) & $0.00 \%$ & $0.00 \%$ & $0.00 \%$ & $0.00 \%$ & $0.00 \%$ & $0.01 \%$ & $0.00 \%$ & $0.00 \%$ & $0.00 \%$ & $0.00 \%$ \\
\hline (r) Natural Gas (in ground) & $-0.52 \%$ & $-2.13 \%$ & $-0.19 \%$ & $0.07 \%$ & $-0.07 \%$ & $0.09 \%$ & $0.01 \%$ & $0.00 \%$ & $-0.01 \%$ & $-0.01 \%$ \\
\hline (r) Oil (in ground) & $-0.12 \%$ & $-0.27 \%$ & $-0.85 \%$ & $0.03 \%$ & $-0.03 \%$ & $0.01 \%$ & $0.24 \%$ & $0.00 \%$ & $-0.24 \%$ & $-0.24 \%$ \\
\hline (a) total Carbon Dioxide (CO2) & $-0.37 \%$ & $-1.51 \%$ & $-0.14 \%$ & $0.01 \%$ & $-0.01 \%$ & $0.01 \%$ & $0.01 \%$ & $-0.04 \%$ & $-0.01 \%$ & $-0.09 \%$ \\
\hline (a) Carbon Monoxide (CO) & $-0.85 \%$ & $-3.31 \%$ & $-1.02 \%$ & $0.04 \%$ & $-0.04 \%$ & $0.00 \%$ & $0.24 \%$ & $-0.53 \%$ & $-0.24 \%$ & $-1.32 \%$ \\
\hline (a) total Hydrocarbons (except $\mathrm{CH} 4$, including VOCs) & $-2.58 \%$ & $-10.50 \%$ & $-1.18 \%$ & $0.29 \%$ & $-0.29 \%$ & $0.37 \%$ & $0.21 \%$ & $-0.28 \%$ & $-0.22 \%$ & $-0.79 \%$ \\
\hline (a) Methane $(\mathrm{CH} 4)$ & $-0.01 \%$ & $-0.02 \%$ & $0.00 \%$ & $0.00 \%$ & $0.00 \%$ & $0.00 \%$ & $0.00 \%$ & $-0.02 \%$ & $0.00 \%$ & $-0.04 \%$ \\
\hline (a) Nitrogen Oxides ( $\mathrm{NOx}$ as $\mathrm{NO}$ ) & $-0.48 \%$ & $-1.94 \%$ & $-0.26 \%$ & $0.01 \%$ & $-0.01 \%$ & $0.00 \%$ & $0.06 \%$ & $-0.03 \%$ & $-0.06 \%$ & $-0.13 \%$ \\
\hline (a) total Particlulates (unspecified) & $-0.01 \%$ & $-0.04 \%$ & $-0.04 \%$ & $0.00 \%$ & $0.00 \%$ & $0.01 \%$ & $0.00 \%$ & $0.00 \%$ & $0.00 \%$ & $-0.01 \%$ \\
\hline (a) Sulfur Oxides (SOx as SO2) & $-0.49 \%$ & $-2.03 \%$ & $-0.17 \%$ & $0.02 \%$ & $-0.02 \%$ & $0.00 \%$ & $0.01 \%$ & $-0.03 \%$ & $-0.01 \%$ & $-0.07 \%$ \\
\hline Electricity & $-7.70 \%$ & $-31.83 \%$ & $-0.87 \%$ & $0.52 \%$ & $-0.52 \%$ & $-0.12 \%$ & $0.01 \%$ & $0.00 \%$ & $-0.01 \%$ & $-0.01 \%$ \\
\hline total Non-Coal Energy & $-1.59 \%$ & $-6.42 \%$ & $-0.92 \%$ & $0.16 \%$ & $-0.16 \%$ & $0.13 \%$ & $0.16 \%$ & $0.00 \%$ & $-0.17 \%$ & $-0.17 \%$ \\
\hline ash - landfilled (dry) & $-30.56 \%$ & $-30.56 \%$ & $0.00 \%$ & $0.00 \%$ & $0.00 \%$ & $0.00 \%$ & $0.00 \%$ & $0.00 \%$ & $0.00 \%$ & $0.00 \%$ \\
\hline ash - total (dry) & $0.00 \%$ & $0.00 \%$ & $0.00 \%$ & $0.00 \%$ & $0.00 \%$ & $0.00 \%$ & $0.00 \%$ & $0.00 \%$ & $0.00 \%$ & $0.00 \%$ \\
\hline FGC waste (dry) - landfilled & $0.00 \%$ & $0.00 \%$ & $0.00 \%$ & $0.00 \%$ & $0.00 \%$ & $0.00 \%$ & $32.80 \%$ & $0.00 \%$ & $-33.60 \%$ & $-33.60 \%$ \\
\hline FGD waste (dry) - total & $0.00 \%$ & $0.00 \%$ & $0.00 \%$ & $0.00 \%$ & $0.00 \%$ & $0.00 \%$ & $0.00 \%$ & $0.00 \%$ & $0.00 \%$ & $0.00 \%$ \\
\hline Waste (hazardous) & $0.00 \%$ & $0.00 \%$ & $-25.35 \%$ & $3.65 \%$ & $-3.65 \%$ & $35.60 \%$ & $0.01 \%$ & $0.00 \%$ & $-0.01 \%$ & $-0.01 \%$ \\
\hline Waste (municipal and industrial) & $-0.01 \%$ & $-0.01 \%$ & $-17.92 \%$ & $11.66 \%$ & $-11.66 \%$ & $94.06 \%$ & $0.05 \%$ & $0.00 \%$ & $-0.05 \%$ & $-0.05 \%$ \\
\hline Waste (unspecified) & $-0.63 \%$ & $-2.60 \%$ & $-0.19 \%$ & $0.08 \%$ & $-0.08 \%$ & $0.09 \%$ & $0.00 \%$ & $0.00 \%$ & $0.00 \%$ & $0.00 \%$ \\
\hline Waste (total) & $-6.44 \%$ & $-6.81 \%$ & $-0.06 \%$ & $0.03 \%$ & $-0.03 \%$ & $0.13 \%$ & $19.93 \%$ & $0.00 \%$ & $-20.41 \%$ & $-20.41 \%$ \\
\hline
\end{tabular}

SENSITIVITY CASE CASE LETTER

Increase plant efficiency by 5 points points Pond versus landfilling of ash from power plant
Construction materials low case

Mining methane emissions using EIA average U.S. numbers
Mine mouth

$$
\begin{gathered}
\text { Average user by land } \\
\text { Farthest user }
\end{gathered}
$$

arthest user No ash recovery - $100 \%$ of plant ash is landfilled
$100 \%$ of recovered ash is used in cement

A
$B$
$C$
$D$
E
F
$G$
$H$
I
$J$

SENSITIVITY CASE CASE LET

$50 \%$ of plant ash is recovered \& percent used in cement remains constant @ $42 \%$ $50 \%$ of plant ash is Plant operating capacity factor $=85 \%$ Increase mining equipment materials by $50 \%$ Decrease mining equipent materials by $50 \%$ Decrease in recycle of materials by $1 / 3$ No FGC recovery - $100 \%$ is landfilled $100 \%$ of recovered FGC is used in asphalt $50 \%$ of plant FCG is recovered \& percent used in asphalt remains constant @ $7.2 \%$
$50 \%$ of plant FCG is recovered \& $100 \%$ of this is used in asphalt 
Table B28: Sensitivity Analysis Condensed Results - NSPS System (underground mining) change from the base case on a per unit of energy produced (i.e., MWh) basis

\begin{tabular}{|c|c|c|c|c|c|c|c|c|c|c|}
\hline & $\begin{array}{c}\mathrm{A} \\
\text { underground }\end{array}$ & $\begin{array}{c}\mathrm{B} \\
\text { underground }\end{array}$ & $\begin{array}{c}\mathrm{C} \\
\text { underground }\end{array}$ & $\begin{array}{c}\mathrm{D} \\
\text { underground }\end{array}$ & $\begin{array}{c}E \\
\text { underground }\end{array}$ & $\begin{array}{c}\mathrm{F} \\
\text { underground }\end{array}$ & $\begin{array}{c}\mathrm{G} \\
\text { underground }\end{array}$ & $\begin{array}{c}\mathrm{H} \\
\text { underground }\end{array}$ & $\begin{array}{c}1 \\
\text { underground }\end{array}$ & $\begin{array}{c}\mathrm{J} \\
\text { underground }\end{array}$ \\
\hline (r) Coal (in ground) (including losses) & $-12.50 \%$ & $16.67 \%$ & $0.00 \%$ & $-0.05 \%$ & $0.00 \%$ & $-0.01 \%$ & $0.00 \%$ & $0.03 \%$ & $0.08 \%$ & $-0.10 \%$ \\
\hline (r) Limestone ( $\mathrm{CaCO}$, in ground) & $-12.50 \%$ & $16.67 \%$ & $0.00 \%$ & $-0.01 \%$ & $0.00 \%$ & $0.00 \%$ & $0.00 \%$ & $0.00 \%$ & $0.00 \%$ & $0.00 \%$ \\
\hline (r) Natural Gas (in ground) & $-12.50 \%$ & $16.67 \%$ & $-0.05 \%$ & $-0.86 \%$ & $0.00 \%$ & $-2.19 \%$ & $0.04 \%$ & $7.24 \%$ & $0.93 \%$ & $-1.27 \%$ \\
\hline (r) Oil (in ground) & $-12.50 \%$ & $16.67 \%$ & $-0.94 \%$ & $-2.65 \%$ & $0.00 \%$ & $-43.27 \%$ & $1.08 \%$ & $143.79 \%$ & $0.15 \%$ & $-0.08 \%$ \\
\hline (a) total Carbon Dioxide (CO2) & $-12.50 \%$ & $16.67 \%$ & $-0.04 \%$ & $-0.46 \%$ & $0.00 \%$ & $-1.70 \%$ & $0.04 \%$ & $5.64 \%$ & $0.47 \%$ & $-0.64 \%$ \\
\hline (a) Carbon Monoxide (CO) & $-12.50 \%$ & $16.67 \%$ & $-0.83 \%$ & $-3.39 \%$ & $0.00 \%$ & $-38.26 \%$ & $1.57 \%$ & $128.80 \%$ & $1.10 \%$ & $-1.41 \%$ \\
\hline (a) total Hydrocarbons (except CH4, including VOCs) & $-12.50 \%$ & $16.67 \%$ & $-0.84 \%$ & $-4.06 \%$ & $0.00 \%$ & $-28.24 \%$ & $0.87 \%$ & $94.23 \%$ & $3.52 \%$ & $-4.74 \%$ \\
\hline (a) Methane $(\mathrm{CH} 4)$ & $-12.50 \%$ & $16.67 \%$ & $0.00 \%$ & $-0.01 \%$ & $117.25 \%$ & $-0.05 \%$ & $0.00 \%$ & $0.15 \%$ & $0.00 \%$ & $0.00 \%$ \\
\hline (a) Nitrogen Oxides (NOx as NO2) & $-12.50 \%$ & $16.67 \%$ & $-0.22 \%$ & $-0.85 \%$ & $0.00 \%$ & $-7.21 \%$ & $0.31 \%$ & $24.36 \%$ & $0.62 \%$ & $-0.82 \%$ \\
\hline (a) total Particlulates (unspecified) & $-12.50 \%$ & $16.67 \%$ & $0.00 \%$ & $-0.11 \%$ & $0.00 \%$ & $-0.16 \%$ & $0.01 \%$ & $0.54 \%$ & $0.01 \%$ & $-0.01 \%$ \\
\hline (a) Sulfur Oxides (SOx as SO2) & $-12.50 \%$ & $16.67 \%$ & $-0.03 \%$ & $-0.54 \%$ & $0.00 \%$ & $-3.43 \%$ & $0.13 \%$ & $11.48 \%$ & $0.63 \%$ & $-0.86 \%$ \\
\hline Electricity & $-12.50 \%$ & $16.67 \%$ & $-0.06 \%$ & $-3.10 \%$ & $0.00 \%$ & $-2.29 \%$ & $-0.02 \%$ & $7.31 \%$ & $11.05 \%$ & $-15.25 \%$ \\
\hline total Non-Coal Energy & $-12.50 \%$ & $16.67 \%$ & $-0.69 \%$ & $-3.05 \%$ & $0.00 \%$ & $-30.79 \%$ & $1.68 \%$ & $105.12 \%$ & $2.09 \%$ & $-2.79 \%$ \\
\hline ash - landfilled (dry) & $-12.50 \%$ & $16.67 \%$ & $0.00 \%$ & $0.00 \%$ & $0.00 \%$ & $0.00 \%$ & $0.00 \%$ & $0.00 \%$ & $38.89 \%$ & $0.00 \%$ \\
\hline ash - total (dry) & $-12.50 \%$ & $16.67 \%$ & $0.00 \%$ & $0.00 \%$ & $0.00 \%$ & $0.00 \%$ & $0.00 \%$ & $0.00 \%$ & $0.00 \%$ & $0.00 \%$ \\
\hline FGC waste (dry) - landfilled & $-12.50 \%$ & $16.67 \%$ & $0.00 \%$ & $0.00 \%$ & $0.00 \%$ & $0.00 \%$ & $0.00 \%$ & $0.00 \%$ & $0.00 \%$ & $0.00 \%$ \\
\hline FGD waste (dry) - total & $-12.50 \%$ & $16.67 \%$ & $0.00 \%$ & $0.00 \%$ & $0.00 \%$ & $0.00 \%$ & $0.00 \%$ & $0.00 \%$ & $0.00 \%$ & $0.00 \%$ \\
\hline Waste (hazardous) & $-12.50 \%$ & $16.67 \%$ & $-0.06 \%$ & $-38.24 \%$ & $0.00 \%$ & $-3.83 \%$ & $-3.14 \%$ & $0.00 \%$ & $0.01 \%$ & $0.00 \%$ \\
\hline Waste (municipal and industrial) & $-12.50 \%$ & $16.67 \%$ & $-0.21 \%$ & $-66.96 \%$ & $0.00 \%$ & $-1.85 \%$ & $-1.52 \%$ & $0.00 \%$ & $0.02 \%$ & $0.00 \%$ \\
\hline Waste (unspecified) & $-12.50 \%$ & $16.67 \%$ & $0.00 \%$ & $-0.56 \%$ & $0.00 \%$ & $-0.04 \%$ & $-0.01 \%$ & $0.11 \%$ & $0.75 \%$ & $-1.03 \%$ \\
\hline \multirow[t]{2}{*}{ Waste (total) } & $-12.50 \%$ & $16.67 \%$ & $0.00 \%$ & $-0.18 \%$ & $0.00 \%$ & $-0.01 \%$ & $0.00 \%$ & $0.02 \%$ & $8.09 \%$ & $-0.20 \%$ \\
\hline & $\begin{array}{c}\mathrm{K} \\
\text { underground }\end{array}$ & $\begin{array}{c}\mathrm{L} \\
\text { underground }\end{array}$ & $\begin{array}{c}\mathrm{M} \\
\text { underground }\end{array}$ & $\begin{array}{c}\mathrm{N} \\
\text { underground }\end{array}$ & $\begin{array}{c}\mathrm{O} \\
\text { underground }\end{array}$ & $\begin{array}{c}\mathrm{P} \\
\text { underground }\end{array}$ & $\begin{array}{c}Q \\
\text { underground }\end{array}$ & $\begin{array}{c}\mathrm{R} \\
\text { underground }\end{array}$ & $\begin{array}{c}\mathrm{S} \\
\text { underground }\end{array}$ & $\begin{array}{c}\mathrm{T} \\
\text { underground }\end{array}$ \\
\hline (r) Coal (in ground) (including losses) & $-0.06 \%$ & $-0.25 \%$ & $-0.02 \%$ & $0.00 \%$ & $0.00 \%$ & $0.01 \%$ & $0.00 \%$ & $0.00 \%$ & $0.00 \%$ & $0.00 \%$ \\
\hline (r) Limestone ( $\mathrm{CaCO} 3$, in ground) & $0.00 \%$ & $0.00 \%$ & $0.00 \%$ & $0.00 \%$ & $0.00 \%$ & $0.01 \%$ & $0.00 \%$ & $0.00 \%$ & $0.00 \%$ & $0.00 \%$ \\
\hline (r) Natural Gas (in ground) & $-0.73 \%$ & $-3.00 \%$ & $-0.27 \%$ & $0.04 \%$ & $-0.04 \%$ & $0.12 \%$ & $0.01 \%$ & $0.00 \%$ & $-0.01 \%$ & $-0.01 \%$ \\
\hline (r) Oil (in ground) & $-0.12 \%$ & $-0.26 \%$ & $-0.82 \%$ & $0.01 \%$ & $-0.01 \%$ & $0.00 \%$ & $0.23 \%$ & $0.00 \%$ & $-0.24 \%$ & $-0.24 \%$ \\
\hline (a) total Carbon Dioxide (CO2) & $-0.37 \%$ & $-1.51 \%$ & $-0.14 \%$ & $0.00 \%$ & $0.00 \%$ & $0.01 \%$ & $0.01 \%$ & $-0.04 \%$ & $-0.01 \%$ & $-0.09 \%$ \\
\hline (a) Carbon Monoxide (CO) & $-0.87 \%$ & $-3.39 \%$ & $-1.05 \%$ & $0.02 \%$ & $-0.02 \%$ & $0.00 \%$ & $0.24 \%$ & $-0.54 \%$ & $-0.25 \%$ & $-1.35 \%$ \\
\hline (a) total Hydrocarbons (except $\mathrm{CH} 4$, including VOCs) & $-2.76 \%$ & $-11.23 \%$ & $-1.26 \%$ & $0.13 \%$ & $-0.13 \%$ & $0.34 \%$ & $0.23 \%$ & $-0.30 \%$ & $-0.23 \%$ & $-0.85 \%$ \\
\hline (a) Methane (CH4) & $0.00 \%$ & $-0.01 \%$ & $0.00 \%$ & $0.00 \%$ & $0.00 \%$ & $0.00 \%$ & $0.00 \%$ & $-0.01 \%$ & $0.00 \%$ & $-0.02 \%$ \\
\hline (a) Nitrogen Oxides (NOx as NO2) & $-0.48 \%$ & $-1.95 \%$ & $-0.26 \%$ & $0.00 \%$ & $0.00 \%$ & $0.00 \%$ & $0.06 \%$ & $-0.03 \%$ & $-0.06 \%$ & $-0.13 \%$ \\
\hline (a) total Particlulates (unspecified) & $-0.01 \%$ & $-0.03 \%$ & $-0.03 \%$ & $0.00 \%$ & $0.00 \%$ & $0.01 \%$ & $0.00 \%$ & $0.00 \%$ & $0.00 \%$ & $-0.01 \%$ \\
\hline (a) Sulfur Oxides ( $\mathrm{SO} x$ as SO2) & $-0.49 \%$ & $-2.03 \%$ & $-0.17 \%$ & $0.01 \%$ & $-0.01 \%$ & $0.00 \%$ & $0.01 \%$ & $-0.03 \%$ & $-0.01 \%$ & $-0.07 \%$ \\
\hline $\begin{array}{l}\text { Electricity } \\
\text { El }\end{array}$ & $-8.68 \%$ & $-35.92 \%$ & $-0.98 \%$ & $0.24 \%$ & $-0.25 \%$ & $-0.11 \%$ & $0.01 \%$ & $0.00 \%$ & $-0.01 \%$ & $-0.01 \%$ \\
\hline total Non-Coal Energy & $-1.64 \%$ & $-6.61 \%$ & $-0.95 \%$ & $0.07 \%$ & $-0.07 \%$ & $0.12 \%$ & $0.17 \%$ & $0.00 \%$ & $-0.17 \%$ & $-0.17 \%$ \\
\hline ash - landfilled (dry) & $-30.56 \%$ & $-30.56 \%$ & $0.00 \%$ & $0.00 \%$ & $0.00 \%$ & $0.00 \%$ & $0.00 \%$ & $0.00 \%$ & $0.00 \%$ & $0.00 \%$ \\
\hline ash - total (dry) & $0.00 \%$ & $0.00 \%$ & $0.00 \%$ & $0.00 \%$ & $0.00 \%$ & $0.00 \%$ & $0.00 \%$ & $0.00 \%$ & $0.00 \%$ & $0.00 \%$ \\
\hline FGC waste (dry) - landfilled & $0.00 \%$ & $0.00 \%$ & $0.00 \%$ & $0.00 \%$ & $0.00 \%$ & $0.00 \%$ & $32.80 \%$ & $0.00 \%$ & $-33.60 \%$ & $-33.60 \%$ \\
\hline FGD waste (dry) - total & $0.00 \%$ & $0.00 \%$ & $0.00 \%$ & $0.00 \%$ & $0.00 \%$ & $0.00 \%$ & $0.00 \%$ & $0.00 \%$ & $0.00 \%$ & $0.00 \%$ \\
\hline Waste (hazardous) & $0.00 \%$ & $0.00 \%$ & $-26.44 \%$ & $1.59 \%$ & $-1.59 \%$ & $37.70 \%$ & $0.01 \%$ & $0.00 \%$ & $-0.02 \%$ & $-0.02 \%$ \\
\hline Waste (municipal and industrial) & $-0.02 \%$ & $-0.02 \%$ & $-20.53 \%$ & $5.57 \%$ & $-5.57 \%$ & $92.73 \%$ & $0.05 \%$ & $0.00 \%$ & $-0.05 \%$ & $-0.05 \%$ \\
\hline Waste (unspecified) & $-0.59 \%$ & $-2.43 \%$ & $-0.17 \%$ & $0.03 \%$ & $-0.03 \%$ & $0.07 \%$ & $0.00 \%$ & $0.00 \%$ & $0.00 \%$ & $0.00 \%$ \\
\hline Waste (total) & $-6.36 \%$ & $-6.72 \%$ & $-0.06 \%$ & $0.01 \%$ & $-0.01 \%$ & $0.11 \%$ & $19.67 \%$ & $0.00 \%$ & $-20.14 \%$ & $-20.14 \%$ \\
\hline
\end{tabular}

SENSITIVITY CASE CASE LETTER Increase plant efficiency by 5 points points Pond vers Construction materials low case Mining methane emissions using EIA average U.S. numbers
Mine mouth Average user by land
Farthest user No ash recovery - $100 \%$ of plant ash is landfilled
$100 \%$ of recovered ash is used in cement

A
B
$C$
D
E
F
G
H
I
$J$

SENSITIVITY CASE CASE LETTER

$50 \%$ of plant ash is recovered \& percent used in cement remains constant @ $42 \%$ $50 \%$ of plant ash is Plant operating capacity factor $=85 \%$ Increase mining equipment materials by $50 \%$ Decrease mining equipment materials by $50 \%$ Decrease in recycle of materials by $1 / 3$
No FGC recovery - $100 \%$ is landfilled No FGC recovery - $100 \%$ is landfilled $100 \%$ of recovered FGC is used in asphalt
a n used in asphalt remains constant @ $7.2 \%$ $50 \%$ of plant FCG is recovered \& percent used in asphalt remains constant @ $7.2 \%$
$50 \%$ of plant FCG is recovered \& $100 \%$ of this is used in asphalt 
Table B29: Sensitivity Analysis Condensed Results - LEBS System (surface mining) $\%$ change from the base case on a per unit of energy produced (i.e., MWh) basis

\begin{tabular}{|c|c|c|c|c|c|c|c|c|}
\hline & $\begin{array}{c}\mathrm{A} \\
\text { surface }\end{array}$ & $\begin{array}{c}\mathrm{B} \\
\text { surface }\end{array}$ & $\begin{array}{c}\mathrm{C} \\
\text { surface }\end{array}$ & $\begin{array}{c}\mathrm{D} \\
\text { surface }\end{array}$ & $\begin{array}{c}\mathrm{E} \\
\text { surface }\end{array}$ & $\begin{array}{c}\mathrm{F} \\
\text { surface }\end{array}$ & $\begin{array}{c}\mathrm{G} \\
\text { surface }\end{array}$ & $\begin{array}{c}\mathrm{H} \\
\text { surface }\end{array}$ \\
\hline (r) Coal (in ground) (including losses) & $-10.64 \%$ & $13.51 \%$ & $0.00 \%$ & $-0.06 \%$ & $0.00 \%$ & $-0.01 \%$ & $0.00 \%$ & $0.03 \%$ \\
\hline (r) Limestone ( $\mathrm{CaCO} 3$, in ground) & $-10.65 \%$ & $13.49 \%$ & $-0.04 \%$ & $-17.11 \%$ & $0.00 \%$ & $-0.41 \%$ & $-0.33 \%$ & $0.00 \%$ \\
\hline (r) Natural Gas (in ground) & $-10.64 \%$ & $13.51 \%$ & $0.00 \%$ & $-0.17 \%$ & $0.00 \%$ & $-0.35 \%$ & $0.01 \%$ & $1.16 \%$ \\
\hline (r) Oil (in ground) & $-10.64 \%$ & $13.51 \%$ & $-0.47 \%$ & $-6.32 \%$ & $0.00 \%$ & $-83.75 \%$ & $2.10 \%$ & $278.34 \%$ \\
\hline (a) total Carbon Dioxide (CO2) & $-10.64 \%$ & $13.51 \%$ & $-0.01 \%$ & $-0.58 \%$ & $0.00 \%$ & $-1.75 \%$ & $0.04 \%$ & $5.81 \%$ \\
\hline (a) Carbon Monoxide (CO) & $-10.64 \%$ & $13.51 \%$ & $-0.22 \%$ & $-4.30 \%$ & $0.00 \%$ & $-39.40 \%$ & $1.62 \%$ & $132.62 \%$ \\
\hline (a) total Hydrocarbons (except $\mathrm{CH} 4$, including VOCs) & $-10.64 \%$ & $13.51 \%$ & $-0.17 \%$ & $-4.03 \%$ & $0.00 \%$ & $-22.75 \%$ & $0.70 \%$ & $75.93 \%$ \\
\hline (a) Methane $(\mathrm{CH} 4)$ & $-10.64 \%$ & $13.51 \%$ & $0.00 \%$ & $-0.01 \%$ & $-52.37 \%$ & $-0.10 \%$ & $0.00 \%$ & $0.32 \%$ \\
\hline (a) Nitrogen Oxides (NOx as NO2) & $-10.64 \%$ & $13.51 \%$ & $-0.20 \%$ & $-3.64 \%$ & $0.00 \%$ & $-25.12 \%$ & $1.08 \%$ & $84.84 \%$ \\
\hline (a) total Particlulates (unspecified) & $-10.64 \%$ & $13.51 \%$ & $-0.08 \%$ & $-10.32 \%$ & $0.00 \%$ & $-12.16 \%$ & $0.61 \%$ & $41.36 \%$ \\
\hline (a) Sulfur Oxides (SOx as SO2) & $-10.64 \%$ & $13.51 \%$ & $-0.02 \%$ & $-1.91 \%$ & $0.00 \%$ & $-9.85 \%$ & $0.37 \%$ & $32.98 \%$ \\
\hline Electricity & $-10.64 \%$ & $13.51 \%$ & $-0.01 \%$ & $-3.45 \%$ & $0.00 \%$ & $-2.06 \%$ & $-0.02 \%$ & $6.60 \%$ \\
\hline total Non-Coal Energy & $-10.64 \%$ & $13.51 \%$ & $-0.18 \%$ & $-3.91 \%$ & $0.00 \%$ & $-32.07 \%$ & $1.75 \%$ & $109.47 \%$ \\
\hline ash - landfilled (dry) & $-10.64 \%$ & $13.51 \%$ & $0.00 \%$ & $0.00 \%$ & $0.00 \%$ & $0.00 \%$ & $0.00 \%$ & $0.00 \%$ \\
\hline ash - total (dry) & $-10.64 \%$ & $13.51 \%$ & $0.00 \%$ & $0.00 \%$ & $0.00 \%$ & $0.00 \%$ & $0.00 \%$ & $0.00 \%$ \\
\hline Waste (hazardous) & $-10.64 \%$ & $13.51 \%$ & $-0.01 \%$ & $-38.48 \%$ & $0.00 \%$ & $-3.13 \%$ & $-2.57 \%$ & $0.00 \%$ \\
\hline Waste (municipal and industrial) & $-10.64 \%$ & $13.51 \%$ & $-0.05 \%$ & $-71.46 \%$ & $0.00 \%$ & $-1.60 \%$ & $-1.32 \%$ & $0.00 \%$ \\
\hline Waste (unspecified) & $-10.64 \%$ & $13.51 \%$ & $-0.01 \%$ & $-8.87 \%$ & $0.00 \%$ & $-0.55 \%$ & $-0.10 \%$ & $1.38 \%$ \\
\hline \multirow[t]{2}{*}{ Waste (total) } & $-10.64 \%$ & $13.51 \%$ & $0.00 \%$ & $-1.01 \%$ & $0.00 \%$ & $-0.05 \%$ & $-0.01 \%$ & $0.09 \%$ \\
\hline & $\begin{array}{c}\text { I } \\
\text { surface }\end{array}$ & $\underset{\text { surface }}{\mathrm{J}}$ & $\begin{array}{c}\mathrm{K} \\
\text { surface }\end{array}$ & $\begin{array}{c}\mathrm{L} \\
\text { surface }\end{array}$ & $\begin{array}{c}M \\
\text { surface }\end{array}$ & $\begin{array}{c}\mathrm{N} \\
\text { surface }\end{array}$ & $\begin{array}{c}0 \\
\text { surface }\end{array}$ & $\begin{array}{c}P \\
\text { surface }\end{array}$ \\
\hline (r) Coal (in ground) (including losses) & $0.08 \%$ & $0.00 \%$ & $-0.06 \%$ & $-0.25 \%$ & $-0.02 \%$ & $0.01 \%$ & $-0.01 \%$ & $0.01 \%$ \\
\hline (r) Limestone (CaCO3, in ground) & $0.00 \%$ & $0.00 \%$ & $0.00 \%$ & $0.00 \%$ & $-5.34 \%$ & $2.75 \%$ & $-2.80 \%$ & $15.73 \%$ \\
\hline (r) Natural Gas (in ground) & $0.15 \%$ & $0.00 \%$ & $-0.12 \%$ & $-0.48 \%$ & $-0.05 \%$ & $0.02 \%$ & $-0.02 \%$ & $0.02 \%$ \\
\hline (r) Oil (in ground) & $0.29 \%$ & $0.00 \%$ & $-0.23 \%$ & $-0.50 \%$ & $-1.96 \%$ & $0.05 \%$ & $-0.05 \%$ & $0.01 \%$ \\
\hline (a) total Carbon Dioxide (CO2) & $0.48 \%$ & $0.00 \%$ & $-0.38 \%$ & $-1.56 \%$ & $-0.18 \%$ & $0.01 \%$ & $-0.01 \%$ & $0.01 \%$ \\
\hline (a) Carbon Monoxide (CO) & $1.14 \%$ & $0.00 \%$ & $-0.90 \%$ & $-3.50 \%$ & $-1.33 \%$ & $0.04 \%$ & $-0.04 \%$ & $0.00 \%$ \\
\hline (a) total Hydrocarbons (except $\mathrm{CH} 4$, including VOCs) & $2.84 \%$ & $0.00 \%$ & $-2.23 \%$ & $-9.07 \%$ & $-1.25 \%$ & $0.25 \%$ & $-0.25 \%$ & $0.34 \%$ \\
\hline (a) Methane $(\mathrm{CH} 4)$ & $0.00 \%$ & $0.00 \%$ & $0.00 \%$ & $-0.02 \%$ & $0.00 \%$ & $0.00 \%$ & $0.00 \%$ & $0.00 \%$ \\
\hline (a) Nitrogen Oxides (NOx as NO2) & $2.15 \%$ & $0.00 \%$ & $-1.69 \%$ & $-6.81 \%$ & $-1.13 \%$ & $0.03 \%$ & $-0.03 \%$ & $0.00 \%$ \\
\hline (a) total Particlulates (unspecified) & $0.82 \%$ & $0.00 \%$ & $-0.64 \%$ & $-2.59 \%$ & $-3.18 \%$ & $0.18 \%$ & $-0.18 \%$ & $0.85 \%$ \\
\hline (a) Sulfur Oxides (SOx as SO2) & $1.80 \%$ & $0.00 \%$ & $-1.42 \%$ & $-5.84 \%$ & $-0.59 \%$ & $0.05 \%$ & $-0.05 \%$ & $0.01 \%$ \\
\hline Electricity & $10.00 \%$ & $0.00 \%$ & $-7.86 \%$ & $-32.51 \%$ & $-1.09 \%$ & $0.53 \%$ & $-0.53 \%$ & $-0.12 \%$ \\
\hline total Non-Coal Energy & $2.18 \%$ & $0.00 \%$ & $-1.71 \%$ & $-6.90 \%$ & $-1.22 \%$ & $0.17 \%$ & $-0.17 \%$ & $0.15 \%$ \\
\hline ash - landfilled (dry) & $38.89 \%$ & $0.00 \%$ & $-30.56 \%$ & $-30.56 \%$ & $0.00 \%$ & $0.00 \%$ & $0.00 \%$ & $0.00 \%$ \\
\hline ash - total (dry) & $0.00 \%$ & $0.00 \%$ & $0.00 \%$ & $0.00 \%$ & $0.00 \%$ & $0.00 \%$ & $0.00 \%$ & $0.00 \%$ \\
\hline Waste (hazardous) & $0.00 \%$ & $0.00 \%$ & $0.00 \%$ & $0.00 \%$ & $-26.60 \%$ & $3.11 \%$ & $-3.11 \%$ & $37.82 \%$ \\
\hline Waste (municipal and industrial) & $0.02 \%$ & $0.00 \%$ & $-0.01 \%$ & $-0.01 \%$ & $-21.91 \%$ & $11.59 \%$ & $-11.59 \%$ & $99.23 \%$ \\
\hline Waste (unspecified) & $9.61 \%$ & $0.00 \%$ & $-7.55 \%$ & $-31.25 \%$ & $-2.76 \%$ & $0.93 \%$ & $-0.93 \%$ & $1.18 \%$ \\
\hline Waste (total) & $36.66 \%$ & $0.00 \%$ & $-28.81 \%$ & $-30.43 \%$ & $-0.31 \%$ & $0.13 \%$ & $-0.13 \%$ & $0.64 \%$ \\
\hline
\end{tabular}

Increase plant efficiency

Decrease plant efficiency by 5 points

Construction materials low case

Mining methane emissions using EIA average U.S. numbers Mine mouth

Average user by land

Farthest user
SENSITIVITY CASE CASE LETTER

No ash recovery - $100 \%$ of plant ash is landfilled

$$
100 \% \text { of recovered ash is used in cement }
$$

$50 \%$ of plant ash is recovered \& percent used in cement remains constant @ $42 \%$ $50 \%$ of plant ash is recovered $\& 100 \%$ of this is used in cement Plant operating capacity factor $=85 \%$ Increase mining equipment materials by $50 \%$ Decrease mining equipment materials by $50 \%$ Decrease in recycle of materials by $1 / 3$

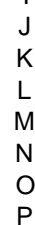


Table B30: Sensitivity Analysis Condensed Results - LEBS System (underground mining) $\%$ change from the base case on a per unit of energy produced (i.e., MWh) basis

\begin{tabular}{|c|c|c|c|c|c|c|c|c|}
\hline & $\begin{array}{c}\mathrm{A} \\
\text { underground }\end{array}$ & $\begin{array}{c}\mathrm{B} \\
\text { underground }\end{array}$ & $\begin{array}{c}\mathrm{C} \\
\text { underground }\end{array}$ & $\begin{array}{c}\mathrm{D} \\
\text { underground }\end{array}$ & $\begin{array}{c}E \\
\text { underground }\end{array}$ & $\begin{array}{c}\mathrm{F} \\
\text { underground }\end{array}$ & $\begin{array}{c}\mathrm{G} \\
\text { underground }\end{array}$ & $\begin{array}{c}\mathrm{H} \\
\text { underground }\end{array}$ \\
\hline (r) Coal (in ground) (including losses) & $-10.64 \%$ & $13.51 \%$ & $0.00 \%$ & $-0.06 \%$ & $0.00 \%$ & $-0.01 \%$ & $0.00 \%$ & $0.03 \%$ \\
\hline (r) Limestone ( $\mathrm{CaCO} 3$, in ground) & $-10.64 \%$ & $13.51 \%$ & $0.00 \%$ & $-0.09 \%$ & $0.00 \%$ & $0.00 \%$ & $0.00 \%$ & $0.00 \%$ \\
\hline (r) Natural Gas (in ground) & $-10.64 \%$ & $13.51 \%$ & $0.00 \%$ & $-0.18 \%$ & $0.00 \%$ & $-0.38 \%$ & $0.01 \%$ & $1.24 \%$ \\
\hline (r) Oil (in ground) & $-10.64 \%$ & $13.51 \%$ & $-0.44 \%$ & $-6.02 \%$ & $0.00 \%$ & $-79.84 \%$ & $2.00 \%$ & $265.35 \%$ \\
\hline (a) total Carbon Dioxide (CO2) & $-10.64 \%$ & $13.51 \%$ & $-0.01 \%$ & $-0.58 \%$ & $0.00 \%$ & $-1.75 \%$ & $0.04 \%$ & $5.81 \%$ \\
\hline (a) Carbon Monoxide (CO) & $-10.64 \%$ & $13.51 \%$ & $-0.22 \%$ & $-4.41 \%$ & $0.00 \%$ & $-40.43 \%$ & $1.66 \%$ & $136.08 \%$ \\
\hline (a) total Hydrocarbons (except $\mathrm{CH} 4$, including VOCs) & $-10.64 \%$ & $13.51 \%$ & $-0.18 \%$ & $-4.27 \%$ & $0.00 \%$ & $-24.11 \%$ & $0.75 \%$ & $80.45 \%$ \\
\hline (a) Methane $(\mathrm{CH} 4)$ & $-10.64 \%$ & $13.51 \%$ & $0.00 \%$ & $-0.01 \%$ & $114.61 \%$ & $-0.05 \%$ & $0.00 \%$ & $0.15 \%$ \\
\hline (a) Nitrogen Oxides (NOx as NO2) & $-10.64 \%$ & $13.51 \%$ & $-0.20 \%$ & $-3.69 \%$ & $0.00 \%$ & $-25.50 \%$ & $1.09 \%$ & $86.11 \%$ \\
\hline (a) total Particlulates (unspecified) & $-10.64 \%$ & $13.51 \%$ & $-0.01 \%$ & $-1.46 \%$ & $0.00 \%$ & $-1.71 \%$ & $0.09 \%$ & $5.83 \%$ \\
\hline (a) Sulfur Oxides (SOx as SO2) & $-10.64 \%$ & $13.51 \%$ & $-0.02 \%$ & $-1.91 \%$ & $0.00 \%$ & $-9.81 \%$ & $0.37 \%$ & $32.85 \%$ \\
\hline Electricity & $-10.64 \%$ & $13.51 \%$ & $-0.01 \%$ & $-3.90 \%$ & $0.00 \%$ & $-2.34 \%$ & $-0.02 \%$ & $7.46 \%$ \\
\hline total Non-Coal Energy & $-10.64 \%$ & $13.51 \%$ & $-0.19 \%$ & $-4.04 \%$ & $0.00 \%$ & $-33.09 \%$ & $1.81 \%$ & $112.98 \%$ \\
\hline ash - landfilled (dry) & $-10.64 \%$ & $13.51 \%$ & $0.00 \%$ & $0.00 \%$ & $0.00 \%$ & $0.00 \%$ & $0.00 \%$ & $0.00 \%$ \\
\hline ash - total (dry) & $-10.64 \%$ & $13.51 \%$ & $0.00 \%$ & $0.00 \%$ & $0.00 \%$ & $0.00 \%$ & $0.00 \%$ & $0.00 \%$ \\
\hline Waste (hazardous) & $-10.64 \%$ & $13.51 \%$ & $-0.01 \%$ & $-39.88 \%$ & $0.00 \%$ & $-3.25 \%$ & $-2.66 \%$ & $0.00 \%$ \\
\hline Waste (municipal and industrial) & $-10.64 \%$ & $13.51 \%$ & $-0.05 \%$ & $-81.76 \%$ & $0.00 \%$ & $-1.83 \%$ & $-1.51 \%$ & $0.00 \%$ \\
\hline Waste (unspecified) & $-10.64 \%$ & $13.51 \%$ & $0.00 \%$ & $-4.73 \%$ & $0.00 \%$ & $-0.29 \%$ & $-0.05 \%$ & $0.73 \%$ \\
\hline \multirow[t]{2}{*}{ Waste (total) } & $-10.64 \%$ & $13.51 \%$ & $0.00 \%$ & $-0.95 \%$ & $0.00 \%$ & $-0.04 \%$ & $-0.01 \%$ & $0.09 \%$ \\
\hline & $\begin{array}{c}\mathrm{I} \\
\text { underground }\end{array}$ & $\begin{array}{c}\mathrm{J} \\
\text { underground }\end{array}$ & $\begin{array}{c}\mathrm{K} \\
\text { underground }\end{array}$ & $\stackrel{\mathrm{L}}{\text { underground }}$ & $\begin{array}{c}\mathrm{M} \\
\text { underground }\end{array}$ & $\stackrel{\mathrm{N}}{\text { underground }}$ & $\begin{array}{c}\mathrm{O} \\
\text { underground }\end{array}$ & $\begin{array}{c}P \\
\text { underground }\end{array}$ \\
\hline (r) Coal (in ground) (including losses) & $0.08 \%$ & $0.00 \%$ & $-0.06 \%$ & $-0.25 \%$ & $-0.02 \%$ & $0.00 \%$ & $0.00 \%$ & $0.01 \%$ \\
\hline (r) Limestone (CaCO3, in ground) & $0.00 \%$ & $0.00 \%$ & $0.00 \%$ & $0.00 \%$ & $-0.03 \%$ & $0.01 \%$ & $-0.01 \%$ & $0.07 \%$ \\
\hline (r) Natural Gas (in ground) & $0.16 \%$ & $0.00 \%$ & $-0.13 \%$ & $-0.52 \%$ & $-0.06 \%$ & $0.01 \%$ & $-0.01 \%$ & $0.02 \%$ \\
\hline (r) Oil (in ground) & $0.28 \%$ & $0.00 \%$ & $-0.22 \%$ & $-0.48 \%$ & $-1.87 \%$ & $0.02 \%$ & $-0.02 \%$ & $0.01 \%$ \\
\hline (a) total Carbon Dioxide (CO2) & $0.48 \%$ & $0.00 \%$ & $-0.38 \%$ & $-1.56 \%$ & $-0.18 \%$ & $0.00 \%$ & $0.00 \%$ & $0.01 \%$ \\
\hline (a) Carbon Monoxide (CO) & $1.17 \%$ & $0.00 \%$ & $-0.92 \%$ & $-3.59 \%$ & $-1.36 \%$ & $0.02 \%$ & $-0.02 \%$ & $0.00 \%$ \\
\hline (a) total Hydrocarbons (except $\mathrm{CH} 4$, including VOCs) & $3.01 \%$ & $0.00 \%$ & $-2.36 \%$ & $-9.61 \%$ & $-1.33 \%$ & $0.11 \%$ & $-0.11 \%$ & $0.31 \%$ \\
\hline (a) Methane (CH4) & $0.00 \%$ & $0.00 \%$ & $0.00 \%$ & $-0.01 \%$ & $0.00 \%$ & $0.00 \%$ & $0.00 \%$ & $0.00 \%$ \\
\hline (a) Nitrogen Oxides (NOx as NO2) & $2.18 \%$ & $0.00 \%$ & $-1.72 \%$ & $-6.91 \%$ & $-1.14 \%$ & $0.01 \%$ & $-0.01 \%$ & $0.00 \%$ \\
\hline (a) total Particlulates (unspecified) & $0.12 \%$ & $0.00 \%$ & $-0.09 \%$ & $-0.37 \%$ & $-0.45 \%$ & $0.01 \%$ & $-0.01 \%$ & $0.10 \%$ \\
\hline (a) Sulfur Oxides (SOx as SO2) & $1.79 \%$ & $0.00 \%$ & $-1.41 \%$ & $-5.81 \%$ & $-0.59 \%$ & $0.02 \%$ & $-0.02 \%$ & $0.01 \%$ \\
\hline Electricity & $11.31 \%$ & $0.00 \%$ & $-8.89 \%$ & $-36.77 \%$ & $-1.23 \%$ & $0.25 \%$ & $-0.25 \%$ & $-0.11 \%$ \\
\hline total Non-Coal Energy & $2.25 \%$ & $0.00 \%$ & $-1.77 \%$ & $-7.13 \%$ & $-1.26 \%$ & $0.07 \%$ & $-0.07 \%$ & $0.14 \%$ \\
\hline ash - landfilled (dry) & $38.89 \%$ & $0.00 \%$ & $-30.56 \%$ & $-30.56 \%$ & $0.00 \%$ & $0.00 \%$ & $0.00 \%$ & $0.00 \%$ \\
\hline ash - total (dry) & $0.00 \%$ & $0.00 \%$ & $0.00 \%$ & $0.00 \%$ & $0.00 \%$ & $0.00 \%$ & $0.00 \%$ & $0.00 \%$ \\
\hline Waste (hazardous) & $0.01 \%$ & $0.00 \%$ & $0.00 \%$ & $0.00 \%$ & $-27.57 \%$ & $1.34 \%$ & $-1.34 \%$ & $39.68 \%$ \\
\hline Waste (municipal and industrial) & $0.02 \%$ & $0.00 \%$ & $-0.02 \%$ & $-0.02 \%$ & $-25.07 \%$ & $5.53 \%$ & $-5.53 \%$ & $98.66 \%$ \\
\hline Waste (unspecified) & $5.13 \%$ & $0.00 \%$ & $-4.03 \%$ & $-16.67 \%$ & $-1.47 \%$ & $0.21 \%$ & $-0.21 \%$ & $0.55 \%$ \\
\hline Waste (total) & $34.61 \%$ & $0.00 \%$ & $-27.20 \%$ & $-28.73 \%$ & $-0.29 \%$ & $0.05 \%$ & $-0.05 \%$ & $0.52 \%$ \\
\hline
\end{tabular}

SENSITIVITY CASE CASE LETTER

Increase plant efficiency by 5 points

Decrease plant efficiency by 5 points

Pond versus landfilling of ash from power plant

Construction materials low case

Mining methane emissions using EIA average U.S. numbers Mine mouth

Average user by land

Farthest user
SENSITIVITY CASE CASE LETTER

No ash recovery - $100 \%$ of plant ash is landfilled

$$
100 \% \text { of recovered ash is used in cement }
$$

$50 \%$ of plant ash is recovered \& percent used in cement remains constant @ $42 \%$ $50 \%$ of plant ash is recovered $\& 100 \%$ of this is used in cemen Plant operating capacity factor $=85 \%$ Increase mining equipment materials by $50 \%$ Decrease mining equipment materials by $50 \%$ Decrease in recycle of materials by $1 / 3$

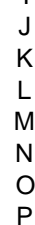


Table B31: Sensitivity Analysis Efficiencies and Energy Ratios - NSPS System

\begin{tabular}{|c|c|c|c|c|c|c|c|c|c|c|c|}
\hline & $\begin{array}{c}\text { nsps - } \\
\text { base case }\end{array}$ & A & B & C & $\mathrm{D}$ & $\mathrm{E}$ & $\mathrm{F}$ & G & $\mathrm{H}$ & 1 & $\mathrm{~J}$ \\
\hline power plant efficiency & $35 \%$ & $40 \%$ & $30 \%$ & $35 \%$ & $35 \%$ & $35 \%$ & $35 \%$ & $35 \%$ & $35 \%$ & $35 \%$ & $35 \%$ \\
\hline life cycle efficiency - surface mining & $-73.2 \%$ & $-68.5 \%$ & $-78.0 \%$ & $-73.2 \%$ & $-73.0 \%$ & $-73.2 \%$ & $-71.3 \%$ & $-73.3 \%$ & $-79.9 \%$ & $-73.3 \%$ & $-73.0 \%$ \\
\hline external energy efficiency - surface mining & $26.8 \%$ & $31.5 \%$ & $22.0 \%$ & $26.8 \%$ & $27.0 \%$ & $26.8 \%$ & $28.7 \%$ & $26.7 \%$ & $20.1 \%$ & $26.7 \%$ & $27.0 \%$ \\
\hline net energy ratio - surface mining & 0.31 & 0.36 & 0.27 & 0.31 & 0.31 & 0.31 & 0.32 & 0.31 & 0.29 & 0.31 & 0.31 \\
\hline external net energy ratio - surface mining & 5.09 & 5.82 & 4.36 & 5.13 & 5.25 & 5.09 & 7.26 & 5.01 & 2.52 & 4.99 & 5.23 \\
\hline life cycle efficiency - underground mining & $-73.0 \%$ & $-68.3 \%$ & $-77.8 \%$ & $-73.0 \%$ & $-72.8 \%$ & $-73.0 \%$ & $-71.1 \%$ & $-73.1 \%$ & $-79.7 \%$ & $-73.2 \%$ & $-72.8 \%$ \\
\hline external energy efficiency - underground mining & $27.0 \%$ & $31.7 \%$ & $22.2 \%$ & $27.0 \%$ & $27.2 \%$ & $27.0 \%$ & $28.9 \%$ & $26.9 \%$ & $20.3 \%$ & $26.8 \%$ & $27.2 \%$ \\
\hline net energy ratio - underground mining & 0.31 & 0.36 & 0.27 & 0.31 & 0.31 & 0.31 & 0.32 & 0.31 & 0.29 & 0.31 & 0.31 \\
\hline external net energy ratio - underground mining & 5.24 & 5.99 & 4.49 & 5.28 & 5.41 & 5.24 & 7.58 & 5.16 & 2.56 & 5.14 & 5.39 \\
\hline & $\begin{array}{c}\text { nsps - } \\
\text { base case }\end{array}$ & $\mathrm{K}$ & $\mathrm{L}$ & $\mathrm{M}$ & $\mathrm{N}$ & $\mathrm{O}$ & $\mathrm{P}$ & Q & $\mathrm{R}$ & $\mathrm{S}$ & $\mathrm{T}$ \\
\hline power plant efficiency & $35 \%$ & $35 \%$ & $35 \%$ & $35 \%$ & $35 \%$ & $35 \%$ & $35 \%$ & $35 \%$ & $35 \%$ & $35 \%$ & $35 \%$ \\
\hline life cycle efficiency - surface mining & $-73.2 \%$ & $-73.1 \%$ & $-72.8 \%$ & $-73.2 \%$ & $-73.2 \%$ & $-73.2 \%$ & $-73.2 \%$ & $-73.2 \%$ & $-73.2 \%$ & $-73.2 \%$ & $-73.2 \%$ \\
\hline external energy efficiency - surface mining & $26.8 \%$ & $26.9 \%$ & $27.2 \%$ & $26.8 \%$ & $26.8 \%$ & $26.8 \%$ & $26.8 \%$ & $26.8 \%$ & $26.8 \%$ & $26.8 \%$ & $26.8 \%$ \\
\hline net energy ratio - surface mining & 0.31 & 0.31 & 0.31 & 0.31 & 0.31 & 0.31 & 0.31 & 0.31 & 0.31 & 0.31 & 0.31 \\
\hline external net energy ratio - surface mining & 5.09 & 5.17 & 5.44 & 5.14 & 5.08 & 5.10 & 5.08 & 5.08 & 5.09 & 5.10 & 5.10 \\
\hline life cycle efficiency - underground mining & $-73.0 \%$ & $-72.9 \%$ & $-72.6 \%$ & $-73.0 \%$ & $-73.0 \%$ & $-73.0 \%$ & $-73.0 \%$ & $-73.0 \%$ & $-73.0 \%$ & $-73.0 \%$ & $-73.0 \%$ \\
\hline external energy efficiency - underground mining & $27.0 \%$ & $27.1 \%$ & $27.4 \%$ & $27.0 \%$ & $27.0 \%$ & $27.0 \%$ & $27.0 \%$ & $27.0 \%$ & $27.0 \%$ & $27.0 \%$ & $27.0 \%$ \\
\hline net energy ratio - underground mining & 0.31 & 0.31 & 0.31 & 0.31 & 0.31 & 0.31 & 0.31 & 0.31 & 0.31 & 0.31 & 0.31 \\
\hline external net energy ratio - underground mining & 5.24 & 5.33 & 5.61 & 5.29 & 5.24 & 5.25 & 5.24 & 5.23 & 5.24 & 5.25 & 5.25 \\
\hline
\end{tabular}

CASE LETTER SENSITIVITY CASE

A Increase plant efficiency by 5 points

B Decrease plant efficiency by 5 points

C Pond versus landfilling of ash from power plant

D Construction materials low case

E Mining methane emissions using EIA average U.S. numbers

F Mine mouth

G Average user by land

$\mathrm{H} \quad$ Farthest user

I No ash recovery $-100 \%$ of plant ash is landfilled

$\mathrm{J} \quad 100 \%$ of recovered ash is used in cement

K $\quad 50 \%$ of plant ash is recovered \& percent used in cement remains constant @ $42 \%$

L $\quad 50 \%$ of plant ash is recovered $\& 100 \%$ of this is used in cement

M Plant operating capacity factor $=85 \%$

$\mathrm{N} \quad$ Increase mining equipment materials by $50 \%$

$\mathrm{O}$ Decrease mining equipment materials by $50 \%$

P Decrease in recycle of materials by $1 / 3$

Q No FGC recovery - $100 \%$ is landfilled

R $100 \%$ of recovered FGC is used in asphalt

S $50 \%$ of plant FCG is recovered \& percent used in asphalt remains constant @ 7.2\%

T $50 \%$ of plant FCG is recovered $\& 100 \%$ of this is used in asphalt 
Table B32: Sensitivity Analysis Efficiencies and Energy Ratios - LEBS System

\begin{tabular}{|c|c|c|c|c|c|c|c|c|c|}
\hline & $\begin{array}{c}\text { lebs - } \\
\text { base case }\end{array}$ & A & B & C & D & $E$ & $F$ & $\mathrm{G}$ & $\mathrm{H}$ \\
\hline power plant efficiency & $42 \%$ & $47 \%$ & $37 \%$ & $42 \%$ & $42 \%$ & $42 \%$ & $42 \%$ & $42 \%$ & $42 \%$ \\
\hline life cycle efficiency - surface mining & $-65.9 \%$ & $-61.1 \%$ & $-70.7 \%$ & $-65.9 \%$ & $-65.7 \%$ & $-65.9 \%$ & $-64.0 \%$ & $-66.0 \%$ & $-72.4 \%$ \\
\hline external energy efficiency - surface mining & $34.1 \%$ & $38.9 \%$ & $29.3 \%$ & $34.1 \%$ & $34.3 \%$ & $34.1 \%$ & $36.0 \%$ & $34.0 \%$ & $27.6 \%$ \\
\hline net energy ratio - surface mining & 0.38 & 0.42 & 0.33 & 0.38 & 0.38 & 0.38 & 0.38 & 0.38 & 0.36 \\
\hline external net energy ratio - surface mining & 6.72 & 7.52 & 5.92 & 6.73 & 6.99 & 6.72 & 9.89 & 6.60 & 3.21 \\
\hline life cycle efficiency - underground mining & $-65.7 \%$ & $-61.0 \%$ & $-70.5 \%$ & $-65.7 \%$ & $-65.5 \%$ & $-65.7 \%$ & $-63.8 \%$ & $-65.8 \%$ & $-72.3 \%$ \\
\hline external energy efficiency - underground mining & $34.3 \%$ & $39.0 \%$ & $29.5 \%$ & $34.3 \%$ & $34.5 \%$ & $34.3 \%$ & $36.2 \%$ & $34.2 \%$ & $27.7 \%$ \\
\hline net energy ratio - underground mining & 0.38 & 0.42 & 0.33 & 0.38 & 0.38 & 0.38 & 0.39 & 0.38 & 0.36 \\
\hline \multirow[t]{2}{*}{ external net energy ratio - underground mining } & 6.93 & 7.76 & 6.11 & 6.95 & 7.22 & 6.93 & 10.36 & 6.81 & 3.25 \\
\hline & $\begin{array}{c}\text { lebs - } \\
\text { base case }\end{array}$ & 1 & J & $\mathrm{K}$ & L & $M$ & $\mathrm{~N}$ & 0 & $P$ \\
\hline power plant efficiency & $42 \%$ & $42 \%$ & $42 \%$ & $42 \%$ & $42 \%$ & $42 \%$ & $42 \%$ & $42 \%$ & $42 \%$ \\
\hline life cycle efficiency - surface mining & $-65.9 \%$ & $-66.0 \%$ & $-65.9 \%$ & $-65.8 \%$ & $-65.5 \%$ & $-65.8 \%$ & $-65.9 \%$ & $-65.9 \%$ & $-65.9 \%$ \\
\hline external energy efficiency - surface mining & $34.1 \%$ & $34.0 \%$ & $34.1 \%$ & $34.2 \%$ & $34.5 \%$ & $34.2 \%$ & $34.1 \%$ & $34.1 \%$ & $34.1 \%$ \\
\hline net energy ratio - surface mining & 0.38 & 0.38 & 0.38 & 0.38 & 0.38 & 0.38 & 0.38 & 0.38 & 0.38 \\
\hline external net energy ratio - surface mining & 6.72 & 6.57 & 6.72 & 6.83 & 7.22 & 6.80 & 6.71 & 6.73 & 6.71 \\
\hline life cycle efficiency - underground mining & $-65.7 \%$ & $-65.9 \%$ & $-65.7 \%$ & $-65.6 \%$ & $-65.3 \%$ & $-65.7 \%$ & $-65.7 \%$ & $-65.7 \%$ & $-65.7 \%$ \\
\hline external energy efficiency - underground mining & $34.3 \%$ & $34.1 \%$ & $34.3 \%$ & $34.4 \%$ & $34.7 \%$ & $34.3 \%$ & $34.3 \%$ & $34.3 \%$ & $34.3 \%$ \\
\hline net energy ratio - underground mining & 0.38 & 0.38 & 0.38 & 0.38 & 0.38 & 0.38 & 0.38 & 0.38 & 0.38 \\
\hline external net energy ratio - underground mining & 6.93 & 6.78 & 6.93 & 7.06 & 7.46 & 7.02 & 6.93 & 6.94 & 6.92 \\
\hline
\end{tabular}

CASE LETTER SENSITIVITY CASE

A Increase plant efficiency by 5 points

Decrease plant efficiency by 5 points

Pond versus landfilling of ash from power plant

Construction materials low case

Mining methane emissions using EIA average U.S. numbers

Mine mouth

Average user by land

Farthest user

No ash recovery - $100 \%$ of plant ash is landfilled

$100 \%$ of recovered ash is used in cement

$50 \%$ of plant ash is recovered \& percent used in cement remains constant @ 42\%

$50 \%$ of plant ash is recovered \& $100 \%$ of this is used in cement

Plant operating capacity factor $=85 \%$

Increase mining equipment materials by $50 \%$

Decrease mining equipment materials by $50 \%$

Decrease in recycle of materials by $1 / 3$ 
Appendix C: Additional Figures 
Figure C1: Yearly Carbon Dioxide Emissions

(underground mining \& average user by river)

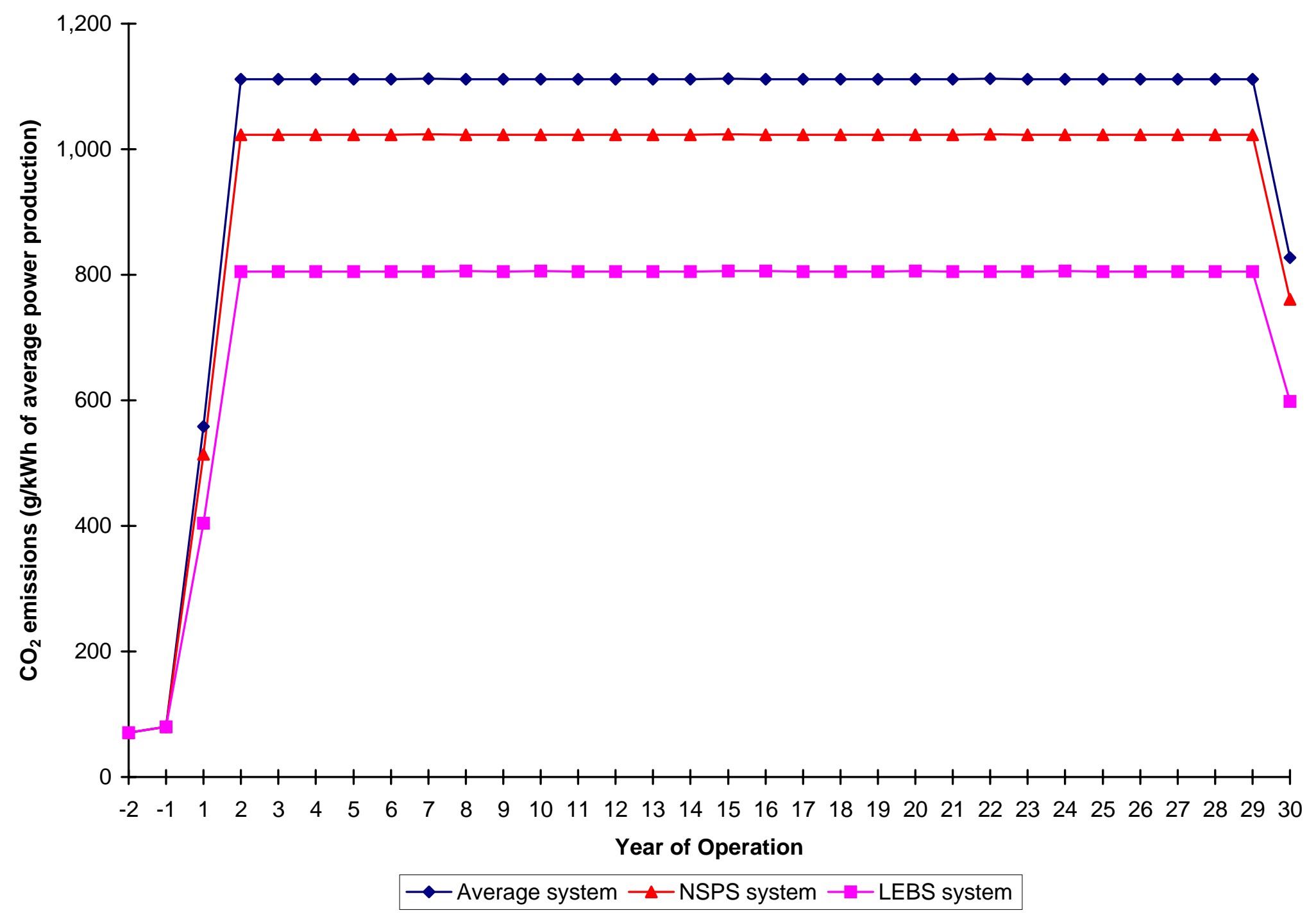


Figure C2: Yearly Sulfur Oxide Emissions $\left(\mathrm{SO}_{\mathrm{x}}\right.$ as $\left.\mathrm{SO}_{2}\right)$

(underground mining \& average user by river)

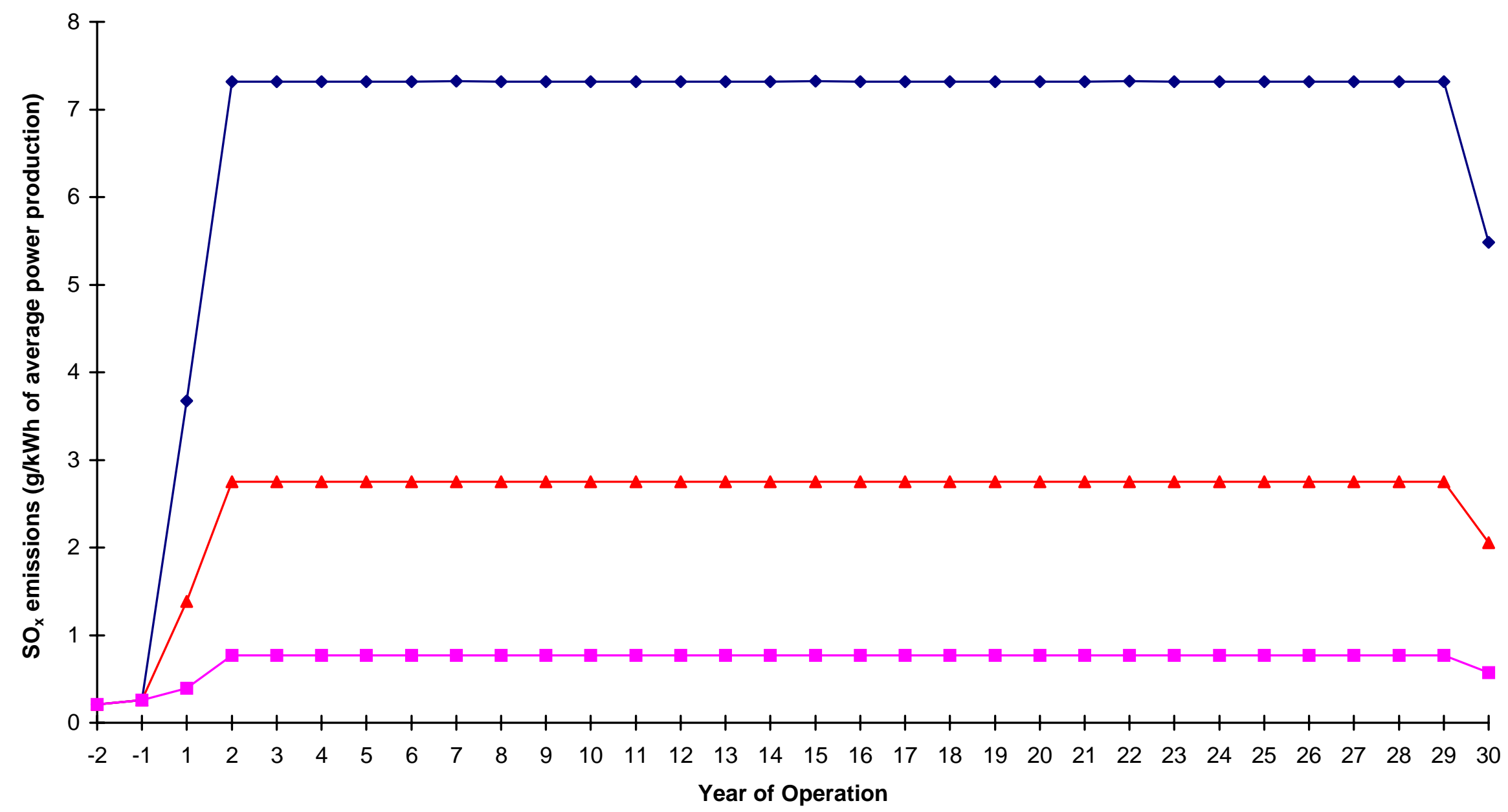

$\rightarrow$ Average system $\multimap$ NSPS system $\rightarrow$ LEBS system 
Figure C3: Yearly Nitrogen Oxide Emissions ( $\mathrm{NO}_{\mathrm{x}}$ as $\left.\mathrm{NO}_{2}\right)$

(underground mining \& average user by river)

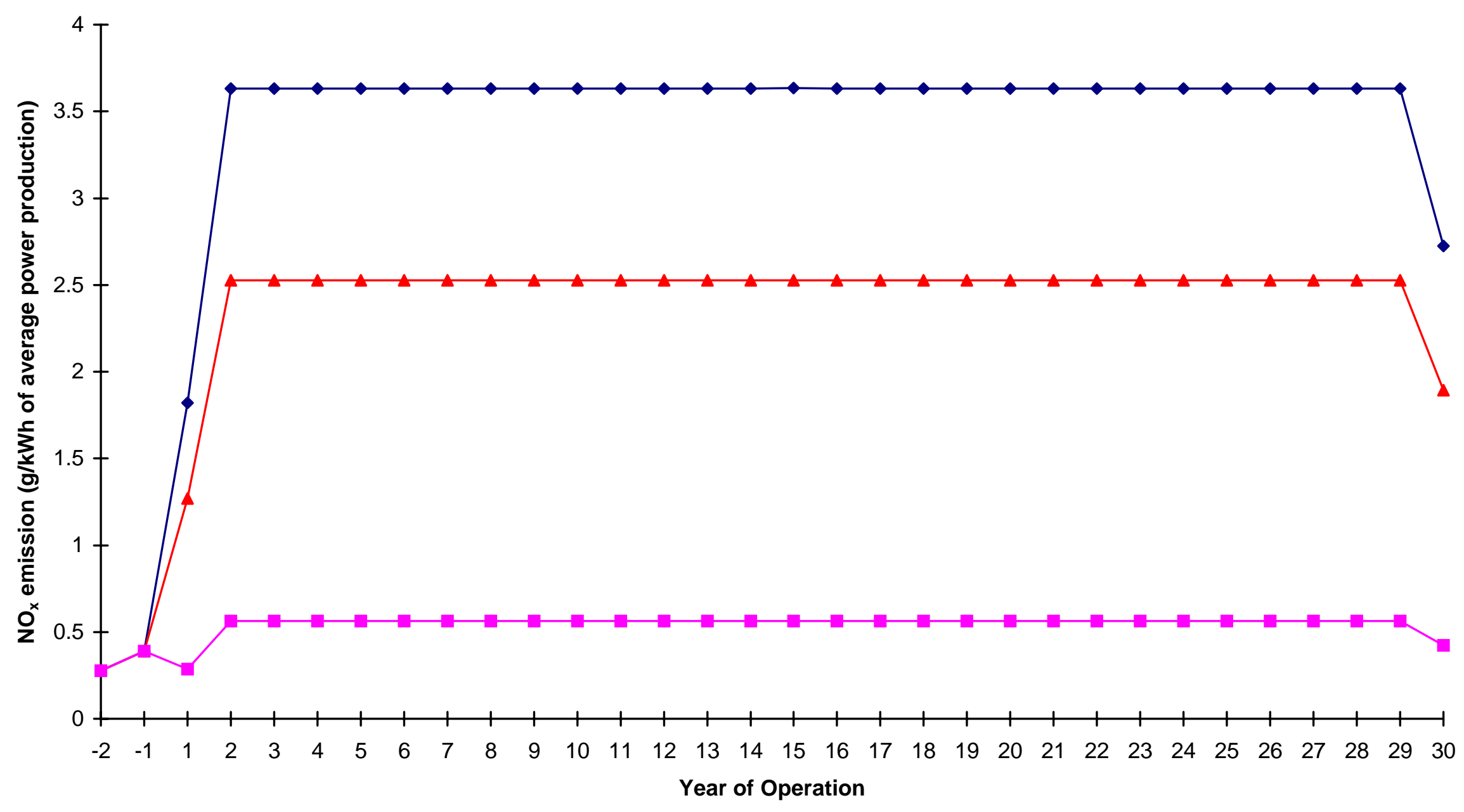

Average system $\multimap$ NSPS system $\rightarrow$ LEBS system 
Figure C4: Yearly Methane Emissions

(underground mining \& average user by river)

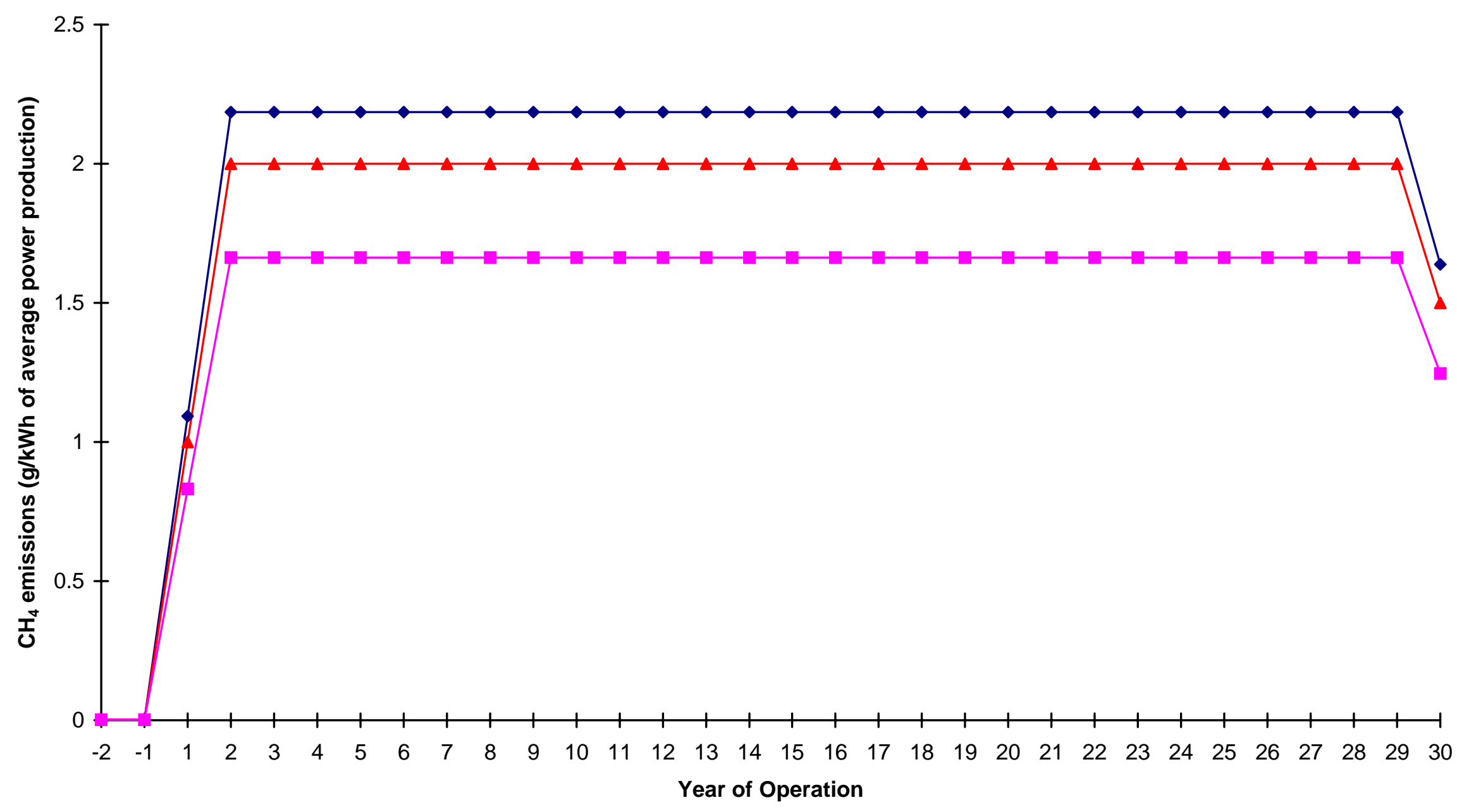


Figure C5: Yearly Total Non-Coal Energy Consumption (underground mining \& average user by river)

(Note: Electricity produced and consumed by the power plant not included)

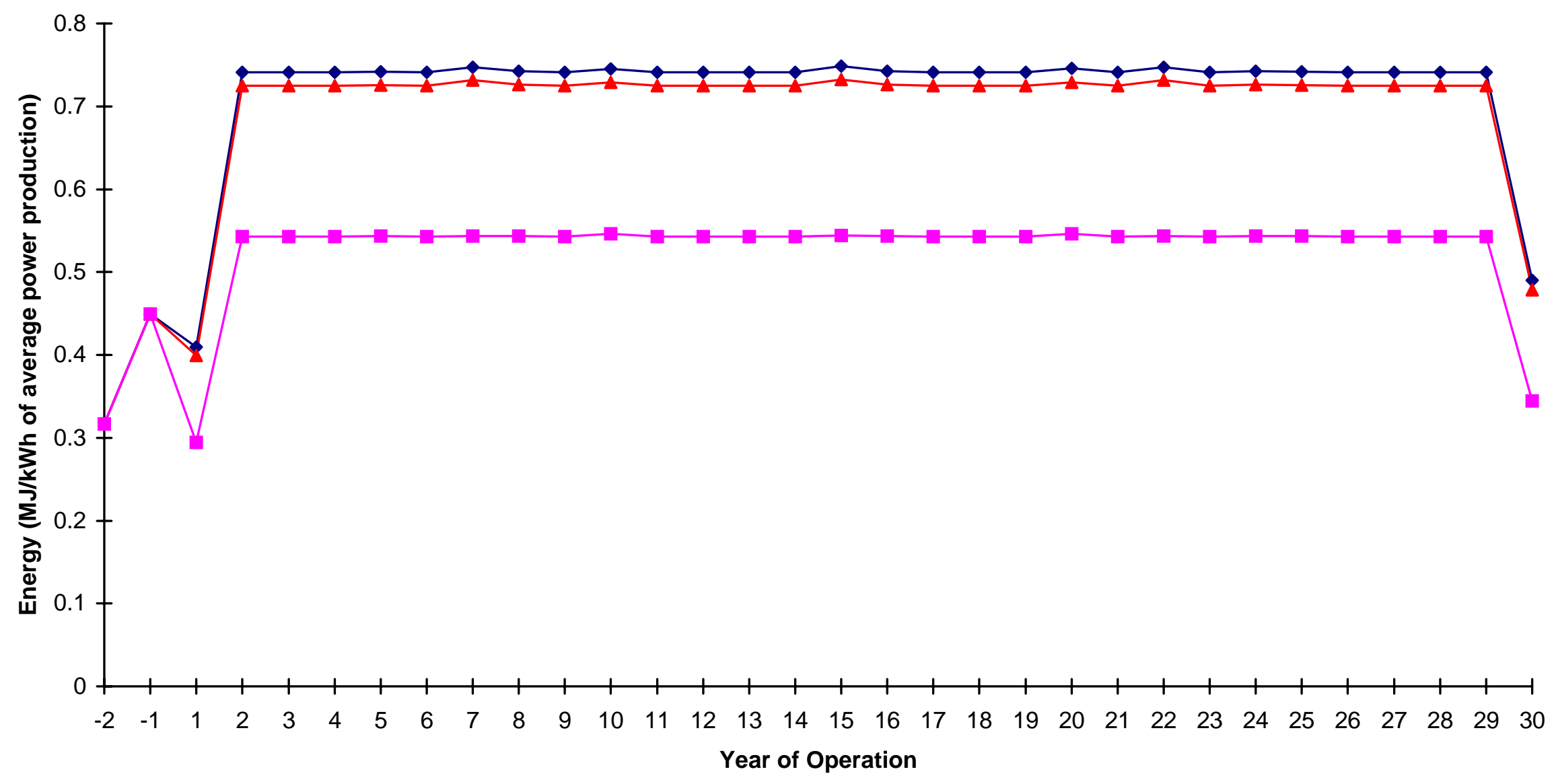

Average system $\multimap$ NSPS system $\rightarrow$ LEBS system 


\section{Key for Sensitivity Cases}

Case

Letter

Increase plant efficiency by 5 points

Decrease plant efficiency by 5 points

Pond versus landfilling of ash from power plant

Construction materials low case

E Mining methane emissions using EIA average U.S. numbers Mine mouth

$G$ Average user by land

$\mathrm{H}$ Farthest user

I No ash recover - $100 \%$ of plant ash is landfilled

J $100 \%$ of recovered ash is used in cement

\author{
Case \\ Letter Sensitivity Case \\ K $50 \%$ of plant ash is recovered \& percent used in cement remains constant @ 42\% \\ L $\quad 50 \%$ of plant ash is recvovered \& $100 \%$ of this is used in cement \\ $\mathrm{M} \quad$ Plant operating capacity factor $=85 \%$ \\ $\mathrm{N} \quad$ Increase mining equipment materials by $50 \%$ \\ $\mathrm{O}$ Decrease mining equipment materials by $50 \%$ \\ $P \quad$ Decrease in recycle of materials by $1 / 3$ \\ Q No FGC recovery - $100 \%$ is landfilled \\ R $100 \%$ of recovered FGC is used in asphalt \\ S $50 \%$ of plant FGC is recovered \& percent used in asphalt remains constant @ $7.2 \%$ \\ T $50 \%$ of plant FGC is recovered \& $100 \%$ of this is used in asphalt
}


Figure C6: Sensitivity results for Life Cycle Efficiency - NSPS System, Surface Mining Case

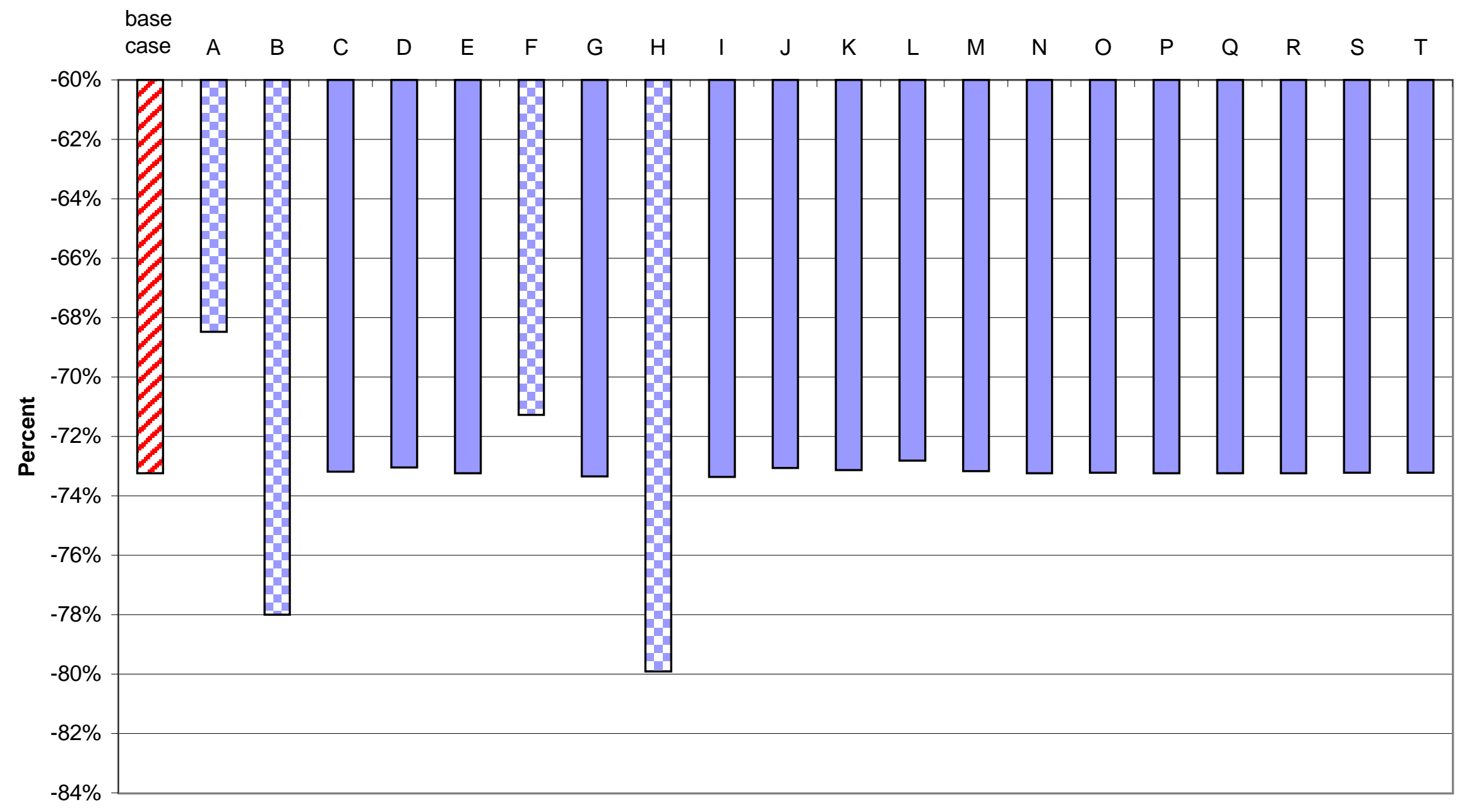

Sensitivity Case

(Refer to the key located before Figure C6) 
Figure C7: Sensitivity Results for External Energy Efficiency - NSPS System, Surface Mining Case

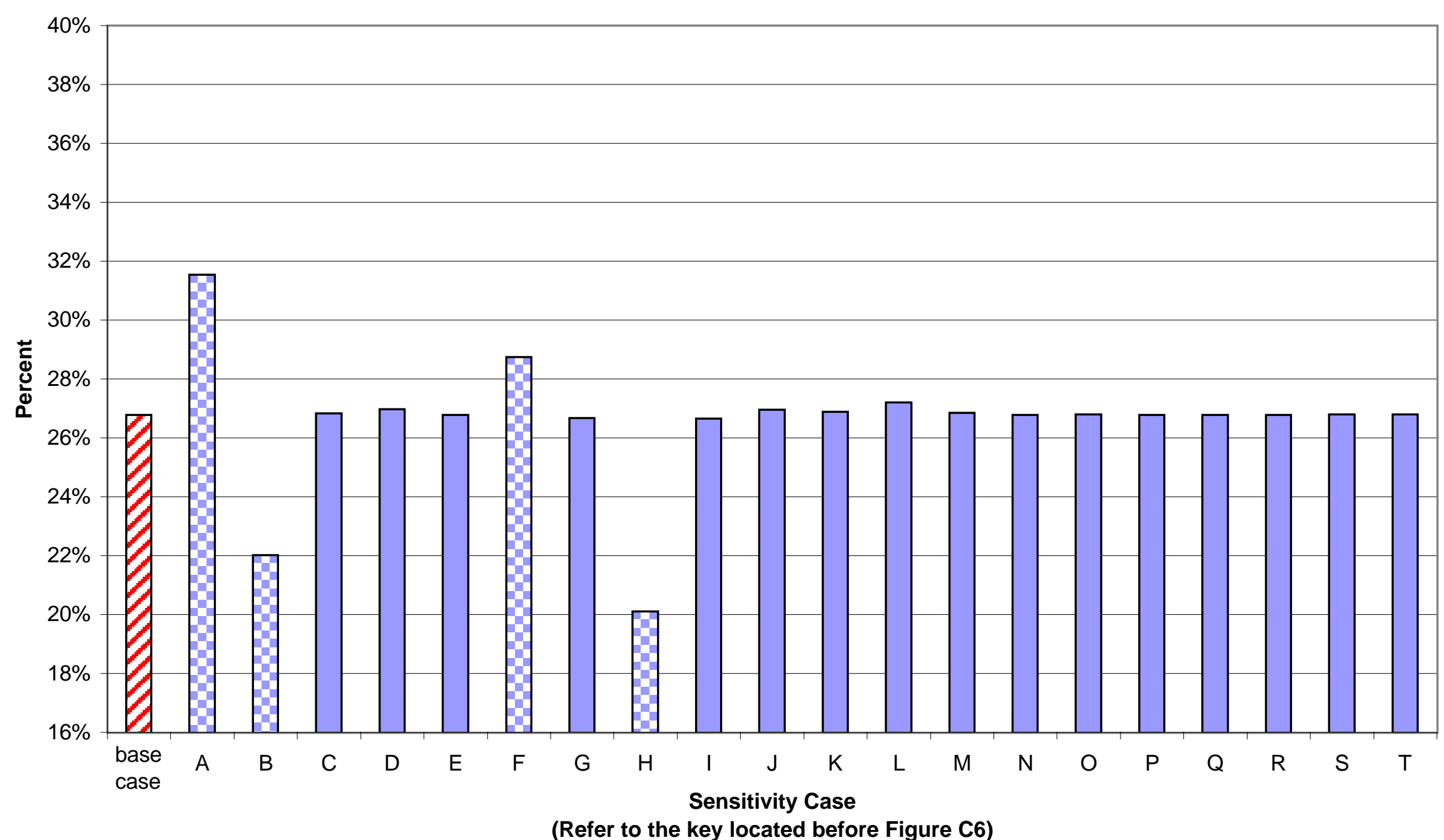


Figure C8: Sensitivity Results for Net Energy Ratio - NSPS System, Surface Mining Case

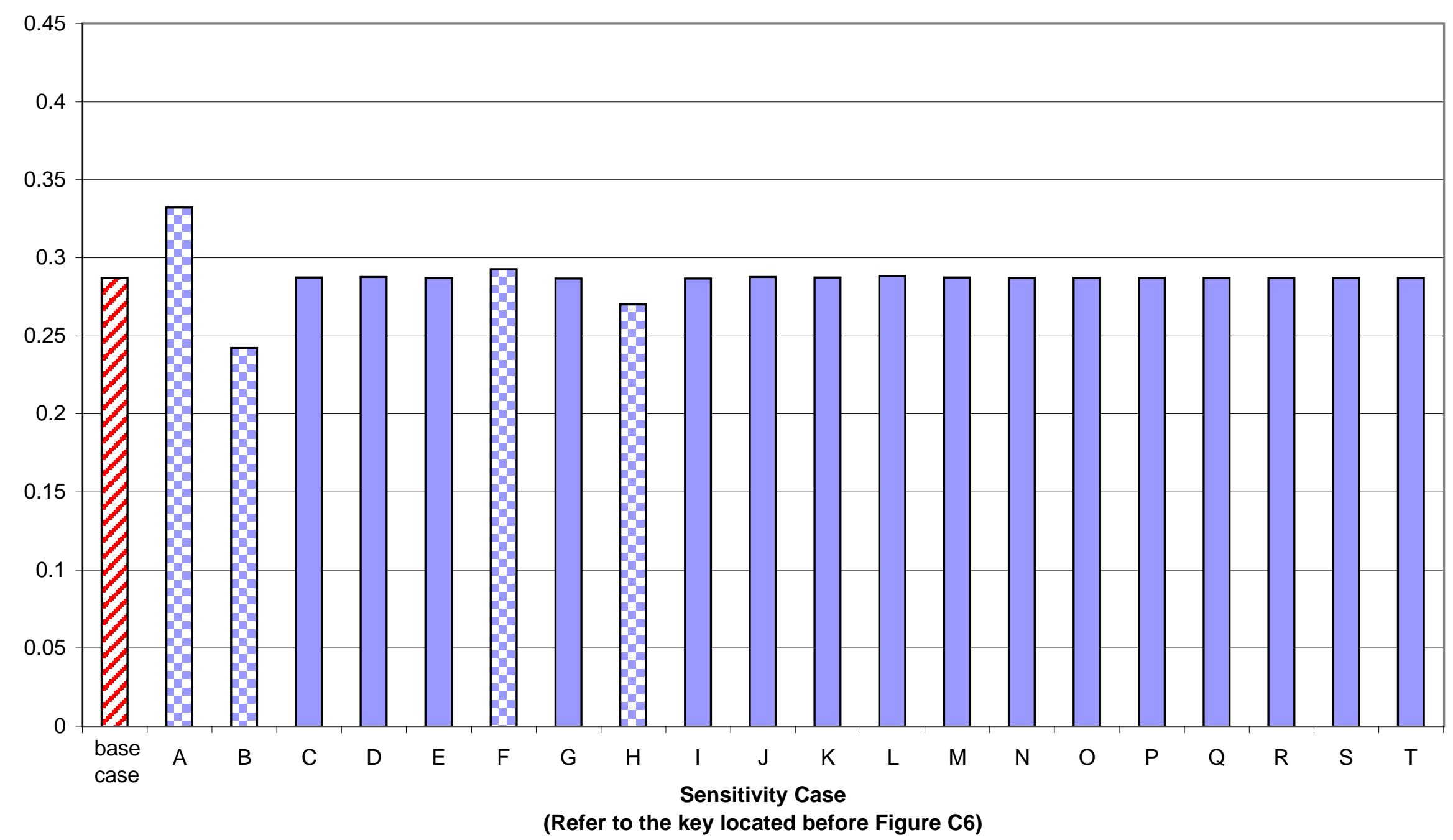


Figure C9: Sensitivity Results for External Net Energy Ratio - NSPS System, Surface Mining Case

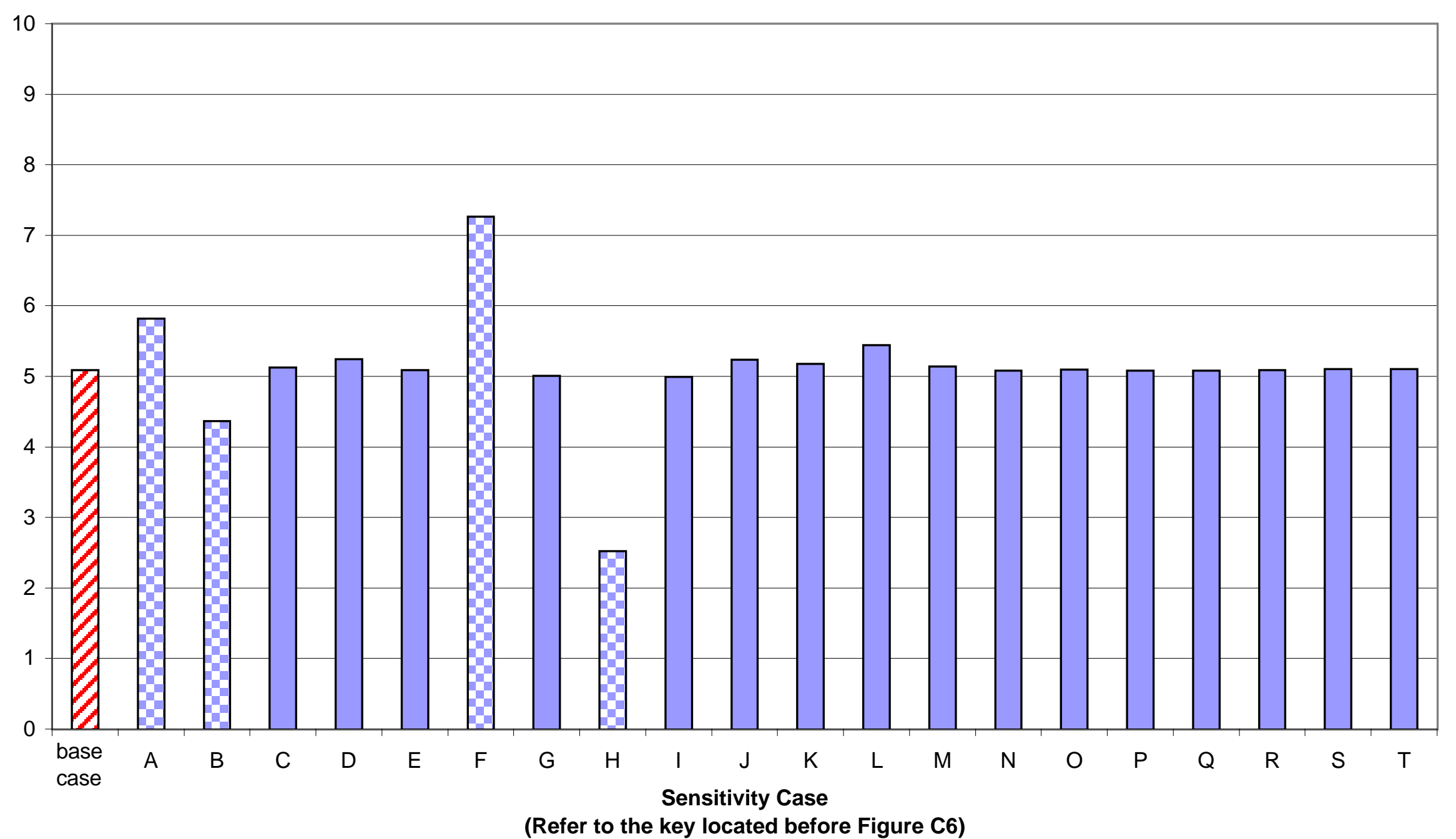


Figure C10: Sensitivity Results for Life Cycle Efficiency - LEBS System, Surface Mining Case

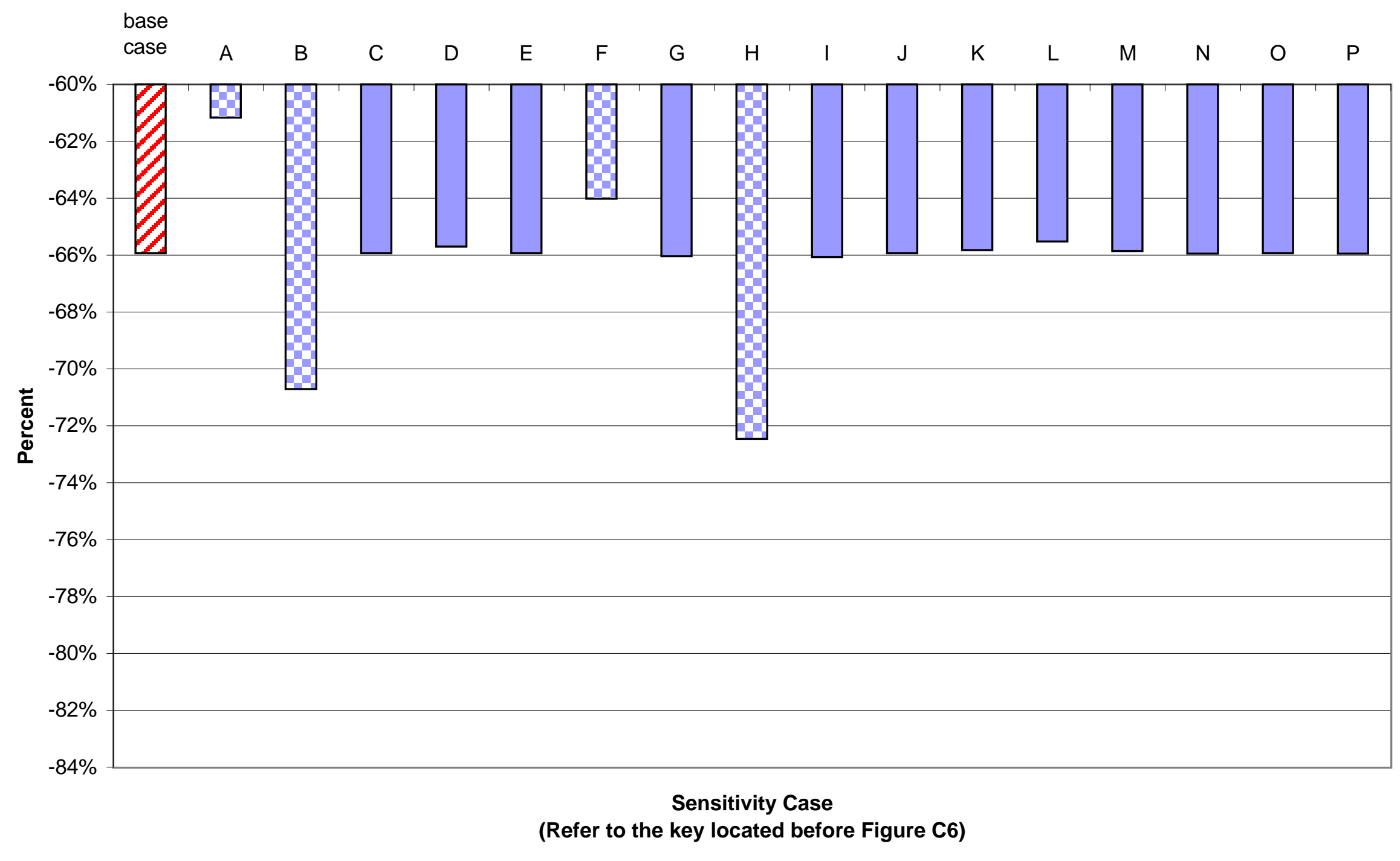


Figure C11: Sensitivity Results for External Energy Efficiency - LEBS Stystem, Surface Mining Case

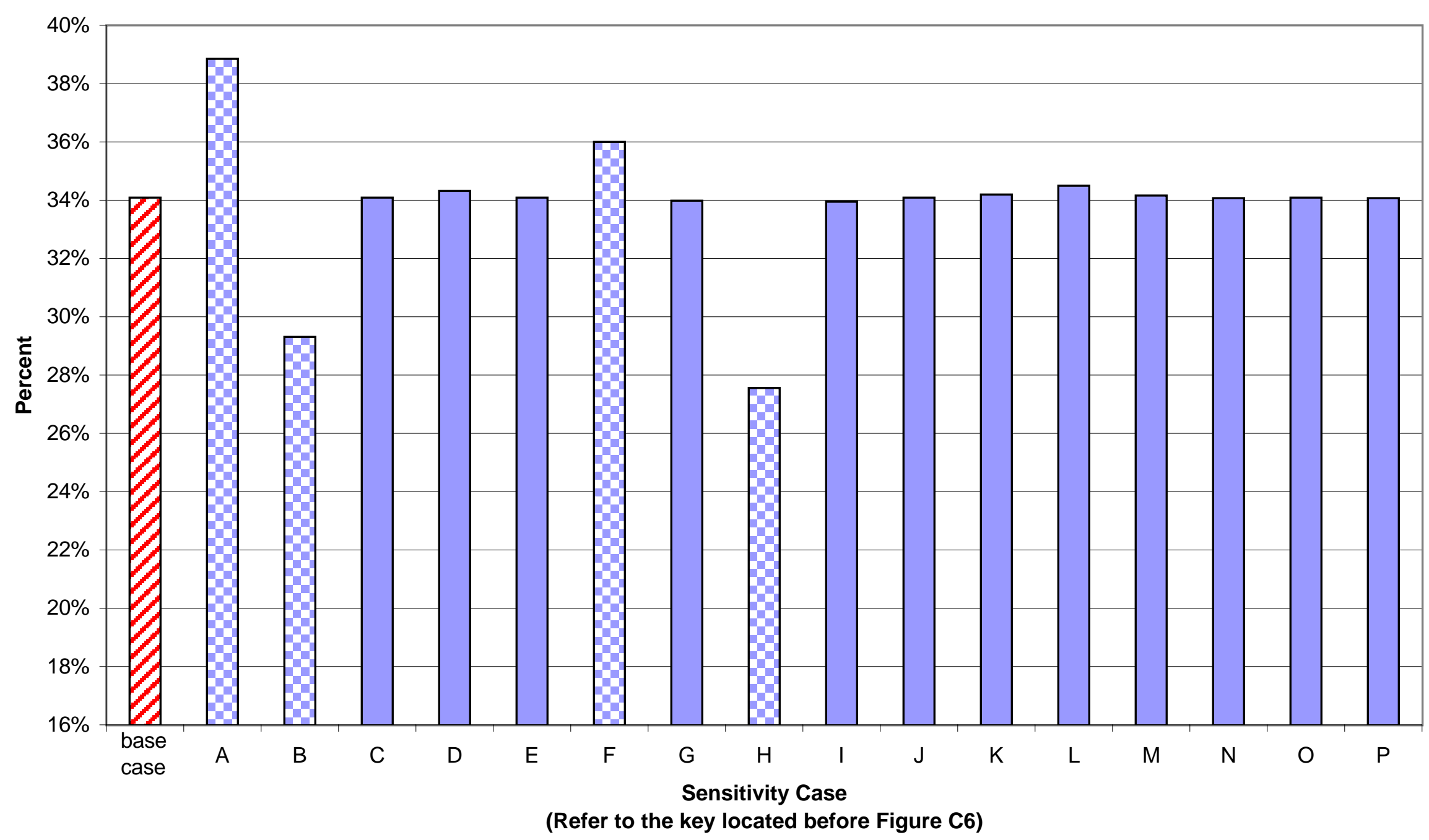


Figure C12: Sensitivity Results for Net Energy Ratio - LEBS System, Surface Mining Case

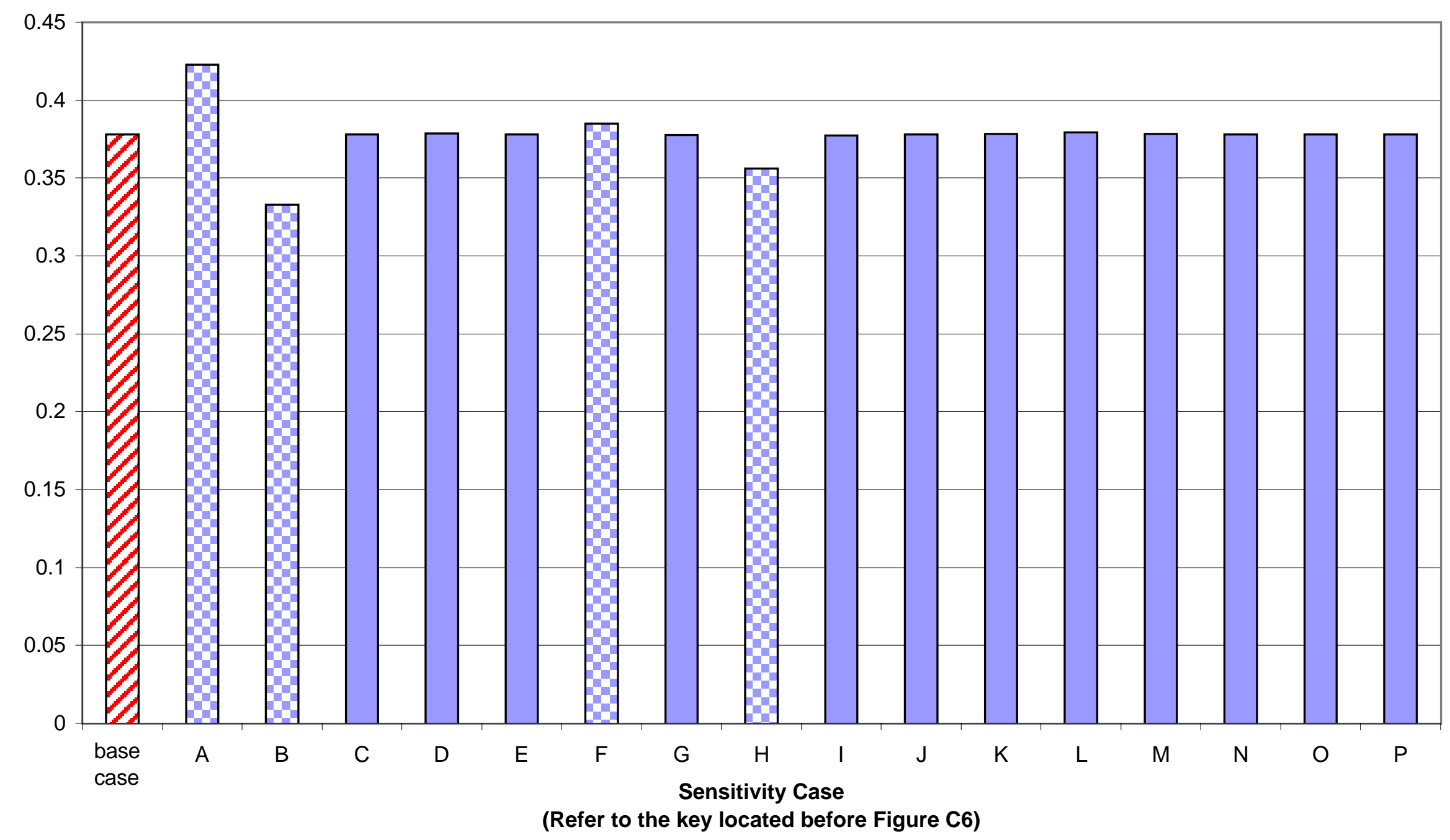


Figure C13: Sensitivity Results for External Net Energy Ratio - LEBS System, Surface Mining Case

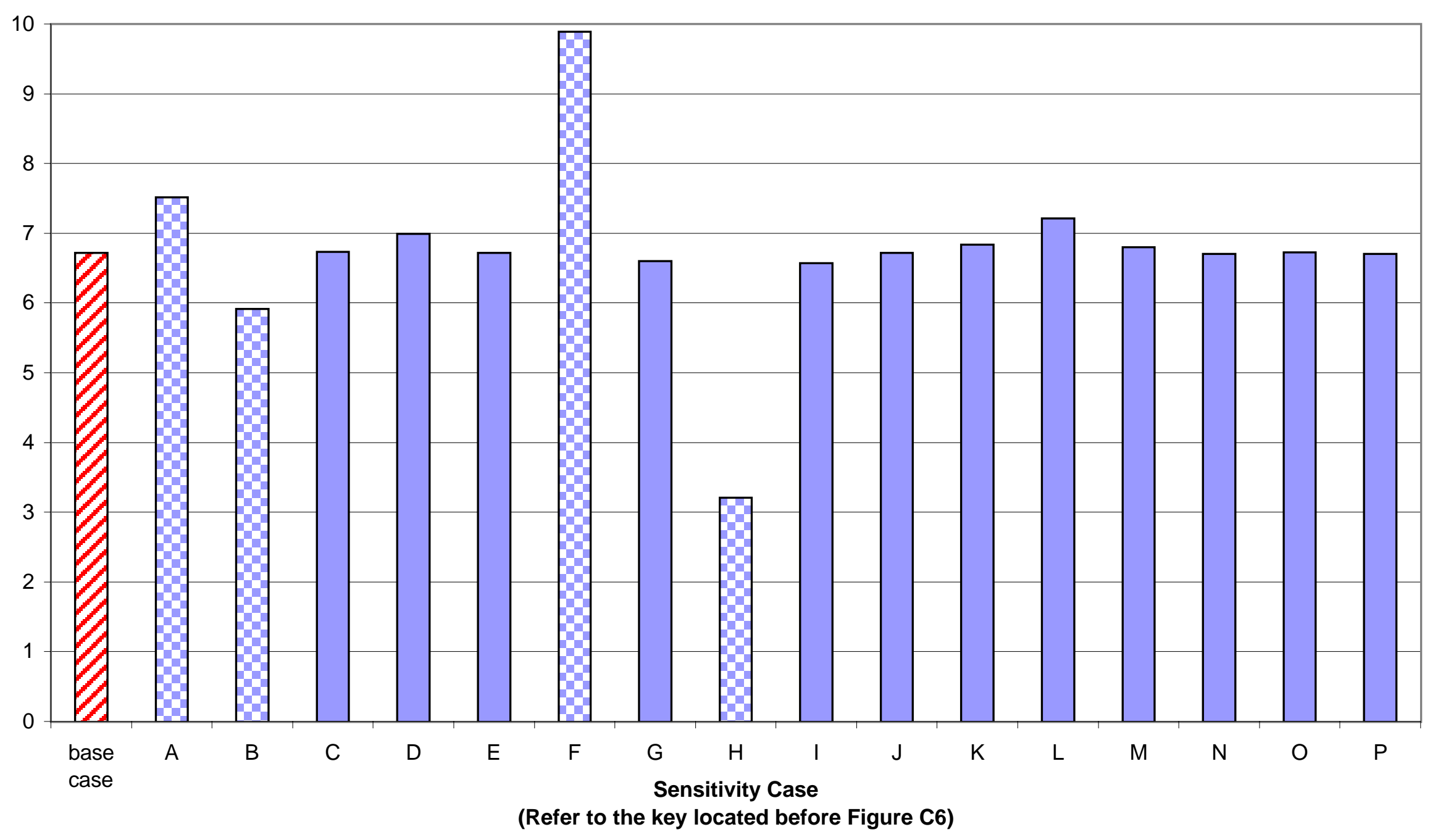




\section{REPORT DOCUMENTATION PAGE}

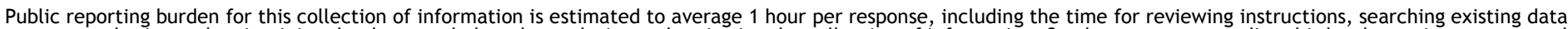

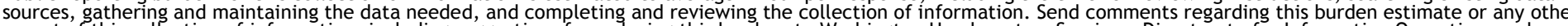

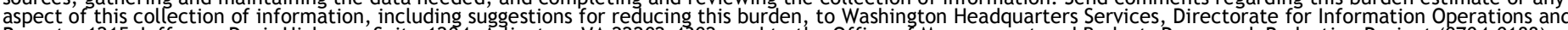

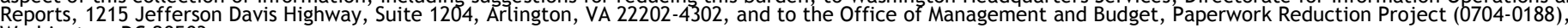
Washington, DC 20503.

\begin{tabular}{|l|l|l|}
\hline 1. AGENCY USE ONLY (Leave blank) & $\begin{array}{l}\text { 2. REPORT DATE } \\
\text { June } 1999\end{array}$ & $\begin{array}{l}\text { 3. REPORT TYPE AND DATES COVERED } \\
1998-1999\end{array}$ \\
\hline 4. TITLE AND SUBTITLE
\end{tabular}

\section{TITLE AND SUBTITLE}

5. FUNDING NUMBERS

Life Cycle Assessment of Coal-fired Power Production

6. AUTHOR(S)

Pamela L. Spath, Margaret K. Mann, Dawn R. Kerr

7. PERFORMING ORGANIZATION NAME(S) AND ADDRESS(ES)

8. PERFORMING ORGANIZATION REPORT NUMBER

BP91.1030

National Renewable Energy Laboratory

1617 Cole Blvd.

Golden, CO 80401-3393

10. SPONSORING/MONITORING

TP-570-25119

\section{SUPPLEMENTARY NOTES}

NREL Technical Monitor:

12a. DISTRIBUTION/AVAILABILITY STATEMENT

National Technical Information Service

12b. DISTRIBUTION CODE

U.S. Department of Commerce

5285 Port Royal Road

Springfield, VA 22161

13. ABSTRACT (Maximum 200 words)

Coal has the largest share of utility power generation in the United States, accounting for approximately $56 \%$ of all utility-produced electricity (U.S. DOE, 1998). Therefore, understanding the environmental implications of producing electricity from coal is an important component of any plan to reduce total emissions and resource consumption. A life cycle assessment (LCA) on the production of electricity from coal was performed in order to examine the environmental aspects of current and future pulverized coal boiler systems. Three systems were examined: 1) a plant that represents the average emissions and efficiency of currently operating coal-fired power plants in the U.S. (this tells us about the status quo), 2) a new coal-fired power plant that meets the New Source Performance Standards (NSPS), and 3) a highly advanced coal-fired power plant utilizing a low emission boiler system (LEBS).

\begin{tabular}{|l|l|l|l|}
\hline \multicolumn{2}{|l|}{ 14. SUBJECT TERMS } & 14. NUMBER OF PAGES \\
$\begin{array}{l}\text { 17. SECURITY CLASSIFICATION } \\
\text { OF REPORT }\end{array}$ & $\begin{array}{l}\text { 18. SECURITY CLASSIFICATION } \\
\text { OF THIS PAGE }\end{array}$ & $\begin{array}{l}\text { 19. SECURITY CLASSIFICATION } \\
\text { OF ABSTRACT }\end{array}$ & 20. LIMITATION OF ABSTRACT \\
\hline
\end{tabular}


